\title{
A enfermagem a partir de uma visão crítica: Excelência das práticas de cuidado
}

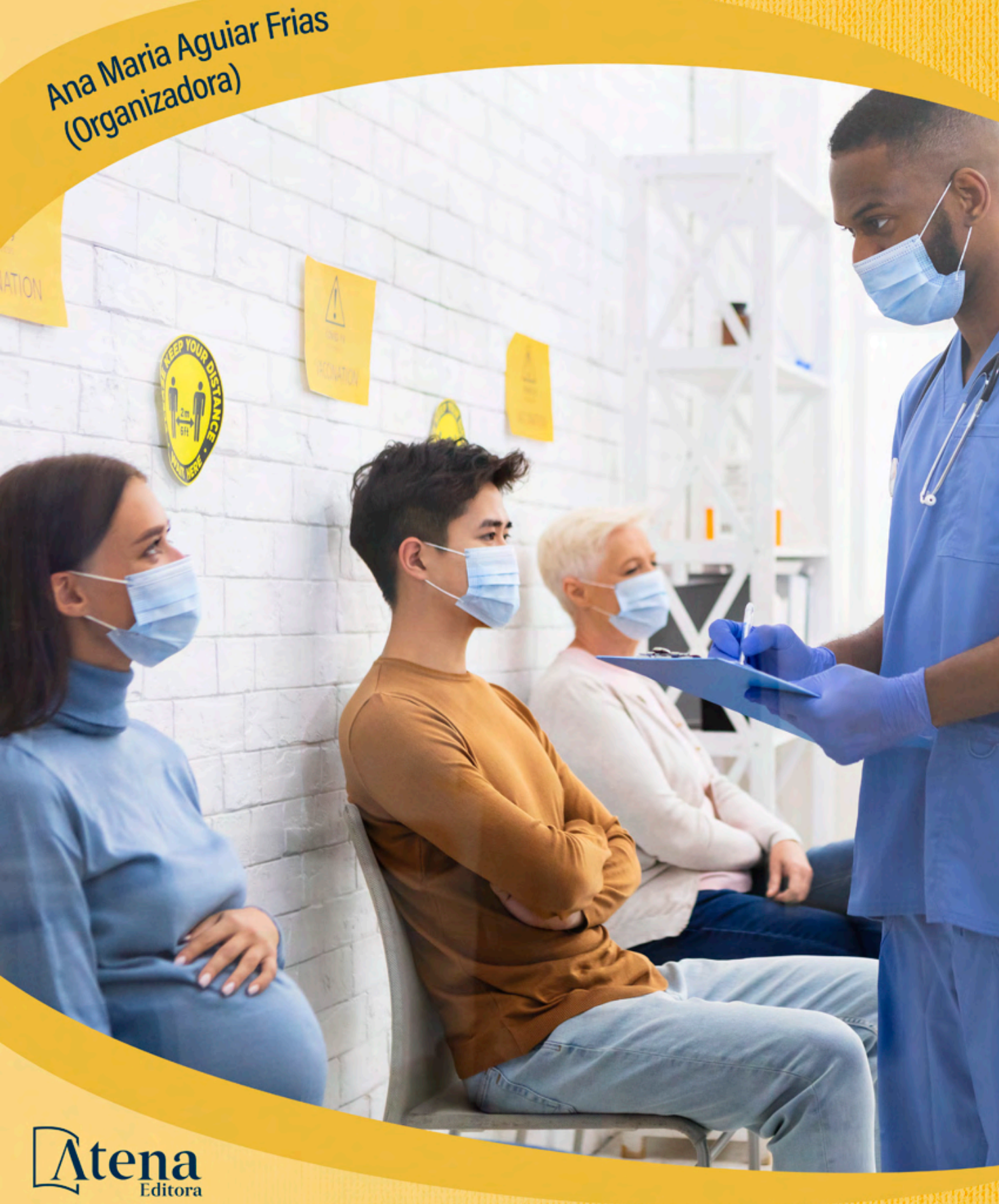

Ano 2021 


\section{A enfermagem a partir de uma visão crítica: Excelência das práticas de cuidado}

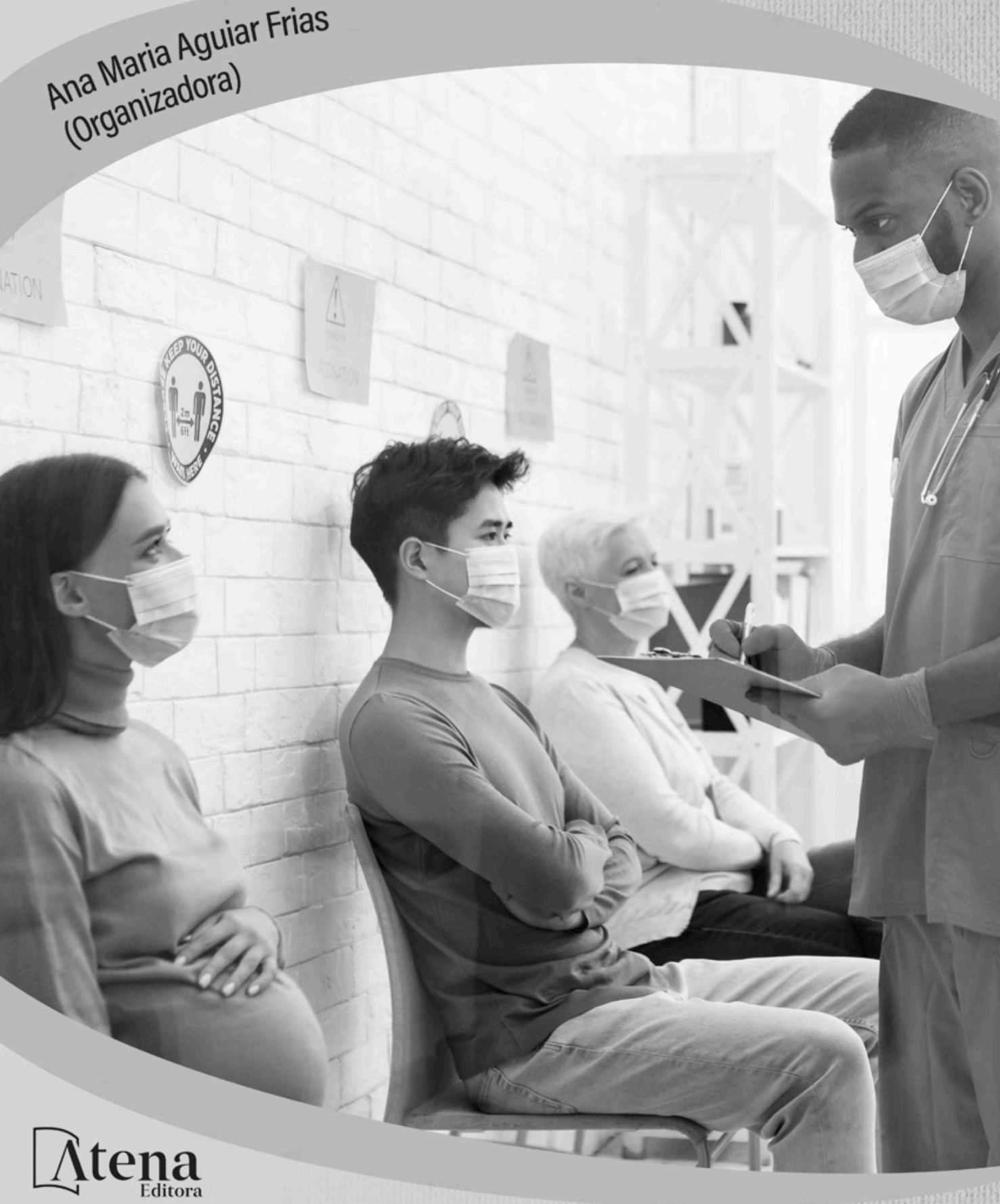

Ano 2021 


\section{Editora chefe}

Prof $^{\mathrm{a}} \mathrm{Dr}^{\mathrm{a}}$ Antonella Carvalho de Oliveira

Assistentes editoriais

Natalia Oliveira

Flávia Roberta Barão

Bibliotecária

Janaina Ramos

Projeto gráfico

Natália Sandrini de Azevedo

Camila Alves de Cremo

Luiza Alves Batista

Maria Alice Pinheiro

Imagens da capa

iStock

Edição de arte

Luiza Alves Batista

Revisão

Os autores

\section{1 by Atena Editora}

Copyright (C) Atena Editora

Copyright do Texto (C) 2021 Os autores

Copyright da Edição (c) 2021 Atena Editora

Direitos para esta edição cedidos à Atena Editora pelos autores.

Open access publication by Atena Editora

\section{(9)(1) $\Theta \Theta$}

Todo o conteúdo deste livro está licenciado sob uma Licença de Atribuição Creative Commons. Atribuição-Não-ComercialNãoDerivativos 4.0 Internacional (CC BY-NC-ND 4.0).

O conteúdo dos artigos e seus dados em sua forma, correção e confiabilidade são de responsabilidade exclusiva dos autores, inclusive não representam necessariamente a posição oficial da Atena Editora. Permitido o download da obra e o compartilhamento desde que sejam atribuídos créditos aos autores, mas sem a possibilidade de alterá-la de nenhuma forma ou utilizá-la para fins comerciais.

Todos os manuscritos foram previamente submetidos à avaliação cega pelos pares, membros do Conselho Editorial desta Editora, tendo sido aprovados para a publicação com base em critérios de neutralidade e imparcialidade acadêmica.

A Atena Editora é comprometida em garantir a integridade editorial em todas as etapas do processo de publicação, evitando plágio, dados ou resultados fraudulentos e impedindo que interesses financeiros comprometam os padrões éticos da publicação. Situações suspeitas de má conduta científica serão investigadas sob o mais alto padrão de rigor acadêmico e ético.

\section{Conselho Editorial}

Ciências Humanas e Sociais Aplicadas

Prof. Dr. Alexandre Jose Schumacher - Instituto Federal de Educação, Ciência e Tecnologia do Paraná

Prof. Dr. Américo Junior Nunes da Silva - Universidade do Estado da Bahia

Prof $^{a}$ Dr $^{a}$ Andréa Cristina Marques de Araújo - Universidade Fernando Pessoa

Prof. Dr. Antonio Carlos Frasson - Universidade Tecnológica Federal do Paraná

Prof. Dr. Antonio Gasparetto Júnior - Instituto Federal do Sudeste de Minas Gerais

Prof. Dr. Antonio Isidro-Filho - Universidade de Brasília

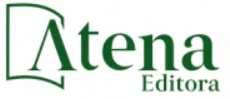

Ano 2021 
Prof. Dr. Arnaldo Oliveira Souza Júnior - Universidade Federal do Piauí

Prof. Dr. Carlos Antonio de Souza Moraes - Universidade Federal Fluminense

Prof. Dr. Crisóstomo Lima do Nascimento - Universidade Federal Fluminense

Prof ${ }^{\mathrm{a}} \mathrm{Dr}^{\mathrm{a}}$ Cristina Gaio - Universidade de Lisboa

Prof. Dr. Daniel Richard Sant'Ana - Universidade de Brasília

Prof. Dr. Deyvison de Lima Oliveira - Universidade Federal de Rondônia

Prof $^{a}$ Dr $^{a}$ Dilma Antunes Silva - Universidade Federal de São Paulo

Prof. Dr. Edvaldo Antunes de Farias - Universidade Estácio de Sá

Prof. Dr. Elson Ferreira Costa - Universidade do Estado do Pará

Prof. Dr. Eloi Martins Senhora - Universidade Federal de Roraima

Prof. Dr. Gustavo Henrique Cepolini Ferreira - Universidade Estadual de Montes Claros

Prof. Dr. Humberto Costa - Universidade Federal do Paraná

Prof $^{\mathrm{a}} \mathrm{Dr}^{\mathrm{a}}$ Ivone Goulart Lopes - Istituto Internazionele delle Figlie de Maria Ausiliatrice

Prof. Dr. Jadson Correia de Oliveira - Universidade Católica do Salvador

Prof. Dr. José Luis Montesillo-Cedillo - Universidad Autónoma del Estado de México

Prof. Dr. Julio Candido de Meirelles Junior - Universidade Federal Fluminense

Prof $^{a}$ Dr $^{\mathrm{a}}$ Lina Maria Gonçalves - Universidade Federal do Tocantins

Prof. Dr. Luis Ricardo Fernandes da Costa - Universidade Estadual de Montes Claros

Prof $^{\mathrm{a}} \mathrm{Dr}^{\mathrm{a}}$ Natiéli Piovesan - Instituto Federal do Rio Grande do Norte

Prof. Dr. Marcelo Pereira da Silva - Pontifícia Universidade Católica de Campinas

Prof $^{a} \operatorname{Dr}^{\mathrm{a}}$ Maria Luzia da Silva Santana - Universidade Federal de Mato Grosso do Sul

Prof. Dr. Miguel Rodrigues Netto - Universidade do Estado de Mato Grosso

Prof. Dr.Pablo Ricardo de Lima Falcão - Universidade de Pernambuco

Profa ${ }^{\mathrm{Da}}{ }^{\mathrm{a}}$ Paola Andressa Scortegagna - Universidade Estadual de Ponta Grossa

Prof $^{a}$ Dr $^{\text {a }}$ Rita de Cássia da Silva Oliveira - Universidade Estadual de Ponta Grossa

Prof. Dr. Rui Maia Diamantino - Universidade Salvador

Prof. Dr. Saulo Cerqueira de Aguiar Soares - Universidade Federal do Piauí

Prof. Dr. Urandi João Rodrigues Junior - Universidade Federal do Oeste do Pará

Prof $^{\mathrm{a}} \mathrm{Dr}^{\mathrm{a}}$ Vanessa Bordin Viera - Universidade Federal de Campina Grande

Prof $^{a} \mathrm{Dr}^{\mathrm{a}}$ Vanessa Ribeiro Simon Cavalcanti - Universidade Católica do Salvador

Prof. Dr. William Cleber Domingues Silva - Universidade Federal Rural do Rio de Janeiro

Prof. Dr. Willian Douglas Guilherme - Universidade Federal do Tocantins

\section{Ciências Agrárias e Multidisciplinar}

Prof. Dr. Alexandre Igor Azevedo Pereira - Instituto Federal Goiano

Prof. Dr. Arinaldo Pereira da Silva - Universidade Federal do Sul e Sudeste do Pará

Prof. Dr. Antonio Pasqualetto - Pontifícia Universidade Católica de Goiás

Prof $^{a}$ Dr $^{a}$ Carla Cristina Bauermann Brasil - Universidade Federal de Santa Maria

Prof. Dr. Cleberton Correia Santos - Universidade Federal da Grande Dourados

Prof $^{a}$ Dr $^{a}$ Diocléa Almeida Seabra Silva - Universidade Federal Rural da Amazônia

Prof. Dr. Écio Souza Diniz - Universidade Federal de Viçosa

Prof. Dr. Fábio Steiner - Universidade Estadual de Mato Grosso do Sul

Prof. Dr. Fágner Cavalcante Patrocínio dos Santos - Universidade Federal do Ceará

Prof $^{a}$ Dr $^{a}$ Girlene Santos de Souza - Universidade Federal do Recôncavo da Bahia

Prof. Dr. Jael Soares Batista - Universidade Federal Rural do Semi-Árido

Prof. Dr. Jayme Augusto Peres - Universidade Estadual do Centro-Oeste

Prof. Dr. Júlio César Ribeiro - Universidade Federal Rural do Rio de Janeiro

$\operatorname{Prof}^{\mathrm{a}} \mathrm{Dr}^{\mathrm{a}}$ Lina Raquel Santos Araújo - Universidade Estadual do Ceará

Prof. Dr. Pedro Manuel Villa - Universidade Federal de Viçosa

Prof $^{a}$ Dr $^{\mathrm{a}}$ Raissa Rachel Salustriano da Silva Matos - Universidade Federal do Maranhão

Prof. Dr. Ronilson Freitas de Souza - Universidade do Estado do Pará

$\operatorname{Prof}^{\mathrm{a}} \mathrm{Dr}^{\mathrm{a}}$ Talita de Santos Matos - Universidade Federal Rural do Rio de Janeiro

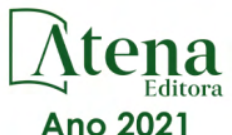

Ano 2021 
Prof. Dr. Tiago da Silva Teófilo - Universidade Federal Rural do Semi-Árido

Prof. Dr. Valdemar Antonio Paffaro Junior - Universidade Federal de Alfenas

\section{Ciências Biológicas e da Saúde}

Prof. Dr. André Ribeiro da Silva - Universidade de Brasília

Prof $^{\mathrm{a}} \mathrm{Dr}^{\mathrm{a}}$ Anelise Levay Murari - Universidade Federal de Pelotas

Prof. Dr. Benedito Rodrigues da Silva Neto - Universidade Federal de Goiás

Prof $^{a}$ Dr $^{a}$ Daniela Reis Joaquim de Freitas - Universidade Federal do Piauí

$\operatorname{Prof}^{a} \operatorname{Dr}^{\mathrm{a}}$ Débora Luana Ribeiro Pessoa - Universidade Federal do Maranhão

Prof. Dr. Douglas Siqueira de Almeida Chaves - Universidade Federal Rural do Rio de Janeiro

Prof. Dr. Edson da Silva - Universidade Federal dos Vales do Jequitinhonha e Mucuri

Prof $^{\mathrm{a}} \mathrm{Dr}^{\mathrm{a}}$ Elizabeth Cordeiro Fernandes - Faculdade Integrada Medicina

Prof $^{\mathrm{a}} \mathrm{Dr}^{\mathrm{a}}$ Eleuza Rodrigues Machado - Faculdade Anhanguera de Brasília

Prof $^{a} \operatorname{Dr}^{\mathrm{a}}$ Elane Schwinden Prudêncio - Universidade Federal de Santa Catarina

Prof $^{a}$ Dr $^{a}$ Eysler Gonçalves Maia Brasil - Universidade da Integração Internacional da Lusofonia Afro-

Brasileira

Prof. Dr. Ferlando Lima Santos - Universidade Federal do Recôncavo da Bahia

Prof $^{\mathrm{a}} \mathrm{Dr}^{\mathrm{a}}$ Fernanda Miguel de Andrade - Universidade Federal de Pernambuco

Prof. Dr. Fernando Mendes - Instituto Politécnico de Coimbra - Escola Superior de Saúde de Coimbra

Prof $^{a} \mathrm{Dr}^{\mathrm{a}}$ Gabriela Vieira do Amaral - Universidade de Vassouras

Prof. Dr. Gianfábio Pimentel Franco - Universidade Federal de Santa Maria

Prof. Dr. Helio Franklin Rodrigues de Almeida - Universidade Federal de Rondônia

Prof $^{\mathrm{a}} \mathrm{Dr}^{\mathrm{a}}$ lara Lúcia Tescarollo - Universidade São Francisco

Prof. Dr. Igor Luiz Vieira de Lima Santos - Universidade Federal de Campina Grande

Prof. Dr. Jefferson Thiago Souza - Universidade Estadual do Ceará

Prof. Dr. Jesus Rodrigues Lemos - Universidade Federal do Piauí

Prof. Dr. Jônatas de França Barros - Universidade Federal do Rio Grande do Norte

Prof. Dr. José Max Barbosa de Oliveira Junior - Universidade Federal do Oeste do Pará

Prof. Dr. Luís Paulo Souza e Souza - Universidade Federal do Amazonas

Prof $^{a}{ }^{D} r^{a}$ Magnólia de Araújo Campos - Universidade Federal de Campina Grande

Prof. Dr. Marcus Fernando da Silva Praxedes - Universidade Federal do Recôncavo da Bahia

Prof $^{a} D^{a}{ }^{a}$ Maria Tatiane Gonçalves Sá - Universidade do Estado do Pará

Prof $^{\mathrm{a}} \mathrm{Dr}^{\mathrm{a}}$ Mylena Andréa Oliveira Torres - Universidade Ceuma

Prof $^{a}$ Dr $^{a}$ Natiéli Piovesan - Instituto Federacl do Rio Grande do Norte

Prof. Dr. Paulo Inada - Universidade Estadual de Maringá

Prof. Dr. Rafael Henrique Silva - Hospital Universitário da Universidade Federal da Grande Dourados

Prof $^{a} \mathrm{Dr}^{\mathrm{a}}$ Regiane Luz Carvalho - Centro Universitário das Faculdades Associadas de Ensino

Prof $^{a} \operatorname{Dr}^{a}$ Renata Mendes de Freitas - Universidade Federal de Juiz de Fora

Profa $^{a}{ }^{a}$ Vanessa da Fontoura Custódio Monteiro - Universidade do Vale do Sapucaí

Prof ${ }^{\mathrm{D}} \mathrm{Pr}^{\mathrm{a}}$ Vanessa Lima Gonçalves - Universidade Estadual de Ponta Grossa

Prof $^{a} \operatorname{Dr}^{\mathrm{a}}$ Vanessa Bordin Viera - Universidade Federal de Campina Grande

Prof $^{\mathrm{a}} \mathrm{Dr}^{\mathrm{a}}$ Welma Emidio da Silva - Universidade Federal Rural de Pernambuco

\section{Ciências Exatas e da Terra e Engenharias}

Prof. Dr. Adélio Alcino Sampaio Castro Machado - Universidade do Porto

ProF $^{\mathrm{a}} \mathrm{Dr}^{\mathrm{a}}$ Ana Grasielle Dionísio Corrêa - Universidade Presbiteriana Mackenzie

Prof. Dr. Carlos Eduardo Sanches de Andrade - Universidade Federal de Goiás

Prof $^{a} \operatorname{Dr}^{\mathrm{a}}$ Carmen Lúcia Voigt - Universidade Norte do Paraná

Prof. Dr. Cleiseano Emanuel da Silva Paniagua - Instituto Federal de Educação, Ciência e Tecnologia de Goiás

Prof. Dr. Douglas Gonçalves da Silva - Universidade Estadual do Sudoeste da Bahia

Prof. Dr. Eloi Rufato Junior - Universidade Tecnológica Federal do Paraná

Prof $^{a}$ Dr $^{a}$ Érica de Melo Azevedo - Instituto Federal do Rio de Janeiro

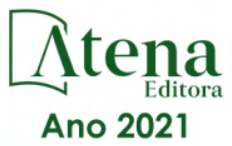


Prof. Dr. Fabrício Menezes Ramos - Instituto Federal do Pará

Prof $^{a}$ Dra. Jéssica Verger Nardeli - Universidade Estadual Paulista Júlio de Mesquita Filho

Prof. Dr. Juliano Carlo Rufino de Freitas - Universidade Federal de Campina Grande

Prof $^{\mathrm{a}} \mathrm{Dr}^{\mathrm{a}}$ Luciana do Nascimento Mendes - Instituto Federal de Educação, Ciência e Tecnologia do Rio Grande do Norte

Prof. Dr. Marcelo Marques - Universidade Estadual de Maringá

Prof. Dr. Marco Aurélio Kistemann Junior - Universidade Federal de Juiz de Fora

Prof ${ }^{a} \mathrm{Dr}^{\mathrm{a}}$ Neiva Maria de Almeida - Universidade Federal da Paraíba

Prof $^{a}$ Dr $^{a}$ Natiéli Piovesan - Instituto Federal do Rio Grande do Norte

Prof $^{a}$ Dr $^{a}$ Priscila Tessmer Scaglioni - Universidade Federal de Pelotas

Prof. Dr. Sidney Gonçalo de Lima - Universidade Federal do Piauí

Prof. Dr. Takeshy Tachizawa - Faculdade de Campo Limpo Paulista

\section{Linguística, Letras e Artes}

Prof ${ }^{\mathrm{D}} \mathrm{rr}^{\mathrm{a}}$ Adriana Demite Stephani - Universidade Federal do Tocantins

Profa Dr $^{a}$ Angeli Rose do Nascimento - Universidade Federal do Estado do Rio de Janeiro

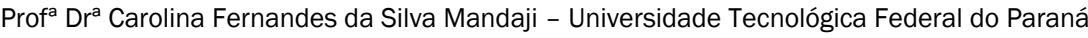

Prof ${ }^{\mathrm{D}} \mathrm{Dr}^{\mathrm{a}}$ Denise Rocha - Universidade Federal do Ceará

Prof $^{a}$ Dra $^{a}$ Edna Alencar da Silva Rivera - Instituto Federal de São Paulo

Prof $^{a}$ Dr ${ }^{\mathrm{a}}$ Fernanda Tonelli - Instituto Federal de São Paulo,

Prof. Dr. Fabiano Tadeu Grazioli - Universidade Regional Integrada do Alto Uruguai e das Missões

Prof. Dr. Gilmei Fleck - Universidade Estadual do Oeste do Paraná

Prof ${ }^{\mathrm{D}} \mathrm{r}^{\mathrm{a}}$ Keyla Christina Almeida Portela - Instituto Federal de Educação, Ciência e Tecnologia do Paraná

Prof $^{a}$ Dr $^{a}$ Miranilde Oliveira Neves - Instituto de Educação, Ciência e Tecnologia do Pará

Prof $^{a}$ Dr $^{\text {a }}$ Sandra Regina Gardacho Pietrobon - Universidade Estadual do Centro-Oeste

Prof $^{a} \mathrm{Dr}^{\mathrm{a}}$ Sheila Marta Carregosa Rocha - Universidade do Estado da Bahia

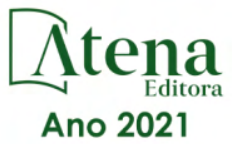




\title{
A enfermagem a partir de uma visão crítica: excelência das práticas de cuidado
}

\author{
Diagramação: Maria Alice Pinheiro \\ Correção: Bruno Oliveira \\ Indexação: Gabriel Motomu Teshima \\ Revisão: Os autores \\ Organizadora: Ana Maria Aguiar Frias
}

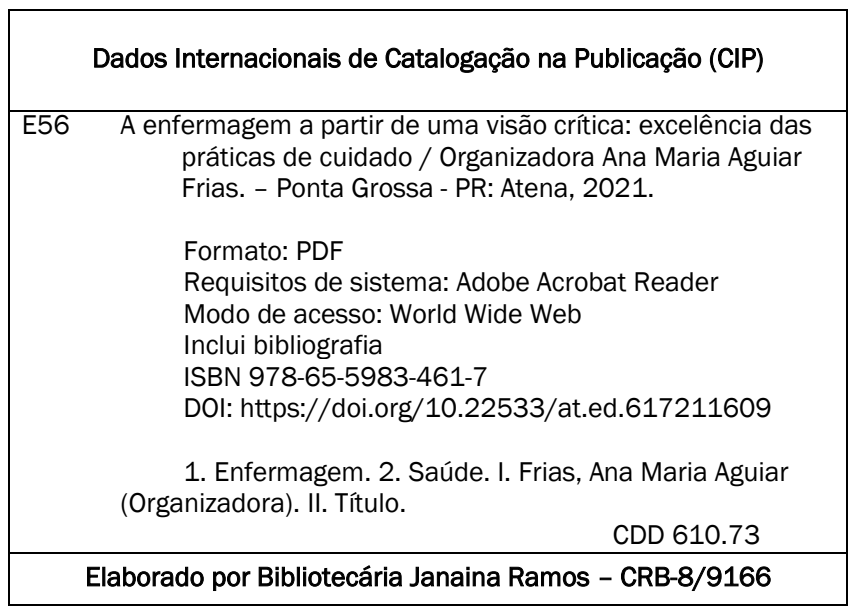

Atena Editora

Ponta Grossa - Paraná - Brasil Telefone: +55 (42) 3323-5493 www.atenaeditora.com.br contato@atenaeditora.com.br 


\section{DECLARAÇÃO DOS AUTORES}

Os autores desta obra: 1 . Atestam não possuir qualquer interesse comercial que constitua um conflito de interesses em relação ao artigo científico publicado; 2. Declaram que participaram ativamente da construção dos respectivos manuscritos, preferencialmente na: a) Concepção do estudo, e/ou aquisição de dados, e/ou análise e interpretação de dados; b) Elaboração do artigo ou revisão com vistas a tornar o material intelectualmente relevante; c) Aprovação final do manuscrito para submissão; 3. Certificam que os artigos científicos publicados estão completamente isentos de dados e/ou resultados fraudulentos; 4 . Confirmam a citação e a referência correta de todos os dados e de interpretações de dados de outras pesquisas; 5 . Reconhecem terem informado todas as fontes de financiamento recebidas para a consecução da pesquisa; 6. Autorizam a edição da obra, que incluem os registros de ficha catalográfica, ISBN, DOI e demais indexadores, projeto visual e criação de capa, diagramação de miolo, assim como lançamento e divulgação da mesma conforme critérios da Atena Editora.

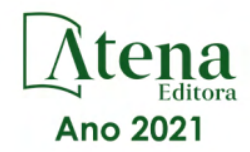




\section{DECLARAÇÃO DA EDITORA}

A Atena Editora declara, para os devidos fins de direito, que: 1. A presente publicação constitui apenas transferência temporária dos direitos autorais, direito sobre a publicação, inclusive não constitui responsabilidade solidária na criação dos manuscritos publicados, nos termos previstos na Lei sobre direitos autorais (Lei 9610/98), no art. 184 do Código penal e no art. 927 do Código Civil; 2. Autoriza e incentiva os autores a assinarem contratos com repositórios institucionais, com fins exclusivos de divulgação da obra, desde que com o devido reconhecimento de autoria e edição e sem qualquer finalidade comercial; 3. Todos os e-book são open access, desta forma não os comercializa em seu site, sites parceiros, plataformas de e-commerce, ou qualquer outro meio virtual ou físico, portanto, está isenta de repasses de direitos autorais aos autores; 4. Todos os membros do conselho editorial são doutores e vinculados a instituições de ensino superior públicas, conforme recomendação da CAPES para obtenção do Qualis livro; 5. Não cede, comercializa ou autoriza a utilização dos nomes e e-mails dos autores, bem como nenhum outro dado dos mesmos, para qualquer finalidade que não o escopo da divulgação desta obra. 


\section{APRESENTAÇÃO}

A coleção intitulada "A enfermagem a partir de uma visão crítica: Excelência das práticas de cuidado" discute temáticas várias e evidencia os cuidados de enfermagem de excelência ao longo do ciclo de vida, desde a gestação ao envelhecimento. A pessoa é cuidada tendo em conta a sua singularidade, capacidade de autocuidado, qualidade de vida e segurança.

Os 89 capítulos que compõem a coleção estão expostos em 4 volumes. O volume 1 relaciona-se com a gravidez, nascimento, recém-nascido, criança, adolescente e saúde do adulto. Fisiopatologias e linhas de orientação respeitantes a patologias várias, ginecológica feminina e masculina são explanadas neste volume. O volume $2 \mathrm{com}$ relevância para a saúde pública, apresenta a questão pandémica do SARS CoV2 e outras infeções. Abarca a prestação de cuidados de Enfermagem em unidades de cuidados intensivos e atuação no processo de doação de órgãos tendo sempre no horizonte a excelência dos cuidados. $O$ volume 3 aborda assuntos de gestão de cuidados e politicas de saúde de forma a melhorar e contribuir para a gestão da qualidade e qualidade de vida. Fica também claro, nos capítulos que compõem este volume, a humanização dos cuidados. O Volume 4 oferece, através dos diversos artigos, respostas aos problemas biopsicossociais, tanto académicas como profissionais, de forma a capacitar estudantes, enfermeiros, utentes e ainda a população em geral para o cuidar e o autocuidar.

Nestes volumes e em cada capítulo conhece-se, apreende-se, recorda-se e reflete-se sobre a enfermagem. Visões criticas e interdisciplinar enriquecem esta obra. Um reconhecimento especial para o trabalho cuidado crítico e minucioso dos autores que objetivam uma leitura prazerosa e refletida sobre as práticas de cuidado.

Investigações e pesquisas, bem conseguidas, necessitam ser divulgadas. Mais uma vez a plataforma Atena Editora revelou-se crucial na publicação destes estudos científicos, de robusta produção de autores e coautores, no âmbito da excelência dos cuidados e com ênfase na saúde da pessoa/população. O desafio é proporcionar aos leitores a reflexão e o aumento do interesse para a realização de outros trabalhos/pesquisas em prole da segurança do cuidar, do bem-estar e qualidade de vida. 


\section{SUMÁRIO}

CAPÍTULO 1

OS BENEFÍCIOS DO EXERCÍCIO FÍSICO NA GRAVIDEZ: REVISÃO DA LITERATURA

Rafaela Alexandra Veiga de Albuquerque e Castro

Telma Filipa Palma Salgueiro

Sofia Maciel Correia

Cristina Margarida Manjate

Ana Maria Aguiar Frias

do https://doi.org/10.22533/at.ed.6172116091

\section{CAPÍTULO 2}

EFEITOS DA NEGLIGÊNCIA DO PRÉ-NATAL EM GESTANTES ADOLESCENTES

Jullia Greque Calabrez

Julia Rocha Franzosi

Lívia Secomandi Toledo

Mariana Louzada Monteiro Lobato Galvão de São Martinho

Talita Barbosa Moreira

d. https://doi.org/10.22533/at.ed.6172116092

CAPÍTULO 3

ASSISTÊNCIA DE ENFERMAGEM À PACIENTE GESTANTE COM DIAGNÓSTICO DE LÚPUS ERITEMATOSO SISTÊMICO: RELATO DE EXPERIÊNCIA

Ravena de Sousa Alencar Ferreira

Herla Maria Furtado Jorge

Andressa Maria Laurindo Souza

Amanda Karoliny Meneses Resende

Waléria Geovana dos Santos Sousa

do) https://doi.org/10.22533/at.ed.6172116093

CAPÍTULO 4 36

ASSSITÊNCIA DE ENFERMAGEM Á GESTANTE COM PICO HIPERTENSIVO NA UNIDADE DE URGÊNCIA E EMERGÊNCIA

Larissa Maria de Oliveira Costa

Ana Patricia de Alencar

Maria Freitas Lima de Farias Pinho

Carlla Sueylla Filgueira Ramalho Souza

Amanda Tamires Ferreira Araujo

Dianne Suêrda Gomes Pereira

Juliana Aparecida Pereira de Lima

Patriciana Carvalho Ferreira

Natasha Priscila Lopes Arrais

Ana Rochele Cruz Sampaio

Ana Patrícia Sampaio Alves

Fátima Tannara Mariano de Lima

do) https://doi.org/10.22533/at.ed.6172116094 
SÍFILIS EM GESTANTE: SITUAÇÃO EPIDEMIOLÓGICA EM PORTO E MOZ/PARÁ ENTRE OS ANOS DE 2017 E 2018

Lília Maria Nobre Mendonça de Aguiar

Uberlan Nogueira Fonceca

Jocireudo de Jesus Carneiro de Aguiar

Silvia Sousa da Silva

Antenor Matos de Carvalho Junior

Gerciane Suely Castro de Souza

Domingas Machado da Silva

Lulucha de Fátima Lima da Silva

do) https://doi.org/10.22533/at.ed.6172116095

CAPÍTULO 6

ASSISTÊNCIA DE ENFERMAGEM À PACIENTE COM ROTURA PREMATURA DAS MEMBRANAS OVULARES

Camilla Pontes Bezerra

Vanessa Cavalcante Pereira

Mayara Santiago Camurça

Lívia Karoline Torres Brito

Erinete Melo da Silva Freire

Josyene de Lima Cardoso

Virgínia Maria Nazário Barbosa

Rosane Reis Rocha

Ana Raquel Bezerra da Silva Almeida

Emanuelle Rabelo Cordeiro

Leandro da Silva Ribeiro

Francisca Glaucineide Mendonça Vieira

d. https://doi.org/10.22533/at.ed.6172116096

CAPÍTULO 7

CARACTERIZAÇÃO DOS PARTOS EM UM MUNICÍPIO DO ESTADO DO CEARÁ

Ana Patricia de Alencar

Katherine Jeronimo Lima

Nathália Lima Sousa

Jéssica Marco Pereira da Cunha

Larissa Maria de Oliveira Costa

Carlla Sueylla Filgueira Ramalho Souza

Ana Thayline Vidal Rosendo

Cícera Erenilde Inácio Furtado

Bárbara Jennifer Bezerra de Oliveira

Isabel Cabral Gonçalves

Dianne Suêrda Gomes Pereira

Maria Freitas Lima de Farias Pinho

d. https://doi.org/10.22533/at.ed.6172116097 
IMPORTÂNCIA DA DEAMBULAÇÃO NO PUERPÉRIO MEDIATO

Ana Gabriella Silva dos Santos

Yasmin Ariadiny Lopes Lacerda

Ana Sarah Soares da Cunha Alencar

Ana Aparecida Santos de Santana

Luana dos Santos Oliveira

Mateus Gomes Ribeiro

Nadia Pereira Natal

do https://doi.org/10.22533/at.ed.6172116098

CAPÍTULO 9

O TÍPICO VIVIDO DA ADOLESCENTE PUÉRPERA NA PERSPECTIVA DA FENOMENOLOGIA SOCIOLÓGICA

Marta Pereira Coelho

Adriana Nunes Moraes-Partelli

Luciana de Cássia Nunes Nascimento

Esther da Fonseca Erothides

do) https://doi.org/10.22533/at.ed.6172116099

CAPÍTULO 10 95

CONHECIMENTO DOS ENFERMEIROS DA ATENÇÃO BÁSICA SOBRE DEPRESSÃO PÓS-PARTO

Emmanuelle de Araújo Ewald

Daniela Priscila Oliveira do Vale Tafner

do) https://doi.org/10.22533/at.ed.61721160910

CAPÍTULO 11 107

O CUIDADO DE ENFERMAGEM COMO FERRAMENTA METODOLÓGICA NA IDENTIFICAÇÃO PRECOCE DE GESTANTES EM RISCO PARA A DEPRESSÃO PÓSPARTO

Fernanda Alves Pinto

Mayra Roberta Faria de Moraes

do) https://doi.org/10.22533/at.ed.61721160911

CAPÍTULO 12

BENEFíCIOS DO CONTATO PELE A PELE ENTRE MÃE E BEBÊ NA UTI NEONATAL

Suellen da Rocha Lage Moraes

Bianca Aparecida do Prado

Isis Vanessa Nazareth

Larissa Marcondes

Gislayne Castro e Souza de Nieto

do) https://doi.org/10.22533/at.ed.61721160912 
HIPOTERMIA TERAPÊUTICA EM RECÉM-NASCIDOS COM ASFIXIA PERINATAL: ASSISTÊNCIA DE ENFERMAGEM

Michelle Cristine de Oliveira Minharro

Débora Fernanda Colombara

Simone Buchignani Maigret

d. https://doi.org/10.22533/at.ed.61721160913

CAPÍTULO 14 136

MANEJO NÃO-FARMACOLOGICO DA DOR EM RECEM-NASCIDO SOB CUIDADOS INTENSIVOS

Nanielle Silva Barbosa

Stefânia Araújo Pereira

José Francisco Ribeiro

Ana Caroline Escórcio de Lima

Amanda Karoliny Meneses Resende

Marianna Soares Cardoso

Emanuelle da Costa Gomes

lara Lima de Andrade Ferreira

Juliete Machado Aguiar Bandeira

Geovana Marques Teixeira

Maria Erislâine de Carvalho Rodrigues

Palloma Ohana de Meneses Moura Lima

do) https://doi.org/10.22533/at.ed.61721160914

CAPÍTULO 15.

CATETERISMO VENOSO PERIFÉRICO EM RECÉM-NASCIDOS EM UTI NEONATAL: UM LEVANTAMENTO BIBLIOMÉTRICO

Higor Pacheco Pereira

Débora Maria Vargas Makuch

Izabela Linha Secco

Andrea Moreira Arrué

Mitzy Tannia Reichembach

d. https://doi.org/10.22533/at.ed.61721160915

CAPÍTULO 16.

ALÉM DA TEORIA A PRÁTICA HUMANISTA: O USO DE BINQUEDOS TERAPÊUTICOS NA ASSISTÊNCIA PEDIÁTRICA

Ana Flávia da Silva Ribeiro

Ana Karina Viana Pereira

Andréa Veruska de Souza Almeida

Anna Thereza Ribeiro Pindaíba Moura

Maria Luiza Visgueira da Silva

Shavia Ravenna Silva Andrade

Maria Tamires Alves Ferreira

do) https://doi.org/10.22533/at.ed.61721160916 
ASSISTENNCIA DE ENFERMAGEM NO CUIDADO À CRIANÇA COM CARDIOPATIA CONGÊNITA

Michelle Cristine de Oliveira Minharro

Nathalia Domingues de Oliveira

Thalita Luiza Madoglio

d. https://doi.org/10.22533/at.ed.61721160917

CAPÍTULO 18. 171

DA ROBOTIZAÇÃO À HUMANIZAÇÃO: A ENFERMAGEM NA HOSPITALIZAÇÃO DA CRIANÇA VÍTIMA DE MAUS-TRATOS

Sabi Barbosa Moraes

Webster de Oliveira Leite

Viviane de Melo Souza

Eric Rosa Pereira

d.) https://doi.org/10.22533/at.ed.61721160918

CAPÍTULO 19

ANÁLISE DOS PRINCIPAIS FATORES DE RISCO PARA O SURGIMENTO DO CÂNCER DE COLO DO ÚTERO

Rafaela Alves de Oliveira

Bentinelis Braga da Conceição

Barbara Maria Rodrigues dos Santos

Nariane Morais do Nascimento Silva

Adriano Nogueira da Cruz

Islaila Maria Silva Ferreira

Ana de Cássia Ivo dos Santos

Mariana Teixeira da Silva

Layane Mayhara Gomes Silva

Maria da Cruz Alves da Silva

Brendon Nathanaell Brandão Pereira

Maria Eugênia Lopes Mendes

Zaíne Araújo Gonçalves

Adriana dos Passos Silva

d.) https://doi.org/10.22533/at.ed.61721160919

CAPÍTULO 20.

CÂNCER DE MAMA E COMPROMETIMENTO DA QUALIDADE DE VIDA DE MULHERES MASTECTOMIZADAS

Camilla Pontes Bezerra

Suyane Pinto de Oliveira Bilhar

Júlio César Lira Mendes

Francisca Glaucineide Mendonça Vieira

Maria Janaides Alves da Silva

Keila Patrícia Bezerra

Carlos Jerson Alencar Rodrigues

Isabelle dos Santos de Lima 
Deuza Maria Pinheiro de Oliveira

Erinete Melo da Silva Freire

Maria Claumyrla Lima Castro

Pâmella de Castro Duarte Pordeus

d. https://doi.org/10.22533/at.ed.61721160920

CAPÍTULO 21

O ENFERMEIRO E O ACOLHIMENTO DE PACIENTES NO PRÉ OPERATÓRIO DE CÂNCER DE MAMA: RELATO DE EXPERIÊNCIA

Michelle Freitas de Souza

Ana Paula de Magalhães Barbosa

d.) https://doi.org/10.22533/at.ed.61721160921

CAPÍTULO 22.

PREVALENCIA DE LINFEDEMA EN UN GRUPO DE MUJERES POSTMASTECTOMIZADAS

Sofía Elena Pérez-Zumano

Lourdes Azucena Matías-Garduño

Luis Manuel Mendoza-Cruz

Mónica Gallegos Alvarado

d.) https://doi.org/10.22533/at.ed.61721160922

CAPÍTULO 23

EPIDEMIOLOGIA DA MORTALIDADE POR CÂNCER DE PÊNIS NO BRASIL 2009-2019

Ângela Maria Melo Sá Barros

Márcia Peixoto César

Ana Inês Souza

Ângela Maria Mendes Abreu

Ikaro Daniel de Carvalho Barreto

Larissa Rodrigues Mattos

Girzia Sammya Tajra Rocha

Weber de Santana Teles

Alejandra Debbo

Max Cruz da Silva

Rute Nascimento da Silva

Ruth Cristini Torres

Anita Cattleya Melo Sá Sales Barros

d.) https://doi.org/10.22533/at.ed.61721160923

SOBRE A ORGANIZADORA. 238

ÍNDICE REMISSIVO 


\section{CAPÍTULO 1 \\ OS BENEFÍCIOS DO EXERCÍCIO FÍSICO NA GRAVIDEZ: REVISÃO DA LITERATURA}

Data de aceite: $20 / 08 / 2021$

Data de submissão: 06/08/2021

Rafaela Alexandra Veiga de Albuquerque e Castro

Unidade de Cuidados Continuados de Longa Duração da Santa Casa da Misericórdia de

Ferreira do Alentejo, Beja, Portugal http://orcid.org/0000-0002-1749-4639

Telma Filipa Palma Salgueiro Fundação Renal Portuguesa de Portalegre, Portugal http://orcid.org/0000-0003-2452-2594

\section{Sofia Maciel Correia}

Centro Hospitalar Universitário do Algarve, Unidade de Faro, Serviço de Bloco de partos,

Faro, Portugal http://orcid.org/0000-0003-4609-8691

\section{Cristina Margarida Manjate}

Hospital Rural do Songo Tete-Moçambique https://orcid.org/0000-0002-7980-9501

\section{Ana Maria Aguiar Frias}

Universidade de Évora, Escola Superior de Enfermagem S. João de Deus, Comprehensive Health Research Centre (CHRC)

Évora, Portugal http://orcid.org/0000-0002a-9038-8576

RESUMO: A prática de exercício físico em mulheres no período gravídico ou pós-parto, sem contraindicações clínicas, é aconselhada com a finalidade de promover benefícios para a saúde materna e fetal. A prática regular de exercício físico durante esta fase, é essencial para a prevenção de doenças associadas à gravidez, bem como de complicações ao recém-nascido. Este estudo visou identificar os benefícios do exercício físico durante a gravidez, para a mulher e para o feto e/ou recém-nascido, através de uma Revisão Integrativa da Literatura e recorrendo à metodologia PICOD, da qual resultou a questão de investigação "Quais os benefícios do exercício físico na gravidez?". Os artigos analisados evidenciam que o exercício físico pode e deve ser recomendado a todas as grávidas saudáveis. A sua prática regular durante a gestação promove inúmeros benefícios físicos e psicológicos, para além de não haver evidências de complicações para o feto e/ou recém-nascido, quando realizados em intensidade leve a moderada. No entanto, poucas grávidas aderem a essa prática e muitas ainda têm receios e dúvidas quanto à segurança da sua realização.

PALAVRAS - CHAVE: Exercício Físico, Gravidez, Benefícios, Saúde da mulher, Enfermagem.

\section{THE BENEFITS OF PHYSICAL EXERCISE IN PREGNANCY: LITERATURE REVIEW}

ABSTRACT: The physical exercise in women during pregnancy or postpartum period, no clinical contraindications, is recommended in order to promote benefits for maternal and fetal health. Regular physical exercise during this phase is essential for the prevention of diseases associated with pregnancy, as well as complications to the newborn. This study aimed to identify the benefits of physical exercise during pregnancy, for the woman and for the fetus and/ 
or newborn, through an Integrative Literature Review and using the PICOD methodology, which resulted in the research question "Which are the benefits of exercise in pregnancy?. The articles analyzed show that exercise can and should be recommended to all healthy pregnant women. Its regular practice during pregnancy promotes numerous physical and psychological benefits, as well as no evidence of complications for the fetus and/or newborn, when performed at light to moderate intensity. However, few pregnant women adhere to this practice and many still have fears and doubts about the safety of its performance.

KEYWORDS: Physical Exercise, Pregnancy, Benefits, Women's Health, Nursing.

\section{I INTRODUÇÃO}

A qualidade de vida está relacionada com a complementaridade entre o bem-estar físico, social e emocional, considerando-se a prática de exercício físico, um dos principais meios para atingir essa condição (MACEDO; GARAVELLO; OKU; MIYAGUSUKU et al., 2003) ${ }^{1}$.

Segundo a Organização Mundial de Saúde (2014)ํㅜㄹ a atividade física é de extrema importância para a prevenção e controle de doenças crónicas. Paralelamente, esta proporciona benefícios para a saúde mental, prevenindo o declínio cognitivo e sintomas associados à depressão e ansiedade. Consiste em qualquer movimento corporal, efetuado pelos músculos esqueléticos, que requer um gasto de energia superior ao gasto energético em repouso, incluindo atividades durante o trabalho e execução de tarefas domésticas. Torna-se importante saber distinguir o conceito de atividade física e exercício físico, considerando o último, uma prática de atividade física planeada, estruturada e repetida, tendo como principal objetivo melhorar ou manter a condição física de um indivíduo e, consequentemente promover benefícios para a saúde do mesmo.

De acordo com a OMS (2020) ${ }^{1}$, é aconselhada a prática de exercício físico em mulheres no período gravídico ou pós-parto, sem contraindicações clínicas, com a finalidade de promover benefícios para a saúde materna e fetal. A prática regular de exercício físico durante esta fase, é essencial para a prevenção de doenças associadas à gravidez, bem como de complicações ao recém-nascido, diminuindo assim a morbimortalidade neonatal.

As mulheres grávidas, apresentam um risco aumentado de desconfortos musculoesqueléticos pois, durante a gravidez, ocorre a rotação anterior da pelve, o aumento da lordose lombar e o aumento da elasticidade dos ligamentos. A evidência mostra que a prática de exercício físico reduz a intensidade desses desconfortos, promovendo a flexibilidade da coluna e melhorando a postura corporal (LIMA; OLIVEIRA, 2005).

Estão definidas pela The American College of Obstetricians and Gynecologists (ACOG) (2020) diversas contraindicações clínicas e/ou obstétricas para a prática regular de exercício físico durante o período de gravidez. Estas podem ser classificadas como contraindicações absolutas e relativas. Algumas contraindicações absolutas são: patologias cardíaca e pulmonar, incompetência istmo-cervical, gravidez múltipla após as 30 semanas 
de idade gestacional, perda hemática durante a gestação, placenta prévia, ameaça de parto pré-termo, rotura prematura de membranas, pré-eclâmpsia ou hipertensão arterial não controlada. As contraindicações relativas podem ser: anemia, arritmia cardíaca, bronquite, diabetes mellitus não controlada, hipertensão arterial crónica, epilepsia, hipotiroidismo ou hipertiroidismo, obesidade ou desnutrição e grandes fumadoras.

Atualmente, ainda existem poucos estudos que abordem as vantagens do exercício físico em relação à saúde mental. No entanto, pode-se afirmar que os estudos existentes concluem que a prática contínua de atividade física traz evidentes benefícios em termos de bem-estar-emocional e equilíbrio da saúde mental da mulher, no período de gravidez e pós-parto (MATA; CHULVI; ROIG; HEREDIA et al., 2010; MANDOLESI; POLVERINO; FOTI et al., 2018).

O presente estudo, através da análise de literatura com evidência científica, tem como objetivo identificar os benefícios do exercício físico durante a gravidez, para a mulher e para o feto e/ou recém-nascido, explicitando especificamente quais os exercícios mais adequados e, em que fases trimestrais da gravidez devem ser realizados.

\section{2 | DESENVOLVIMENTO}

O artigo assenta numa Revisão Integrativa da Literatura que, segundo o Centro Cochrane no Brasil, citado pelo Grupo Anima Educação (2014), deve seguir sete (7) passos: formulação da pergunta, localização e avaliação crítica dos estudos, recolha de dados, análise e apresentação destes, interpretação dos mesmos, aprimoramento e atualização da revisão. Assim, foi formulada a pergunta de investigação a partir do método PICOD, segundo Ramalho (2005), resultando a questão de investigação "Quais os benefícios do exercício físico na gravidez?".

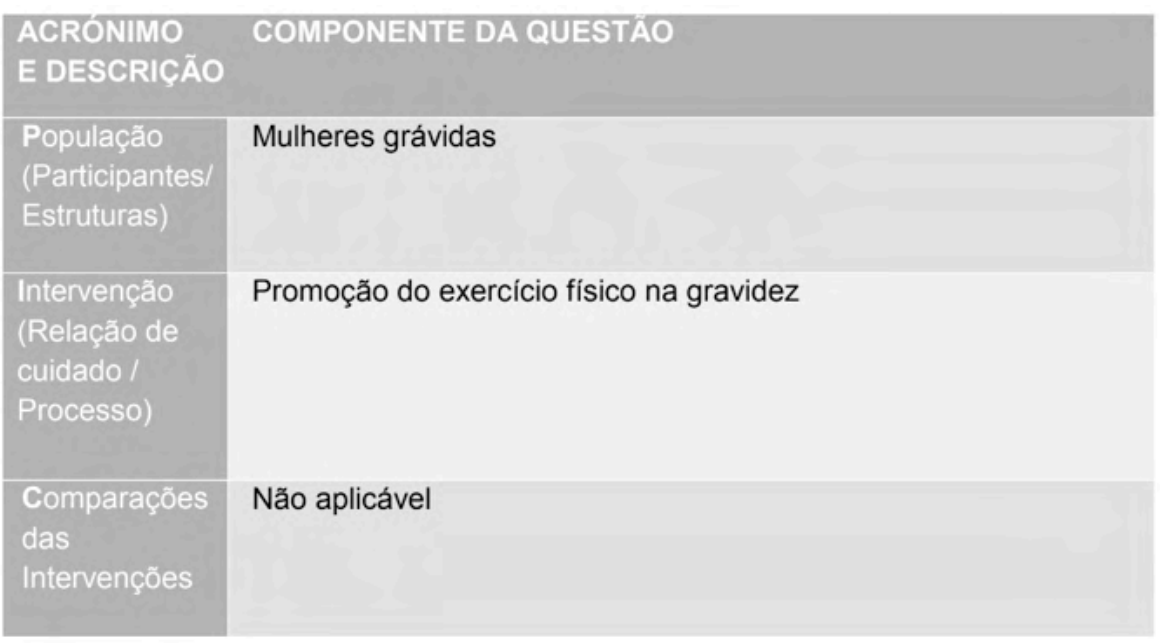




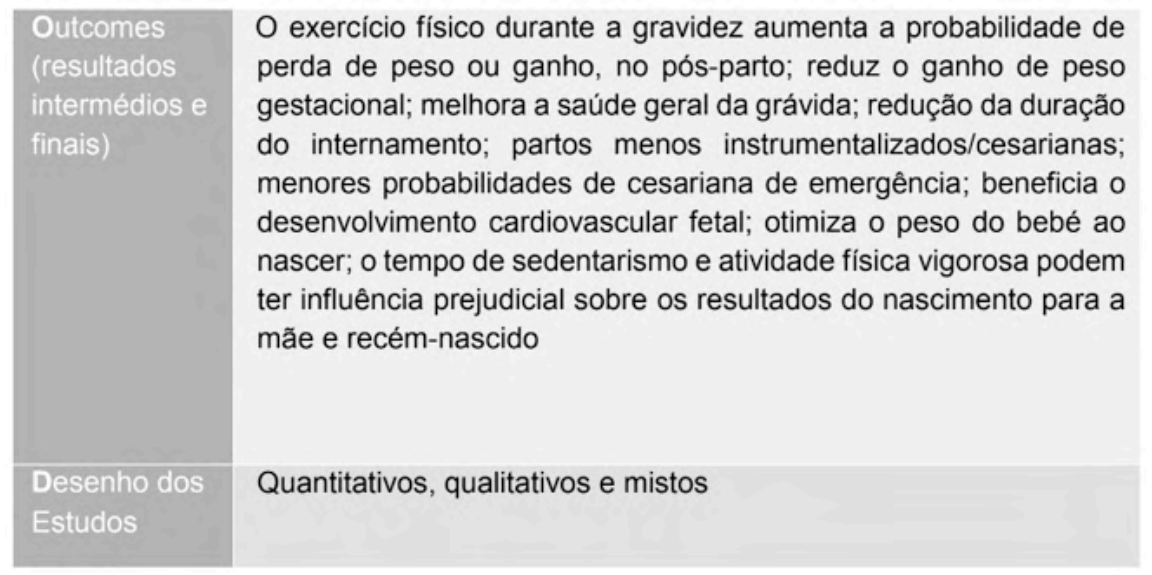

Tabela 1. Componentes da Questão de Investigação Fonte: Elaborado pelos autores

A Revisão Integrativa da Literatura foi realizada recorrendo aos motores de busca: Biblioteca do Conhecimento Online (B-on), Elton Bryson Stephens Company (EBSCOhost) e Biblioteca Nacional de Medicina (NLM®) dos Estados Unidos - PubMed ${ }^{\circledR}$. Foram selecionadas e utilizadas palavras-chave relevantes à pesquisa, tanto inseridas nos Descritores em Ciências da Saúde (DeCs) como no Medical Subject Headings (MeSH) pregnancye exercise. O operador booleano utilizado nas pesquisas realizadas nas bases de dados referidas foi "AND". A seleção dos artigos foi realizada de acordo com o representado na Figura 1, de acordo com o diagrama "Preferred Reporting Items for Systematic Review and Meta- Analyses (PRISMA)"(PAGE; MCKENZIE; BOSSUYT; BOUTRON et al., 2021). 


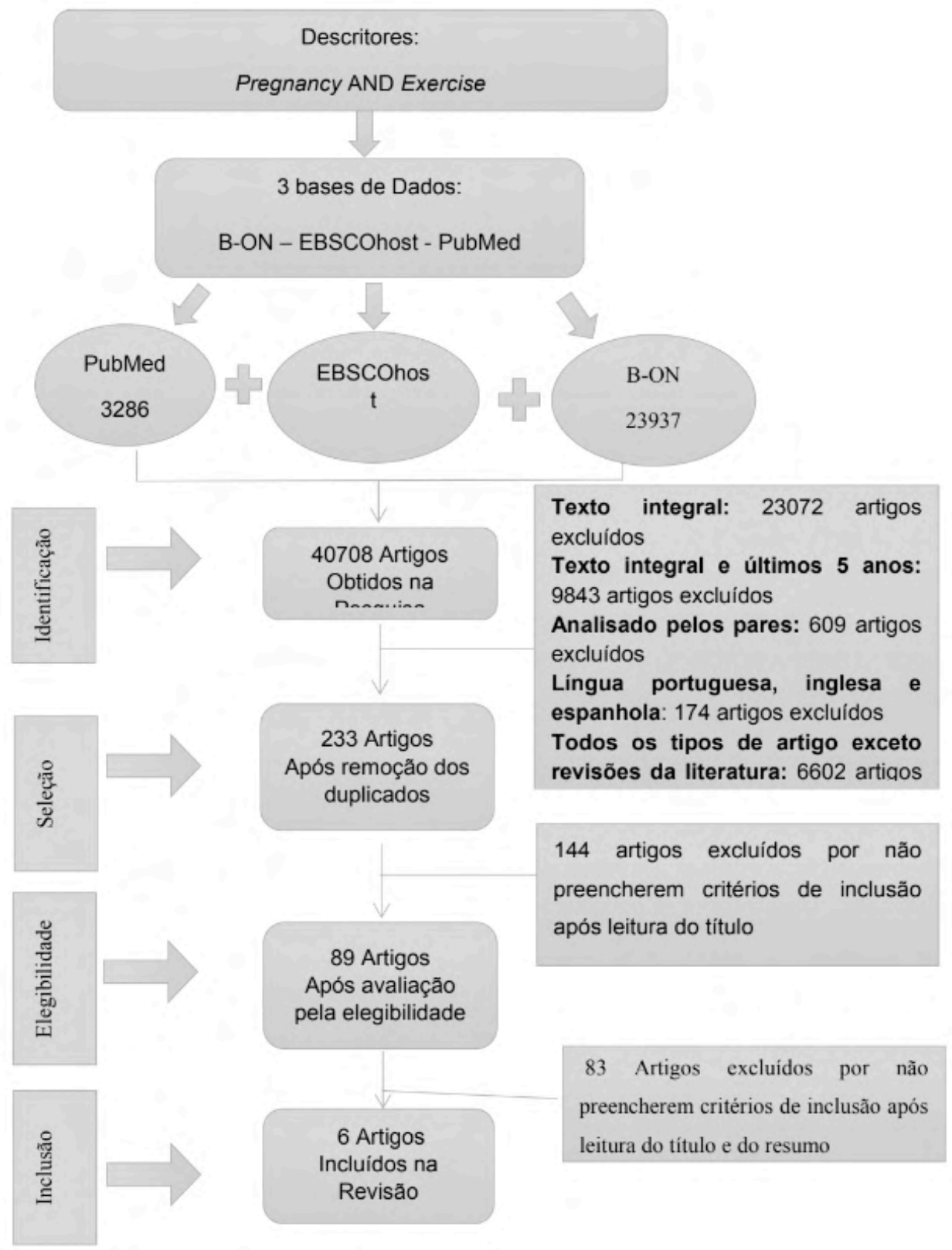

Figura 1. Diagrama PRISMA dos estudos identificados, incluídos e excluídos.

Fonte: Elaborado pelos autores

Os 6 artigos selecionados, tendo em consideração os objetivos desta revisão e questão de investigação, encontram-se esquematizados nas tabelas seguintes de forma a facilitar a sua interpretação. 


\section{ARTIGO 1 \\ "Does exercise during pregnancy impact on maternal weight gain and fetal cardiac function? A randomized controlled trial"}

\section{(O exercício físico durante a gravidez afeta o ganho de peso materno e a função cardíaca fetal? Estudo controlado randomizado) (2019)}

\section{ARTIGO 2 \\ "Comparing the effects of progressive muscle relaxation and physical activity on pregnant women's general health"}

(Comparação entre os efeitos do relaxamento muscular progressivo e da atividade física na saúde geral de mulheres grávidas) (2018)
Avaliar a relação entre o exercício físico durante a gravidez e o ganho de peso gestacional materno e função cardíaca fetal.
Não foram identificadas diferenças entre os dois grupos, relativamente ao peso materno avaliado às $20,28,36$ e 38 semanas de gestação. No entanto, verificou-se que a porção de mulheres com perda de peso igual ou superior a $9 \mathrm{Kg}$ nas seis semanas seguintes após o parto, é superior em mulheres que seguiram o programa de exercício físico durante a gravidez.

Relativamente ao tipo de parto, idade gestacional no momento do nascimento, necessidade de indução do trabalho de parto e peso do recém-nascido após o nacimento, não existem diferenças significativas em relação aos dois grupos sujeitos ao ensaio.

A prática de exercício físico moderado durante a gravidez não está inteiramente relacionada com a redução do ganho de peso materno durante o período gravídico, mas verifica-se que aumenta a probabilidade de perda de peso seis semanas após o parto.

Após a realização e análise dos resultados do ensaio, verificou-se que o exercício físico praticado ao longo da gravidez, está associado ao benéfico desenvolvimento cardiovascular fetal.

Este estudo mostrou que RMP e AF melhoram a saúde geral das

Apesar da eficácia de ambos os métodos na melhoria da saúde geral das participantes, não

Investigar e comparar os efeitos do relaxamento muscular progressivo (RMP) e da atividade física (AF) na saúde geral de gestantes. houve diferenças significantes entre os grupos RMP e AF. Cada técnica pode ser utilizada para melhorar a saúde geral das gestantes. Mulheres que praticavam exercício físico regularmente podem continuar a fazê-lo, desde que sua condição permaneça estável. Os efeitos do relaxamento na saúde mental da grávida mostraram-se úteis a nível físico e psicológico. 
ARTIGO 3

"Effect of diet and

exercise intervention

in Chinese pregnant

women on gestational weight gain and perinatal outcomes:

A quasi-experimental study"

(Efeito da dieta e da intervenção de exercícios em mulheres grávidas chinesas sobre o ganho de peso gestacional e os resultados perinatais:

um estudo quase experimental) (2017)
Avaliar o efeito de uma dieta e intervenção de exercícios em mulheres grávidas, no ganho de peso gestacional total, ganho de peso semanal, ganho de peso nos 42 dias após o parto, tipo de parto e peso do bebé ao nascer.
O ganho de peso gestacional total e o ganho de peso médio por semana no grupo de intervenção foram significativamente menores do que no grupo controle. $\mathrm{O}$ peso do bebé ao nascer foi significativamente menor no grupo de intervenção. O ganho de peso no pós-parto foi, também, significativamente menor no grupo de intervenção. Não houve diferenças significativas em relação ao tipo de parto, entre os dois grupos.
O estudo demonstra que a intervenção no estilo de vida das gestantes reduziu significativamente o ganho de peso gestacional, otimizou o peso do bebé ao nascer e diminuiu o ganho de peso no pós-parto. A promoção

do controle do peso gestacional é necessária e as crenças culturais de saúde sobre a gravidez e as práticas após o parto devem ser consideradas ao desenvolver o plano de intervenção.

\section{ARTIGO 4 \\ Association of sedentary time and physical activity during pregnancy with maternal and neonatal birth outcomes. The} GESTAFIT Project

(Associação do tempo de sedentarismo e da atividade física durante a gravidez com desfechos maternos e neonatais. Projeto GESTAFIT) (2019) (a) Analisar

a associação do tempo de sedentarismo (ST) e atividade física (AF) durante o início do segundo trimestre da gravidez, com as consequências para a mãe e para o recém-nascido, de forma a evitar desfechos menos positivos em partos e cesarianas.

(b) Explorar se ST e AF interferem no tipo de parto.
Pela gasometria umbilical, um maior tempo de sedentarismo foi associado a $\mathrm{pH}$ mais ácido do sangue do cordão umbilical assim como uma maior pressão parcial de dióxido de carbono $\left(\mathrm{PCO}_{2}\right)$, traduzindo uma pior perfusão placentária. Atividade física moderada, moderada a vigorosa

(AFMV), total e número de passos por dia, foram associadas a resultados positivos a nível da saturação de oxigénio do sangue arterial. Mais passos por dia traduz-se numa diminuição da idade gestacional e da duração da primeira fase do trabalho de parto, associada a partos menos instrumentalizados. AF total e leve foi associado a um $\mathrm{pH}$ mais alcalino na veia umbilical. AF vigorosa associou-se a um índice de APGAR mais baixo no primeiro e quinto minutos. Não foram observadas diferenças significativas que demonstrassem que ST ou AF influenciavam o tipo de parto.
No geral, nesta população de mulheres grávidas de baixo risco, percebeu-se que maiores níveis de AF leve, moderada, moderada a vigorosa e total, bem como passos por dia, durante o início segundo trimestre de gravidez, foram associados a resultados positivos, maternos, de parto e neonatais. Ao contrário, ST e AF vigorosa podem ter influência prejudicial sobre os resultados do nascimento para a mãe e recémnascido. 


\section{ARTIGO 5 \\ The effect of exercise on childbirth in primiparous women: A clinical trial study}

(O efeito do exercício no parto em mulheres primíparas: um estudo clínico)

(2016)
Determinar os efeitos do exercício físico no processo de parto e tipo de parto em mulheres primigestas.
Os resultados mostraram diferenças significativas na hospitalização na fase ativa do trabalho de parto, sendo que o grupo que realizou o protocolo

de atividade física teve um aumento significativo em relação ao grupo de controle. A taxa de parto natural foi superior no grupo que praticou atividade física, com percentagens na ordem dos $85 \%$, enquanto o grupo de controle apresentou uma taxa de cesarianas de $65 \%$.
Caminhada regular com intensidade e duração adequadas, está

diretamente relacionada com a redução da

duração do internamento e com partos menos instrumentalizados/

cesarianas. A atividade física, devidamente

ajustada a cada idade gestacional, é benéfica para gestações saudáveis.

\section{ARTIGO 6 \\ What is the effect of physical activity on duration and mode of delivery? Secondary analysis from the Norwegian Fit for Delivery trial}

(Qual é o efeito da atividade física na duração e no modo de parto?

Análise secundária do teste Norwegian Fit for Delivery) (2018)

\section{Estudar o efeito} da intervenção utilizada no ensaio Norwegian Fit for Delivery (NFFD) no parto (indução do parto, uso de analgesia, duração do trabalho de parto, tipo de parto, risco de pós-parto, peso da placenta) e nos resultados do nascimento (índice de APGAR, admissão na unidade de terapia intensiva neonatal) $e$ no nível de atividade física no final da gravidez.
No grupo de baixa atividade, $65 \%$ dos participantes pertenciam originalmente ao grupo controle e $35 \%$ ao grupo de intervenção, enquanto os números correspondentes para o grupo de alta atividade eram $33,6 \%$ pertencentes ao grupo de controle e $66,4 \%$ ao grupo de intervenção. Relativamente à duração do trabalho de parto, as participantes com baixo nível de AF apresentaram em média mais cinquenta e oito (58) minutos que aquelas que tinham alto nível de AF. O grupo de baixa atividade era mais propenso a usar analgesia epidural durante

o trabalho de parto do que o grupo de alta atividade. Já relativamente à probabilidade de ter um parto vaginal e de

não ter uma cesariana de emergência, estes valores foram favoráveis para o grupo que se manteve altamente ativo. Já a probabilidade de ter um parto por cesariana foi de $15 \%$ no grupo de baixa intensidade e $6,9 \%$ no grupo de alta intensidade. Relativamente aos resultados neonatais não se apuraram diferenças significativas entre os grupos analisados.
A intervenção do estilo de vida NFFD, resultou num primeiro

estágio do trabalho de parto um pouco mais longo no grupo de intervenção do que no grupo de controle. $\mathrm{O}$ alto nível de atividade física no final da gravidez foi associado a menores probabilidades de cesariana de emergência, em comparação com um baixo nível de atividade física. Os resultados do presente estudo confirmam que os exercícios no final da gravidez não parecem influenciar negativamente os resultados obstétricos.

Tabela 2. Síntese de dados

Fonte: Elaborado pelos autores

\section{I RESULTADOS E DISCUSSÃO}

exercício físico é uma prática que agrega benefícios para a saúde da mulher ao longo de toda a sua vida, principalmente no planeamento da gestação, no ciclo gravídico- 
puerperal e no pós-parto, possibilitando que a gravidez seja mais saudável, o período puerperal e a amamentação mais prazerosos e confortáveis, proporcionando que o retorno às atividades de vida diárias, seja mais fácil (PEREIRA; AGUIAR, 2016).

A gravidez é caracterizada por modificações fisiológicas locais e sistémicas, com o principal objetivo de promover o crescimento e desenvolvimento fetal. Tendo em conta essas adaptações, as mulheres grávidas beneficiam da prática de atividade física regular, no entanto, grande parte das gestantes interrompe a prática durante a gravidez, devido ao medo do parto prematuro ou dano fetal (SYTSMA; ZIMMERMAN; MANNING; JENKINS et al., 2018). Por outro lado, a prática de exercício físico regular antes da gestação ou mesmo no período pré-natal pode prevenir o desenvolvimento de algumas doenças maternas como a hipertensão arterial (HTA), obesidade, diabetes gestacional (DG) e pré-eclâmpsia (PE) (OMS, 2020).

A perceção das grávidas, relativamente à prática de exercício físico durante a gravidez, tem sido alterada ao longo do tempo, mais propriamente por influências culturais do que por evidências científicas recentemente demonstradas. Contudo, o avanço da ciência, associada a uma crescente procura de informação por parte das grávidas, levantou importantes questões sobre a relação risco/benefício do exercício durante a gravidez, tornando-se assim imprescindível a criação de consensos relativamente às suas recomendações (GOUVEIA; MARTINS; SANDES; NASCIMENTO et al., 2007).

Sendo assim, percebeu-se que é fundamental promover a prática de exercício físico durante o período gestacional, informando as mulheres sobre os benefícios da mesma. Essa orientação deve ser feita tanto para as mulheres fisicamente ativas quanto para aquelas que possuem uma atitude mais sedentária. No caso de abordarmos grávidas sedentárias, temos que as orientar para a prática de exercício físico de leve ou moderada intensidade, neste contexto, os exercícios aeróbios podem ser uma boa opção. Para as mulheres fisicamente ativas, deve ser aconselhada a manutenção da prática, alertando para a adaptação da intensidade e para exercícios considerados de risco, durante o período gestacional (NASCIMENTO; GODOY; SURITA; SILVA, 2014).

De acordo com os estudos anteriormente analisados, percebeu-se que mulheres grávidas de baixo risco, que praticavam atividade física durante o período gravídico, de intensidade ligeira ou moderada, possuíam redução no tempo de internamento hospitalar, menos probabilidade de serem submetidas a partos instrumentados ou cesariana, manifestando resultados bastante positivos em termos maternos, neonatais e no decorrer do parto.

Segundo Vargas-Terrones, Nagpal, e Barakat (2019), as mulheres que praticam exercício de forma regular, têm maior probabilidade de manter um peso adequado durante a gravidez e diminuir o peso corporal ou limitar o seu ganho no período pós-parto. Consequentemente, a atividade física também promove um adequado peso do bebé no momento do nascimento. 
Da análise dos estudos selecionados verificamos que, a prática de atividade física de forma regular, ao longo da gravidez, está associada ao benéfico desenvolvimento cardiovascular fetal, prevenindo complicações como a hipoglicémia neonatal, baixo peso ao nascer e parto prematuro.

Deste modo, considera-se de extrema importância a intervenção dos profissionais de saúde, no estilo de vida das gestantes, de modo a promover a melhoria no estado de saúde geral da grávida. Neste sentido apresenta-se de seguida os exercícios mais adequados e em que trimestres da gravidez devem ser realizados.

\subsection{Exercício físico aconselhado durante o período gravídico}

$\mathrm{Na}$ ausência de contraindicações clínicas absolutas para a prática de exercício físico durante o período gestacional, é recomendado que todas as grávidas mantenham ou adotem um estilo de vida ativo (OMS, 2020). O exercício físico de intensidade leve a moderada é considerado uma prática segura, tanto para mãe como para o feto (BAENAGARCÍA; OCÓN-HERNÁNDEZ; ACOSTA-MANZANO; COLL-RISCO et al., 2019).

A mulher grávida deve optar por exercícios que melhor se adequem aos seus interesses pessoais e às suas necessidades, prevendo-se, deste modo, uma maior adesão à prática regular de exercício físico. Devem ser sempre evitadas práticas que coloquem a gestante e o feto em risco, como as atividades de alto impacto, com risco de queda ou trauma abdominal, e os desportos de contacto (NASCIMENTO; GODOY; SURITA; SILVA, 2014).

\subsubsection{Exercícios Aeróbicos ou Exercícios Cardiorrespiratórios}

Dentro da panóplia de exercícios que são aconselhados no período gravídico pela ACOG (2020), os exercícios aeróbicos são os mais estudados e aconselhados. O principal objetivo destes exercícios é manter ou melhorar a capacidade cardiorrespiratória e a condição física da mulher grávida, de forma a prevenir o surgimento de patologias associadas à gravidez descritas anteriormente, promovendo também uma melhoria significativa de alguns desconfortos característicos da mesma. Por norma, a caminhada é o exercício de eleição das grávidas, sendo que estas também são aconselhadas a praticar corrida ligeira, bicicleta estacionária, natação, hidroginástica e dança.

Torna-se importante perceber que, em gestantes sem complicações clínicas e/ ou obstétricas, considerando o feto saudável, este é capaz de desenvolver mecanismos compensatórios não demonstrando sinais de sofrimento durante ou após a prática de exercício físico, o que revela existir uma homeostase das trocas gasosas, impedindo efeitos adversos como a hipoxia fetal, mesmo em situações de atividade física moderada a intensa em mulheres grávidas previamente pouco ativas (NASCIMENTO; GODOY; SURITA; SILVA, 2014). 


\subsubsection{Treino de Resistência Muscular}

O fortalecimento muscular é extremamente importante, uma vez que permite o aumento e/ou manutenção da força muscular. Assim, existe uma melhor adaptação do organismo materno às alterações posturais, provenientes do período gestacional, prevenindo e aliviando determinadas dores e desconfortos músculo-esqueléticos comuns na gravidez (MONTENEGRO, 2014).

Segundo Nascimento, Godoy, Surita e Silva (2014) é aconselhável, que o fortalecimento muscular seja direcionado maioritariamente para a musculatura paravertebral, lombar e cintura escapular, de forma a envolver, preferencialmente, os grandes grupos musculares. Recomenda-se que o peso escolhido para a realização destes exercícios seja apenas o peso corporal, ou utilização de faixas elásticas, em vez de se utilizar máquinas de musculação ou alteres. Alerta-se também para que as grávidas evitem a utilização de cargas elevadas, exercícios isométricos intensos repetidos e posturas que coloquem a gestante em risco, principalmente aquelas que possam afetar o equilíbrio da mesma, aumentando o risco de queda.

Existem vários exercícios de resistência muscular, aconselhados para grávidas, como: yoga, pilates, musculação com cargas leves e treino com circuito (NASCIMENTO; GODOY; SURITA; SILVA, 2014).

\subsubsection{Treino Muscular do Assoalho Pélvico}

Vários autores como Honorato e Rodrigues (2018), Nascimento, Godoy, Surita e Silva (2014), Mata, et al.(2010), evidenciam a importância do treino muscular do assoalho pélvico (TMAP) durante a gestação, tendo como principal objetivo diminuir o risco de incontinência urinária após o parto. Durante a gravidez, torna-se importante realizar ensinos de forma que as mulheres introduzam a prática de exercícios perineais na sua rotina. Não existem quaisquer contraindicações para sua prática durante e após a gestação. A mulher grávida deve realizar o TMAP através de contrações sustentadas localizadas nos músculos do assoalho pélvico: primeiramente deve contrair e manter essa contração durante cinco a dez segundos; posteriormente deve realizar contrações rápidas e sucessivas. $O$ aconselhado é realizar diariamente duas séries de oito contrações sustentadas por cinco segundos e duas séries de dez contrações rápidas (NASCIMENTO; GODOY; SURITA; SILVA, 2014).

\subsubsection{Alongamento Muscular}

O alongamento muscular é uma componente fundamental na prática de exercício físico. Este não deve ser esquecido, uma vez que permite o aumento da flexibilidade, o relaxamento muscular e consequentemente ajuda na adaptação postural, prevenindo dores músculo-esqueléticas (MANN; KLEINPAUL; TEIXEIRA; KONOPKA, 2008). Esta prática deve ser complementada com os exercícios aeróbios de fortalecimento muscular. 


\subsection{Recomendações de exercício físico por trimestre de gravidez}

\subsubsection{Primeiro Trimestre}

Segundo a ACOG (2020), a grávida deve apenas iniciar ou retomar a sua própria rotina de exercícios físicos após a primeira consulta pré-natal, quando é estabelecida a ausência de risco gestacional e após recomendação médica. Segundo esta entidade (2020) o exercício físico de intensidade leve a moderada é recomendado a todas as grávidas, mesmo as sedentárias que desejam iniciá-la durante a gestação, sendo que, nesse caso, a recomendação atual é que devem iniciar de forma gradual (baixa intensidade e curtos períodos).

As grávidas fisicamente ativas antes de engravidar podem manter as suas atividades, inclusive no primeiro trimestre, adaptando a intensidade, frequência e duração dos exercícios aeróbicos. Porém, este trimestre pode ser uma fase de desconfortos causados pelas alterações hormonais, que determinam com relativa frequência mal-estar, como náuseas e vómitos, para além de sonolência e indisposição, o que pode dificultar a aderência e a disposição para os exercícios. Os alongamentos podem ser realizados, sem contraindicações. Já os exercícios para o fortalecimento muscular são recomendados, desde que de forma supervisionada (NASCIMENTO; GODOY; SURITA; SILVA, 2014).

\subsubsection{Segundo Trimestre}

Por norma, este é o melhor trimestre para a prática de exercício físico, pois a mulher encontra-se mais bem-disposta e, em geral, livre dos inconvenientes do início da gravidez (NASCIMENTO; GODOY; SURITA; SILVA, 2014). As mulheres que não praticavam exercício previamente podem iniciar sua prática a partir do segundo trimestre. A partir da 20. ${ }^{a}$ semana de gestação, com o crescimento acelerado do volume uterino, deve haver um maior cuidado com a realização dos exercícios em posição supina, por tempo prolongado, de modo a evitar a síndrome da hipotensão supina.

Os exercícios aeróbicos continuam a ser recomendados. Quanto aos alongamentos, embora recomendados, deve ter-se em conta alguns cuidados a partir da $10 .^{a}$ semana de gestação, que é quando ocorre o pico da hormona relaxina circulante, levando a uma maior flexibilidade dos tecidos articulares e ligamentos, logo, os alongamentos extensos e extremos podem aumentar o risco de lesões dessas estruturas.

Os exercícios para o fortalecimento muscular, exercícios perineais, mobilizações articulares e relaxamento, seguem as mesmas recomendações do primeiro trimestre (NASCIMENTO; GODOY; SURITA; SILVA, 2014). 


\subsubsection{Terceiro Trimestre}

Durante este trimestre, a grávida tende a diminuir a intensidade dos exercícios em função do aumento de peso corporal e outros desconfortos e limitações (WHITE; PFEIFER; HOLZMAN; \& PIVARNIK, 2020). Contudo, a prática de exercícios leves deve continuar a ser mantida. Neste período, a ACOG (2020) recomenda atividades na água, como a natação e a hidroginástica, e as caminhadas, de forma a manter a capacidade aeróbica e 0 condicionamento físico, bem como os exercícios de respiração, mobilizações e relaxamento envolvidos na preparação para o parto.

O TMAP deve continuar durante este trimestre, não havendo contraindicação para a sua prática. Para as mulheres que o realizaram durante a gestação, este trimestre é o momento ideal para tomarem consciência sobre o relaxamento dos músculos e o aumento da sua flexibilidade. No entanto, enquanto a efetividade deste treino durante a gestação está bem estabelecida na literatura para a prevenção de sintomas urinários, a utilização de técnicas como massagem perineal ainda necessita de mais estudos para esclarecer 0 seu efeito protetor durante e após o parto (NASCIMENTO; GODOY; SURITA; SILVA, 2014).

\section{I CONSIDERAÇÕES FINAIS}

Após a realização desta revisão, observa-se que é comum a falta de informação acerca desta temática, sendo pertinente a preocupação com determinados "tabus", decorrentes do quotidiano, em relação ao facto do que realmente é recomendado às grávidas no que respeita à prática de exercício físico durando o período gestacional.

Éimportante que se desmistifiquem falsas especulações, incentivando os profissionais de saúde a atualizarem as informações necessárias às suas intervenções, tendo em vista a transmissão, de forma clara, dos benefícios que o exercício físico proporciona às grávidas. Toda a atividade física que seja avaliada, orientada e acompanhada por um profissional de saúde, capacitado para tal, será uma intervenção mais segura, eficiente e tranquilizadora, permitindo um maior sucesso da mesma.

As grávidas saudáveis devem ser incentivadas a iniciar ou manter a prática de atividade física, com o objetivo de um melhor bem-estar físico, social e mental, contemplando os múltiplos benefícios proporcionados pelo exercício físico. Como confirmado nesta revisão, a atividade física reduz o risco de algumas doenças específicas da gravidez, do ganho excessivo de peso, de complicações no parto e de depressão no pós-parto, de complicações no recém-nascido, de efeitos adversos do peso ao nascer e do risco de natimortalidade.

Podemos concluir que a atividade física durante a gestação se tem demonstrado benéfica, tanto de forma preventiva, como forma de atenuar a dor e os desconfortos inerentes a este período, resultantes das alterações fisiológicas da gravidez, importantes 
para o normal crescimento do feto. Assim, esta revisão foi importante para conhecer os benefícios do exercício físico na gravidez, considerando, sempre, os riscos associados e as necessidades fisiológicas de cada mulher grávida, como uma individualidade.

\section{REFERÊNCIAS}

BAENA-GARCÍA, L.; OCÓN-HERNÁNDEZ, O.; ACOSTA-MANZANO, P.; COLL-RISCO, I. et al. Association of sedentary time and physical activity during pregnancy with maternal and neonatal birth outcomes. The GESTAFIT Project. Scandinavian Journal of Medicine \& Science in Sports, 29, n. 3, p. 407-414, 2019.

BRIK, M.; FERNÁNDEZ-BUHIGAS, I.; MARTIN-ARIAS, A.; VARGAS-TERRONES, M. et al. Does exercise during pregnancy impact on maternal weight gain and fetal cardiac function? A randomized controlled trial. Ultrasound in obstetrics \& gynecology : the official journal of the International Society of Ultrasound in Obstetrics and Gynecology, 53, n. 5, p. 583-589, 2019.

Committee Opinion Number 804, April 2015, Physical Activity and Exercise During Pregnancy and the Postpartum Period. The American College of Obstetricians and Gynecologists, p. 178-188, 2020.

Diretrizes da OMS para atividade física e comportamento sedentário: num piscar de olhos. Tradução CAMARGO, E. M. D. e AÑEZ, C. R. R. Genebra: Organização Mundial de Saúde, 2020.

GOUVEIA, R.; MARTINS, S.; SANDES, A. R.; NASCIMENTO, C. et al. Gravidez e exercício físico : mitos, evidências e recomendações. Acta Médica Portuguesa, 20, p. 209-214, 2007.

HONORATO, Y. D.; RODRIGUES, A. L. D. L. A Importância dos Exercícios Físicos Durante a Gravidez, sob o Olhar do Profissional de Educação Física. Revista Saúde e Educação, 2, p. 22-23, 2018.

LIMA, F. R.; OLIVEIRA, N. Gravidez e Exercício. Revista Brasileira de Reumatologia, 45, n. 3, p. 188-190, 2005.

LIU, Y. Q.; LIU, Y.; HUA, Y.; CHEN, X. L. Effect of diet and exercise intervention in Chinese pregnant women on gestational weight gain and perinatal outcomes: A quasi-experimental study. Applied nursing research : ANR, 36, p. 50-56, 2017.

MACEDO, C. D. S. G.; GARAVELLO, J. J.; OKU, E. C.; MIYAGUSUKU, F. H. et al. Benefícios do exercício físico para a qualidade de vida. Revista Brasileira de Atividade Física e Saúde, 8, n. 2, p. 19-27, 2003.

MANDOLESI, L.; POLVERINO, A.; S., M.; FOTI, F. et al. Effects of Physical Exercise on Cognitive Functioning and Wellbeing: Biological and Psychological Benefits. Frontiers in Psychology, 9, p. 509520, Abril 2018.

MANN, L.; KLEINPAUL, J.; TEIXEIRA, C.; KONOPKA, C. DOR LOMBO-PÉLVICA E EXERCÍCIO FÍSICO DURANTE A GESTAÇÃO. Fisioterapia em Movimento, 21 n. 2, p. 99-105, 2008.

Manual Revisão Bibliográfica Sistemática Integrativa: a pesquisa baseada em evidências. Belo Horizonte: GRUPO ĂNIMA EDUCAÇÃO, 2014. 
MATA, F.; CHULVI, I.; ROIG, J.; HEREDIA, J. R. et al. Prescripción del ejercicio físico durante el embarazo. Revista Andaluza de Medicina del Deporte, 3, n. 2, p. 68-79, Junho 2010.

MONTENEGRO, L. D. P. MUSCULAÇÃO: ABORDAGENS PARA A PRESCRIÇÃOE RECOMENDAÇÕES PARA GESTANTES. Revista Brasileira de Prescrição e Fisiologia do Exercício, 8, n. 47, p. 494-498, 2014.

NASCIMENTO, S. L. D.; GODOY, A. C.; SURITA, F. G.; SILVA, J. L. P. E. Recomendações para a prática de exercício físico na gravidez: uma revisão crítica da literatura. Revista Brasileira de Ginecologia e Obstetrícia, 36, n. 9, p. 423-431, 2014.

Organização Mundial de Saúde: Atividade Física - Folha Informativa № 385. OMS, Disponível em: https://actbr.org.br/uploads/arquivo/957_FactSheetAtividadeFisicaOMS2014_port_REV1.pdf. Acesso em Fevereiro 2021.

PAGE, M. J.; MCKENZIE, J. E.; BOSSUYT, P. M.; BOUTRON, I. et al. BMJ. The PRISMA 2020 statement: an updated guideline for reporting systematic reviews. 3722021.

PEREIRA, J. F.; AGUIAR, V. L. S. D. Atividade física e gestação: Uma breve revisão sistemática de literatura. 55 p. 2016.

PINHÃO, C. D. R. G. R. C. Mapear o cuidado para regressar a casa. Instituto Politécnico de Setúbal. Setúbal. 2012.

RAMALHO, A. Manual para a redacção de estudos e projectos de revisão sistemática com e sem metanálise. Coimbra: Formasau, 2005.

SADEGHI, B.; SIRATI-NIR, M.; HAJIMINI, Z.; EBADI, A. et al. Comparing the Effects of Progressive Muscle Relaxation and Physical Activity on Pregnant Women's General Health. Iranian journal of nursing and midwifery research, 23, n. 4, p. 298-304, 2018.

SANDA, B.; VISTAD, I.; SAGEDAL, L. R.; HAAKSTAD, L. et al. What is the effect of physical activity on duration and mode of delivery? Secondary analysis from the Norwegian Fit for Delivery trial. Acta obstetricia et gynecologica Scandinavica, 97, n. 7, p. 861-871, 2018.

SYTSMA, T. T.; ZIMMERMAN, K. P.; MANNING, J. B.; JENKINS, S. M. et al. Perceived Barriers to Exercise in the First Trimester of Pregnancy. The Journal of perinatal education, 27, n. 4, p. 198-206, 2018.

VARGAS-TERRONES, M.; NAGPAL, T. S.; BARAKAT, R. Impact of exercise during pregnancy on gestational weight gain and birth weight: an overview. Brazilian journal of physical therapy, 23, n. 2, p. 164-169, 2019.

WHITE, E.; PFEIFER, K.; HOLZMAN, C.; \& PIVARNIK, J. Motives for and barriers to exercising across trimesters of pregnancy in health club members. Human Movement, 21, n. 3, p. 21-30, 2020.

ZAREZADEH, T.; NEMATI, N. The effect of exercise on childbirth in primiparous women: A clinical trial study. Nursing Practice Today, 3, n. 2, p. 36-48, 2016. 
Data de aceite: $20 / 08 / 2021$

Data de submissão: 04/06/2021

Jullia Greque Calabrez

Escola de Ciências da Santa Casa de

Misericórdia de Vitória (EMESCAM)

Vitória - Espírito Santo

http://lattes.cnpq.br/0127566458668330

Julia Rocha Franzosi

Escola de Ciências da Santa Casa de

Misericórdia de Vitória (EMESCAM)

Vitória - Espírito Santo

http://lattes.cnpq.br/1331690187056330

Lívia Secomandi Toledo

Escola de Ciências da Santa Casa de

Misericórdia de Vitória (EMESCAM)

Vitória - Espírito Santo

http://lattes.cnpq.br/7783566767628628

Mariana Louzada Monteiro Lobato Galvão de

São Martinho

Escola de Ciências da Santa Casa de

Misericórdia de Vitória (EMESCAM)

Vitória - Espírito Santo

http://lattes.cnpq.br/0092501332066418

Talita Barbosa Moreira

Escola de Ciências da Santa Casa de

Misericórdia de Vitória (EMESCAM)

Vitória - Espírito Santo

http://lattes.cnpq.br/0369709113926985

RESUMO: Introdução: A gravidez na adolescência ainda é algo recorrente. Gestar é algo que demanda abdicação e responsabilidade.
No entanto, percebe-se certo grau de descuido com as consultas pré-natais, o que pode resultar em graves consequências para a saúde da mãe e, principalmente, para a saúde do neonato. Diante do contexto, a gravidez na adolescência é visto como uma questão de saúde pública e a realização de um pré-natal de qualidade, como o preconizado pelo Sistema único de Saúde (SUS), é de fundamental importância a fim de minimizar os riscos à saúde da mãe e da criança. Objetivo: Identificar as consequências para o recém-nascido e para a gestante adolescente que não realiza o pré-natal ou o faz de maneira inapropriada. Método: Revisão sistematizada na base de dados PubMed, SciELO e Lilacs de 2010 a 2017. Discussão/Resultado: A gravidez na adolescência gera grandes modificações psicológicas, emocionais e sociais, e como parte de uma questão de saúde pública é objeto de diretrizes e preconizações do SUS. A realização de pré-natal com, minimamente, 06 consultas com início no primeiro trimestre e a de exames clínico-obstétricos e laboratoriais diminuem a incidência de síndrome Hipertensiva da gravidez, anemia, diabetes gestacional, complicações no parto. Além de reduzir a ocorrência de bebês com baixo peso ao nascer (BPN), doenças respiratórias, tocotraumatismo, frequência de complicações neonatais e mortalidade infantil. Conclusão: A frequência das consultas prénatais, superior a seis, são essenciais para a qualidade da saúde da mãe e do recém-nato.

PALAVRAS - CHAVE: Gravidez na adolescência; Cuidado pré-natal; Brasil e Análise de consequências. 
ABSTRACT: Introduction: Teenage pregnancy is still something recurrent. Pregnancy is something that demands abdication and responsibility. However, there is a certain degree of carelessness with prenatal consultations, which can result in serious consequences for the health of the mother and, especially, for the health of the newborn. In light of the context, teenage pregnancy is seen as a public health issue and quality prenatal care, as recommended by the Unified Health System (SUS), is of fundamental importance in order to minimize the risks to mother and child health. Objective: To identify the consequences for the newborn and for the adolescent pregnant woman who does not perform prenatal care or does so inappropriately. Method: Systematized review in the PubMed, SciELO and Lilacs database from 2010 to 2017. Discussion/Result: Teenage pregnancy generates major psychological, emotional and social changes, and as part of a public health issue, it is the object of guidelines and recommendations of the SUS. Prenatal care with at least 06 consultations starting in the first trimester and clinical-obstetric and laboratory tests reduce the incidence of Hypertensive Syndrome of pregnancy, anemia, gestational diabetes, complications in childbirth. In addition to reducing the occurrence of babies with low birth weight (LBW), respiratory diseases, birth trauma, frequency of neonatal complications and infant mortality. Conclusion: The frequency of prenatal consultations, above six, is essential for the quality of health of the mother and newborn.

KEYWORDS: Pregnancy in Adolescence; Prenatal Care; Brazil e Consequence Analysis.

\section{I INTRODUÇÃO}

A adolescência é definida pela Organização Mundial da Saúde (OMS) como o período entre dez e dezenove anos. É caracterizado por profundas e extensas mudanças tanto no aspecto físico como no psicológico, com repercussão individual, familiar e social.

Restringindo a adolescência ao plano reprodutivo, de acordo com BERRETA (2006)., a maioria desses jovens, em nosso meio, chega à maturidade sexual antes de atingir a maturidade social, emocional ou a independência econômica. Dentre múltiplas determinações, a erotização do adolescente, promovida pela mídia, segundo aponta FUJIMORI et al (1997), estimula a iniciação sexual precoce que, na ausência do domínio das práticas contraceptivas, pode resultar em gravidez não desejada.

A gestação em adolescentes pode estar relacionada a comportamentos de risco como, por exemplo, a utilização de álcool e drogas ou mesmo a precária realização de acompanhamento pré-natal durante a gravidez (CAPUTO E BORDIN, 2007).

Algumas complicações como tentativas de abortamento, anemia, desnutrição, sobrepeso, hipertensão, pré-eclâmpsia, desproporção céfalo-pélvica e depressão pósparto estão associadas à experiência de gravidez na adolescência. (BELARMINO et al, 2009)

Por outro lado, no que tange à saúde do bebê, a gestação na adolescência encontrase associada a situações de prematuridade, baixo peso ao nascer, morte perinatal, 
epilepsia, deficiência mental, transtornos do desenvolvimento, baixo quociente intelectual, cegueira, surdez, aborto natural, além de morte na infância. (AQUINO-CUNHA et al, 2002)

O bebê prematuro apresenta maiores riscos na adaptação à vida extrauterina devido à imaturidade dos órgãos e sistemas; além de uma maior vulnerabilidade ao desenvolvimento de doenças. Os riscos da gestação na adolescência ainda estão associados à baixa adesão ao atendimento pré-natal demonstrado pelas adolescentes. (CARNIEL et al, 2006)

Cabe ressaltar que o acompanhamento pré-natal tem efeito protetor sobre a saúde da gestante e do recém-nascido, uma vez que contribui para uma menor incidência de mortalidade materna, baixo peso ao nascer e mortalidade perinatal. (GAMA E SZWARCWALD, 2002)

A assistência às adolescentes grávidas, geralmente, acontece na Unidade de Atenção Primária à Saúde (UAPS) por meio da consulta de pré-natal com enfermeiros e médicos. De acordo com o Ministério da Saúde, dentre as atividades de acompanhamento seguem as de orientar sobre os aspectos específicos da gestação, cuidados consigo e com o bebê, para que a gestação e o parto ocorram com menos riscos de complicações.

Em contrapartida, estudos realizados em diferentes regiões brasileiras mostram que a assistência pré-natal ao público adolescente ainda se encontra muito aquém do preconizado, principalmente no tocante à oferta de orientações, captação precoce e continuidade da assistência. As atividades de orientação/educação são preteridas em virtude do excesso de atribuições do profissional, outras demandas e tempo restrito à consulta de pré-natal. (CAMINHA, 2012), (FERNANDES, 2015)

Segundo Oliveira, em estudo realizado em 2010 na Unidade de Atenção Primária à Saúde no município de Fortaleza, Ceará, percebia-se que as adolescentes não participavam ativamente das consultas de pré-natal. Havia um número considerável de gestantes adolescentes na área de cobertura da UAPS e apesar dos esforços dos enfermeiros e dos agentes comunitários de saúde em captá-las precocemente para a consulta de pré-natal e de inseri-las no grupo de gestantes, os problemas de assiduidade eram recorrentes e, muitas vezes, as adolescentes não realizavam os exames e outros cuidados, aumentando os riscos associados à gravidez.

Durante a consulta individual, uma das pesquisadoras, que trabalhava na UAPS, questionava as adolescentes sobre o não comparecimento às atividades do grupo. Dentre os motivos relatados destaca-se a falta de interesse nos assuntos trabalhados e vergonha de partilhar suas dúvidas e dificuldades com as outras participantes. (OLIVEIRA, 2015)

\section{2। OBJETIVO}

Identificar as consequências para o recém-nascido e para a gestante adolescente que não realiza o pré-natal ou o faz de maneira inapropriada. 


\section{3| MÉTODO}

Esse estudo foi realizado a partir de uma revisão de artigos entre os anos de 2010 a 2017 selecionados, por meio da busca eletrônica nas bases de dados, PubMed, SciELO e Lilacs, sendo esses artigos 3 do PubMed, 10 da SciELO e 7 do Lilacs. Destes, foram utilizados 6 como fonte de consulta para a realização da revisão.

Foram utilizados os termos descritores cadastrados no DeCS e MeSH, sendo eles: gravidez na adolescência (Pregnancy in Adolescence), cuidado pré-natal (Prenatal Care), Brasil (Brazil) e análise de consequências (Consequence Analysis).

A procura por artigos foi feita entre o mês de setembro e outubro de 2017. Os textos foram filtrados por idioma (português e inglês), artigos disponíveis para leitura completa, estudos realizados apenas em humanos e data de publicação.

\section{Critério de inclusão e exclusão}

Artigos não relacionados com o assunto abordado foram selecionados por meio da leitura dos títulos. Mediante análise dos resumos, foram excluídos artigos que fugiam ao tema. Os trabalhos restantes foram lidos integralmente e selecionados pela relevância do assunto e contribuição, mesmo que mínima, ao tema.

De acordo com o Sistema Único de Saúde (SUS), o número mínimo de consultas pré-natais é seis. Portanto, foram excluídos artigos que apresentavam uma recomendação menor que a descrita pelo SUS.

Em concordância com o objetivo desta revisão, foram selecionados apenas artigos que abordavam o tema a nível Brasil e de uma forma mais atual. Diante disso, foram excluídos artigos publicados antes de 2010.

\section{I DISCUSSÃO/RESULTADOS}

A adolescência é o período que se caracteriza pela transição da infância para a idade adulta, ou seja, pela perda da identidade infantil, busca da identidade adulta, sendo, assim, uma fase de profunda instabilidade emocional e mudanças corporais.

Segundo a Organização Mundial da Saúde, $22 \%$ dos adolescentes fazem sexo pela primeira vez aos 15 anos de idade. É nesta fase importante de autoconhecimento e incertezas que a falta de informação pode gerar uma gravidez inesperada ou mesmo a contaminação por doenças sexualmente transmissíveis.

Nesse raciocínio, percebe-se que o ambiente familiar também tem relação direta com o início da atividade sexual. Experiências sexuais precoces são observadas em adolescentes cuja família, os irmãos mais velhos já apresentam vida sexual ativa. É comum encontrar adolescentes grávidas cujas mães também iniciaram a vida sexual precocemente ou engravidaram durante a sua adolescência (BECK et al, 2010), (FRASER et al, 1995), 
(RIBEIRO, 2000).

Desse modo, a problemática se instaura na perspectiva de que a gravidez na adolescência é um fenômeno complexo, pois o risco à saúde da mãe e da criança é real, considerando que nem sempre o corpo da adolescente está preparado fisiologicamente para o desenvolvimento da gestação. Segundo a Secretaria de Atenção à Saúde outros riscos, além do biológico, também são apontados, como a maior vulnerabilidade relacionada à situação social, falta de informação e falta de competência emocional, que podem trazer agravantes na condução do ciclo gravídico puerperal, no cuidado com o recém-nascido e no autocuidado materno.

Até aproximadamente meados do século $X X$, a gestação na adolescência não era considerada uma questão de saúde pública, e também não recebia a atenção de pesquisadores como recebe hoje em dia. De acordo com o Instituto Brasileiro de Geografia e Estatística, no Brasil, esse fenômeno tornou-se mais visível com o aumento da proporção de nascimentos em mães menores de 20 anos que se observou ao longo da década de 90 , quando os percentuais passaram de 16,38\% em 1991 para 21,34\% em 2000.

Segundo o Ministério da Saúde, no ano de 2015, dados do Sistema de Informações sobre Nascidos Vivos (SINASC) constam 53.400 gestantes entre 10 e 14 anos e 1.041 .728 entre 15 e 19 anos, no Brasil.

A gravidez pode acontecer, tanto pela legítima vontade de querer ser mãe, quanto pela simples falta de informação sobre a sexualidade, saúde reprodutiva e métodos contraceptivos. Pode ainda estar relacionada com aspectos comportamentais, como a falta de habilidade da jovem em convencer ou até sugerir ao seu parceiro o uso do preservativo, ou ainda pela falta de noção quanto aos riscos a que se expõem não praticando sexo seguro. (SANTOS, 2012)

Em termos sociais, a gravidez na adolescência pode estar associada com pobreza, evasão escolar, desemprego, ingresso precoce em um mercado de trabalho não-qualificado, separação conjugal, situações de violência e negligência, diminuição das oportunidades de mobilidade social, além de maus tratos infantis. (ALMEIDA E AQUINO, 2006)

A maioria das adolescentes abandona os estudos para cuidar da criança, ocorrendo aumento dos riscos de desemprego, mudança de estrato socioeconômico e dependência econômica dos familiares, perpetuando-se assim, a pobreza, educação limitada, abuso e violência familiar tanto à mãe quanto à criança. (SUZUKI et al, 2007)

Um fator social que pôde ser observado foi a interação entre a idade da gestante e o seu estado civil, com a chance de mães menores de 18 anos sem parceiros terem bebês com baixo peso ao nascer (BPN). Essa interação foi cerca de três vezes maior do que as mães com idade entre 20 e 24 anos. Não houve associação entre a idade materna com BPN nas mães que reportaram que viviam com seu parceiro. (GUIMARÃES et al, 2013)

No intuito de ofertar uma atenção qualificada e humanizada a essas gestantes, segundo Manual Técnico de Pré-natal e Puerpério (2006), o Ministério de Saúde recomenda 
o número mínimo de seis consultas para uma gestação a termo, com o início do pré-natal no primeiro trimestre e a realização de alguns procedimentos básicos, que incluem exames clínico-obstétricos e laboratoriais, entre outros.

O ministério da Saúde orienta que a primeira consulta de pré-natal, deve ser realizada anamnese, abordando aspectos epidemiológicos, além dos antecedentes familiares, pessoais, ginecológicos e obstétricos e a situação da gravidez atual. Deverão ser realizados exames físicos e laboratoriais que se desenvolvem da seguinte maneira:

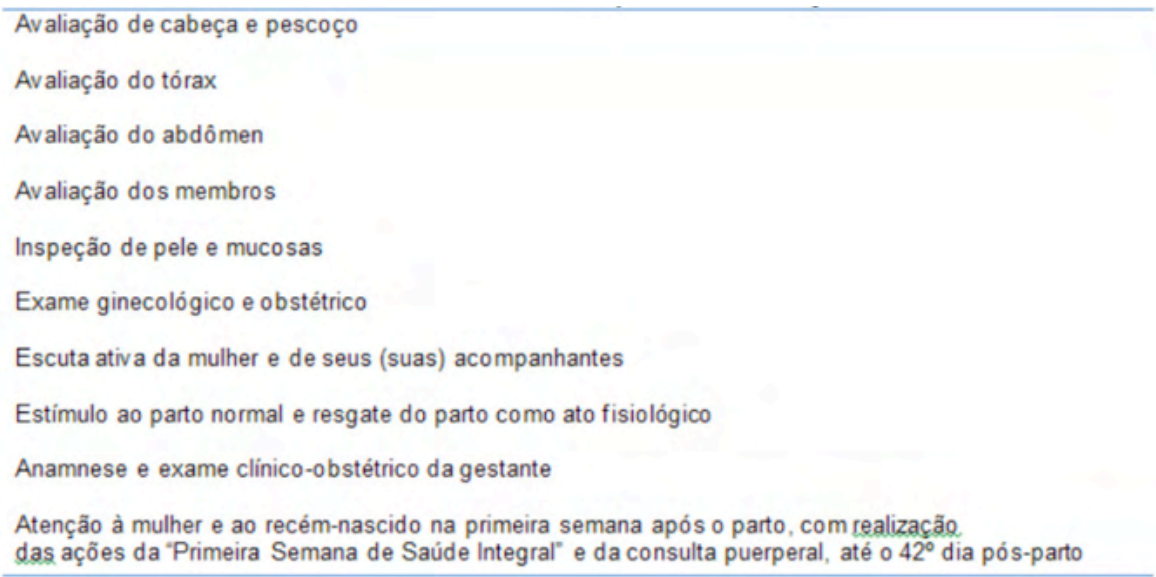

Tabela 1 - Exames físicos e primeiras orientações.

Fonte: Manual Técnico Pré - Natal e Puerpério - Ministério da Saúde.

\begin{abstract}
ABO-Rh, hemoglobina/hematócrito, na primeira consulta.
Glicemia de jejum, um exame na primeira consulta e outro próximo à $30^{4}$ semana de gestação

VDRL, um exame na primeira consulta e outro próximo à $30^{4}$ semana de gestação

Urina tipo 1, um exame na primeira consulta e outro próximo à $30^{4}$ semana de gestação

Testagem anti-HIV, com um exame na primeira consulta e outro próximo à $30^{\circ}$ semana de gestação, sempre que possivel.

Sorologia para hepatite $\mathrm{B}(\mathrm{HBs} A g)$, com um exame, de preferência, próximo à $30^{\star}$ semana de gestação, se disponivel.

Sorologia para toxoplasmose na primeira consulta, se disponivel.

Avaliação do estado nutricional da gestante e monitoramento por meio do SISVAN
\end{abstract}

Tabel 2 - Exames laboratoriais.

Fonte: Dados fictícios, apenas fins ilustrativos.

Após esses primeiros exames, quando uma adolescente dá continuidade à gestação e passa pelo momento do parto, ocorre a sobreposição de "crises" de forma que "as gestantes adolescentes vivenciam uma sobrecarga emocional" que requer uma assistência diferenciada durante todo o ciclo grávido-puerperal. 
Embora se saiba que "condutas baseadas somente nos aspectos físicos não são suficientes", ${ }^{25}$ em nosso país vigora um modelo de assistência em que o domínio do evento fisiológico, muitas vezes, é mais relevante que o bem-estar da parturiente. Esse modelo caracteriza-se pelo enfoque nos riscos potenciais, os quais justificam a execução de um grande número de procedimentos invasivos, como o uso de ocitócitos (DIAS, 2006) e até mesmo intervenções danosas como "a proibição de alimentação durante o trabalho de parto, a exigência de tricotomia, a realização rotineira da episiotomia, a imposição de posição de litotomia, além da exclusão da presença de familiares e/ou amigos(as) do processo de parturição" (MCCALLUM e REIS, 2006). Na realidade, a sofisticação tecnológica da prática obstétrica tornou-se mecanizada e massificada, o que em muitos casos, gera maior insegurança e ansiedade na mulher, prejudicando o trabalho de parto. (BEZERRA e CARDOSO, 2006)

Assim, a associação dessas imposições e a ausência de um pré-natal adequado, como citado anteriormente, geram do ponto de vista biológico, consequências à gravidez para a adolescente, sendo as maiores incidências de síndrome hipertensiva da gravidez (SHG), anemia, diabetes gestacional, complicações no parto, determinando aumento da mortalidade materna e infantil (AZEVEDO e SAMPAIO, 2003), (ELFENBEIN, 2003) e (CARVALHO et al, 2006). É importante notar que alguns estudos têm demonstrado aumento na incidência de intercorrências pré-natais, intraparto e pós-parto entre gestantes adolescentes. 32,33

No tocante aos problemas com o recém-nascido, a gravidez na adolescência está associada a taxas mais elevadas de baixo peso ao nascer (BPN), parto pré-termo, doenças respiratórias e tocotraumatismo, além de maior frequência de complicações neonatais e mortalidade infantil.

O bebê prematuro apresenta maiores riscos na adaptação à vida extrauterina devido à imaturidade dos órgãos e sistemas; além de uma maior vulnerabilidade ao desenvolvimento de doenças. (AQUINO-CUNHA, 2003), (ROCHA, 2007), (CHALEM, 2006)

Agravidez na adolescência, certamente, acarreta grandes modificações psicológicas, emocionais e sociais, e os resultados, muitas vezes, são contraditórios e representam as ambivalências e as contradições próprias da adolescência retratando a complexidade da maternidade nessa etapa de desenvolvimento. A nova realidade apresentada pelo nascimento do bebê se dá de forma impactante, modificando intensamente os projetos de vida de cada adolescente. (CASTRO, 2016)

\section{I CONCLUSÃO}

A negligência no acompanhamento pré-natal - consultas pré-natais inferior a seis, segundo o SUS - podem resultar em problemas graves de saúde para a mãe e para o bebê. Aborto, anemia, hipertensão, pré-eclâmpsia, desproporção céfalo-pélvica e depressão 
pós-parto são os principais agravos que acometem a jovem mãe. O mais afetado com a realização inapropriada do pré-natal, no entanto, é o recém-nato. São diversas complicações que podem acometê-lo ainda na vida intrauterina e seguir-se na vida extra uterina, como a prematuridade, o baixo peso ao nascer, a morte ao nascer, a epilepsia, a deficiência mental, os transtornos de desenvolvimento, o baixo quociente intelectual, a cegueira, a surdez, o aborto natural e a morte na infância.

\section{REFERÊNCIAS}

ALMEIDA, M. C. C.; AQUINO, E. M. L. School Trajectory And Teenage Pregnancy in three Brazilian state capitals. Cadernos de Saúde Pública, [s. I, v. 22, p. 1397-1409, 2006.

AQUINO-CUNHA, Margarida et al. Gestação na Adolescência: Relação com o Baixo Peso ao Nascer. Revista Brasileira de Ginecologia e Obstetrícia [online]. 2002, v. 24, n. 8 [Acessado 3 Junho 2021] , pp. 513-519. Disponível em: <https://doi.org/10.1590/S0100-72032002000800003>. Epub 21 Jan 2003. ISSN 1806-9339. https://doi.org/10.1590/S0100-72032002000800003.

AQUINO-CUNHA, Margarida et al. Gestação na Adolescência: Relação com o Baixo Peso ao Nascer. Revista Brasileira de Ginecologia e Obstetrícia [online]. 2002, v. 24, n. 8 [Acessado 3 Junho 2021] , pp. 513-519. Disponível em: <https://doi.org/10.1590/S0100-72032002000800003>. Epub 21 Jan 2003. ISSN 1806-9339. https://doi.org/10.1590/S0100-72032002000800003.

AZEVEDO, Daniela Vasconcelos de; SAMPAIO, Helena Alves de Carvalho. Fatores de risco associados à gestação na adolescência / Risk factors associated of adolescence pregnancy. LILACS , [s. I.], 31 maio 2021.

BECK, Stacy et al. The world wide incidence of preterm birth: a systematic review of maternal mortality and morbidity. Bull World Health Organ, Genebra, v. 88, n. 1, p. 31-38, jan. 2010.

BELARMINO, Glayriann Oliveira et al. Risco nutricional entre gestantes adolescentes. Acta Paulista de Enfermagem [online]. 2009, v. 22, n. 2 [Acessado 3 Junho 2021] , pp. 169-175. Disponível em: <https://doi.org/10.1590/S0103-21002009000200009>. Epub 03 Jun 2009. ISSN 1982-0194. https://doi. org/10.1590/S0103-21002009000200009.

BERETTA, Maria Isabel Ruiz; DENARI, Fátima Elisabeth; PEDRAZZANI, João Carlos. Estudo sobre a incidência de partos na adolescência em um município do Estado de São Paulo. Revista LatinoAmericana de Enfermagem [online]. 1995, v. 3, n. 2 [Acessado 3 Junho 2021] , pp. 181-191. Disponível em: <https://doi.org/10.1590/S0104-11691995000200013>. Epub 19 Jun 2006. ISSN 1518-8345. https://doi.org/10.1590/S0104-11691995000200013.

BEZERRA, Maria Gorette Andrade e CARDOSO, Maria Vera Lucia Moreira Leitão. Fatores culturais que interferem nas experiências das mulheres durante o trabalho de parto e parto. Revista Latino-Americana de Enfermagem [online]. 2006, v. 14, n. 3 [Acessado 3 Junho 2021] , pp. 414-421. Disponível em: <https://doi.org/10.1590/S0104-11692006000300016>. Epub 10 Jul 2006. ISSN 15188345. https://doi.org/10.1590/S0104-11692006000300016.

BRASIL. Ministério da Saúde, Secretaria de Atenção à Saúde. Departamento de Atenção Básica. Atenção ao pré-natal de baixo risco. Brasília, 2012. 
BRASIL. Ministério da Saúde. Área Técnica de Saúde da Mulher. Pré-natal e puerpério: atenção qualificada e humanizada. Brasília, 2005.

BRASIL. Ministério da Saúde. Secretaria de Atenção à Saúde. Departamento de Ações Programáticas e Estratégicas. Manual Técnico de Pré- Natal e Puerpério. Brasília, 2006.

BRASIL. Sistema de Informações Sobre Nascidos Vivos. Ministério da Saúde (org.). Tabulação de dados de nascidos Vivos. 2017. Portal Datasus. Disponível em: <http://tabnet.datasus.gov.br/cgi/ tabcgi.exe?sinasc/nv/nvcuf.def>. Acesso em: 08 nov. 2017.

CAMINHA, Náira de Oliveira et al. Gestação na adolescência: descrição e análise da assistência recebida. Revista Gaúcha de Enfermagem [online]. 2012, v. 33, n. 3 [Acessado 3 Junho 2021] , pp. 81-88. Disponível em: <https://doi.org/10.1590/S1983-14472012000300011>. Epub 29 Out 2012. ISSN 1983-1447. https://doi.org/10.1590/S1983-14472012000300011.

CAPUTO, Valéria Garcia e Bordin, Isabel Altenfelder. Problemas de saúde mental entre jovens grávidas e não-grávidas. Revista de Saúde Pública [online]. 2007, v. 41, n. 4 [Acessado 3 Junho 2021] , pp. 573-581. Disponível em: <https://doi.org/10.1590/S0034-89102007000400011>. Epub 06 Jul 2007. ISSN 1518-8787. https://doi.org/10.1590/S0034-89102007000400011.

CARNIEL, Emília de Faria et al. Características das mães adolescentes e de seus recém-nascidos e fatores de risco para a gravidez na adolescência em Campinas, SP, Brasil. Revista Brasileira de Saúde Materno Infantil [online]. 2006, v. 6, n. 4 [Acessado 3 Junho 2021] , pp. 419-426. Disponível em: <https://doi.org/10.1590/S1519-38292006000400009>. Epub 02 Fev 2007. ISSN 1806-9304. https://doi. org/10.1590/S1519-38292006000400009.

CARVALHO, Regina Coeli Marques de et al. Fatores preditivos de hipertensão gestacional em adolescentes primíparas: análise do pré-natal, da MAPA e da microalbuminúria. Arquivos Brasileiros de Cardiologia [online]. 2006, v. 87, n. 4 [Acessado 3 Junho 2021] , pp. 487-495. Disponível em: <https://doi.org/10.1590/S0066-782X2006001700014>. Epub 21 Nov 2006. ISSN 1678-4170. https://doi.org/10.1590/S0066-782X2006001700014.

CASTRO, ASVP; PEREIRA, BS. Representação social de adolescentes frente à gravidez. Rev psique, [s. I], v. 1, n. 1, p. 86-101, 2016.

CHALEM, Elisa et al. Gravidez na adolescência: perfil sócio-demográfico e comportamental de uma população da periferia de São Paulo, Brasil. Cadernos de Saúde Pública [online]. 2007, v. 23, n. 1 [Acessado 3 Junho 2021] , pp. 177-186. Disponível em: <https://doi.org/10.1590/ S0102-311X2007000100019>. Epub 14 Dez 2006. ISSN 1678-4464. https://doi.org/10.1590/S0102$311 \times 2007000100019$.

DIAS, Marcos Augusto Bastos. Humanização da assistência ao parto: conceitos, lógicas e práticas no cotidiano de uma maternidade pública. Repositório Institucional da Fiocruz , [s. I.], 2006. ELFENBEIN, Dianne S; FELICE, Marianne E. Adolescent pregnancy: review. Pediatr clin North Am, [s. ], v. 50, n. 4, p. 781-800, ago. 2003.

FERNANDES, Rita Fernanda Monteiro et al. Characteristics of antenatal care for adolescents from state capitals in Southern and Northeastern Brazil1 1 Paper taken from the dissertation - Prenatal care in adolescence, presented to the School of Nursing at Universidade Federal de Pelotas (UFPel), in 2011. This study is an excerpt from a multicenter research entitled - Social support networks for fatherhood during adolescence, coordinated by the School of Nursing at UFpel in partnership with Universidade Federal da Paraíba (UFPB) and Universidade Federal de Santa Catarina (UFSC), under 
CNPq funding 551222/2007. Texto \& Contexto - Enfermagem [online]. 2015, v. 24, n. 1 [Acessado 3 Junho 2021] , pp. 80-86. Disponível em: <https://doi.org/10.1590/0104-07072015001230012>. ISSN 1980-265X. https://doi.org/10.1590/0104-07072015001230012.

FRASER, A. M.; BROKERT, E.; WARD, R. H. Association of young maternal age with adverse reproductive outcomes. N Engl J Med. Massachusetts, p. 1113-1117. abr. 1995.

FUJIMORI, Elizabeth et al. Perfil socioeconómico y biológico de embarazadas adolescentes de una maternidad de beneficencia en São Paulo, Brasil. Cuad. Méd.-Soc. (Santiago de Chile), Santiago, v. 38, n. 2, p. 97-104, jun. 1997.

GAMA, Silvana Granado Nogueira da; SZWARCWALD, Célia Landmann e LEAL, Maria do Carmo. Experiência de gravidez na adolescência, fatores associados e resultados perinatais entre puérperas de baixa renda. Cadernos de Saúde Pública [online]. 2002, v. 18, n. 1 [Acessado 3 Junho 2021] , pp. 153-161. Disponível em: <https://doi.org/10.1590/S0102-311X2002000100016>. Epub 18 Mar 2002. ISSN 1678-4464. https://doi.org/10.1590/S0102-311X2002000100016.

Governo do Brasil. Campanhas educativas previnem a gravidez precoce no País. Acesso em: 08 de novembro de 2017. Disponível em: http://www.brasil.gov.br/saude/2012/04/campanhas-educativasprevinem-a-gravidez-precoce-no-pais.

GUIMARÃES, AM, et al. Is adolescent pregnancy a risk factor for low birth weight? Rev Saúde Pública, [s. I], v. 47, n. 1, p. 9-11, fev. 2013.

IACOBELLI S, ROBILLARD PY, GOUYON JB, HULSEY TC, BARAU G, BONSANTE F. Obstetric and neonatal outcomes of adolescent primiparous singleton pregnancies: a cohort study in the South of Reunion Island, Indian Ocean. J Matern Fetal Neonatal Med. 2012 Dec;25(12):2591-6. doi: 10.3109/14767058.2012.718003. Epub 2012 Sep 7. PMID: 22889253.

Instituto Brasileiro de Geografia e Estatística. (2002). Estatística do Registro Civil (vol. 29). Rio de Janeiro:MCCALLUM, Cecilia e REIS, Ana Paula dos. Re-significando a dor e superando a solidão: experiências do parto entre adolescentes de classes populares atendidas em uma maternidade pública de Salvador, Bahia, Brasil. Cadernos de Saúde Pública [online]. 2006, v. 22, n. 7 [Acessado 3 Junho 2021] , pp. 1483-1491. Disponível em: <https://doi.org/10.1590/S0102-311X2006000700012>. Epub 14 Jun 2006. ISSN 1678-4464. https://doi.org/10.1590/S0102-311X2006000700012.

MICHELAZZO, Daniela et al. Indicadores sociais de grávidas adolescentes: estudo caso-controle. Revista Brasileira de Ginecologia e Obstetrícia [online]. 2004, v. 26, n. 8 [Acessado 3 Junho 2021] , pp. 633-639. Disponível em: <https://doi.org/10.1590/S0100-72032004000800007>. Epub 23 Nov 2004. ISSN 1806-9339. https://doi.org/10.1590/S0100-72032004000800007.

OLIVEIRA, Denize Cristina de. Prioridades de pesquisa em enfermagem e as linhas de pesquisa: dando continuidade ao debate [Nursing research priorities and research lines: an on-going discussion]. Revista Enfermagem UERJ, [S.I.], v. 22, n. 5, p. 712-716, mar. 2015. ISSN 0104-3552. Disponível em: $<$ https://www.e-publicacoes.uerj.br/index.php/enfermagemuerj/article/view/12771>. Acesso em: 03 jun. 2021. doi:https://doi.org/10.12957/reuerj.2014.12771.

Organização Mundial da Saúde. El embarazo y el aborto en la adolescência. Genebra, 1975. 
RIBEIRO, Eleonora RO et al. Comparação entre duas coortes de mães adolescentes em município do Sudeste do Brasil. Revista de Saúde Pública [online]. 2000, v. 34, n. 2 [Acessado 4 Junho 2021] , pp. 136-142. Disponível em: <https://doi.org/10.1590/S0034-89102000000200006>. Epub 06 Ago 2001. ISSN 1518-8787. https://doi.org/10.1590/S0034-89102000000200006.

ROCHA, Ricardo Cristiano Leal da et al. Prematuridade e baixo peso entre recém-nascidos de adolescentes primíparas. Revista Brasileira de Ginecologia e Obstetrícia [online]. 2006, v. 28, n. 9 [Acessado 3 Junho 2021] , pp. 530-535. Disponível em: <https://doi.org/10.1590/S010072032006000900005>. Epub 18 Jan 2007. ISSN 1806-9339. https://doi.org/10.1590/S010072032006000900005.

SANTOS, Antonía Alizandra Gomes dos et al. Sentidos atribuídos por profissionais à promoção da saúde do adolescente. Ciência \& Saúde Coletiva [online]. 2012, v. 17, n. 5 [Acessado 3 Junho 2021] , pp. 1275-1284. Disponível em: <https://doi.org/10.1590/S1413-81232012000500021>. Epub 25 Maio 2012. ISSN 1678-4561. https://doi.org/10.1590/S1413-81232012000500021.

SECRETÁRIA DE ATENÇÃO A SAUDE. Ministério da Saúde (BR). 2010. Diretrizes Nacionais para a Atenção Integral à Saúde de Adolescentes e Jovens na Promoção, Proteção e Recuperação da Saúde, Brasília - DF, 2010

SUZUKI, Cristina Mika et al . Análise comparativa da freqüência de prematuridade e baixo peso entre filhos de mães adolescentes e adultas. Rev. bras. crescimento desenvolv. hum., São Paulo, v. 17, n. 3, p. 95-103, dez. 2007 . Disponível em <http://pepsic.bvsalud.org/scielo.php?script=sci_ arttext\&pid=S0104-12822007000300010\&Ing=pt\&nrm=iso>. acessos em 03 jun. 2021. 


\section{CAPÍTULO 3}

\section{ASSISTÊNCIA DE ENFERMAGEM À PACIENTE GESTANTE COM DIAGNÓSTICO DE LÚPUS ERITEMATOSO SISTÉMICO: RELATO DE EXPERIÊNCIA}

Data de aceite: $20 / 08 / 2021$

Data de submissão: 01/06/2021

Ravena de Sousa Alencar Ferreira Universidade Federal do Piauí (UFPI) Departamento de Enfermagem

Teresina - Piauí https://orcid.org/0000-0001-7311-2212

Herla Maria Furtado Jorge Universidade Federal do Piauí (UFPI) Departamento de Enfermagem Teresina - Piauí https://orcid.org/0000-0001-9706-5369

Andressa Maria Laurindo Souza Universidade Federal do Piauí (UFPI) Departamento de Enfermagem Teresina - Piauí https://orcid.org/0000-0002-3705-0605

Amanda Karoliny Meneses Resende Universidade Federal do Piauí (UFPI) Departamento de Enfermagem

Teresina - Piauí https://orcid.org/0000-0001-7414-999X Waléria Geovana dos Santos Sousa Universidade Federal do Piauí (UFPI) Departamento de Enfermagem Teresina - Piauí https://orcid.org/0000-0003-0807-2888 diagnóstico de lúpus eritematoso sistêmico. MÉTODO: Trata-se de um estudo descritivo do tipo relato de experiência, realizado por residentes de enfermagem obstétrica em uma maternidade pública de referência para o Estado do Piauí. A produção do estudo se deu a partir das etapas: coleta de dados, diagnósticos de enfermagem, planejamento, intervenção e avaliação de enfermagem. RESULTADOS: Elencou-se os principais problemas de enfermagem como perda de líquido transvaginal em pouca quantidade; nefrite lúpica; infecção do trato urinário e hipertensão arterial sistêmica. Entre os diagnósticos de enfermagem, destacouse: eliminação urinária prejudicada relacionada a múltiplas causas evidenciado por proteinúria, hematúria, flora bacteriana na urina e risco de infecção caracterizado por ruptura prematura de membranasamnióticas.CONCLUSÃO:Destacouse a importância da atuação da enfermagem no aconselhamento e acompanhamento dessas gestantes, a fim de contribuir no seu tratamento e promover um melhor prognóstico. Abordou-se que o lúpus eritematoso sistêmico não é fator de contraindicação de gravidez, no entanto a doença provoca alterações fisiológicas que podem comprometer a mãe e o feto, o que requer acompanhamento multiprofissional.

PALAVRAS - CHAVE: Lúpus eritematoso sistêmico. Gestantes. Cuidados de enfermagem.

RESUMO: OBJETIVO: relatar a experiência sobre a implementação da sistematização da assistência de enfermagem à gestante com 


\title{
NURSING ASSISTANCE TO PREGNANT PATIENT WITH DIAGNOSIS OF SYSTEMIC LUPUS ERYTHEMATOSUS: EXPERIENCE REPORT
}

\begin{abstract}
OBJECTIVE: to report the experience on the implementation of systematization of nursing care to a pregnant woman diagnosed with systemic lupus erythematosus. METHOD: This is a descriptive study of the experience report type, carried out by obstetric nursing residents in a public maternity of reference for the State of Piauí. The study was produced based on a few steps: data collection, nursing diagnoses, nursing planning, intervention and evaluation. RESULTS: The main nursing problems were listed, such as a small amount of transvaginal fluid loss; lupus nephritis; urinary tract infection and systemic arterial hypertension. Among the nursing diagnoses, the following stood out: impaired urinary elimination related to multiple causes evidenced by proteinuria, hematuria, bacterial flora in the urine; risk of infection characterized by premature rupture of amniotic membranes. CONCLUSION: The importance of nursing performance in counseling and monitoring these pregnant women was highlighted, in order to contribute to their treatment and promote a better prognosis. It was approached that systemic lupus erythematosus is not a contraindication factor for pregnancy, however the disease causes physiological changes that can compromise the mother and the fetus, which requires multiprofessional monitoring.
\end{abstract}

KEYWORDS: Lupus Erythematosus, Systemic. Pregnant Women. Nursing Care

\section{I INTRODUÇÃO}

O Lúpus Eritematoso Sistêmico (LES) é uma doença autoimune com padrão predominantemente inflamatório, que pode acometer diversos sistemas, sendo o tegumentar e o articular os mais comuns. A intensidade de progressão é variável (semanas a meses), a etiologia não é claramente definida, mas sabe-se que há participação de vários fatores (genéticos, virais, hormonais e ambientais) associados a um desequilíbrio no funcionamento do sistema imunológico. Os pacientes com LES possuem maior concentração de anticorpos nucleares, principalmente anti-DNA, anti-Sm, anti-RNP, anti-SSA (Ro) e antiSSB (JÚNIOR et al., 2019).

A prevalência da doença é cerca de 40 a 200 casos por 100.000 habitantes, sendo mais comum entre descendentes africanos e asiáticos. No Brasil, sua prevalência atinge cerca de 8,7 por 100 mil habitantes. A ocorrência predomina no sexo feminino, afetando especialmente mulheres em idade reprodutiva, com proporção de nove mulheres para cada homem (SURITA; PASTORE, 2019).

No contexto das gestantes, essa doença autoimune pode apresentar um maior risco de complicações durante esse período, mas ressalta-se que nem sempre a gravidez é contra-indicada. Para uma gravidez mais saudável em pacientes com LES, torna-se necessário controle da doença durante a gestação e um pré-natal rigoroso, sendo comum ocorrer neste período a reativação da doença, comprometimento renal, cardiopulmonar e pré-eclâmpsia/ eclâmpsia. Assim, quando a gestação não é planejada e não é acompanhada por toda a equipe multiprofissional, a mulher pode desenvolver algumas complicações 
(SEVERIANO; PASSOS; CARNEIRO, 2016).

Quanto ao tratamento de LES na gestação, deve-se adaptá-lo às necessidades de cada paciente. Ressalta-se que na ausência de alterações clínicas, o tratamento não deve ser modificado de forma rotineira. Entre os problemas no acompanhamento da gravidez de pacientes com LES, destaca-se a escolha do medicamento certo para tratar a mãe sem prejudicar o feto. Acredita-se que a melhor prevenção para o aumento da atividade do LES durante a gravidez é o atraso da concepção até que a doença esteja em repouso por pelo menos 6 meses, o que nem sempre é possível (SILVA; RIBEIRO, 2015).

Nesse cenário, as pacientes são submetidas a alta carga medicamentosa, muitos deles tóxicos e teratógenos e que, antes e durante a gravidez, deve ser suprimida ou substituída por outras para não causar danos ao feto e não agravar a própria doença. Isso causa medos, ansiedade, depressão ou outros distúrbios patológicos nessas mulheres. Para tanto, a enfermagem, em conjunto com uma equipe multiprofissional, deve abordar essas mulheres de forma integral, por meio de suporte psicológico, bem como orientações com base em estudos científicos que sustentam os objetivos dos cuidados e promovam bem-estar nas pacientes (MESA-ABAD et al., 2020).

Diante do exposto, considerando as manifestações do LES no contexto da gestação e a importância da assistência de enfermagem, este estudo tem como objetivo: relatar a experiência sobre a implementação da sistematização da assistência de enfermagem (SAE) à gestante com diagnóstico de LES.

\section{2 | MÉTODO}

Trata-se de um estudo descritivo do tipo relato de experiência, realizado por residentes de enfermagem obstétrica em uma maternidade pública de referência para o Estado do Piauí, que presta assistência médica, hospitalar e ambulatorial, desenvolvendo as atividades específicas nas áreas de obstetrícia geral, pré-natal, gravidez de alto risco, revisão puerperal, neonatologia, exames e atividades complementares (SESAPI, 2020).

A coleta de dados ocorreu nos mês de julho de 2020, no setor de enfermaria da referida maternidade, destinado para o tratamento de gestantes com comorbidades associadas. A produção do estudo se deu a partir de algumas etapas: coleta de dados, diagnósticos de enfermagem, planejamento, intervenção e avaliação de enfermagem.

Desse modo, a primeira etapa, realizou-se por meio da anamnese e exame físico da paciente, que permitiu a identificação dos principais problemas de enfermagem. Em seguida, partiu-se para a elaboração dos diagnósticos de enfermagem, para tanto, utilizouse os diagnósticos de enfermagem do NANDA (HERMAN; KAMITSURU et al., 2018). A partir deles, elaborou-se o planejamento dos cuidados, intervenção e avaliação de enfermagem, sendo utilizados as taxonomias NIC (BULECHEK et al., 2016) e NOC (MOORHEAD et al., 2010). Ressalta-se que também se obteve acesso aos dados do prontuário da paciente. 
Todas as etapas dessa pesquisa respeitou a resolução $n^{\circ} 466 / 2012$, que trata da realização de pesquisas com seres humanos. Ressalta-se que não foi necessário submetêla a um Comitê de Ética e Pesquisa por tratar-se de um relato de experiência.

\section{I RESULTADOS}

Em 28/06/2020, às 13:09 horas, a paciente foi admitida na maternidade campo deste estudo e durante a classificação de risco, realizou-se a anamnese e exame físico pelos profissionais presentes no setor:

13:09 h. M.L.A.S, 34 anos, G4P3(N)A0, último parto normal há 9 anos, idade gestacional (IG) (Ultrassonografia- US) 31s5d. Nega intercorrências nas gestações anteriores. Alérgica a dipirona, deu entrada na maternidade com queixa de dor em baixo ventre, dor lombar, sangramento transvaginal e perda de líquido em pouca quantidade. Relata corrimento vaginal fétido e esbranquiçado. Tem diagnóstico de lúpus há 13 anos. Realizava tratamento com hidroxicloroquina 400mg/dia e prednisona 40mg/dia, suspendeu a medicação por conta própria quando descobriu a gestação e relata não estar fazendo acompanhamento ambulatorial com reumatologista. Relata ter história de nefrite lúpica e hipertensão arterial sistêmica (HAS) prévia à gestação. Fazia uso de atenolol, losartana e furosemida antes da gestação, quando iniciou o pré-natal foi orientada a substituir as medicações citadas por metildopa 250mg 8/8h, porém não fez uso da medicação. Durante a gestação apresentou exame de urina (EAS- elementos anormais do sedimento) sugestivo de infecção do trato urinário (ITU), relata que realizou tratamento com cefalexina durante 7 dias. Nega outras comorbidades e refere que fez uso de ácido fólico e sulfato ferroso durante gestação. Ao exame físico (EF): Consciente, orientada, normocorada, anictérica, acianótica, afebril $\left(T=36,0^{\circ} \mathrm{C}\right)$, normosfigma $(P=87)$, hipertensa $(150 / 100 \mathrm{mmHg})$, respirando espontaneamente em ar ambiente (AA), eupneica, saturação de 02 (98\%) avaliação da dor (4). Escala de coma de Glasgow (15). Exame obstétrico: Colo grosso, posterior, amolecido, semipérvio, sangramento discreto de odor levemente fétido.

O seguinte quadro (Quadro 1) apresenta a prescrição médica do momento da admissão. Em seguida, a paciente foi transferida para uma ala destinada para gestantes em tratamento de comorbidades.

\section{DIETA}

1. Dieta branda hipossódica

\section{MEDICAMENTOS}

2. Metildopa $500 \mathrm{mg}, 1$ comprimido, via oral (VO), $8 / 8 \mathrm{hs}$

3. Paracetamol $200 \mathrm{mg} / \mathrm{ml} 15 \mathrm{ml}$, se dor ou febre, $\mathrm{VO}, 6 / 6 \mathrm{hs}$

4. Escopolamina $10 \mathrm{mg} / \mathrm{ml} 10 \mathrm{ml}$, se dor tipo cólica, 1 ampola, endovenosa (EV), 6/6hs

5. Ondansentrona $4 \mathrm{mg} / 2 \mathrm{ml}$ amp, se náusea ou vômito, 1 ampola, EV, 8/8hs 
6. Betametazona fosfato $3 \mathrm{mg} / 1 \mathrm{ml}, 2$ ampolas, intramuscular (IM), 24/24hs

7. Azitromicina $1 \mathrm{~g}$, frasco ampola, por dois dias, EV, 6/6hs

8. Sulfato ferroso $200 \mathrm{mg}, 1$ comprimido, $\mathrm{VO}, 30 \mathrm{~min}$ antes do almoço

9. Rotina Hellp e infecciosa

Quadro 1. Prescrição médica no momento da admissão em 28/06/2020

Fonte: Dados do prontuário

Apresenta-se a seguir a evolução de enfermagem da gestante realizada em 06/07/2020 pelos residentes autores deste estudo, quando a paciente encontrava-se no $8^{\circ}$ dia de internação hospitalar (DIH) em uma ala destinada para gestantes em tratamento de comorbidades:

08:05h. $8^{\circ} \mathrm{DIH}$. LES + HAS crônica + ruptura prematura das membranas ovulares (RPMO). G4P3(N)A0, IG (US) 32s5d. Evolui consciente, orientada, normocorada, anictérica, acianótica, afebril $\left(T=36,2^{\circ} \mathrm{C}\right)$, normosfigma $(P=68)$, normotensa $(P A=110 / 70$ $\mathrm{mmHg}$ ), respirando espontaneamente em AA, eupneica, saturação de $\mathrm{O} 2$ (98\%). Tórax simétrico, Ausculta cardíaca (AC): BNF/2T/RR, ausculta pulmonar: murmúrios vesiculares $(\mathrm{MV})$ + bilateralmente. Abdome gravídico, dinâmica uterina (DU) ausente, movimentos fetais $(M F)+, B C F=133-142$ bpm. Nega sangramento transvaginal e perda de líquido transvaginal no momento. Refere melhora da dor em baixo ventre (BV). Relata melhora do corrimento vaginal e está em uso de metronidazol. Sem acesso venoso periférico (AVP), membros inferiores (MMII) com edema (1+/4+). Dieta VO bem aceita, diurese espontânea, evacuações ressecadas, sono e repouso insatisfatórios segundo informações colhidas (SIC). A paciente relatou estar ansiosa devido à sua condição de saúde e preocupação com os filhos. Segue aos cuidados da equipe.

O quadro a seguir (Quadro 2) apresenta a prescrição médica na mesma data em que a avaliação de enfermagem apresentada anteriormente foi realizada ( 06/07/2020).

\section{DIETA}

1. Dieta branda hipossódica

\section{MEDICAMENTOS}

2. Metildopa $500 \mathrm{mg}$ comp, $1 \mathrm{comp}, \mathrm{VO}, 8 / 8 \mathrm{hs}$

3. Paracetamol $200 \mathrm{mg} / \mathrm{ml} 15 \mathrm{ml}$, se dor ou febre, VO, 6/6hs

4. Escopolamina $10 \mathrm{mg} / \mathrm{ml} 10 \mathrm{ml}$, se dor tipo cólica, 1 ampola, EV, 6/6hs

5. Ondansentrona $4 \mathrm{mg} / 2 \mathrm{ml}$ ampola, se náusea ou võmito, 1 ampola, EV, $8 / 8 \mathrm{hs}$

6. Hidroxicloroquina 400mg comp, $1 \mathrm{comp}, 1 \mathrm{x} / \mathrm{dia}$, VO, 24/24hs

7. Metronidazol $250 \mathrm{mg}$ comp, 2 comprimidos VO, 12/12h, por 7 dias

8. Sulfato ferroso $200 \mathrm{mg}, 1 \mathrm{comp}, \mathrm{VO}, 30 \mathrm{~min}$ antes do almoço

9. Hidralazina $20 \mathrm{mg} / \mathrm{ml}, 1 \mathrm{amp}+9 \mathrm{ml}$ de água destilada, fazer $2,5 \mathrm{ml}$ se PAS $>=160$ e/ou PAD $>=110, \mathrm{EV}, 4 \mathrm{x} / \mathrm{dia}$ 
10. Cardiotocografia (CTG) em dias alternados

11. Exames $1 x /$ semana

12. US gestacional com dopler $1 \mathrm{x} /$ semana

Quadro 2. Prescrição médica em 06/07/2020

Fonte: Dados do prontuário

Com base na anamnese e exame físico, foram elencados os principais problemas de enfermagem: dor em baixo ventre, dor lombar; perda de líquido transvaginal em pouca quantidade por RPMO; corrimento transvaginal fétido; sono e repouso insatisfatórios; nefrite lúpica; ITU; HAS, ansiedade e medo. Em seguida, elaborou-se os diagnósticos de enfermagem, planejamento, intervenções e resultados esperados, conforme está apresentado no Quadro 3.

\begin{tabular}{|c|c|c|}
\hline $\begin{array}{l}\text { DIAGNÓSTICOS DE } \\
\text { ENFERMAGEM }\end{array}$ & $\begin{array}{l}\text { INTERVENÇÕES DE } \\
\text { ENFERMAGEM }\end{array}$ & $\begin{array}{l}\text { RESULTADOS } \\
\text { ESPERADOS }\end{array}$ \\
\hline $\begin{array}{l}\text { 1.Eliminação urinária prejudicada } \\
\text { relacionada a múltiplas causas } \\
\text { (nefrite lúpica/ ITU) evidenciado } \\
\text { por proteinúria, hematúria, flora } \\
\text { bacteriana na urina e piócitos } 7-8 \\
\text { p/c. }\end{array}$ & $\begin{array}{l}\text {-Orientar a paciente a monitorar o } \\
\text { aparecimento de sinais e sintomas } \\
\text { de ITU. } \\
\text { - Monitorar e registrar a eliminação } \\
\text { urinária, inclusive frequência, } \\
\text { consistência, odor, volume e cor } \\
\text {-Comunicar à equipe em caso de } \\
\text { alteração do débito urinário }\end{array}$ & $\begin{array}{l}\text {-Redução do risco de } \\
\text { infeccção } \\
\text { - Melhora da eliminação } \\
\text { urinária }\end{array}$ \\
\hline $\begin{array}{l}\text { 2.Ansiedade relacionado a } \\
\text { estressores, evidenciado por } \\
\text { preocupações em razão de } \\
\text { mudança em eventos de vida }\end{array}$ & $\begin{array}{l}\text {-Oferecer suporte emocional } \\
\text {-Avaliar nível de ansiedade } \\
\text {-Encorajar métodos de } \\
\text { enfrentamento }\end{array}$ & $\begin{array}{l}\text {-Redução do nível de } \\
\text { ansiedade } \\
\text {-Melhora do estado } \\
\text { emocional }\end{array}$ \\
\hline $\begin{array}{l}\text { 3. Dor no trabalho de parto } \\
\text { relacionado à dilatação cervical } \\
\text { evidenciado por expressão facial } \\
\text { de dor }\end{array}$ & $\begin{array}{l}\text { - Monitorar e registrar presença de } \\
\text { dor } \\
\text { - Oferecer métodos de alívio da dor }\end{array}$ & - Promover alívio da dor \\
\hline
\end{tabular}

- Monitorar e registrar perda de líquido

4. Risco de infecção caracterizado por ruptura prematura de membranas amnióticas
- Orientar a paciente quanto a identificar sinais de perda de líquido - Administrar terapia com antibióticos, conforme apropriado

- Orientar o paciente a tomar antibióticos, conforme prescrito
-Redução do risco de infecção

-Promoção do conhecimento da paciente quanto aos riscos

5. Distúrbio no padrão de sono relacionado ao padrão de sono não restaurador evidenciado por relato sono verbal

Quadro 3. Diagnósticos de enfermagem, intervenções de enfermagem e resultados esperados

Fonte: elaborada pelos autores do estudo 


\section{4 | DISCUSSÃO}

Os resultados deste estudo convergem com dados da literatura como em um estudo observacional realizado com gestantes de um Hospital de Campinas, que evidenciou RPMO $(16,6 \%)$ e ameaça de parto prematuro (12,7\%) como as complicações mais freqüentes de LES em gestantes (PASTORE; COSTA; SURITA, 2019). Outro estudo, uma revisão da literatura, destacou que a descontinuação da terapia antimalárica e a presença de glomerulonefrite ativa no momento da concepção representam fatores de risco para a exacerbação do lúpus, assim como foi sugerido no caso abordado (SILVA; RIBEIRO, 2015).

Ressalta-se entre as complicações da gestante deste estudo, a ocorrência de RPMO. De modo convergente, a literatura também aponta que o histórico de lúpus grave como nefrite e mau passado obstétrico também aumentam o risco de maus desfechos. Essas complicações incluem perdas gestacionais, prematuridade, baixo peso (neonato com menos de $2500 \mathrm{~g}$ ), restrição do crescimento intrauterino (RCIU) e pré-eclâmpsia, sendo esta mais comum nas pacientes com histórico de nefrite lúpica (SCHAD et al., 2017). Destacase que o manual de gestação de alto risco do Ministério da Saúde (2012) desaconselha a gravidez no caso de atividade da doença, especialmente na vigência de nefropatia, como ocorre na paciente referida. Quanto à terapêutica implementada para o tratamento, também condiz com o preconizado no manual (medicamentos anti-hipertensivos e corticoide).

Quanto à ativação da nefrite lúpica, sabe-se que esta ocorre pelo aumento dos anticorpos anti-DNA causando diminuição dos níveis de complemento e aumento do sedimento urinário. Ressalta-se que o feto também passa por riscos devido à hipertensão materna e uso de medicação anti-hipertensiva. Um dos destaques é o lúpus neonatal, uma doença rara que se desenvolve devido a um processo autoimune transitório ocasionado pela presença de autoanticorpos maternos na circulação fetal (SEVERIANO; PASSOS; CARNEIRO, 2016).

Acerca dos principais problemas e diagnósticos de enfermagem identificados, verificou-se semelhança com os achados da literatura: outro estudo de caso em paciente com diagnóstico de LES e HAS crônica durante a gestação apresentou como destaques o histórico de picos pressóricos e nefropatia. As intervenções de enfermagem abordaram a pesquisa dos sinais e sintomas de complicação da HAS (níveis pressóricos elevados, cefaleia frontal ou occipital persistente, comprometimento neurológico e distúrbios visuais); estímulo ao repouso no leito em decúbito dorsal, fowler $45^{\circ}$ e monitorar sinais de desconforto respiratório (MARQUES et al., 2016).

\section{I CONCLUSÃO}

Este estudo atingiu seu objetivo, uma vez que relatou a experiência sobre a aplicação da SAE a uma gestante com LES. Desse modo, foi possível destacar a importância da atuação da enfermagem no aconselhamento e acompanhamento dessas gestantes, a fim 
de contribuir no seu tratamento e promover um melhor prognóstico.

Abordou-se que o LES não é fator de contraindicação de gravidez, no entanto a doença provoca alterações fisiológicas que podem comprometer a mãe e o feto, o que requer acompanhamento multiprofissional. Espera-se com este relato de experiência gerar subsídios para pesquisas na área e incentivar os gestores quanto a incentivos destinados ao tratamento da doença, bem como capacitação profissional.

\section{REFERÊNCIAS}

BRASIL. Ministério da Saúde. Secretaria de Atenção à Saúde. Departamento de Ações Programáticas Estratégicas. Gestação de alto risco: manual técnico / Ministério da Saúde, Secretaria de Atenção à Saúde, Departamento de Ações Programáticas Estratégicas. $5^{a}$ ed. Brasília: Editora do Ministério da Saúde, 2012. 302 p.

BULECHEK, G. M. et al. NIC Classificação das intervenções de enfermagem. Tradução da $5^{a}$ ed. Rio de Janeiro: Elsevier Editora Ltda, 2016.

HERMAN, T. H.; KAMITSURU, S. Diagnósticos de enfermagem da NANDA-I: definições e classificação 2018-2020 [recurso eletrônico] / [NANDA International]; tradução: GARCEZ, R. M.; revisão técnica: BARROS, A. L. B. L. et al.], 11ª ed, Porto Alegre: Artmed, 2018.

JÚNIOR, C. J. P. et al. Abordagem e manejo do lúpus eritematoso sistêmico na gestação. Rev e-Scienti, v. 12, n. 2, p. 1-5, 2019.

MARQUES, C. R. G. et al. Lúpus eritematoso sistêmico a gestação e os rins. Anais 2016: $18^{a}$ Semana de Pesquisa da Universidade Tiradentes. "A prática interdisciplinar alimentado a Ciência", p. $1-3,2016$.

MESA-ABAD, P. et al. Gravidez em mulheres com lúpus eritematoso sistêmico: uma revisão integrativa. Enferm Nefrol, v. 23, n. 1, p. 1-19, 2020.

MOORHEAD, S. et al. NOC Classificação dos Resultados de Enfermagem. Tradução da $4^{a}$ ed. Rio de Janeiro: Elsevier Editora Ltda, 2010.

PASTORE, D. E. A.; COSTA, M.L.; SURITA, F. G. Lúpus eritematoso sistêmico e gravidez: o desafio de melhorar o atendimento pré-natal e os resultados. Lupus, v. 28, n. 12, p. 1417-26, 2019.

SCHADE, L. et al. Perfil clínico de gestantes portadoras de lúpus eritematoso sistêmico do Hospital de Clínicas da Universidade Federal do Paraná. Medicina (Ribeirão Preto, Online.), v. 50, n. 3, p. 16976, 2017.

SESAPI. SECRETARIA DE SAÚDE DO ESTADO DO PIAUÍ. Identificação da instituição. Disponível em: <http://www.mder.pi.gov.br/institucional/>. Acesso em: 14 dez. 2020.

SEVERIANO, D. L. R.; PASSOS, X. S.; CARNEIRO, F. G. Lúpus eritematoso sistêmico a gestação e os rins. Revista da Universidade Vale do Rio Verde, v. 14, n. 2, p. 106-13, 2016. 
SILVA, L. V.; RIBEIRO, L. H. Lúpus eritematoso sistêmico e gravidez: uma revisão da literatura. Rev Soc Bras Clin Med, v. 13, n. 4, p. 289-95, 2015.

SURITA, F. G. C; PASTORE, D. E. A. Lúpus eritematoso sistêmico e gravidez. FEMINA, v. 247, n. 6, p. 322-49, 2019. 


\section{CAPÍTULO 4}

\section{ASSSITÊNCIA DE ENFERMAGEM Á GESTANTE COM PICO HIPERTENSIVO NA UNIDADE DE URGÊNCIA E EMERGÉNCIA}

Data de aceite: $20 / 08 / 2021$

Data de submissão: 29/05/2021

Larissa Maria de Oliveira Costa Centro Universitário Leão Sampaio - Unileão Juazeiro do Norte - CE http://lattes.cnpq.br/4281292443094802

Ana Patricia de Alencar Centro Universitário Leão Sampaio - Unileão Juazeiro do Norte - Ceará http://lattes.cnpq.br/1019429681210907

Maria Freitas Lima de Farias Pinho Centro Universitário Leão Sampaio - Unileão Juazeiro do Norte - CE http://lattes.cnpq.br/0977434990719155

Carlla Sueylla Filgueira Ramalho Souza Centro Universitário Leão Sampaio - Unileão Juazeiro do Norte - CE http://lattes.cnpq.br/3479609139952609

Amanda Tamires Ferreira Araujo Centro Universitário Leão Sampaio - Unileão Juazeiro do Norte - CE http://lattes.cnpq.br/0002270254748500

\section{Dianne Suêrda Gomes Pereira}

Centro Universitário Leão Sampaio - Unileão Juazeiro do Norte - CE http://lattes.cnpq.br/5710586989877550

Juliana Aparecida Pereira de Lima Centro Universitário Leão Sampaio - Unileão Juazeiro do Norte - CE http://lattes.cnpq.br/3150537604074199
Patriciana Carvalho Ferreira Centro Universitário Leão Sampaio - Unileão Juazeiro do Norte - CE http://lattes.cnpq.br/1579412999758633

Natasha Priscila Lopes Arrais Universidade Federal do Piauí - UFPI

Picos - PI http://lattes.cnpq.br/0408955592691

Ana Rochele Cruz Sampaio Centro Universitário Leão Sampaio - Unileão Juazeiro do Norte - CE http://lattes.cnpq.br/3294372730893244

Ana Patrícia Sampaio Alves Fundação Universidade Pernambucana Recife-PE

http://lattes.cnpq.br/9407533044519648

Fátima Tannara Mariano de Lima Centro Universitário Leão Sampaio - Unileão Juazeiro do Norte - CE http://lattes.cnpq.br/ 2454345423429665

RESUMO: O aumento agudo e súbito da Pressão Arterial (PA) tem sido definido por diferentes termos. De certo, pode-se atestar suas características, como sendo uma condição clínica, multifatorial, com níveis elevados e sustentados da PA ( $\geq 140$ e/ou $90 \mathrm{mmHg}$ ), que frequentemente está associado a alterações funcionais ou estruturais do coração, rins, encéfalo, vasos sanguíneos ou alterações metabólicas, que é didaticamente dividida em urgência e emergência hipertensiva .O estudo trata-se de uma revisão de literatura 
que objetivou analisar o que há disponível na literatura cientifica acerca da assistência de enfermagem à gestante com quadros hipertensivos no serviço de urgência e emergência. As publicações inseridas no estudo passaram por critérios de elegibilidade como: Artigos dos últimos dez anos (2007-2017) indexados nas bases de dados da LILACS, SciELO, BDENF, através dos descritores: Enfermagem; Assistência de Enfermagem; Eclâmpsia e Assistência ambulatorial. Após análise da literatura disponível, 19 estudos foram selecionados para compor o estudo. Dentro das diversas formas de prestar cuidados destaca-se o Processo de Enfermagem (PE) sendo uma ferramenta considerada indispensável para uma assistência de maior efetividade. Iniciado na Atenção Primária, o acompanhamento pré-natal é uma forma de cuidar essencial na prevenção de grandes repercussões no binômio mãe-bebê. Os cuidados e intervenções de enfermagem são primordiais, prestados no intuito de evitar a pré-eclâmpsia grave e consequentes complicações da mesma. A mortalidade materna e fetal, a princípio por causas preveníveis, traz repercussões negativas ao país que perduram por tempos, o que com estudos mais atualizados dá viés ao desenvolvimento de ações mais precisas por profissionais mais seguros. Sugere-se então a produção de mais estudos na área bem como realização de debates a respeito da assistência prestada no âmbito primário, secundário e terciário ao binômino mãe-bebê.

PALAVRA - CHAVE: Enfermagem. Assistência de Enfermagem. Eclâmpsia. Assistência ambulatorial.

\section{NURSING ASSISTANCE TO PREGNANT WOMEN WITH HYPERTENSIVE PEAK IN THE EMERGENCY AND EMERGENCY UNIT}

ABSTRACT: The sharp and sudden increase in Blood Pressure (BP) has been defined by different terms. Certainly, one can attest to its characteristics, as being a clinical, multifactorial condition, with elevated and sustained BP levels ( $\geq 140$ and / or $90 \mathrm{mmHg}$ ), which is often associated with functional or structural changes of the heart, kidneys, brain, blood vessels or metabolic changes, which is didactically divided into urgency and hypertensive emergency. The study is a literature review that aimed to analyze what is available in the scientific literature about nursing care for pregnant women with hypertensive conditions in the health service. urgency and emergency. The publications included in the study went through eligibility criteria such as: Articles from the last ten years (2007-2017) indexed in the databases of LILACS, SciELO, BDENF, through the descriptors: Nursing; Nursing Assistance; Eclampsia and outpatient care. After analyzing the available literature, 19 studies were selected to compose the study. Among the different ways of providing care, the Nursing Process (NP) stands out, being a tool considered indispensable for a more efetivei assistance. Started in Primary Care, prenatal care is an essential form of care in preventing major repercussions in the motherbaby binomial. Nursing care and interventions are essential, provided in order to avoid severe pre-eclampsia and its consequent complications. Maternal and fetal mortality, at first due to preventable causes, brings negative repercussions to the country that last for a while, which with more up-to-date studies bias the development of more precise actions by safer professionals. It is therefore suggested to produce more studies in the area as well as to hold debates about the assistance provided in the primary, secondary and tertiary spheres to the mother-baby binomial.

KEYWORDS: Nursing. Nursing Assistance. Eclampsia. Outpatient care. 


\section{I INTRODUÇÃO}

O aumento agudo e súbito da Pressão Arterial (PA) tem sido definido por diferentes termos. De certo, pode-se atestar suas características, como sendo uma condição clínica, multifatorial, com níveis elevados e sustentados da PA ( $\geq 140$ e/ou $90 \mathrm{mmHg}$ ), que frequentemente está associado a alterações funcionais ou estruturais do coração, rins, encéfalo, vasos sanguíneos ou alterações metabólicas, que é didaticamente dividida em urgência e emergência hipertensiva (SBC, 2016).

A dispor disto, a Sociedade Brasileira de Cardiologia (SBC) traz a Urgência Hipertensiva $(\mathrm{UH})$ como sendo a detecção da PA sistólica $\geq 120 \mathrm{mmHg}$ com paciente com estado clínico estável e sem envolvimento de órgãos alvos. Porém detendo maiores chances de futuros eventos cardiovasculares quando comparados aos pacientes que nunca apresentaram a UH. Já a Emergência Hipertensiva $(E H)$ é a elevação súbita da PA que pode ocasionar graves danos cerebrais e em outros órgãos (SBC, 2016).

Furtado, Coelho e Nobre (2003) no seu estudo sobre as urgências e emergências hipertensivas, trazem diversas condições atreladas ao aparecimento de quadros hipertensivos. Entre as de UH encontra-se a suspensão da medicação anti-hipertensiva, a hipertensão maligna e algumas cirurgias (Hipertensão Arterial Sistêmica grave no período operatório, pós-operatório e pós-transplante renal). Já relacionado as $\mathrm{EH}$ o edema agudo de pulmão, epilepsia, ingestão excessiva de drogas, infarto agudo do miocárdio e a eclâmpsia são algumas das mencionadas.

No grupo das emergências hipertensivas, evidencia-se a eclâmpsia, como sendo uma Síndrome Hipertensiva Específica da Gestação (SHEG) que juntamente com a préeclâmpsia, hipertensão gestacional e a hipertensão crônica, são importantes causas de morbidade aguda grave, incapacidade prolongada e morte materna-fetal nos países desenvolvidos e em desenvolvimento, afetando cerca de $10 \%$ de todas as mulheres gravidas em todo mundo (VETTORE, 2011; BRASIL, 2014).

A eclâmpsia é a evolução grave da pré-eclâmpsia, que surgem após a $20^{a}$ semana de gestação associadas ao aumento da PA, proteinúria e ou edema. A pré-eclâmpsia se apresenta como uma forma não convulsiva enquanto a eclâmpsia é caracterizada por apresentar episódios convulsivos tônico-clônicos generalizadas decorrente dos efeitos cerebrais profundos da pré-eclâmpsia (ANGONESI; POLATO, 2007; BRASIL, 2010).

Dentre as principais complicações maternas e perinatais da pré-eclâmpsia encontrase respectivamente: acidente vascular encefálico, descolamento prematura da placenta, insuficiência cardíaca e insuficiência renal aguda, edema pulmonar, HELLP, trombose venosa profunda, retardo do crescimento intra-uterino, parto prematuro, anóxia cerebral, infecção neonatal e morte perinatal (NEME, 2005).

Mediante riscos e complicações, com objetivo de retarda-los, de início exige-se intervenções de prevenção e diagnóstico precoce, porém quando se tratando do problema 
já instalado, a situação exige a atuação de uma equipe multiprofissional preparada, ágil, com capacidade de reconhecer os problemas que possam ocasionar danos maiores a saúde da mãe/bebê ofertando cuidados diferenciados. Em alguns casos a internação pode ser obrigatória, sendo necessário a avaliação criteriosa materna/feto, bem como uma decisão de interrupção ou não da gestação (BRASIL, 2010; BRITO, 2011; SANTOS; NERY; MATUMOTO, 2013).

O enfermeiro como membro da equipe multiprofissional deve desfrutar dos conhecimentos técnicos-científicos, adquiridos na formação e experiência laboral, para sistematizar sua assistência de forma segura e eficaz, visando a minimização de sequelas e ausência de complicações que podem levar a gestante e o feto a letalidade (SANDE, 2010).

Neste sentido, o presente estudo objetiva analisar o que há disponível na literatura cientifica acerca da assistência de enfermagem à gestante com quadros hipertensivos no serviço de urgência e emergência. Mostrando-se significativo em razão da contribuição no aprofundamento do conhecimento do assunto, exercendo influencia na pratica profissional, visto o constante surgimento de novas abordagens e modelos a serem seguidos do cuidar em enfermagem materna.

\section{I METODOLOGIA}

Para o desenvolvimento do presente estudo utilizou-se o método de revisão bibliográfica. A pesquisa bibliográfica é um método de busca, apreciação e descrição de um conhecimento com base em material já elaborado. Ela abrange o material pertinente que é escrito sobre o tema pesquisado como: Livros, artigos de periódicos, registros históricos, relatórios governamentais, teses, dissertações entre outros, em busca de uma resposta para determinada pergunta (FONSECA, 2002; GIL, 2008).

Para escolha das publicações a serem inseridas na revisão elegeu-se como critérios de inclusão: trabalhos disponíveis na íntegra, estarem no idioma portuguêsBrasil e publicados nos últimos dez anos (2007-2017). Foram excluídos estudos que se repetiam simultaneamente na mesma base de dados ou demais pesquisadas, bem os que se distanciavam do objetivo proposto.

A busca foi realizada nas bases de dados da Literatura Latino-Americano e do Caribe em Ciências da Saúde-LILACS, Scientific Electronic Library Online (SciELO) e Base de Dados da Enfermagem (BDENF), utilizando os descritores em ciências da saúde (DeCS): Enfermagem; Assistência de Enfermagem; Eclâmpsia; Assistência ambulatorial.

Com a utilização do booleano "AND", os descritores foram cruzados nas bases de dados, correspondendo uma busca com os dois primeiros descritores (Assistência de enfermagem AND Eclâmpsia) e a segunda com a utilização dos três descritores (Assistência de enfermagem AND Eclâmpsia AND assistência ambulatorial) no intuito de expandir o 
acervo de estudos. Este método de busca procedeu-se nas três bases de dados.

Diversas tentativas de cruzamento foram testadas com os demais descritores, porém os estudos se mostram escassos ou inexistentes, ou ainda existentes apenas na literatura internacional. A vista disso, novas buscas foram realizadas com foco nos descritores em fontes disponíveis e confiáveis, obedecendo aos critérios de inclusão e exclusão já mencionados.

A busca foi realizada no mês de agosto de 2017. Incialmente 50 estudos foram selecionados para serem avaliados. Após a leitura de títulos e resumos 14 estudos foram excluídos, restando apenas 36 para avaliação na integra. Destes 19 estudos foram selecionados para composição desta revisão.

\section{I RESULTADOS}

As discursões que aqui se seguem, foram compilações dos diversos estudos já publicados a respeito dos cuidados de enfermagem prestados a pacientes com quadros hipertensivos, cuidados estes que vão desde o pré-natal a um cuidado mais especializado. Por exigir grande responsabilidade na prestação da assistência, o profissional precisa da atenção e agilidade dobrada, levando em consideração a existência de pacientes com risco iminente de morte ou complicações.

Dentro das diversas formas de assistencialista, tem-se o Processo de Enfermagem $(\mathrm{PE})$, tratado na resolução COFEN-358/2009. Este é um instrumento de cuidado que deve ser realizado de forma deliberada e sistemática em todos os ambientes que ocorre o cuidado do profissional de enfermagem. Ao profissional incumbe a liderança no PE, o competindo da privatividade do diagnóstico de enfermagem, bem como as prescrições das ações/Intervenções de enfermagem a serem desenvolvidas.

A assistência de forma sistematizada e organizada é uma ferramenta considerada indispensável para uma assistência de maior efetividade. E se falando de distúrbios hipertensivos, como sendo as principais complicações maternas ao longo do ciclo gravídicopuerperal, o cuidado se inicia em uma unidade de Atenção Primária, com o pré-natal, desenvolvendo ações na detecção e redução de complicações e mortes maternas/fetais. A maioria das mortes entre essa população, principalmente por eclâmpsia, há estreita relação com a inexistência da organização e sistematização das ações (GIONINI, 2010).

Independentemente dos benefícios resultantes da utilização da sistematização da assistência, Cunha e Barros (2005), discutem em seu estudo, que em várias instituições prestadores de serviço de saúde, os enfermeiros assistencialistas não a utilizavam, considerando que estes desenvolviam suas ações e tomavam decisões não relacionadas ao raciocínio clínico e não se atentavam com a qualidade dos registros relativos ao planejamento do cuidado. O cuidado sistematizado amplia a capacidade de intervenção e oportuniza a de priorização do diagnóstico, atuando de forma mais efetiva com 
possibilidades de avaliação das ações.

Numerosas vezes, a morte materna mantém relações com ineficiente acesso ao serviço e limitações na qualidade das ações de prevenção e promoção de uma saúde sexual e reprodutiva mais orientada. A descontinuidade de ações e ineficiente aproximação entre serviços e profissionais contribuem-na quebra do vínculo entre a mulher e o serviço e reduz a qualidade almejada na assistência materna e fetal. A existência de lacunas na assistência ao pré-natal propicia a evolução de uma simples morbidade durante o período gravídico para ocorrências de maior gravidade (MANDÚ; ANTIQUEIRA; LANZA, 2009; HERCULANO et al., 2012).

Neste sentido, um acompanhamento de pré-natal com qualidade é indispensável na prevenção de grandes repercussões no binômio mãe-bebê. Na unidade de saúde, quando detectado alterações nos níveis pressóricos maternos, com PA igual ou superior a $14 \times 90 \mathrm{mmHg}$ ou com sinais de pré-eclâmpsia grave, esta deve ser encaminhada a hospitalização com monitorização da PA e do eletrocardiograma (BRASIL, 2006; BRASIL, 2010; HERCULANO et al, 2011; GUERREIRO et al, 2012).

A morbidade e mortalidade materna ainda são elevadas no Brasil, sendo que maioria das mortes e complicações que surgem na gravidez, parto e puerpério são preveníeis. Apesar da elevada cobertura da assistência pré-natal, a mortalidade materna por hipertensão arterial continua elevada. Isto tem estreita relação com a má qualidade do atendimento pré-natal e desinformações por parte da gestante. Um estudo transversal mostrou que a má qualidade da assistência estava relacionada a falta de experiência no atendimento por parte dos profissionais que atuavam no serviço bem como a escassez de curso de atualizações na área, segundo depoimento dos participantes (BRASIL, 2010; VETTORE et al., 2011; DUARTE; MAMEDE, 2012).

Quando se tratando do setor urgência e emergência, este é considerado o ambiente que mais ocorre casos de crises hipertensivas, relacionado tanto ao fator pré-natal de baixa qualidade, como também a não adesão das pacientes ao tratamento correto. Prevenir a eclâmpsia e diminuir os níveis pressóricos são cuidados que podem estar sendo prestados no intuito de evitar a prematuridade do nascimento fetal, visto ser importante fator de morbimortalidade perinatal com elevadas chances de sequelas imediatas e tardias. Quando há eminência de morte ou complicações mais graves, habitualmente a conduta obstétrica é a interrupção da gravidez (AMORIM, et al., 1998; COELHO et al., 2004).

Estudos mostram que, entre as causas obstétricas de internação em unidades de cuidados mais especializados como Unidades de Terapias Intensivas-UTI, a pré-eclâmpsia grave e a eclâmpsia se formam a principal causa $(71,3 \%)$, constituindo os extremos de idade e as adolescentes jovens o público de maior incidência, relacionado na grande maioria a primeira gestação (REINERS, et al., 2009; SILVA, et al., 2010; DIAS; AGNOLO, et al., 2014; SANTOS, 2016).

Um estudo documental desenvolvido em 2014 no Pará, mostrou que entre os anos 
de 2009 e 2012, 2.970 pacientes foram internadas com diagnostico de DHEG. No mesmo período, 122 pacientes evoluíram a óbito, sendo que dessas 33 possuíam o diagnóstico de DHEG. Esses dados corresponderam a uma média de 1,08\% no índice de letalidade por DHEG e uma prevalência de $27 \%$ de morte por DHEG entre os 122 óbitos maternos, destacando os autores a magnitude da doença como causa de mortalidade materna (GUERREIRO et al., 2014).

Os cuidados e intervenções da enfermagem que podem serem implementados a gestante quando internada, por exemplo, com a pré-eclâmpsia leve, segundo Neme (2005); Cunha e coautores (2007); Vettore e colaboradores (2011) baseia-se em: Estar atento aos sinais e sintomas da pré-eclâmpsia grave/eclâmpsia, realizar o controle da PA a cada quatro horas ou menos, de acordo com a necessidade, controlar infecções, estimular o repouso em decúbito lateral esquerdo, mensurar peso, estimular uma boa dieta, avaliar cotidianamente a proteinúria, controle da diurese nas 24 horas, administrar medicamentos da prescrição médica, estimular a comunicação, tirar dúvidas, monitorar os batimentos cardíacos fetais a cada quatro horas, entre outros.

Outros cuidados como o acolhimento por intermédio de uma escuta qualificada, expressa preocupação com a gestante em sua subjetividade e sentimentos manifestados por essas, essencialmente importantes para o desenvolvimento do vínculo e empatia. Prevenir a doença e suas complicações se mostra também como cuidado essencial. O fornecimento de informações à gestante também é necessário, como a respeito das medicações anti-hipertensivas, seu uso correto e continuidade, visando a garantia de um melhor bem estar materno e fetal (REINERS, 2009; SANTORO, 2011; OLIVEIRA et al, 2016).

Vários desses cuidados são prestados baseados na sintomatologia da doença. Isso requer do profissional conhecimento mais aprofundado da fisiopatologia e suas repercussões na mulher. Trabalhar em cima dos diagnósticos mais frequentes possibilita o desenvolvimento de uma atenção mais elaborada e uma intervenção mais efetiva. Os diagnósticos mais frequentes segundo Sampaio e coautores (2013); Aguiar e colaboradores (2010) são: Risco de infecção, dor aguda, baixa autoestima situacional, volume de líquidos excessivo, náusea, privação do sono, risco de função hepática prejudicada, Eliminação urinária prejudicada, constipação, nutrição desequilibrada: menos/mais do que as necessidades corporais, ansiedade.

Na prestação desses cuidados, o profissional enfermeiro se põe na linha de frente à sua execução. No entanto, se tratando de especificidade, a enfermagem obstétrica ganha destaque, tendo esse profissional papel fundamental na qualificação do serviço e na prestação do cuidado a mulher no momento do parto, favorecendo a melhoria à saúde materna. O enfermeiro(a) obstetra, assim como os demais, possui uma formação éticohumanista, porém este se diferencia em sua formação por se tratar de uma especialidade pautada em competências e habilidades complementares que os caracterizam como 
capacitados aos fornecimentos dos cuidados à parturiente, por albergar os variados e complexos aspectos que abrange a evolução do parto de forma mais segura, com comportamentos menos tecnicistas e mais humanizados (OLIVEIRA, 2015; REIS et al., 2015).

Apesar da gama de cuidados que podem e devem ser ofertados a gestante, 0 estudo de Aguiar e colaboradores (2014), Oliveira et al (2016) mostraram que, as ações de enfermagem se apresentavam de forma limitada e muito mecanizada, resumindo tais ações ao fácil preenchimento de um protocolo de admissão, seguimento na verificação da PA e administração dos medicamentos prescritos, negligenciando muitas vezes a singularidade, os aspectos psicológicos e os sociais dos pacientes.

A satisfação do paciente gera reflexos positivos no seu bem estar. Esta satisfação esta muitas atrelada a aspectos tantos ambientais como a forma do atendimento ofertado. Neste quesito, Queiroz e coautores (2007) no seu estudo com usuários de um serviço de saúde, mostraram que $74 \%$ dos participantes se encontravam satisfeitos no serviço, estando esta satisfação relacionada ao bom atendimento e atenção dos profissionais, higiene do estabelecimento e pontualidade no serviço. O grau de insatisfação estava relacionado a descaso de alguns profissionais, falta de educação destes, ou ainda uma escuta insatisfatória.

\section{I CONSIDERAÇÕES FINAIS}

Esta revisão permitiu a aquisição de um maior conhecimento a respeito dos cuidados de enfermagem mediante a pré-eclâmpsia/eclâmpsia. Observou-se que para uma maior efetivação no cuidado, a sistematização da assistência como método cientifico, organizado e contínuo, otimiza a prática profissional e direciona o cuidado de forma mais adequada.

O enfermeiro, na utilização desse instrumento, garante uma intervenção mais direciona e prioriza as reais necessidades no cuidado ofertado a gestante hipertensa em qualquer nível assistencial, desempenhando suas ações indelegáveis e fortalecendo a papel do profissional dentro da equipe multiprofissional.

Observou-se também a importância da enfermagem obstétrica que, pela sua formação, esses profissionais dispõem de conhecimentos e habilidades adicionais que os configuram como capacitados na prestação da assistência no período gravídico, cooperando significativamente na redução de morte materna e perinatal, que ainda atualmente se encontra em níveis elevados.

O trabalho desses profissionais ainda possui grandes influências no fortalecimento da assistência de pré-natal, exigindo investimentos em uma formação de qualidade no atendimento à mulher no ciclo gravídico e puerperal, com ações de promoção e prevenção, que pode ser desenvolvido com mais maestria por profissionais de formação na enfermagem obstétrica. 
Quando se tratando de um ambiente mais crítico, o profissional enfermeiro além de grandes habilidades precisa contar com os conhecimentos mais científicos e ter eficiência na tomada de decisões. Por haver pacientes com risco de morte ou complicações é importante a presença integral do profissional, desenvolvendo os cuidados a eles cabíveis de forma mais humanizada e menos mecanicistas.

Sugere-se a produção de mais estudos na área bem como a realização de debates a respeito da assistência prestada no âmbito primaria, secundário ou terciário ao binômio mãe-bebê. A mortalidade materna e fetal, a princípio por causa preveníeis, traz repercussões negativas ao país que perduram por tempos, o que com estudos mais atualizados e com grande evidencia científica de efetividade dá viés ao desenvolvimento de ações mais precisas por profissionais mais seguros.

A universidade se mostra como pontapé inicial à formação de profissionais mais críticos e treinados a uma visão mais crítica e panorâmica da realidade. Um bom aluno se torna um bom profissional em caminho a excelência da qualificação. Um profissional qualificado na assistência que se presta, garante uma assistência mais efetiva e com ótimos resultados.

\section{REFERÊNCIAS}

AGNOLO, C. M. D, et al. Mulheres em idade fértil: causas de internação em Unidade de Terapia Intensiva e resultados. Revista ABCS health sciences, v. 39. n. 2, pag. 77-82, Maringá-PR, 2014.

AGUIAR, L. R. S. et al. Análise de estudos sobre as condutas de enfermagem no cuidado à gestante com doença hipertensiva. Revista Interdisciplinar, v. 7, n. 1, p. 204-215, jan. fev. mar. 2014.

AGUIAR, M. I. F. et al. Sistematização da assistência de enfermagem a paciente com síndrome hipertensiva específica da gestação. Revista Rene. Fortaleza, v. 11, n. 4, pag. 66-75, out/dez. 2010.

AMORIN, M. R. et al. Acurácia do teste de clementes para avaliação da maturidade pulmonar fetal em gestantes com doença hipertensiva específica da gestação. Revista Brasileira de Ginecologia Obstétrica [online]. 1998, vol.20, n.5, pag.253-260, 1998.

ANGONESI J; POLATO, A. Doença Hipertensiva Específica da Gestação (DHEG), incidência à evolução para Síndrome de HELLP. Revista Brasileira de Análises Clinicas. v. 39, n. 4, pag. 243-245, 2007.

BRASIL. Ministério da Saúde. Secretaria de Atenção à Saúde. Departamento de Ações Programáticas Estratégicas. Gestação de alto risco: manual técnico-5. ed. - Brasília: Editora do Ministério da Saúde, 2010.

Ministério da Saúde. Secretaria de Atenção à Saúde. Departamento de ações programáticas estratégicas. Área técnica de saúde da mulher. Pré-natal e puerpério: atenção qualificada e humanizada - Manual técnico, Brasília-Ministério da Saúde, 2006. 
BRITO, M. O.L. Atuação da enfermagem no atendimento às emergências obstétricas: Eclâmpsia e Pré-Eclâmpsia. Monografia (Especialização em enfermagem em emergência) - Salvador-Bahia, Universidade Castelo Branco, 2011. 69p.

COELHO, T. M et al. Proteinúria nas síndromes hipertensivas da gestação: prognóstico materno e perinatal. Revista Associação Médica Brasileira, v., 50, n. 2, São Paulo Abr./Jan. 2004

CUNHA, K. J. B; OLIVEIRA, J. O; NERY, I. S. Assistência de enfermagem na opinião das mulheres com pré-eclâmpsia. Escola Anna Nery Revista de Enfermagem; v.11, n. 2, pag. 254-60, jun., 2007.

CUNHA S. M. B, BARROS, A. L. B. L. Análise da implementação da sistematização da assistência de Enfermagem, segundo o modelo conceitual de Horta. Revista Brasileira de Enfermagem, v. 58, n. 5, pag. 568-72, 2005.

DIAS, R. M. M; SANTOS, S. N. Perfil epidemiológico das mulheres com síndromes hipertensivas na gestação e sua repercussão na prematuridade neonatal em uma maternidade pública de Belém/PA. Revista Enfermagem Brasil, v. 15, n. 1, Belém-PA, 2016.

DUARTE, S. J. H; MAMEDE, M. V. Estudo das competências essenciais na atenção pré-natal: ações da equipe de enfermagem em Cuiabá, MT. Revista Enfermagem em Foco, v. 3, n. 2, pag. 7580, 2012.

FONSECA, J. J. S. Metodologia da pesquisa científica. Fortaleza: UEC, 2002. Apostila.

FURTADO, R.G; COELHO, E.B \& NOBRE, F. Urgências e emergências hipertensivas. Medicina, Ribeirão Preto, 36: 338-344, abr./dez. 2003

BRASIL. Ministério da Saúde. República de Cabo Verde. Relatório estatístico 2013, Praia, 2014.

GIL, A. C. Métodos e técnicas de pesquisa social. 6. ed. São Paulo: Atlas, 2008.

GUERREIRO, D. D et al. Mortalidade materna relacionada à Doença Hipertensiva Especifica da Gestação (DHEG) em uma maternidade no Pará. Revista de Enfermagem da UFSM, v. 4, n. 4, pag. 825-834, out/Dez, 2014.

GUERREIRO, E. M, et al. 0 cuidado pré-natal na atenção básica de saúde sob o olhar de gestantes e enfermeiros. Revista Mineira de Enfermagem, v. 16, n. 3, pag. 315-323, jul./set., 2012.

HERCULANO, M. M. S et al. Aplicação do processo de enfermagem a paciente com hipertensão gestacional fundamentada em orem. Revista Rene, Fortaleza, v. 12, n. 2, pag. 401-8, abri/jun 2011.

HERCULANO, M. M. S, et al. Óbitos maternos em uma Maternidade Pública de Fortaleza: um estudo epidemiológico. Revista da Escola de Enfermagem da USP, São Paulo, v. 46, n. 2, pag. 295301, abril, 2012.

MANDÚ, E. N. T; ANTIQUEIRA, V. M. A; LANZA, R. A. C. Mortalidade materna:

Implicações para o Programa Saúde da Família. Revista de enfermagem UERJ, Rio de Janeiro, v. 17, n. 2, pag. 278-84, abr/jun, 2009.

NEME, B. Obstetrícia básica. São Paulo: Sarvier; 2005. 
NOVO, J. L. V. G; GIANINI, R. J. Mortalidade materna por eclâmpsia. Revista Brasileira de Saúde Materno Infantil, Recife, v. 10, n. 2, Apri/jun., 2010.

OLIVEIRA, K. K. P. A. et al. Assistência de enfermagem a parturientes acometidas por préeclâmpsia. Revista de enfermagem UFPE on line, Recife, v.10, n. 5, pag. 1773-80, maio, 2016.

OLIVEIRA, J. D. G. Atuação do Enfermeiro Obstetra na Assistência à Parturiente: Percepções do Profissional. Monografia (bacharel em enfermagem) - Santa Cruz-RN: Faculdade de Ciências da Saúde do Trairi/Universidade Federal do Rio Grande do Norte, 2015. 23p.

QUEIROZ, M. V. Os et al. Indicadores de qualidades das assistências aos nascimentos baseados na satisfação de puérperas. Texto Contexto Enfermagem, Florianópolis, v. 16, n. 3. Pag. 479-87, Jul/ Set, 2007.

REIS, T. R. et al. Enfermagem obstétrica: contribuições às metas dos Objetivos de Desenvolvimento do Milênio. Revista Gaúcha de Enfermagem, v. 36 (esp.), pag. 94-101, 2015.

REINERS, A. O, et al. Diagnósticos de enfermagem em gestantes hipertensas. Revista Mineira de Enfermagem, v 13, n. 2, pag. 232-237, abr./jun., 2009

Resolução COFEN-358/2009. Dispõe sobre a Sistematização da Assistência de Enfermagem e a implementação do Processo de Enfermagem. Brasília-DF, 15 de outubro de 2009. Disponível em < http://www.cofen.gov.br/resoluo-cofen-3582009_4384.html> Acessado em 25/08/2017.

SAMPAIO, T. A. F. Cuidados de enfermagem prestados a mulheres com hipertensão gestacional e pré-eclâmpsia. Revista Saúde Física \& Mental- UNIABEU, v.2 n.1 janeiro - julho 2013.

SANDE, C. M. Condutas do enfermeiro no atendimento emergencial ao paciente politraumatizado: uma revisão bibliográfica. Monografia (Especialização em Enfermagem em Emergência) - Salvador-Bahia, Universidade Castelo Branco, 2010. 47p.

SANTORO, D. C. Urgência e emergência. Rio de Janeiro: Águia Dourada Ltda, 2011.

SANTOS, F. P. A; NERY, A. A; MATUMOTO, S. A produção do cuidado a usuários com hipertensão arterial e as tecnologias em saúde. Revista da Escola de Enfermagem da USP, v. 47, n. 1, p.107-14, 2013. Disponível em: <http://www.scielo.br/pdf/reeusp/v47n1/a14v47n1.pdf>. Acesso em: agosto, 2017.

SILVA, M. P, et al. Avaliação das condutas de prevenção da síndrome hipertensiva específica da gravidez entre adolescentes. Revista da Rede de Enfermagem do Nordeste-Rev Rene. Fortaleza, v. 11, n. 4, p. 57-65, out./dez. 2010.

Sociedade Brasileira de Cardiologia. Sociedade Brasileira de Hipertensão. Sociedade Brasileira de Nefrologia. VII Diretrizes Brasileiras de Hipertensão. Arquivos Brasileiros de Cardiologia, Volume 107, № 3, Suplemento 3, setembro 2016.

VETTORE, M. V. et al. Cuidados pré-natais e avaliação do manejo da hipertensão arterial em gestantes do SUS no Município do Rio de Janeiro, Brasil. Caderno de Saúde Pública, Rio de Janeiro, v. 27, n. 5, p. 1021-1034, maio, 2011. Disponível em: <http://www.scielo.br/pdf/csp/v27n5/19. pdf $>$. Acesso em: agosto, 2017. 


\section{SÍFILIS EM GESTANTE: SITUAÇÃO \\ EPIDEMIOLÓGICA EM PORTO E MOZ/PARÁ ENTRE OS ANOS DE 2017 E 2018}

Data de aceite: $20 / 08 / 2021$

Data de submissão: 23/07/2021

Lília Maria Nobre Mendonça de Aguiar Enfermeira Lília Mendonça: prevenção, saúde

e bem-estar

Santarém, Pará http://lattes.cnpq.br/3149704261770731 / https://orcid.org/0000-0003-2786-2391

Uberlan Nogueira Fonceca

Santarém, Pará https://orcid.org/0000-0002-7261-1180

Jocireudo de Jesus Carneiro de Aguiar Laboratório LACON

Santarém, Pará

http://lattes.cnpq.br/0630231948597108

Silvia Sousa da Silva

Centro Universitário da Amazônia - UNAMA

Santarém, Pará http://lattes.cnpq.br/5819408850309338

Antenor Matos de Carvalho Junior Hospital Regional do Baixo Amazonas

Waldemar Penna

Santarém, Pará

http://lattes.cnpq.br/2838717520870004

Gerciane Suely Castro de Souza

Santarém, Pará

https://orcid.org/0000-0002-7811-2227

Domingas Machado da Silva

Santarém, Pará

http://lattes.cnpq.br/5202168262491743
Lulucha de Fátima Lima da Silva

Santarém, Pará http://lattes.cnpq.br/8943071874230659

RESUMO: OBJETIVO: Investigar casos de sífilis em gestante e verificar a epidemiologia na cidade de Porto de Moz, Pará, no ano de 2017 e 2018. MATERAIS E METODOS: Estudo epidemiológico descritivo quantitativo, transversal, com os dados Departamento de Informática do Sistema Único de Saúde. RESULTADOS: Foram analisados 6 casos confirmados durante o ano de 2017 e 2018, em 2017 apenas 16,66\% apresentou infecção da doença e no ano de 2018 foram $88,33 \%$ de 5 gestantes apresentam positividade para sífilis gestacional, a pesquisa identificou que $66,66 \%$ eram mães com idade de 20 a 34 anos e a maioria eram mulheres com a raça parda apresentando 66,66\%.CONLUSÃO: É necessário a melhoria de assistência no momento do pré-natal para evitar o número significativo de sífilis em gestantes e prevenir para que não ocorre complicações futuras.

PALAVRAS - CHAVE: Transmissão. Bactéria. Saúde pública. Mulheres.

SYPHILIS IN PREGNANT WOMEN: SITUATION EPIDEMIOLOGY IN PORT AND MOZ/PARÁ BETWEEN THE YEARS 2018 AND 2019

ABSTRACT: OBJECTIVE: To investigate cases of syphilis in pregnant women and to verify epidemiology city of Porto and Moz, Pará, in 2017 and 2018. MATERAIS AND METHODS: 
Quantitative, cross-sectional descriptive epidemiological study, with data Department of Informatics of the Unified Health System. RESULTS: 6 confirmed cases were analyzed during 2017 and 2018, in 2017 only $16.66 \%$ had disease infection and in 2018 were $88.33 \%$ of 5 pregnant women who were positive for gestational syphilis, the research identified that $66.66 \%$ were mothers aged 20 to 34 years and most were brown women with $66.66 \%$. CONLUSION: it is necessary to improve care at the time of prenatal care to avoid the significant number of syphilis in pregnant women and prevent future complications.

KEYWORD: Transmission Bacteria. Public health. Women.

\section{I INTRODUÇÃO}

A sífilis na gestação é um grave problema de saúde pública, sendo uns dos fatores mais responsáveis por índices altos de morbimortalidade, avalia-se que pelo menos 50\% das gestações são acometidas finais perinatais, associadas a infecções intrauterina ou até mesmo asfixia, além disso, a maioria das mulheres que são infectadas identificam a doença durante a gestação ou no momento do parto'.

A sífilis trata-se de uma doença sexualmente transmissível (DST) causada pela bactéria Treponema pallidum, podendo agredir vários órgãos e sistemas, normalmente apresenta 3 fases distintas com sintomas próprios (sífilis primaria, secundaria e terciaria), a sua transmissão pode ocorrer através do contato sexual sem camisinha com uma pessoa infectada, ou para criança durante a gravidez ou no parto ${ }^{2}$.

De acordo com dados, 95\% dos casos de sífilis a contaminação ocorre pelos órgãos genitais, e outras formas de transmissão que possuem um menor interesse são por via indireta, ou seja, através de matérias contaminados como agulhas e tatuagens e por transfusão sanguínea ${ }^{(4)}$. A doença é provocada por uma bactéria do filo espiroqueta, o treponema pallidum, pertencente à família dos treponemataceae, tendo, aproximadamente, de 5-20 mm de comprimento e 0,1 a 0,2 de espessura, não apresenta membrana celular ${ }^{3}$.

Clinicamente, a sífilis primaria é determinada por uma lesão chamada cancro duro ou protossifiloma, surge no período de 20 a 90 dias em média 21 dias, podendo desaparecer no período de quatro semanas, já a secundaria pode durar de seis a oito semanas, podendo afetas órgãos internos ou até mesmo pelo corpo todo, e a terciaria pode surgir de 2 a 40 anos após o início da infecção e pode ocorrer a formação de granulomas como se fosse gomas. No homem é mais comum o aparecimento na localização do prepúcio, meato uretral e no sulco balanoprepucial e nas mulheres podem aparecer nos pequenos lábios, parede vaginal e colo uterino, podendo ser assistemático ou não 4 .

No Brasil o Ministério da Saúde publicou uma nota sobre os dados do boletim epidemiológico de sífilis em 2018, no qual apontam o aumento no número de casos de sífilis em todos os cenários da infecção ${ }^{5}$. No ano de 2016 constatou-se aumento de $28,5 \%$ na taxa de detecção em gestantes, $16,4 \%$ na incidência de sífilis congênita e $31,8 \%$ na incidência de sífilis adquirida. 
Segundo o Boletim do ministério da saúde no Brasil passou de 44,1/100 mil/ habitante a taxa de detecção da sífilis adquirida em 2016 para 58,1 casos para cada 100 mil habitantes em 2017. Já em gestante, cresceu de 10,8 casos por 1 mil nascidos vivos em 2016 para 17,2 casos a cada 1 mil nascidos vivos em 2017 e em sífilis congênita passou 21.183 casos em 2016, para 24.666 em $2017^{5}$.

Para o diagnóstico da sífilis e a escolha do exame laboratorial e tratamento mais adequado deve-se considerar a fase evolutiva da doença, Sendo: prova direta (exame em campo escuro, pesquisa direta com material corado e imunofluorescência direta), provas sorológicas (teste não treponemos), teste treponemos e exame do líquor ${ }^{6}$. Já o tratamento a escolha deve-se a penicilina bizantina, que está disponível no Sistema Único de Saúde (SUS) $)^{5}$

A sífilis, entretanto, consiste em uma doença que tem se alastrado em grande parte da população, e neste caso, em gestantes, portanto, o desenvolvimento deste estudo se dá pela necessidade de conhecer a situação epidemiológica da sífilis nas gestantes em Porto de Moz/Pará, entre os anos de 2017 e 2018.

O presente estudo teve como contribuição, relativamente, o embasamento em caráter teórico e científico, afim de despertar o conhecimento sobre essa abordagem tanto para o mundo acadêmico da área da saúde, quanto para a comunidade cientifica e a sociedade civil em todos os seus níveis de classe social.

\section{I METODOLOGIA}

O Presente estudo intitulado como investigação de sífilis em gestantes: Situação Epidemiológica na cidade de Porto de Moz Pará no ano de 2017 e 2018.

\subsection{Tipo de Estudo}

Trata-se de um estudo epidemiológico descritivo, transversal com análise detalhada com os dados do Departamento de Informática do Sistema Único de Saúde ${ }^{7}$.

\subsection{Local de Estudo}

O local de estudo foi realizado na cidade de Porto de Moz, Pará, Brasil, sobre uma área de 17 423,2 km² e contando com uma população de 33951 habitantes em 2019, situado a 24 metros de altitude, de Porto de Moz tem as seguintes coordenadas geográficas: Latitude: $1^{\circ} 44^{\prime} 54^{\prime \prime}$ Sul, Longitude: 52 14' 18' Oeste ${ }^{8}$.

\subsection{Delimitação do Público Alvo}

Para seleção de resultados foram utilizados como critério a inclusão todos os casos de sífilis gestacional e congênita em residentes de Porto de Moz, registrados no DATASUS - Departamento de Informática do Sistema Único de Saúde, o período escolhido foram os anos 2017 e 2018 onde selecionei somente o que atenderam ao critério de definição de 
caso confirmado segundo o Ministério da Saúde e os casos excluídos foram aqueles que resultados duplicados e ignorados.

Os casos de sífilis congênita identificados foram caracterizados de acordo com as seguintes variáveis presentes na base de dados: Idade (em anos: 10 a 14; 15 a 19; 20 a 34; 35 a 49), Cor: branco, negro e parda, Momento do diagnóstico materno $\left(1^{\circ}, 2^{\circ}, 3^{\circ}\right.$ trimestre ou idade gestacional ignorada) e Classificação clínica da doença (primária; secundária; terciária; latente; ignorada/em branco).

Neste trabalho também foram utilizados artigos científicos disponibilizados no banco de dados do SciELO e LILACS. Os dados foram coletados no mês de MAIO E JUNHO, logo após, foi elaborado uma planilha para tabular todos os dados e realizado a contabilização para apresentar tabelas e gráficos no artigo.

\section{I RESULTADOS E DISCUSSÃO}

Foram confirmados no total 6 casos de sífilis congênita no município de Portos Moz, com a incidência anual média do período de estudo (2017 e 2018) de 1.000 nascidos vivos. Entretanto, esse número apresentou elevação no ano de 2018, contabilizando 5 gestantes contaminadas, observando-se, conforme Gráfico 1, 88,33\% em relação ao ano de 2017 , com $16,66 \%$.

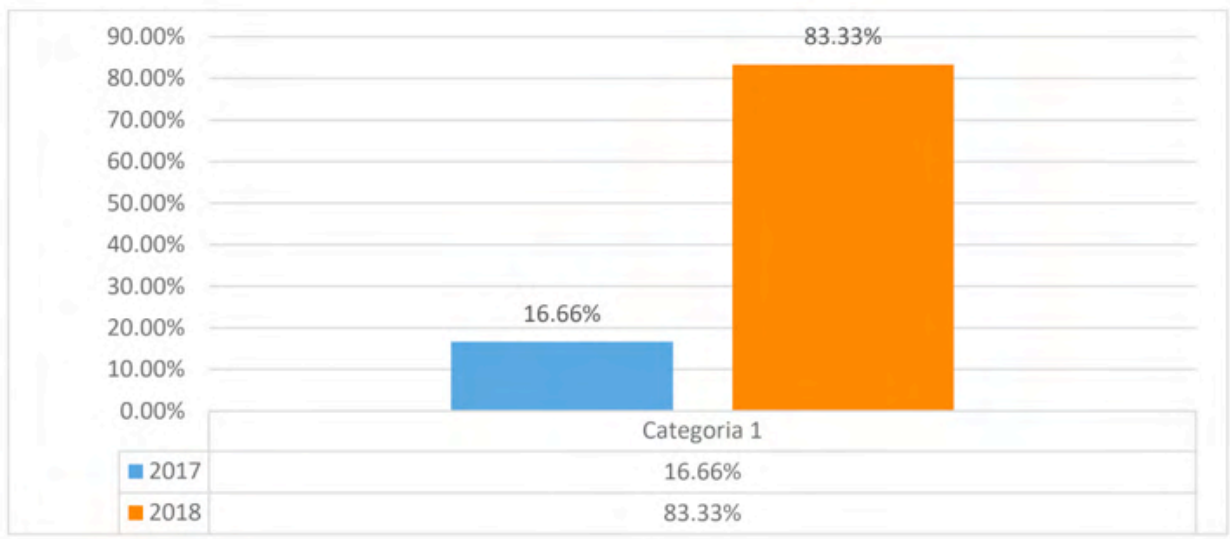

Gráfico 1: Percentual de gestantes positiva para sífilis.

Fonte: autoria própria (2020).

De acordo com os dados foi possível avaliar o perfil epidemiológico de sífilis gestacional em mulheres com vida sexual ativa com idade entre 10 a 49 anos, e foi verificado que o índice maior de mulheres com a sífilis gestacional foram mães com idade de 20 a 34 anos com o total de $66.66 \%(n=4)$, na tabela1 mostra a quantidade total e a percentagem de sífilis congênita. 


\begin{tabular}{|c|c|c|c|c|}
\hline \multicolumn{5}{|c|}{$\begin{array}{l}\text { Casos de sífilis congênita segundo faixa etária da mãe por ano de diagnóstico. 2017- } \\
2018 \text {. }\end{array}$} \\
\hline \multirow[t]{2}{*}{ IDADE } & \multicolumn{2}{|c|}{2017} & \multicolumn{2}{|c|}{2018} \\
\hline & $\mathrm{n}=$ & (\%) & $n=$ & (\%) \\
\hline $10-14$ & 0 & $0 \%$ & 0 & $0 \%$ \\
\hline $15-19$ & 1 & 16,67 & 4 & $66,66 \%$ \\
\hline $20-34$ & 0 & $0 \%$ & 0 & $0 \%$ \\
\hline $35-49$ & 0 & $0 \%$ & 1 & $16,67 \%$ \\
\hline
\end{tabular}

Tabela 1: Classificação 6 casos de sífilis congênita no município de Porto de Moz, e percentual do perfil epidemiológico de sífilis.

Fonte: autoria própria.

Segundo Lima e colaboradores ${ }^{12}$, em sua pesquisa demostrou um índice maior de mulheres com idade de 20 a 29 anos, apresentando $57 \%$ de 296 casos, sendo que acima de 30 anos apresentou 27\%, 10 anos a 19 anos foram apenas $16 \%$, semelhante com a pesquisa de Motta $^{13}$, que em sua pesquisa também demostrou um alto índice de gestante contaminadas com a idade de 20 a 34 anos, de acordo com o Ministério da saúde, 2018, no país, o aumento foi de $31,8 \%$ (de 44,1 para 58,1 casos por 100 mil habitantes).

Regionalmente, o incremento foi de $45 \%$ na Região Norte (de 22,9 para 33,2 casos por 100 mil habitantes), o sexo feminino é o mais afetado pela bactéria Treponema pallidum, na faixa etária entre 20 a 29 anos geralmente sendo jovens e negras onde ocupam $26,2 \%$ do total de casos notificados, já os homens representam $13,6 \%$ na mesma faixa etária ${ }^{5}$.

Diante do aumento da incidência deste agravo nessas idades, pode-se dizer que há uma grande deficiência na assistência de pré-natal oferecida do sistema de saúde para gestantes, pois, de acordo com os dados oferecido pelo sistema, no período de 2017 e 2018, nenhuma gestante realizou pré-natal.

Sabe-se que com a assistência do pré-natal de maneira adequada, iria reduzir os casos de sífilis imprevistos durante a gravidez por meio de aconselhamento e estímulo ao uso de preservativo 9 .

Este estudo também identificou fatores de risco em casos de sífilis congênita segundo a raça ou cor da mãe, visto que o maior índice ocorreu em mulheres parda no ano de 2018, na tabela 2 mostra a percentagem de cada cor, apresentando 66,66\% de 4 mulheres, enquanto a cor branca demostrou apenas $16,67 \%$ de 1 mulher.

Estudo realizado por Jesus $^{3}$ foi também evidenciado que $63 \%$ das mulheres declararam a cor da pele como parda, $21 \%$ sendo a cor da pele como preta, 19\% branca, e Cavalcante e colaboradores ${ }^{10}$ mostrou em sua pesquisa um tamanho formidável da população com sintomas da doença no ano de 2012, e comprovou fatores que tiverem extrema significância sobre a maior prevalência da sífilis foi à cor da pele pardas. 


\begin{tabular}{lllll}
\hline \multicolumn{6}{l}{ Casos de gestantes com sifilis segundo raça/cor por ano de diagnóstico. } \\
\hline RAÇA/COR & 2017 & & 2018 & \\
\hline & $\mathrm{n}=$ & $(\%)$ & $\mathrm{n}=18$ & $(\%)$ \\
BRANCA & 0 & $0 \%$ & 1 & $16.67 \%$ \\
NEGRA & 0 & $0 \%$ & 0 & $0 \%$ \\
PARDA & 1 & $16,7 \%$ & 4 & $66.66 \%$ \\
\hline
\end{tabular}

Tabela 2: classificação 6 casos de sífilis congênita no município de Porto de Moz, e percentual da raça/ cor da mãe.

Fonte: autoria própria.

Foi possível avaliar o nível de escolaridade, e na tabela 3 demostrou um índice relativo, apenas duas mulheres apresentavam o ensino médio completo, 33,33\% e uma apresentou somente o fundamental completo, $16,67 \%$ e a outra mulher possuía o $4^{\circ} \mathrm{e}$ $5^{\circ}$ incompleto em 2018, e apenas uma mulher em 2017 havia somente o fundamental completo.

De acordo com Jesus ${ }^{3}$, em sua pesquisa afirma que o nível de escolaridade pode estar ligado ao acesso deficiente as informações e cuidados a saúde, e por conta da falta de acesso a essas informações, a população está mais exposta a essa patologia. No entanto, o aumento da incidência pode estar relacionado a situações vulneráveis, envolvendo as características comportamentais e reprodutivas ao praticar relações sexuais inseguras ${ }^{9}$.

\begin{tabular}{|c|c|c|c|c|}
\hline $\begin{array}{l}\text { Casos de gestante } \\
\text { 2017-2018. }\end{array}$ & com & undo $\mathrm{e}$ & por & nósticc \\
\hline ESCOLARIDADE & 2017 & & & \\
\hline & $n=$ & $(\%)$ & $\mathrm{n}=$ & (\%) \\
\hline $4^{\circ}$ e $5^{\circ}$ incompleto & 0 & $0 \%$ & 1 & $16.67 \%$ \\
\hline Fund. Completo & 1 & $16,6 \%$ & 1 & $16,67 \%$ \\
\hline Médio incompleto & 0 & $0 \%$ & 1 & $16,67 \%$ \\
\hline Médio completo & 0 & $0 \%$ & 2 & $33,33 \%$ \\
\hline Superior incompleto & 0 & $0 \%$ & 0 & $0 \%$ \\
\hline Superior completo & 0 & $0 \%$ & 0 & $0 \%$ \\
\hline
\end{tabular}

Tabela 3: classificação de nível de escolaridade de gestantes de porto de Moz.

Fonte: autoria própria.

Segundo os dados obtidos pelo sistema, os casos de gestantes com sífilis na descoberta gestacional, a tabela 4 , mostra que houve índice elevado no $1^{\circ}$ trimestre e no $3^{\circ}$ trimestre da gravidez, ambos em 2018, o $1^{\circ}$ trimestre apresentou 33,33\% de 2 mulheres e no $3^{\circ}$ semestre 33,33 de 2 mulheres, e apenas uma mulher no $2^{\circ}$ semestre foi diagnosticada com a doença, em 2017, apenas uma mulher no $2^{\circ}$ semestre apresentou a doença.

Não foi possível encontrar estudos semelhantes para correlacionar com esta pesquisa, porém foi possível encontrar na pesquisa de Lima e colaboradores $^{12}$, a demonstração da ausência de gestantes realizando os exames para detectar a sífilis no primeiro e terceiro trimestre da gestante, o que torna preocupante para saúde brasileira. 
Em se tratando do parágrafo anterior, um dos principais fatores de risco para a sífilis gestacional no estudo foi a realização de consulta pré-natal na cidade de Porto de Moz.

Nesse mesmo sentido, um estudo semelhante, o de Lima ${ }^{12}$, afirma em sua pesquisa sobre as mulheres que não receberam nenhum auxilio no pré-natal, apresentam a chance de onze vezes maior, do que as gestantes que realizaram pelo menos uma consulta prénatal.

\begin{tabular}{|c|c|c|c|c|}
\hline \multicolumn{5}{|c|}{$\begin{array}{l}\text { Casos de gestantes com sífilis segundo idade gestacional por ano de diagnóstico. } \\
\text { Brasil, 2017-2018. }\end{array}$} \\
\hline $\begin{array}{l}\text { Idade } \\
\text { gestacional }\end{array}$ & 2017 & & 201 & \\
\hline & $\mathrm{n}=$ & $(\%)$ & $\mathrm{n}=$ & $(\%)$ \\
\hline $1^{\circ}$ trimestre & 0 & $0 \%$ & 2 & $33,33 \%$ \\
\hline $2^{\circ}$ trimestre & 1 & 16.67 & 1 & $16.67 \%$ \\
\hline $3^{\circ}$ trimestre & 0 & $0 \%$ & 2 & $33,33 \%$ \\
\hline
\end{tabular}

Tabela 4: classificação casos segundo a idade gestacional de mulheres com sífilis na cidade de porto de Moz.

Fonte: autoria própria.

Em relação a evolução clínica da sífilis, na qual possuem características específicas para cada fase, sendo elas com período de atividades e latentes, e de acordo com as classificações dos dados à tabela 5 mostra o maior índice é na fase primaria com $50 \%$ de 3 casos, e em comparação com o ano de 2017 e 2018, o ano de 2018 foi o que teve mais casos na sífilis primaria, em 2017 ocorreu apenas 16,6\% com um 1 caso na fase primaria.

\begin{tabular}{lllll}
\hline \multicolumn{6}{c}{ Classificação clínica da sífilis segundo o diagnóstico. Brasil, 2017-2018. } \\
\cline { 2 - 6 } Classificação clinica & $\mathrm{n}=$ & $(\%)$ & 2018 & \\
Primaria & 1 & $16,6 \%$ & 3 & $(\%)$ \\
Secundaria & 0 & $0 \%$ & 0 & $50 \%$ \\
Terciaria & 0 & $0 \%$ & 1 & $0 \%$ \\
Latente & 0 & $0 \%$ & 1 & $16,7 \%$ \\
\hline
\end{tabular}

Tabela 5: classificação clínica da sífilis no município de porto de Moz.

Fonte: autoria própria.

Segundo CARDOSO ${ }^{11}$, mostrou a relação clínica e verificou que os maiores casos foram gestantes com sífilis primaria e terciaria e acredita-se que houve falhas, pois, sabe-se que o diagnóstico de sífilis primaria na gestante é incomum, uma vez que a seu aparecimento, o cancro duro, tem um tempo limitado e breve de permanência, podendo surgir em regiões não visíveis da genitália ou fora da região genital, e por essa causa, acredita-se que a grande maioria dos diagnósticos ocorra na fase latente ou tardia. 


\section{I CONCLUSÃO}

O presente estudo determinou o perfil epidemiológico na cidade de Porto de Moz, onde apresentou a prevalência em gestante com idade de 20 e 34 anos, e em mulheres pardas. A sífilis é uma doença que pode gerar os maiores danos em gestantes, apesar de seu tratamento, ainda sim, é um grande problema para saúde pública, pois, mesmo com o tratamento, o controle inadequado torna-se incapaz de evitar a transmissão do treponema. Além disso, as gestantes não estão recebendo assistência adequada, na qual se torna ainda maior o problema. E para que seja evitado esses transtornos, torna-se necessário o incentivo do uso de preservativo e o acompanhamento do pré-natal, além disso o aconselhamento aos jovens é de suma importância, assim combatendo a doença de maneira correta e a capacitação de profissionais da área.

\section{REFERÊNCIAS}

1. MAGALHÃES, D.M.S et al. A sífilis na gestação e sua influência na morbimortalidade maternoinfantil. Com. Ciências Saúde - 22 Sup 1:S43-S54, 2011.

2. MINISTERIO DA SAÚDE, Boletim epidemiológico de sifilis; Secretaria de Vigilância em Saúda; Brasil, Volume 48, 2017.

3. JESUS, N. M. T. Avaliação de sífilis em mulheres com vida sexual ativa cadastradas no esf mamoeiro de Unaí-MG [tese]. Faculdade TECSOMA; 2015.

4. AVELLEIRA, J.; BOTTINO, G. Sífilis: diagnóstico, tratamento e controle. An Bras Dermatol, 81(2):111-26; 2006.

5. MINISTERIO DA SAÚDE, Boletim Epidemiológico de Sífilis; Secretaria de Vigilância em Saúde; Ministério da Saúde, Volume 49 I Nº 45 I Out. 2018.

6. PIRES, A. C. S., et al. Ocorrência de sífilis congênita e os principais fatores relacionados aos índices de transmissão da doença no Brasil da atualidade-revisão de literatura. Revista UNINGA Review, v. 19, n. 1, 2014.

7. DATA SUS Departamento de Informática do Sistema Único de Saúde, Disponível em < http:// indicadoressifilis.aids.gov.br/ > Acessado em 06/10/2020.

8. GOOGLE, Google Earth website. Disponível em: < https://earth.google.com/web/search/ Porto+de+Moz,+Par\%c3\%a1,+Brasil/ >. Acesso: 12 de agosto de 2020.

9. MACEDO, V. C., et al. Fatores de risco para sífilis em mulheres: estudo caso-controle. Revista de saúde pública, v.51,p. 78,2017.

10. CAVALCANTE, A. E. S., et al. Diagnóstico e Tratamento da Sífilis: uma Investigação com Mulheres Assistidas na Atenção Básica em Sobral, Ceará. DST - J bras Doenças Sex Transm. 2012 
11. CARDOSO, A. R. P., et al. Análise dos casos de sífilis gestacional e congênita nos anos de 2008 e 2010 em Fortaleza, Ceara, Brasil. Ciência \& Saúde Coletiva, v. 23, p. 563-574, 2018.

12. LIMA, M. G., et al. Incidência e fatores de risco para sífilis congênita em belo horizonte, Minas Gerais, 2001-2008. Ciência \& Sáude coletiva, v.18, p 499-506,2013.

13. MOTTA, I. A., et al. Sífilis congênita: por que sua prevalência continua tão alta? Rev med minas gerais, v. 28, n. Supl 6, p. S280610, 2018. 


\section{CAPÍTULO 6}

\section{ASSISTÊNCIA DE ENFERMAGEM À PACIENTE COM ROTURA PREMATURA DAS MEMBRANAS OVULARES}

Data de aceite: 20/08/2021

Data de submissão: 06/08/2021

Camilla Pontes Bezerra Universidade Federal de São Paulo, Escola Paulista de Enfermagem São Paulo - São Paulo http://lattes.cnpq.br/0240028136282226

Vanessa Cavalcante Pereira Universidade de Fortaleza, Curso de Bacharelado em Enfermagem Fortaleza - Ceará http://lattes.cnpq.br/0312267203016272

Mayara Santiago Camurça Centro Universitário Estácio do Ceará, Curso de Bacharelado em Enfermagem Fortaleza - Ceará http://lattes.cnpq.br/7225310602650050

Lívia Karoline Torres Brito Universidade da Integração Internacional da Lusofonia Afro-Brasileira, Curso de Bacharelado em Enfermagem Fortaleza - Ceará http://lattes.cnpq.br/1744509748514083

Erinete Melo da Silva Freire Centro Universitário Estácio do Ceará, Curso de Bacharelado em Enfermagem Fortaleza - Ceará http://lattes.cnpq.br/6023459528782036 Josyene de Lima Cardoso Centro Universitário Estácio do Ceará, Curso de Bacharelado em Enfermagem Fortaleza - Ceará http://lattes.cnpq.br/4055293748470893
Virgínia Maria Nazário Barbosa Centro Universitário Estácio do Ceará, Curso de Bacharelado em Enfermagem

Fortaleza - Ceará http://lattes.cnpq.br/6363754813668268

Rosane Reis Rocha Centro Universitário Estácio do Ceará, Curso de Bacharelado em Enfermagem Fortaleza - Ceará http://lattes.cnpq.br/3057303636038461

Ana Raquel Bezerra da Silva Almeida Centro Universitário Estácio do Ceará, Curso de Bacharelado em Enfermagem

Fortaleza - Ceará http://lattes.cnpq.br/2874255569541926

Emanuelle Rabelo Cordeiro Universidade Federal do Ceará, Departamento de Enfermagem Fortaleza - Ceará http://lattes.cnpq.br/2735020127306963 Leandro da Silva Ribeiro

Faculdade Uninassau, Curso de Bacharelado em Enfermagem

Fortaleza - Ceará http://lattes.cnpq.br/1905550361985766

Francisca Glaucineide Mendonça Vieira Faculdade Metropolitana da Grande Fortaleza, Curso de Enfermagem Fortaleza - Ceará http://lattes.cnpq.br/8707117911037826 
RESUMO: O estudo tem por objetivo apresentar relato de caso acerca da assistência de enfermagem à paciente com Rotura Prematuras das Membranas Ovulares - RPMO. Tratase de um estudo descritivo, transversal do tipo relato de caso, realizado em novembro de 2019 , sobre os cuidados e diagnósticos de enfermagem à paciente com rotura prematura das membranas ovulares realizado durante as atividades práticas da unidade curricular de Saúde da Mulher dos estudantes de Graduação em Enfermagem de uma instituição de ensino superior, situada na cidade de Fortaleza-CE. Foi entrevistada uma mulher e a experiência foi vivenciada em uma unidade hospitalar referência de atenção terciária de alta complexidade e de ensino. A coleta de dados possibilitou a identificação dos diagnósticos de enfermagem e necessidades de intervenção, fundamental para a elaboração do plano de cuidados. Durante o estágio supervisionado em obstetrícia, os discentes tiveram a oportunidade de realizar a aplicabilidade eficaz da Sistematização da Assistência de Enfermagem, que resultou na melhora do quadro clínico da paciente, potencializando o cuidado oferecido pela equipe de enfermagem. Por meio deste estudo, fica evidente que a realização da anamnese e exame físico de forma criteriosa é fundamental para subsidiar a elaboração dos diagnósticos de enfermagem e suas intervenções.

PALAVRAS - CHAVE: Cuidados de Enfermagem. Trabalho de Parto Prematuro. Ruptura Prematura de Membranas Fetais.

\section{NURSING CARE FOR A PATIENT WITH PREMATURE RUPTURE OF OVULAR MEMBRANES}

ABSTRACT: The study aims to present a case report on nursing care for patients with Premature Rupture of Ovular Membranes (PROM). This is a descriptive, cross-sectional case-report study, carried out in November 2019, on nursing care and diagnoses for patients with premature rupture of the ovular membranes, carried out during practical activities of the curricular unit on women's health for nursing students of a higher education institution in the city of Fortaleza-CE. A woman was interviewed and the experience was lived in a reference hospital unit of tertiary care of high complexity and teaching. Data collection enabled the identification of nursing diagnoses and intervention needs, essential for the development of a care plan. During the supervised internship in obstetrics, students had the opportunity to carry out the effective applicability of the Systematization of Nursing Care, which resulted in the improvement of the patient's clinical condition, enhancing the care provided by the nursing team. Through this study, it is evident that a careful conduct of anamnesis and physical examination is essential to support the development of nursing diagnoses and their interventions.

KEYWORDS: Nursing Care. Obstetric Labor, Premature. Fetal Membranes, Premature Rupture.

\section{I INTRODUÇÃO}

A Rotura Prematura das Membranas Ovulares (RPMO), também conhecida como amniorrexe prematura, é uma das complicações mais comuns da gravidez e tem importante correlação com casos de morbidade e mortalidade perinatal. Estas complicações são 
responsáveis direta ou indiretamente por grande número de partos prematuros. Existem várias causas que indicam os riscos intrinsicamente ligados à RPMO, destacam-se: as infecções maternas, as cervicites, a incompetência istmocervical, as gestações múltiplas, tabagismo e defeito na estrutura do saco amniótico, além de outros fatores (SILVEIRA et al., 2018).

A RPMO afeta de 5 a 15\% das gestações, sendo que 75 a $80 \%$ estão enquadradas no termo. Todavia, é responsável por 30 a $40 \%$ dos partos prematuros e $20 \%$ das mortes perinatais. Desse modo, a uniformização de procedimentos para o tratamento da RPMO propende a diminuir as suas complicações durante a gestação, como a prematuridade extrema. A RPMO é responsável por cerca de um terço dos partos prematuros (SILVA et al., 2016). Geralmente, quando a bolsa rompe horas antes do trabalho de parto, a mulher inicia um processo natural para o nascimento do bebê, que pode durar até 24 horas. Quando ocorre a amniorrexe prematura ou rotura prematura, a mulher corre o risco de aborto.

Existem fatores que serve de alerta para essa ocorrência, como o acúmulo vaginal de líquido amniótico ou verniz caseoso visível ou mecônio; avaliação do fluido vaginal, mostrando cristalização ou alcalinidade (cor azul) em papel de nitrazina(com aspecto de samambaia quando o líquido vaginal seca), os resultados dos testes de nitrazina podem ser falso-positivo se o sangue, sêmen, antissépticos alcalinos ou urina contaminarem a amostra ou se a mulher tem vaginose bacteriana; a amniocentese às vezes guiada por ultrassom com tintura para a confirmação. Efetua-se exame especular com material estéril para confirmar ruptura prematura das membranas, estimar a dilatação cervical, coletar líquido amniótico para culturas e testes de maturidade pulmonar fetal, bem como para obter amostras de culturas cervicais. O exame pélvico digital aumenta o risco de infecção e deve ser evitado, a não ser que um parto iminente seja antecipado. Confirmado o diagnóstico de RPMPT sem trabalho de parto, é indicado a internação hospitalar das gestantes, dando-se início ao esquema medicamentoso com corticoide, visando acelerar a maturidade pulmonar do feto e antibiótico profilático para amenizar ou evitar o risco de infecção que a mulher se encontra exposta.

Infere-se a necessidade de que os profissionais envolvidos despertem uma ótica mais específica a respeito dos fatores que permeiam a RPMO, para que dessa forma seja voltada uma assistência mais especializada, levando em conta todos os fatores apontados antes e que desenvolvam mecanismos de medidas antecipadas para que possa contribuir para a preservação da saúde do binômio. Logo, a necessidade de trazer à tona assistência de enfermagem acerca dessa problemática proporciona despertar uma visão aguçada do profissional de enfermagem a estabelecer métodos precoces através de boas práticas nos cuidados de enfermagem para paciente com RPM. 


\section{I OBJETIVO}

Apresentar relato de caso acerca da assistência de enfermagem à paciente com Rotura Prematuras das Membranas Ovulares- RPMO.

\section{3 | MÉTODO}

Trata-se de um estudo descritivo, transversal do tipo relato de caso sobre os cuidados e diagnósticos de enfermagem à paciente com rotura prematura das membranas ovulares realizado durante as atividades práticas da unidade curricular de Saúde da Mulher dos estudantes de Graduação em Enfermagem de uma instituição de ensino superior, situada na cidade de Fortaleza-CE. Foi entrevistada uma mulher e a experiência foi vivenciada em uma unidade hospitalar referência de atenção terciária de alta complexidade e de ensino, de referência em São Paulo nas áreas de Clínica médica, Cirúrgica, Ginecologia, Obstetrícia e Neonatal, no período de novembro de 2019.

O processo de enfermagem foi realizado em cinco etapas: histórico de enfermagem, diagnósticos de enfermagem, planejamento, implementação e avaliação da assistência prestada. Para o histórico de enfermagem, utilizou-se instrumento de coleta de dados com base nos domínios do NANDA-I para elencar os principais diagnósticos de enfermagem.

A análise dos dados foi realizada mediante identificação dos problemas para estabelecer os diagnósticos de enfermagem e fundamentado na literatura referente à temática.

Em relação aos aspectos éticos, inicialmente o diretor da instituição onde foi realizada a coleta de dados, foi informado sobre a pesquisa e o consentimento se deu por meio de uma carta de apresentação da pesquisa, anexada ao seu anteprojeto.

Como exigido, o estudo foi submetido ao Comitê de Ética e Pesquisa da Universidade Federal de São Paulo (CEP-UNIFESP) e aprovado sob o № 4.329.246, para atender aos preceitos ético-legais (autonomia, não maleficência, beneficência e justiça) recomendados na resolução $n^{\circ} 466 / 12$ sobre pesquisas envolvendo seres humanos do Conselho Nacional de Saúde-Ministério da Saúde (BRASIL, 2012).

\section{I RESULTADOS}

Foi realizada assistência de enfermagem pelas graduandas de enfermagem a uma paciente de 33 anos, $G_{5} P_{3} A_{1}$ com H.D de rotura prematura das membranas ovulares no prétermo (RPMPT), com 33 semanas de gestação, sendo que no relato do histórico obstétrico a primeira gestação foi gemelar com óbito neonatal devido ao trabalho de parto prematuro -TPP, e as demais, foram de filhos únicos e a termo. Foi realizada a coleta dos sinais vitais em que FC: 107, FR: 20 rpm, P.A: 150x 95 mmHg, T: 36,6, Spo $297 \%$. No exame físico foi realizado o exame Clínico das mamas sem alterações, mamilos protusos, palpação 
obstétrica: AU: $32 \mathrm{~cm}$, o foco de ausculta cardíaca fetal foi encontrado no quadrante superior direito, na altura da cicatriz umbilical, com presença de movimentos fetais, com feto pélvico, BCF: $148 \mathrm{bpm}$.

Foram solicitados exames complementares para análise do quadro de saúde do binômio mãe-filho para manter o controle da situação para evitar possíveis agravamentos da saúde da mulher e do bebê, dentre os exames, foram solicitados/realizados hemograma completo, glicemia em jejum, teste rápido para sífilis, teste rápido para HIV, teste rápido para hepatite $B$, teste para toxoplasmose, exame de urina, e demais exames solicitados pela equipe multidisciplinar. Mediante a situação da RPMPT, foi submetido antibioticoterapia com o objetivo de prevenir possíveis infecções do trato urinário e complicações das membranas ovulares. Mesmo com esse quadro de risco de infecção, todos os resultados dos exames se mostraram dentro do padrão da normalidade. Seguindo o tempo cronológico da sistematização da assistência de enfermagem, foram traçados diagnósticos baseados no NANDA-I (MOORHEAD; JOHNSON, 2010; PATRIOTA et al., 2014; BARROS et al., BARROS et al., 2018; DOCHTERMAN; BULECHEK, 2018).

\section{5| DISCUSSÃO}

Durante o estágio supervisionado em obstetrícia, os discentes tiveram a oportunidade de realizar a Sistematização da Assistência de Enfermagem, que em dado momento se deu pelo acompanhamento da paciente do estudo G.P.P.B., sexo feminino, 33 anos, no $3^{\circ}$ trimestre de gestação (33 semanas e $1 \mathrm{dia}$ ), natural e procedente de Fortaleza/CE, no $9^{\circ} \mathrm{DIH}$, e portadora da Hipertensão Arterial Sistêmica (HAS). A hipertensão crônica na gestação é definida como a elevação da pressão arterial (PA>140 x $90 \mathrm{mmHg}$ ), observada antes da concepção ou de 20 semanas da gestação (NHBPEP, 2000). Sibai B (2002) vem ressaltar que a mensuração da pressão arterial deve ocorrer em, ao menos, duas ocasiões com intervalo mínimo de 4 horas entre elas.

De acordo com NHBPEP (2000), o diagnóstico de hipertensão crônica torna-se bastante simples, porém, o que dificulta esse diagnóstico precoce está associado ao início tardio do pré-natal (>20 semanas), após a ocorrência da queda fisiológica da pressão no $2^{\circ}$ trimestre e pela inconstância da história pré-concepcional da gestante. Na anamnese, G.P.P.B. apresentava boa aceitação e adaptação do quadro clínico e ao ambiente hospitalar, porém, manifestou alterações emocionais no decorrer de sua internação como tristeza, ansiedade, preocupação, medo e nervosismo pela falta de informação sobre seu prognóstico, recebendo apoio familiar e da equipe multidisciplinar. Como forma de tranquilizá-la, os discentes buscaram proporcionar um ambiente agradável que favorecesse um diálogo claro e objetivo entre a equipe e a paciente. Ao término, os acadêmicos elaboraram um plano assistencial de acordo com a evolução e diagnósticos de enfermagem traçados pela Classificação de Diagnóstico de Enfermagem da NANDA Internacional. 


\section{Evolução de Enfermagem}

Às 9:00h foi realizada visita de enfermagem à gestante G.P.P.B., cujo histórico obstétrico é ( $5^{\mathrm{a}}$ gestação, 3 partos e 1 aborto anterior. Data da Última Menstruação (DUM): 28/12/2018, Data Prevista do Parto (DPP): 04/10/2019, Idade Gestacional (IG) pela Ultrassonografia (USG): 34 semanas/ Idade Gestacional (IG) de acordo com a Data da Última Menstruação (DUM): 33 semanas e 1 dia), encontra-se em trabalho de parto relacionado com o quadro de Rotura Prematura das Membranas Ovulares, consciente, orientada, ansiosa, com medo, colaborativa, eupneica, acianótica, anictérica com pele e mucosas íntegras e normocoradas. Queixa principal: Dor em baixo ventre, cefaleia, perda de tampão mucoso e de líquido amniótico. Sinais Vitais: Normocárdica, normotensa, eupneica e afebril. Ao Exame Físico: Couro cabeludo íntegro e limpo, pele e mucosas hipocoradas, sem presença de gânglios infartados. Tórax: simétrico com boa expansividade, ausculta cardíaca (AC): bulhas cardíacas normofonéticas em 2 Tempos e sem sopros, ausculta pulmonar (AP): murmúrios vesiculares presentes e sem ruídos adventícios, mamas: turgidas e simétricas, mamilos protusos com presença de colostro espontâneo. Abdômen gravídico com movimentos fetais presentes, batimentos cardíacos fetais (BCF): 145 batimentos por minuto (bpm), altura uterina 30 centímetros, feto único em situação longitudinal, posição dorso a direita, apresentação cefálica. Genitália íntegra apresentando perda de tampão mucoso com sangue. Membros Superiores e Inferiores (MMSS/II): simétricos, apresentando cacifo (-), com boa perfusão periférica, Acesso Venoso Periférico (AVP) salinizado em antebraço esquerdo. Aceita bem a dieta oferecida. Padrão de eliminação urinário alterado, caracterizado pelo aumento de idas ao banheiro em curtos espaços de tempo e padrão de eliminação intestinal preservado e espontâneo.

Foi realizado o diagnóstico de Rotura Prematura das Membranas Ovulares. Foram realizadas as seguintes condutas: orientações sobre resultados de exames, vacinas, esclarecimentos de dúvidas. Aplicada escala numérica de dor que deu como resultado 3 , classificando como dor leve em baixo ventre devido contrações uterinas que alivia ao se deitar em decúbito lateral esquerdo melhorando o retorno venoso pela descompressão da veia cava inferior.

\section{Sistematização da Assistência de Enfermagem (SAE)}

De acordo com os dados obtidos na evolução e apoio do NANDA, os autores traçaram os seguintes diagnósticos de enfermagem (DE): Risco de infecção intrauterina relacionada com a rotura da barreira amniótica; Ansiedade caracterizada por relato verbal e relacionada com a gravidez e seu desfecho; Dor aguda caracterizada por expressão facial e corporal relacionada com as contrações uterinas; Risco de infecção relacionada ao acesso venoso periférico; Medo caracterizado por relato verbal, relacionado a possibilidade de sofrimento ou morte fetal, assim como, trocas de gases fetal prejudicada caracterizada pela diminuição do líquido amniótico relacionado a RPMO. 
A partir dos diagnósticos de enfermagem definidos em concordância com o NANDA, serão apresentados os cuidados oferecidos. Ressaltamos que os mesmos foram estabelecidos levando em consideração a história da paciente e suas principais queixas e complicações.

As principais intervenções identificadas para o risco de infecção intrauterina são: Atentar para a presença de líquido amniótico e secreção vaginal e anotar suas características, quantidade e odor. Verificar batimentos cárdicos fetais (BCF) atentando para bradicardia ou taquicardia a cada $4 / 4 \mathrm{~h}$.

As intervenções nos casos de ansiedade e do medo. Cabe a enfermagem e a equipe multidisciplinar fornecer informações de maneira clara e direta sobre o quadro clínico da paciente e seus possíveis desfechos, permitindo que a paciente faça perguntas e retire suas dúvidas. Atentar para alterações fisiológicas associadas a ansiedade como: elevação da pressão arterial sistêmica, taquicardia ou taquipneia mãos frias e úmidas.

Para Schiavo RA et al. (2018), a ansiedade na gestação é uma das características comuns de alterações psicológicas durante a gravidez, que pode sofrer variação em sua intensidade quando se considera os diferentes aspectos socioculturais em que a gestante está inserida.

Schetter CD e Tanner L (2012) afirmam que, quando as gestantes começam apresentar taxas elevadas de ansiedade, podem ressaltar em complicações e/ou intercorrências obstétricas, como parto/nascimento pré-maturo e de baixo peso.

Para o diagnóstico de dor as intervenções consistem em: Aplicar escala numérica de dor, e anotar sua frequência, localização e intensidade a cada $6 / 6 \mathrm{~h}$ e se necessário. Proporcionar medidas de conforto como: troca de decúbito, massagem e técnicas de relaxamento a cada $6 / 6$ h ou conforme necessidade.

Quanto ao risco de infecção relacionado ao acesso venoso central, as intervenções consistem em: Avaliar o local de acesso intravenoso quanto aos sinais de flebite ou infiltração de 6/6 h. Trocar curativo do acesso diariamente ou se necessário, assim como, trocar acesso venoso periférico a cada $92 \mathrm{~h}$.

As intervenções em casos de troca de gases fetais prejudicada relacionada a RPMO são: Estimular a ingesta hídrica materna (manhã/tarde/noite). Atentar para soroterapia rigorosa conforme prescrição médica. Verificar batimentos cárdicos fetais (BCF) atentando para bradicardia ou taquicardia a cada $4 / 4 \mathrm{~h}$.

Diante das intervenções de enfermagem realizadas nos diagnósticos acima, os discentes tiveram a oportunidade de vivenciar com a paciente G.P.P.B., uma evolução significativa e satisfatória do seu quadro clínico. Essa experiência se deu a partir da aplicabilidade eficaz da Sistematização da Assistência de Enfermagem potencializando os cuidados oferecidos pelos enfermeiros, técnicos e/ou auxiliar de enfermagem que lidam diretamente com o paciente.

Sendo assim, o processo de enfermagem realizado pelos discentes contribuiu para o 
amadurecimento pessoal e profissional durante a graduação, apontando para a relevância do enfermeiro (a) na assistência a gestante de alto risco.

\section{I CONSIDERAÇÕES FINAIS}

Por meio desse estudo, observou-se que a prática humanizada contribuiu para diminuir o sofrimento vivenciado pela paciente durante sua internação hospitalar.

A experiência vivenciada dentro da Unidade hospitalar por acadêmicos de enfermagem por meio da disciplina foi extremamente enriquecedora pois possibilitou alinhar os conhecimentos teóricos vistos em sala de aula, durante os semestres anteriores.

É possível observar a importância da atuação dos profissionais de enfermagem no dia a dia dos pacientes de urgência e emergência, e internados, desde a realização da anamnese até os preparativos para a alta hospitalar, possibilitando a vivência das etapas do processo de enfermagem de forma integral.

Através dessa experiência foi possível identificar os diagnósticos de enfermagem, intervenções e resultados esperados à paciente com ruptura das membranas ovulares, relatar a experiência acadêmica e traçar um plano de cuidado para o público-alvo.

Desta forma, fica evidenciado a importância de o enfermeiro (a) assistir o paciente de forma integral através da utilização da SAE, uma vez que a sistematização da sua assistência é uma ferramenta imprescindível que facilita o seu cuidado prestado.

\section{REFERÊNCIAS}

BARROS, L. el al. International. Nursing diagnoses: definitions \& classification NANDA - 2018-2020. $11^{\mathrm{a}}$ ed. Porto Alegre: Artmed, 2018.

BRASIL. Comissão Nacional de Ética em Pesquisa. Resolução n 466, de 12 de dezembro de 2012. Aprova as diretrizes e normas regulamentadoras de pesquisas envolvendo seres humanos. Brasília, 2012.

DOCHTERMAN J. M.; BULECHEK, G. M. Classificação das intervenções de enfermagem (NIC). $4^{\text {a }}$ ed. Porto Alegre: Artmed, 2018.

MOORHEAD S.; JOHNSON M.; MAAS, M. Classificação dos resultados de enfermagem - NOC.

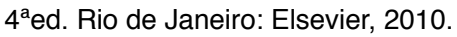

NATIONAL HIGH BLOOD PRESSURE EDUCATION PROGRAM WORKING GROUP REPORT ON HIGH BLOOD PRESSURE IN PREGNANCY. Am J Obstet Gynecol, 2000.

PATRIOTA, A. F et al. Volume de líquido amniótico e os desfechos maternos em gestantes com ruptura prematura das membranas pré-termo. Rev. Bras. Ginecol. Obstet. [online], v.36, n.4, 2014.

SCHETTER CD, TANNER L. Anxiety, depression and stress in pregnancy: Implications for mother, children, research, and practice. Current Opinion in Psychiatry, 25(2), 2012. 
SCHIAVO RA, et al. Variáveis Associadas à Ansiedade Gestacional em Primigestas e Multigestas.

Trends Psychol., Ribeirão Preto, vol. 26, nº 4, 2018.

SIBAI B. Chronic Hypertension in Prograncy. Obstet gynecol.100: 369 (8), 2002.

SILVA, S. M. M. et al. Morbidade e mortalidade perinatal em gestações que cursaram com amniorrexee prematura em maternidade pública do Norte do Brasil. Rev. Bras. Ginecol. Obstet. [online], v. 36, n. 10, 2016.

SILVEIRA, M. L. et al. Desfecho neonatal em gestações que evoluíram com amniorrexee prematura.

Rev. RENE, v. 15, n. 3, 2018. 


\section{CAPÍTULO 7}

\section{CARACTERIZAÇÃO DOS PARTOS EM UM MUNICÍPIO DO ESTADO DO CEARÁ}

Data de aceite: $20 / 08 / 2021$

Data de submissão: 27/05/2021

Ana Patricia de Alencar

Centro Universitário Leão Sampaio - Unileão Juazeiro do Norte - Ceará http://lattes.cnpq.br/1019429681210907

Katherine Jeronimo Lima Universidade Estadual do Ceará - UECE Fortaleza - CE http://lattes.cnpq.br/4977823780884971

\section{Nathália Lima Sousa}

Universidade Estadual do Ceará - UECE

Fortaleza - CE

http://lattes.cnpq.br/0772783308747982

Jéssica Marco Pereira da Cunha

Faculdade de Juazeiro do Norte - FJN Juazeiro do Norte - CE

http://lattes.cnpq.br/0434427518545152

Larissa Maria de Oliveira Costa Centro Universitário Leão Sampaio - Unileão Juazeiro do Norte - CE http://lattes.cnpq.br/4281292443094802

\section{Carlla Sueylla Filgueira Ramalho Souza}

Centro Universitário Leão Sampaio - Unileão Juazeiro do Norte - CE

http://lattes.cnpq.br/3479609139952609

\section{Ana Thayline Vidal Rosendo}

Centro Universitário Leão Sampaio - Unileão Juazeiro do Norte - CE http://lattes.cnpq.br/2955460813354618
Cícera Erenilde Inácio Furtado Fundação de Ensino Superior de Olinda FUNESO

Olinda - PE http://lattes.cnpq.br/0560075155902001

Bárbara Jennifer Bezerra de Oliveira Centro Universitário Leão Sampaio - Unileão Juazeiro do Norte - CE http://lattes.cnpq.br/4443378399517645

Isabel Cabral Gonçalves

Faculdade de Juazeiro do Norte - FJN Juazeiro do Norte - CE http://lattes.cnpq.br/8573813057148833

Dianne Suêrda Gomes Pereira Centro Universitário Leão Sampaio - Unileão Juazeiro do Norte - CE http://lattes.cnpq.br/5710586989877550

Maria Freitas Lima de Farias Pinho Centro Universitário Leão Sampaio - Unileão Juazeiro do Norte - CE http://lattes.cnpq.br/0977434990719155

RESUMO: O Brasil apresenta um percentual de $56 \%$ de partos por cirurgia cesariana, o que o coloca como segundo país no mundo com maior incidência do mesmo, fator bastante preocupante para a saúde pública brasileira. Dessa forma, o presente trabalho teve como objetivo caracterizar os tipos de parto no município de Porteiras-CE. Trata-se de uma pesquisa de corte transversal, com abordagem descritiva, realizada a partir de 265 fichas de parturientes, obtidas pelo Sistema de Informação de SINASC do município de 
Porteiras-CE, no período de 2014-2017. Os resultados apontam que $77 \%$ das parturientes se encontrava na faixa etária entre $20-34$ anos, 58,3\% possuía entre 8-11 anos de estudo, o parto cesáreo predominou entre as multíparas (75\%), $82 \%$ realizou 7 ou mais consultas pré-natais e o parto mais prevalente foi o cesáreo. Observou-se a predominância do desfecho da gestação do parto cesáreo, apesar do desenvolvimento de políticas públicas brasileiras destinadas a assegurar os direitos de mulheres e crianças, com atenção maior para assistência ao pré-natal, parto e puerpério, através de programas destinados a este público. Percebe-se a necessidade de estudos detalhados sobre o assunto, que possibilitem o planejamento de novas estratégias de enfrentamento dos altos índices de partos cesáreos.

PALAVRAS - CHAVE: Parturiente, Parto normal, Cesárea.

\section{CHARACTERIZATION OF BIRTHS IN A MUNICIPALITY OF THE STATE OF CEARÁ}

ABSTRACT: Brazil has a percentage of $56 \%$ of deliveries by cesarean surgery, which makes it the second country in the word with the highest incidence of this type of childbirth, quite worrying fator for Brazilian public health. The aim of the paper was therefone to characterize the types of childbirth in the municipality of Porteiras-CE. It is a cross-sectional research, with descriptive approach, based on 265 parturient records, obtained through the SINASC information system of the municipality of Porteiras-CE, in the 2014-2017 period. The results shows that $77 \%$ of the parturientes werw aged between 20 and 34 years, 58,3\% werw aged between 8 and 11 years of study, cesarean delivery predominated multiparous women (75\%), $82 \%$ had 7 or more antenatal consultations and the most prevalente birth was observed. Despite the development of Brazilian public policies aimed at ensuring the rights of women and children, with greater attention to prenatal care, childbirth and puerperium, through programs aimed at this audience. It is noticed the need of detailed studies on the subject, that allow the planning of nem strategies to cope with the high of cesarean childbirth.

KEYWORDS: Parturient, Normal birth, Cerarean.

\section{I INTRODUÇÃO}

Em todo o mundo, a cirurgia cesariana vem se tornando cada vez mais comum, tanto em países desenvolvidos quanto nos países em desenvolvimento1. Tornar-se mãe para muitas mulheres é tido como experiência única repleta de significados e sentimentos, contudo, nascer no Brasil na maioria dos casos não tem sido uma experiência natural.

Nas últimas décadas, o Brasil passou por uma mudança relacionada ao padrão de nascimento, no qual as operações cesarianas tornaram-se a via de parto mais comum, sendo a taxa de cesarianas no Brasil de $55 \%^{12}$, o que o coloca como segundo país no mundo com maior incidência nessa via de parto², variando entre os serviços públicos e privados, chegando a $85 \%$ nos serviços privados de saúde, e de $40 \%$ no sistema público, que é consideravelmente menor, mas ainda sim elevada, considerando a recomendação da Organização Mundial de Saúde, de 15\%.

No Ceará, em conformidade com a realidade do país, também incide alta taxa de 
cesarianas (48,5\%) e declínio na proporção de partos por via vaginal (24.3\%), efetuados pelo Sistema Único de Saúde, no período de 2011 a $2016^{3}$.

De acordo com dados obtidos através do Departamento de Informática do SUS, do ano de 2011 a 2016, o Município de Porteiras se manteve acima da média ideal para partos por cirurgia cesariana. Neste período, observou-se o crescente número de partos cesáreos, com destaque para o ano de 2016, que atingiu o percentual de 62,2\% (149/238). Fato este que demonstra que o Município não está distante e nem ocluso da realidade do País e do mundo nos últimos anos ${ }^{4}$.

A alta prevalência de partos cesarianos no Brasil não parece estar vinculada a mudanças no risco obstétrico e sim a outros fatores de ordem socioeconômica e cultural, destacando-se o controverso fenômeno da "cultura da cesariana"s.

Deve-se ressaltar que, uma cesariana quando realizada sob indicação médica específica, é uma cirurgia essencial para a saúde materna e infantil. Porém, ela pode levar ao aumento do risco de complicações graves quando realizada sem a correta indicação'.

O momento do parir, antigamente visto como um momento natural, uma experiência vivida por mulheres e entre mulheres, entre as quais havia rica troca de experiências, apoio e aconselhamentos, migrou com o passar do tempo para o ambiente hospitalar como uma tentativa de assegurar parto e nascimento saudável, migração na qual acabou implicando mudanças e redefinição de papéis, inclusive da gestante e sua família ${ }^{6}$.

A assistência obstétrica e neonatal atualmente legitimada na maioria dos países, inclusive no Brasil caracteriza-se por encarar a saúde como um problema, ou seja, cheia de riscos e está quase sempre em constante perigo. Assim nesse ponto de vista, o nascimento é visto como um problema médico, considerando que todas as gestações são potencialmente patológicas, até que se prove o contrário 3 .

A gravidez não deve ser tratada como doença e sim como expressão de saúde, e o nascimento como processo fisiológico e natural. Portanto, as intervenções desnecessárias, sem embasamento científico, devem ser evitadas, já que existe um grande corpo de evidências demonstrando que a facilitação do processo natural do nascimento, permitindo que ocorra de acordo com suas características normais, pode originar melhores resultados maternos e perinatais. Apenas em raras ocasiões, podem surgir complicações que justifiquem a adoção de intervenções. Havendo desvios da normalidade, constatado por meio dos controles maternos e fetais periódicos, com avaliação contínua de risco, é que se justifica qualquer tipo de intervenção nesse processo ${ }^{3}$.

A determinação da via de parto e seu momento ideal, principalmente nas gestações de alto risco, representa um dilema, porém gravidez de risco não é sinônimo de cesariana. Torna-se fundamental o esclarecimento para gestante e sua família, informações completas e compreensíveis, devendo ser garantida sua participação no processo decisório. Em muitas situações, é possível a indução do parto visando seu término por via vaginal, ou mesmo aguardar seu início espontâneo ${ }^{7}$. 
Através da vivência da autora enquanto residente de Saúde da Família e Comunidade no município de Porteiras-CE, observou-se que, partos cesarianos eram bastante incidentes no município e que, muitos relatos trazidos pelas gestantes em várias ocasiões, faziam referências negativas relacionadas ao parto normal, fato este que chamou atenção e instigou a pesquisar sobre a temática no município em questão.

Desta forma, a presente pesquisa teve como objetivo: Caracterizar os tipos de parto no município de Porteiras-Ceará.

\section{I METODOLOGIA}

Trata-se de uma pesquisa de corte transversal, com abordagem descritiva. O local da sua realização foi o município de Porteiras-CE, localizado no Nordeste brasileiro, na Região Sul Cearense, pertencente a XIX Região de Saúde, na Macrorregião do Cariri e Microrregional de saúde de Brejo Santo, realizada no ano de 2019.

A população deste estudo foi composta por parturientes residentes no município de Porteiras-Ceará. No cálculo da amostra considerou-se o número de partos informados no Sistema de Nascidos Vivos (SINASC) do DATASUS ${ }^{4}$, somando-se em 1.281, no período de 2014 a 2017. Utilizou-se a proporção de 63\% (638) de partos cesáreos, estabelecendo erro amostral de 5\% e nível de confiança de 95\%. Para cálculo da proporção de operações cesarianas, relacionou-se o número total de nascidos vivos de partos cesáreos com o total de nascimentos de partos hospitalares, no período considerado, multiplicado por 1008 . Ao final, a amostra foi constituída de 265 fichas de parturientes com residência no município de Porteiras, que realizaram partos no período de 01 de fevereiro de 2014 até 31 de dezembro de 2017.

Utilizou-se como fonte de dados a Declaração de Nascidos Vivos (DN), oriundas do Sistema de Informação de Nascidos Vivos (SINASC) pertencente do setor de Vigilância Epidemiológica da Secretaria Municipal de Saúde de Porteiras-CE. Para coleta de dados foi utilizado um Formulário, contendo dados sociodemográficos: idade, escolaridade, situação conjugal, e dados obstétricos: número de gestações, número de aborto, número de filhos vivos, idade gestacional de inicio de pré-natal, idade gestacional no momento do parto e desfecho da gestação.

Os dados coletados foram inseridos no programa Microsoft Office Excel (versão 13) e analisados estatisticamente por meio do programa Statistical Package for the Social Scienses (SPSS), versão 18.0. Foi realizada análise estatística descritiva dos dados, bem como a construção de gráficos e tabelas de frequência, com apresentação dos valores absolutos e percentuais.

A pesquisa foi desenvolvida obedecendo às recomendações da Resolução $n^{\circ} 466$ de 12 de dezembro de 2012, do Conselho Nacional de Saúde/Ministério da Saúde, com aprovação do Comitê de Ética em Pesquisa (CEP) da Escola de Saúde Pública do Ceará - 


\section{I RESULTADOS}

No período de 2014 a 2017, pode-se observar que, na variável idade, a maior porcentagem de parturientes se encontra na faixa etária de 20-34 anos (77\%). Sendo possível verificar nessa faixa etária a maior prevalência $(50 \%)$ de partos por cirurgia cesariana.

Segundo a escolaridade, o Município se destaca por possuir a grande maioria das mulheres com 8-11 anos de estudo (58,3\%). De acordo com estado civil a maioria das parturientes se declarou casada $(63,3 \%)$ (Tabela 1$)$.

\begin{tabular}{lcccccc}
\hline & Cesariana* & \multicolumn{3}{c}{ Vaginal $^{*}$} & \multicolumn{3}{c}{ Total } \\
Variável & $\mathbf{N}$ & $\%$ & $\mathbf{N}$ & $\%$ & $\mathbf{N}$ & $\%$ \\
\hline Idade (anos) & 18 & 6,8 & 21 & 8 & 39 & 14,8 \\
$14-19$ & 132 & 50 & 71 & 27 & 203 & 77 \\
$20-34$ & 19 & 7,1 & 3 & 1,1 & 22 & 8,2 \\
$>35$ anos & & & & & & \\
Escolaridade (anos) & 3 & 1,1 & 3 & 1.1 & 6 & 2,2 \\
Nenhuma & 8 & 3,1 & 9 & 3,5 & 17 & 6,6 \\
1 a 3 anos & 34 & 13,2 & 25 & 10 & 59 & 23,2 \\
4 a 7 anos & 98 & 38,1 & 52 & 20,2 & 150 & 58.3 \\
8 a 11 anos & 22 & 8,6 & 3 & 1,1 & 25 & 9.7 \\
12 anos ou mais & 114 & 44,6 & 48 & 18,7 & 162 & 63,3 \\
Situação conjugal & 38 & 14,8 & 30 & 11,7 & 68 & 26.5 \\
Casada & 13 & 5,1 & 13 & 5,1 & 26 & 5,2 \\
Solteira & & & & & & \\
União Consensual & & & & & & \\
\hline
\end{tabular}

Tabela 1: Perfil sociodemográficos de puérperas do Município de Porteiras-CE nos anos de 2014-2017.

*Nota: em algumas variáveis a amostra apresentada não correspondeu ao tamanho da amostra estabelecida para a pesquisa.

${ }^{*}$ Fonte: Elaborado pelos autores.

Vale destacar, que se pretendia avaliar as seguintes variáveis: Cor, cirurgia cesárea anterior, parto natural anterior e trabalho de parto induzido, no entanto, as mesmas foram descartadas do estudo, devido à ausência destes dados em mais de $50 \%$ nas fichas do SINASC.

Com base no perfil obstétrico-assistencial das mulheres, é possível observar que, 
o parto cesáreo predominou, independente com o número de gestações, sendo mais incidente nas puérperas multíparas de 2-3 gestações somados a 4 ou mais gestações $(35,4 \%)$, entre as puérperas $78 \%$ nunca tiveram aborto e a grande maioria (82\%) realizou 7 ou mais consultas pré-natais (Tabela 2).

\begin{tabular}{|c|c|c|c|c|c|c|}
\hline \multirow[b]{2}{*}{ Variável } & \multicolumn{2}{|c|}{ Cesariana* } & \multirow{2}{*}{$\begin{array}{c}\text { Vaginal* } \\
\mathrm{N}\end{array}$} & \multicolumn{3}{|c|}{ Total } \\
\hline & $\mathrm{N}$ & $\%$ & & $\%$ & $\mathrm{~N}$ & $\%$ \\
\hline \multicolumn{7}{|l|}{$\mathrm{N}^{\circ}$ de gestações } \\
\hline 1 gestação & 73 & 28 & 37 & 14,2 & 110 & 42,2 \\
\hline 2-3 gestações & & 28,8 & 44 & 17 & 119 & 45.8 \\
\hline 4 ou mais gestações & 17 & 6,6 & 14 & 5,4 & 31 & 12 \\
\hline \multicolumn{7}{|l|}{$\mathrm{N}^{\circ}$ de Abortos } \\
\hline Nenhum & 132 & 50 & 74 & 28 & 206 & 78 \\
\hline 1 aborto & 31 & 11,7 & 17 & 6,4 & 49 & 18.1 \\
\hline 2 abortos ou mais & 6 & 2,3 & 4 & 1,6 & 10 & 3,9 \\
\hline \multicolumn{7}{|l|}{$\mathrm{N}^{\circ}$ de filhos vivos } \\
\hline Nenhum & 72 & 27,4 & 33 & 12,5 & 105 & 39.8 \\
\hline 1 a 2 filhos & 85 & 32,3 & 52 & 20 & 137 & 52.3 \\
\hline 3 ou mais filhos & 12 & 4,5 & 9 & 3,4 & 21 & 7.9 \\
\hline \multicolumn{7}{|c|}{$\begin{array}{l}N^{\circ} \text { de consultas de pré- } \\
\text { natal }\end{array}$} \\
\hline Nenhuma & 3 & 1,1 & 4 & 1,6 & 7 & 2,7 \\
\hline 1 a 3 & 2 & 0,7 & 1 & 0,4 & 3 & 1,1 \\
\hline 4 a 6 & 16 & 6,2 & 21 & 8 & 37 & 14,2 \\
\hline 7 ou mais & 147 & 56 & 68 & 26 & 216 & 82 \\
\hline \multicolumn{7}{|l|}{$\begin{array}{l}\text { Idade Gestacional } \\
\text { momento do parto }\end{array}$} \\
\hline 37 a 41 semanas & 149 & 56,5 & 76 & 29 & 226 & 85,5 \\
\hline 42 semanas ou mais & 7 & 2,7 & 3 & 1,1 & 10 & 3,8 \\
\hline
\end{tabular}

Tabela 2: Perfil obstétrico-assistencial de puérperas do Município de Porteiras-CE do ano de 20142017.

*Nota: em algumas variáveis a amostra apresentada não correspondeu ao tamanho da amostra estabelecida para a pesquisa.

${ }^{*}$ Fonte: Elaborado pelos autores.

Com relação à prevalência dos tipos de parto, o gráfico 1, chama atenção pois a taxa de cesarianas aumentou gradativamente ano após ano, com exceção apenas para 2016, sendo maior no ano 2017, tendo uma média de 42,25 partos por cesariana e de 23,75 por parto normal. Além do mais, em todos os anos demonstrados, as taxas de parto por cirurgia cesariana se manteve em níveis elevados, acima do preconizado pelo Ministério da Saúde. 


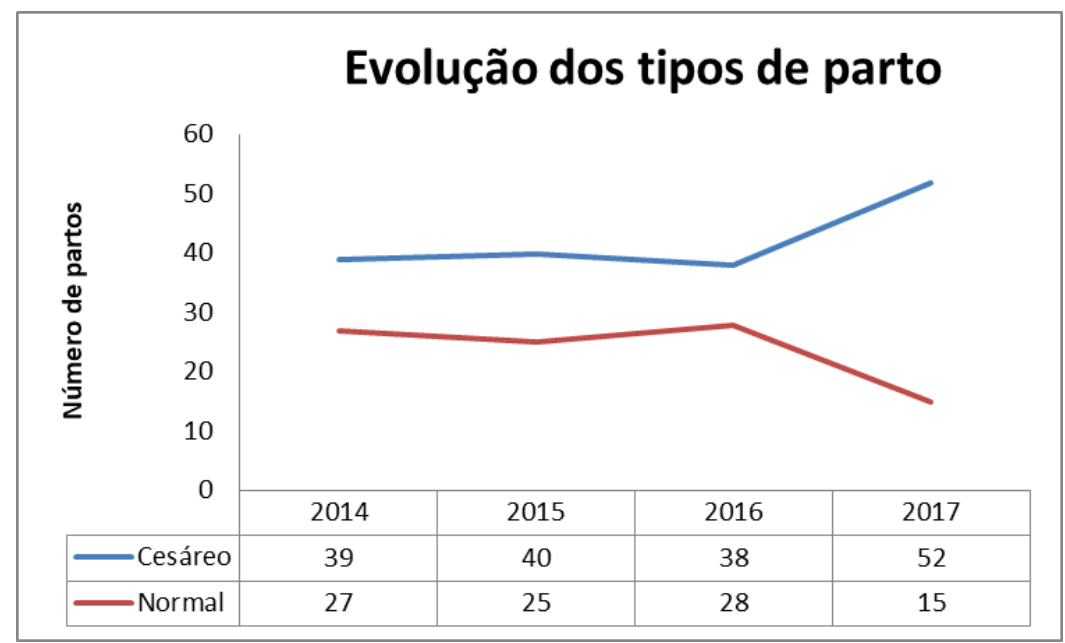

Gráfico 1: Distribuição dos partos Cesáreos e Normais de puérperas do Município de Porteiras-CE nos anos de 2014-2017.

${ }^{*}$ Fonte: Elaborado pelos autores.

\section{I DISCUSSÃO}

O estudo apontou prevalência de parturientes na faixa etária de 20-34 anos. O que vem a concordar com outros estudos ${ }^{9}{ }^{10}$. Salienta-se que em cinco macrorregiões brasileiras há um predomínio de parturientes entre 18 e 35 anos, apresentando percentuais semelhantes, com exceção da região Norte e Nordeste, onde o percentual de parturientes com menos de 18 anos foi maior em relação às demais regiões do país ${ }^{11}$.

Pode observar também que ao relacionar a idade das parturientes ao tipo de parto efetuado, a maioria, na faixa etária de 20 a 35 anos, tiveram seus filhos por meio de parto cesáreo, corroborando a outras pesquisas ${ }^{9}{ }^{10}$. Porém, em parturientes com menos de 20 anos houve predominância da via de parto normal (69\%), o que concorda com outro estudo no qual nas regiões Norte e Nordeste, parturientes com 18 anos ou menos, tiveram percentuais de partos normais $(63,37 \%)$ que superam os partos cesáreos $(36,63 \%)^{11}$.

Segundo a escolaridade, o município se destacou por possuir a grande maioria das mulheres com 8-11 anos de estudo (58,3\%) com prevalência do parto cesáreo ${ }^{10}$. Situação que se sobressai, uma vez que nos municípios com até 20 mil habitantes, a proporção de mães com pelo menos ensino fundamental completo é de $49 \%$, enquanto que essa proporção se eleva a $73 \%$ em municípios com 500 mil habitantes ou mais. É possível perceber que o aumento da escolaridade materna tem acompanhado o aumento da escolaridade da população no geral. O que está inversamente relacionado ao indicador de parto normal em municípios pequenos ${ }^{9}$.

Entretanto, observa-se que na realidade nacional, estudos concordam que quanto 
menor o porte do município, menor a proporção de mães com oito anos ou mais de estudo, principalmente em regiões como o Nordeste ${ }^{11}{ }^{12}$. Situação divergente do município em estudo, pois o mesmo se apresenta como de pequeno porte, tendo menos de 15 mil habitantes, localizado no Nordeste Brasileiro e interior do Ceará. Contudo, o nível de escolaridade de 8 a 11 anos de estudo foi maioria, acima do esperado e houve equilíbrio entre os níveis de escolaridade e a escolha pelo parto cesáreo, não demonstrando estar diretamente ligado ao nível de instrução, o que vêm a concordar com outro estudo ${ }^{11}$.

Há de destacar que os marcadores sociais estão associados ao número de consultas de acompanhamento pré-natal, que é diretamente proporcional à escolaridade materna. Enquanto apenas $36,9 \%$ das mães com escolaridade de zero a três anos realizaram sete ou mais consultas, $80 \%$ daquelas que possuem escolaridade de 12 anos ou mais realizaram sete ou mais consultas, dados apontados no ano de $2009^{12}$.

Em relação à paridade, a maioria das parturientes eram nulíparas $(36,9 \%)$ e o seguimento que possuía histórico de apenas um parto anterior correspondeu a $28,4 \%$. A multiparidade esteve presente entre $34,7 \%$ das mulheres ${ }^{13}$.

Segundo o perfil obstétrico-assistencial das mulheres o parto cesáreo predominou independente do número de gestações, sendo mais incidente $(36.5 \%)$ em puérperas que já estavam da segunda gestação em diante, mesmo a grande maioria tendo realizado 7 ou mais consultas pré-natais (82\%).

No que se refere ao número de consultas de pré-natal, observa-se que os maiores percentuais estiveram dentro do número de 6 a 9 consultas. Em idade gestacional, constatou que de 37 a 40 semanas de gestação foi o intervalo mais prevalente, demonstrando semelhanças a outras pesquisas ${ }^{9}$.

Pode-se observar que, as taxas de cesáreas se mantém ultrapassando o preconizado pelo Ministério de Saúde ao longo dos anos estudados, com destaque para o ano de 2017, ano de maior ocorrência. Estando a mulher imersa num contexto cultural que adota o parto cesáreo como uma regra, onde a mulher tem que afirmar pra si mesma e para toda sociedade o motivo da sua escolha pela via natural de parto. Observa-se que houve uma inversão de valores e de significados em relação à forma de nascer no Brasil ${ }^{17}$, o qual passou por uma mudança relacionada ao padrão de nascimento, onde as operações cesarianas tornaram-se a via de parto mais comum ${ }^{1}$. Muitas mulheres escolhem o parto cesáreo antes mesmo de engravidar ou entrar em trabalho de parto, como uma forma não dolorosa de ter filhos ${ }^{17}$.

Ainda sobre questões relacionadas ao desfecho da gestação, no Brasil, revelam as elevadas taxas de cesariana como um grave "problema de saúde pública" e um quadro que deve ser revertido. Prevalecendo a ideia de que a responsabilidade pelo crescimento da cirurgia é dos profissionais e que a maioria das mulheres brasileiras prefere o parto vaginal. Acredita-se que ainda é necessário buscar novas compreensões do fenômeno, pois ainda prevalece um debate atrelado à questão de "quem decide" a via de parto ou se as mulheres 
"preferem" a via vaginal ou cesariana ${ }^{14}$.

Comparando os estudos supracitados é possível observar que, a incidência de cesarianas no país tem crescido, ou pelo menos não regredido ao longo do tempo, apesar do desenvolvimento de políticas públicas destinadas a assegurar os direitos de mulheres e crianças, com atenção maior para assistência ao pré-natal, parto e puerpério, através de programas destinados a este público.

Deve-se levar em consideração o alto custo do parto cesáreo no Brasil, tendo em vista que o custo total da assistência aos partos e nascimentos para as primíparas e multíparas sem cicatriz uterina foi de US $\$ 707,5$ milhões para o ano de 2016 . Considerando apenas o parto vaginal para essas gestantes, houve uma redução de custos de US\$76,5 milhões ao ano. Para multíparas, a comparação gerou economia de mais de US\$ 4 milhões ao ano. A taxa de cesarianas em excesso projetada de 2016 a 2020 geraria um impacto de mais de US\$ 80 milhões ao ano para o SUS ${ }^{16}$.

A cesariana possui um custo $38 \%$ superior ao do parto vaginal, e o principal direcionador de custo nos dois procedimentos foram os recursos humanos (89\% do custo no parto vaginal e $81 \%$ na cesariana). Para o custo total (procedimento e permanência em alojamento conjunto), esse custo permanece maior para a cesariana, uma vez que o procedimento demanda uma maior permanência hospitalar ${ }^{17}$.

Os altos e crescentes índices de partos por cirurgia cesariana se alicerçam no processo de normalização da cesárea como forma de nascer, se relacionando ao desenvolvimento de um estilo de pensamento da comunidade de práticas dos obstetras, que opera num conceito de cesariana de um procedimento cirúrgico para uma forma de parto normal ${ }^{19}$.

Entre as limitações do estudo, pode-se apontar a incompletude de determinados campos de preenchimento das fichas do SINASC pesquisadas. Desta forma, verificouse que as categorias cor, cirurgia cesárea anterior, parto natural anterior, trabalho de parto induzido tiveram que ser excluídas devido à ausência de dados, não sendo possível analisar e apresentar tais variáveis na pesquisa.

Alguns campos são relevantes para a análise da situação de saúde materna e infantil, embora, nota-se frequência de preenchimento insatisfatório nas fichas impressas do SINASC ${ }^{6}$. É importante lembrar que o próprio Manual de Instrução para o preenchimento da Declaração de Nascido Vivo, distribuído pelo Ministério da Saúde, dedica especial atenção ao tema, ressaltando que variável cor não admite alternativa ignorada ${ }^{15}$. Pensase que tal fato ocorra em virtude da falta de entendimento dos profissionais sobre a suma importância do preenchimento total de todos os campos da ficha de nascido vivo. Assim, permiti repensar em mecanismos mais efetivos para a melhoria da completitude das informações.

Ademais, a pesquisa expôs outras considerações, pois ao analisar os números de parto por cesariana, induz a uma reflexão sobre a qualidade da assistência à gestação e 
ao parto, onde apesar do número de consultas de pré-natal se apresentar de acordo e/ ou acima do preconizado pelo Ministério da Saúde, observou-se a predominância como desfecho da gestação o parto cesáreo, levando a indagações sobre a qualidade desse acompanhamento no que se referente à atenção à saúde realizada a nível primário, bem como a informação, humanização e direito de escolha da gestante no nível secundário de assistência à saúde, deixando assim sugestões de temas paras outras pesquisas na área.

\section{I CONCLUSÕES}

A prevalência de partos por intervenção cesariana no município se manteve acima do preconizado pelo Ministério da Saúde ao longo dos anos estudados, bem como o crescimento de sua incidência ao longo dos anos, revelando situação condizente com a realidade do país.

O estudo apontou que a maioria das parturientes se concentrava na faixa etária entre 20-34 anos, tinham entre 8-11 anos de estudo. Observou-se que o parto cesáreo prevaleceu independentemente do número de gestações, a maior parte não tinha histórico de aborto, bem como possuía mais de um filho vivo. Além disso, realizaram sete ou mais consultas pré-natais e os partos no período a termo.

Através das respostas obtidas com a pesquisa se possibilita a identificação e o entendimento de fragilidades em torno de questões como a prevalência de partos cesarianos e normais no município estudado, bem como a definição do perfil sociodemográfico e obstétrico das parturientes, tornando possível, a partir de então, o planejamento e elaboração de estratégias para melhorias de indicadores, com base nos resultados obtidos.

\section{REFERÊNCIAS}

1. Brasil. Diretrizes de atenção à gestante: A operação cesariana. Relatório de recomendação. Ministério da Saúde / CONITEC, Brasília-DF, 2015.

2. Batista Filho, M; Rissin, A. A OMS e a epidemia de cesarianas. Revista Brasileira de Saúde Materno Infantil. Recife, ed. 18, vol. 1, pag. 5-6, 2018.

3. Lima, KJ., et al. Parto normal e cesáreo efetuados no Sistema Único de Saúde: Uma pesquisa sobre sua evolução temporal no Ceará. Universidade Fortaleza, 2017.

4. Departamento de Informática do SUS (DATASUS). Produção Hospitalar (SIH/SUS). Brasília, 2011 a 2016. Extraído de [http://tabnet.datasus.gov.br/cgi/deftohtm.exe?sinasc/cnv/nvCE.def] acesso em [02 de julho de 2018].

5. Brasil. Nascer no Brasil: Pesquisa revela o número excessivo de cesarianas. Fiocuz, Rio de Janeiro, 2014. Extraído de [https://portal.fiocruz.br/noticia/nascer-no-brasil-pesquisa-revela-numeroexcessivo-de-cesarianas] acesso em [07 de novembro de 2017]. 
6. Gramacho, R. C. C. V; Silva, R. C. V. Enfermagem na Cena. In: BRASIL. Humanização do parto e do nascimento / Ministério da Saúde. Universidade Estadual do Ceará. Brasília: Ministério da Saúde, 2014. p.185-200.

7. Brasil. Conselho Nacional de Saúde. Resolução $N^{\circ}$ 466. 12 de Dezembro de 2012. Aprova diretrizes e normas regulamentadoras de pesquisa envolvendo seres humanos. Extraído de [http://conselho.saude.gov.br/resolucoes/2012/Reso466.pdf] acesso em [04 de Outubro de 2018].

8. Brasil. Rede Interagencial de Informação para a Saúde. Indicadores básicos para a saúde no Brasil: conceitos e aplicações. 2. ed. Brasília: Organização Pan-Americana da Saúde, 2008.

9. Aguiar JC, Versiani CC, Dias CLO, Moreira DC, Andrade DCS, Xavier DC. Revista de EnfermagemUFPE online. Indicadores de assistência às vias de parto. Recife, 2018. Extraído de [https:// periodicos.ufpe.br/revistas/revistaenfermagem/article/view/230890] acesso em [26 de abril de 2019].

10. Guimarães RM, et al. Fatores associados ao tipo de parto em hospitais públicos e privados no Brasil. Rev. Bras. Saúde Matern. Infant., Recife, 17 (3): 581-590 jul. / set., 2017. Extraído de [http:// dx.doi.org/10.1590/1806-93042017000300009] acesso em [27 de novembro de 2019].

11. SHILLER EF. A relação entre perfis de parturientes e vias de parto no Brasil. Universidade de Brasília, Brasília-DF, 2015. Extraído de [http://bdm.unb.br/handle/10483/12862] acesso em [26 de abril de 2019].

12. Calvo MCM, Lacerda JT, Colussi CF, Schneider IJC, Rocha TAH. Epidemiologia Serviço e Saúde. Estratificação de municípios para avaliação de desempenho em saúde, 2016. Extraído de [https:// www.scielosp.org/article/ssm/content/raw/?resource_ssm_path=/media/assets/ress/v25n4/2237-9622ress-25-04-00767.pdf] acesso em: [08 de maio de 2019].

13. Medeiros RMK, Teixeira RC, Nicolini AB, Alvares AS, Correa ACP, Martins DP. Humanized Care: insertion of obstetric nurses in a teaching hospital. Rev Bras Enferm [Internet]. 2016; 69(6): 102936. Extraido de [http://dx.doi.org/10.1590/0034-7167-2016-0295] acesso em [08 de maio de 2019].

14. Riscado LC, Janotti CB, Barbosa RHS. Texto \& Contexto - Enfermagem. A decisão pela via de parto no Brasil: Temas e tendências na produção de saúde coletiva. 2016. Extraído de [http://www. scielo.br/scielo.php?pid=S0104-07072016000100501\&script=sci_abstract] acesso em [26 de abril de 2019].

15. Brasil. Ministério da Saúde. Secretaria de Vigilância em Saúde. Departamento de Análise de Situação de Saúde. Manual de Instruções para o preenchimento da Declaração de Nascido Vivo / Ministério da Saúde, Secretaria de Vigilância em Saúde, Departamento de Análise de Situação de Saúde. - Brasília: Ministério da Saúde, 2011.

16. Entringer AP, Gomes MASM, Costa ACC, Pinto M. Impacto orçamentário do parto vaginal espontâneo e da cesariana eletiva sem indicação clínica no Brasil. Rev Panam Salud Publica. 2018;42:e116. Extraído de [https:// doi.org/10.26633/RPSP.2018.116] acesso em [21 de novembro de 2019].

17. Oliveira VJ, Penna CMM. Every birth is a story: process of choosing the route of delivery. Rev Bras Enferm [Internet]. 20; 71(Suppl 3):1228-36. [Thematic Issue: Health of woman and child]. Extraído de [http://dx.doi.org/10.1590/0034-7167-2016-049] acesso em [27 de novembro de 2018]. 
18. Guedes CDFS. Percepções de gestantes sobre a promoção do parto normal no pré-natal. Revista Ciência Plural, 2017. Extraído de [https://periodicos.ufrn.br/rcp/article/view/12869] acesso em [27 de novembro de 2019].

19. Nakano AR. Bonen C, Teixeira I LA. O trabalho de parto do obstetra: estilo de pensamento e normalização do "parto cesáreo" entre obstetras. Revista de Saúde Coletiva. Rio de Janeiro, 2017. Extraído de [http://dx.doi.org/10.1590/S0103-73312017000300003] acesso em [21 de novembro de 2019]. 
Data de aceite: $20 / 08 / 2021$

Data de submissão: 05/07/2021

Ana Gabriella Silva dos Santos Escola Superior de Ciências da Saúde - ESCS Brasília - DF http://lattes.cnpq.br/5952450299191580

Yasmin Ariadiny Lopes Lacerda Escola Superior de Ciências da Saúde - ESCS Brasília - DF http://lattes.cnpq.br/7010204203690471

Ana Sarah Soares da Cunha Alencar Escola Superior de Ciências da Saúde - ESCS Brasília - DF http://lattes.cnpq.br/7248077114292963

Ana Aparecida Santos de Santana Escola Superior de Ciências da Saúde - ESCS Brasília - DF http://lattes.cnpq.br/4849829025145720

Luana dos Santos Oliveira Escola Superior de Ciências da Saúde - ESCS Brasília - DF http://lattes.cnpq.br/5704329675164348

\section{Mateus Gomes Ribeiro}

Escola Superior de Ciências da Saúde - ESCS Brasília - DF http://lattes.cnpq.br/8237756257611794

Nadia Pereira Natal Escola Superior de Ciências da Saúde - ESCS Brasília - DF http://lattes.cnpq.br/1320083927424652
RESUMO: Projeto de intervenção na realidade realizado no Hospital Materno Infantil de Brasília (HMIB) embasado nos cinco passos do Arco de Maguerez. Abordou-se a prática da deambulação no puerpério mediato como forma de prevenção de complicações, enfatizando seus benefícios, indicações e contraindicações, bem como a importância da comunicação efetiva como ferramenta na atuação do profissional de enfermagem. Utilizou-se metodologia da educação em saúde por meio de ferramentas visuais e verbais, onde foram fixadas placas sobre o tema abordado nas enfermarias e no posto de enfermagem, além de orientações verbais às puérperas sobre a importância e os benefícios da deambulação. Observou-se que a educação em saúde é de suma importância como estratégia de empoderamento e autocuidado no ambiente hospitalar, assim como a comunicação efetiva, que deve ser colocada em prática pelos profissionais de saúde visando a eficácia das orientações.

PALAVRAS - CHAVE: Deambulação; Puerpério mediato; Comunicação efetiva.

\section{IMPORTANCE OF DEAMBULATION IN THE MEDIATE PUERPERIUM}

ABSTRACT: Intervention project in reality carried out at the Maternal and Child Hospital of Brasília (HMIB) based on the five steps of the Arc of Maguerez. It addressed the practice of walking in the immediate puerperium as a way to prevent complications, emphasizing its benefits, indications and contraindications, as well as the importance of effective communication as a tool in the performance of nursing professionals. We 
used the methodology of health education through visual and verbal tools, where posters about the topic were fixed in the wards and in the nursing station, as well as verbal guidance to puerperae about the importance and benefits of walking. It was observed that health education is of paramount importance as a strategy for empowerment and self-care in the hospital environment, as well as effective communication, which should be put into practice by health professionals aiming at the effectiveness of the guidelines.

KEYWORDS: Deambulation; Mediate puerperium; Effective communication.

\section{1| INTRODUÇÃO}

Devido às alterações anatomofisiológicas puerperais, especialmente as cardiocirculatórias, a mulher fica sensível a complicações como trombose e embolia pulmonar no período puerperal. A deambulação neste período pode prevenir tais complicações e deve ser encorajada e norteada pelos profissionais no intuito de diminuir os riscos às puérperas. $O$ objetivo desta intervenção foi orientar e estimular as mulheres a deambularem no puerpério mediato, abordando os benefícios, as complicações relacionadas à não deambulação e a comunicação efetiva nas orientações a serem prestadas pelos profissionais de saúde.

\section{I MÉTODOS}

Foram fixadas placas no mural do alojamento conjunto com dizeres que estimulam a deambulação, bem como um cartaz informativo no posto de enfermagem abordando a comunicação efetiva voltada aos profissionais. Durante a aplicação da intervenção, realizou-se orientações verbais às puérperas em todas as enfermarias do alojamento conjunto expondo os benefícios da deambulação e as complicações relacionadas a não deambulação.

\section{3। DISCUSSÃO}

Durante as vivências no alojamento conjunto do HMIB, observou-se pouca deambulação no puerpério mediato devido à falta de orientações ou recebimento de orientações superficiais. Frente a tal realidade julgou-se necessário intervir nessa temática, já que a deambulação permite melhor recuperação das alterações fisiológicas no puerpério. A deambulação pode ser iniciada logo após o parto, respeitando apenas um período de repouso de seis horas para o parto normal e doze horas para o parto cesárea, devendo ser intercalada com períodos de repouso. Caminhar favorece a circulação sanguínea prevenindo fenômenos tromboembólicos, melhorando o retorno venoso e diminuindo o edema puerperal, além de apressar a involução uterina, promover a drenagem da loquiação, melhorar o funcionamento da bexiga urinária e do intestino auxiliando na eliminação de flatos. Ao orientar acerca da deambulação, é importante que os profissionais utilizem a comunicação efetiva, um instrumento básico na atuação do enfermeiro, para 
que os profissionais se adequem levando em consideração a cultura, escolaridade e nível socioeconômico da puérpera, para que os pacientes, acompanhantes e servidores estejam aptos e informados.

\section{I CONSIDERAÇÕES FINAIS}

A realização deste projeto evidenciou a fragilidade das puérperas em relação ao acesso à informação e demonstrou a importância da educação em saúde no ambiente hospitalar como estratégia de empoderamento e autocuidado, bem como a relevância da comunicação efetiva como ferramenta para garantir adequada compreensão entre pacientes e profissionais.

\section{REFERÊNCIAS}

ANDRADE, Beatriz Amélia Monteiro de. Tromboembolismo venoso no ciclo gravídico puerperal. Revista FEMINA, v.37 n.11. 2009.

BARROS, Sonia Maria Oliveira de. Enfermagem no ciclo gravídico puerperal; Manole: Barueri-SP, 2006

PEREIRA, Maria Amália Miranda, et al. Trombose venosa profunda proximal no puerpério. Revista Médica de Minas Gerais; v.21 n.4. 2011.

PONTES, Alexandra Carvalho. Et al. Comunicação terapêutica em Enfermagem: instrumento essencial do cuidado. Revista Brasileira de Enfermagem; v.61. n.1. 2007. 


\section{CAPÍTULO 9 \\ O TÍPICO VIVIDO DA ADOLESCENTE PUÉRPERA NA PERSPECTIVA DA FENOMENOLOGIA SOCIOLÓGICA}

Data de aceite: $20 / 08 / 2021$

Data de submissão: 06/07/2021

Marta Pereira Coelho

Universidade Federal do Espírito Santo (UFES), Centro Universitário Norte do Espírito Santo (CEUNES), Departamento de Ciências da Saúde (DCS). São Mateus - Espírito Santo

https://orcid.org/0000-0002-2046-6954

Adriana Nunes Moraes-Partelli

Universidade Federal do Espírito Santo (UFES), Centro Universitário Norte do Espírito Santo (CEUNES), Departamento de Ciências da Saúde (DCS). São Mateus - Espírito Santo

https://orcid.org/0000-0002-2046-6954

Luciana de Cássia Nunes Nascimento

Universidade Federal do Espírito Santo (UFES), Centro de Ciências da Saúde (CCS),

Departamento de Enfermagem (DE)

Vitoria - Espírito Santo

https://orcid.org/.0000-0003-4947-17480

\section{Esther da Fonseca Erothides}

Enfermeira graduada pela Universidade Federal do Espírito Santo (UFES) - Cento

Universitário Norte do Espírito Santo (CEUNES) - São Mateus - Espírito Santo - ES ORCID: https://orcid.org/0000-0002-8495-2476

RESUMO: Objetivo: compreender a perspectiva da adolescente puérpera acerca da maternidade precoce, pelas suas vivências e o significado atribuido acerca da maternidade. Método: pesquisa qualitativa descritiva, baseada na fenomenologia compreensiva sociológica de Alfred Schutz. Coleta de dados, deu-se em um hospital publico, com adolescentes puérperas internadas. Aprovação do Comitê de Ética em Pesquisa, CAEE: 80135817.0.0000.5063.

Resultados: emergiram quatro categorias em relação às adolescentes puérperas e a maternidade precoce: Ser adolescente; Conceito de Maternidade; Sentimentos Maternos; Perspectiva e ansiedades com relação ao futuro do filho. Considerações Finais: Compreendeuse que as participantes vislumbram a experiência sentimental obtida com a maternidade como o significado da mesma e portanto, muito gratificante, tornando-se cada vez mais único e especial. A maternidade precoce é um profundo desafio para a adolescente e que já está habituada a esse processo. Percebeu-se que as entrevistadas concordaram que essa nova fase é de mudanças e responsabilidades, mas também de experiências boas marcadas pelo amor intenso expresso pelos seus filhos.

PALAVRAS - CHAVE: Enfermagem. Maternidade Precoce. Adolescente. Fenomenologia.

\section{THE TYPICAL EXPERIENCE OF THE PUERPERAL ADOLESCENT FROM THE PERSPECTIVE OF SOCIOLOGICAL PHENOMENOLOGY}

ABSTRACT: Objective: to understand the perspective of the puerperal adolescent about early motherhood, through their experiences and the meaning attributed to motherhood. Method: This is a descriptive qualitative research, based on Alfred Schutz's sociological understanding phenomenology. The data collection took place in 
the São Mateus hospital and maternity ward, and the participants were postpartum adolescents hospitalized. This research had the approval of the Committee of Ethics in Research, CAEE: 80135817.0.0000.5063. Results: four categories emerged in relation to the puerperal adolescents and the early maternity: To be a teenager; Concept of Maternity; Maternal feelings; Perspectives and anxieties about the future of the child. Final Considerations: It was understood that the participants perceive the sentimental experience obtained with motherhood as the meaning of the same and therefore, very rewarding, becoming more and more unique and special. It was understood that early motherhood is a profound challenge for the adolescent who experiences it and who, despite being already accustomed to this process. For this reason, the interviewees agreed that this new phase is about changes and responsibilities, but also about good experiences marked by intense love expressed by their children.

KEYWORDS: Nursing. Early Maternity. Adolescent. Phenomenology.

\section{I INTRODUÇÃO}

Para a Organização Mundial da Saúde (OMS, 1986), a adolescência é o período da vida que perdura entre os 10 a 19 anos contando com suas subdivisões entre menores (10 a 14 anos) e maiores (15 a 19 anos).

O período de transição entre infância e idade adulta é o mais longo e complexo do ciclo evolutivo da vida, e para que o desenvolvimento de leis, políticas sociais e sistemas de serviços sejam realizados de forma ampla e inclusiva, é necessário que o conceito de adolescência seja expandido de 10 a 19 anos para 10 a 24 anos, pois essa é a idade mais próxima do crescimento do indivíduo e compreensão popular sobre essa fase da vida (SAWYER e col, 2018).

No Brasil, em 2015, houveram 3 milhões de nascimentos de bebês de mães adolescentes entre 10 e 14 anos de idade alertando sobre a necessidade de empenho urgente das autoridades e sociedade para reversão dessa problemática (BRASIL, 2015).

A partir da chegada do anticoncepcional a população geral dissociou a ideia do sexo único e exclusivamente para a procriação. Permitindo a separação da experiência da primeira relação sexual e do casamento. Casais adolescentes que usaram métodos anticoncepcionais na primeira relação sexual tiveram as chances de ter filhos indesejados reduzida significativamente por sua vez, mais chances de estar usando anticoncepcionais diversos na última relação sexual. Diante disso é possível notar que essas práticas delimitam o comportamento sexual de uma vida (LONGO, 2016).

Na maioria dos casos quando uma adolescente descobre que está gravida, não há muitas dúvidas sobre o acolhimento do bebê: este será acolhido, seja pelos pais ou pelos avós. A questão pertinente é que, salvo raras exceções, os familiares não sabem lidar com a nova situação. São em momentos assim que faz-se tão importante a participação do profissional enfermeiro não apenas como detentor do conhecimento cientifico mas também 
apossado de toda a humanidade que a profissão requer, para aconselhar e minimizar danos aos envolvidos (CABRAL, 2016).

Entre os atributos de ser mãe, a responsabilidade e maturidade são as maiores consequências. Nessa nova etapa as jovens são encarregadas de outro ser vivo, reconhecendo exigência de uma mudança comportamental para que a atenção e cuidado de seu filho não sejam negligenciados. Sob outra perspectiva, a maternagem nessa fase pode ser interpretada como uma privação de liberdade para essa jovem, que a partir de então, deixa de realizar tarefas comuns e por vezes, prazerosas em função da criança. Essa limitação pode estar associada a assistência integral prestada exclusivamente ao bebê (LIMA et al.,2017).

As mudanças são mais impactantes para as adolescentes de classes sociais mais carentes, pois o curso de suas vidas são mudados, perpetuando assim o ciclo de dependência do companheiro e da família, diminuindo a independência dessas mulheres (OGIDO; SCHOR, 2012).

O presente estudo teve como questões norteadoras: como é compreendida e qual a perspectiva da adolescente puérpera frente a maternidade baseado na fenomenologia compreensiva de Alfred Schultz? Portanto, o objeto dessa pesquisa é compreender a perspectiva da adolescente puérpera acerca da maternidade precoce, pelas suas vivências e o significado atribuido acerca da maternidade.

\section{2| MÉTODO}

Pesquisa qualitativa descritiva, baseada na fenomenologia compreensiva sociológica de Alfred Schutz, entendendo os "motivos para" e "motivos porque" aplicado nas respostas das adolescentes sobre tema proposto.

A fenomenologia é por si só é um ramo da filosofia que se propõem a estudar os fenômenos humanos ocorridos na consciência humana. Desse modo, a fenomenologia se propõe a compreender o mundo mas sem a obrigatoriedade de explicar; olhando para o fenômeno que compreende a relação sujeito objeto (ser no mundo) (SCHUTZ, 2012).

Participaram deste estudo 18 adolescentes puérperas, internadas em uma maternidade publica, que atenderam aos critérios de inclusão: está na faixa etária de 10 a 19 anos completos (segundo a OMS); primíparas e/ou multíparas; residentes na região norte do Espírito Santo; que aceitaram participar da pesquisa e concordaram em assinar o Termo de Concentimento Livre e Esclarecido (TCLE) e o TALE (Termo de Assentimento Livre e Esclarecido para as menores de idade e ainda o TCLE pelos responsáveis); que pariram; mães de bebês prematuros ou não. Os critérios de exclusão foram: adolescentes acima de 19 anos, 11 meses e 29 dias de idade; menores de idade sem autorização do responsável; adolescentes puérperas que não aceitaram participar da pesquisa. Para preservar a identidade das adolescentes considerou-se a sigla AP (Adolescente Puerpera) seguindo do 
número de ordem da participação na pesquisa (ex: AP1; AP2). A coleta de dados se iniciou após aprovação do Comitê de Ética em Pesquisa (CAEE $n^{\circ}$ 80135817.0.0000.5063), com início em março de 2018 e término em maio de 2018.

As participantes foram entrevistadas por meio de um questionário semiestruturado composto por questões sobre o perfil socioeconômico, a percepção sobre seus bebês e o futuro, somado a quatro perguntas fenomenológicas. Após esse levantamento responderam a entrevista semiestruturada individualmente, numa sala privativa em horário conveniente para as mesmas, disponibilizada pela maternidade.

Os dados foram transcritos na íntegra e seguiu algumas etapas na perspectiva de compreender o típico da ação vivenciada pelas participantes, com a descrição compreensiva dos relatos sobre a vivência de cada participante, procurando a qualidade diferenciada das percepções dos mesmos sobre suas experiências em relação a ação social da experiência da maternidade precoce.

Para que seja possível obter diferentes significados, a pesquisa usou como análise e interpretação, categorias que variaram em função da intersubjetividade de cada participante. E que, para que fosse possível chegar ao típico da ação dos sujeitos, utilizouse a metodologia fenomenológica ou seja: Apreensão das falas, para descrever o tipo vivido dos sujeitos; Transcrição imediatas das entrevistas, excluindo os erros de português, visando preservar a subjetividade da relação face a face-pesquisador-sujeito do estudo; Leitura atentiva e minuciosa, para que possa transformar o que se mostrou subjetivo em objetivo, com a finalidade de agrupar em categorias as significações encontradas; A intencionalidade do tipo vivido dos participantes, através dos motivos para e motivos porque (MESSIAS, 2013).

Emergiram assim as categorias: Ser adolescente; Conceito de Maternidade; Sentimentos Maternos; Perspectiva e ansiedades com relação ao futuro do filho.

\section{I RESULTADOS E DISCUSSÃO}

A distribuição por idades das participantes, revelou um predomínio de puérperas de 16 e 17 anos $(n=13)$, sendo que apenas duas puérperas $(3,6 \%)$ cursavam a série ideal para sua idade. Duas participantes concluíram o ensino médio, evidenciando um acentuado atraso escolar entre as participantes. Entretanto, todas elas expressaram o desejo de continuar estudando.

Outra característica que chamou atenção foi que em relação a condição financeira da população estudada, sendo que nenhuma das participantes trabalhavam no período da gestação, duas adolescentes se consideram donas de casa $(3,6 \%)$ e outras duas $(3,6 \%)$ relatam ter a profissão de manicure e doméstica porém todas as puérperas dizem não ter renda provindas de seu trabalho. Com referência a situação conjugal das adolescentes, cinco $(27,7 \%)$ moravam com suas mães ao passo que todas as participantes se declararam 
solteiras. Entretanto nove delas (50\%) residem junto a seus parceiros.

Quando questionadas sobre o período de gestação, todas afirmaram ter feito o pré-natal nas unidades básicas de saúde dos bairros onde residem fazendo entre 5 e 13 consultas sendo que a maioria $(38,8 \%)$ fizeram 7 consultas de pré-natal cumprindo assim o mínimo de 6 consultas conforme preconizado pelo Ministério da Saúde.

Intercorrências no período gestacional como anemia, diabetes gestacional, bronquite e dor foram apontadas por 6 adolescentes. Infecção do trato urinário foi o principal relato das participantes do estudo pois acometeu 2 participantes (3,6\%). Em relação ao tipo de parto, o mais frequente nesse estudo foi o natural, sendo que apenas 4 crianças nasceram de parto cesariana (22,2\%). Com relação a amamentação, apenas 1 puérpera $(5,5 \%)$ não estava conseguindo amamentar, por motivos que a mesma não soube explicar.

Para entender com exatidão o fenômeno da maternidade precoce, foi necessário procurar captar a intencionalidade da adolescente puérpera frente ao fenômeno no cenário do puerpério em suas múltiplas relações estabelecidas no âmbito de uma rede social. Sendo assim, após a leitura exaustiva das entrevistas de todas as puérperas, procedeuse a uma análise com base na fenomenologia compreensiva de Alfred Schutz, que foram apresentadas em quatro categorias.

\section{Ser adolescente}

Quando questionadas sobre o significado da adolescência de acordo com cada perspectiva, as jovens afirmaram que se trata de um período, fase da vida onde ocorrem várias mudanças físicas e comportamentais que são entendidas como uma transformação necessária para se adentrar na fase adulta.

Alguns relatos acerca de ser adolescente são expressos nessa categoria e encontram-se a seguir.

“É só um período de vida”(AP3);

"Para mim é mudança. Adolescente é uma pessoa que está começando a vida" (AP11);

"É só uma fase da vida. O que muda é o crescimento e amadurecimento. Agora eu fiquei mais velha, tenho que pensar no futuro"(AP12);

"(Adolescente) é alguém sem objetivos... A forma de pensar, falar, ver as coisas mudando" (AP14).

A adolescência é um período da vida particularmente saudável, o que evidencia que os agravos em saúde decorrem de hábitos e comportamentos, que vulnerabilizam esta população. Trata-se de vulnerabilidade produzida pelo contexto social, resultante dos processos históricos de exclusão e discriminação, e que determinam os direitos e as oportunidades dos adolescentes brasileiros (BRASIL, 2018).

Nos dias atuais, a adolescência é tida como uma etapa necessária para a evolução humana que apresenta características específicas, e muitas vezes estigmatizadas, que o 
indivíduo deve efetuar correspondentes a expectativas impostas pela sociedade, como a formação intelectual/profissional e independência financeira com ingresso no mercado de trabalho.

Sendo assim, a adolescência pode também ser associada com mudanças e transformação; um período de suma importância para a construção do indivíduo cidadão consciente, responsável e ativo no meio social. É necessário compreender que as mudanças de cunho psicológico não são universais, por esse motivo o conceito para cada jovem, é de igual modo, diferenciado.

Um dos principais conceitos amplamente discutidos por Alfred Schutz (2012) é a subjetividade e a intersubjetividade que entende que o mundo não é fechado mas sim, compartilhado de interpretado a todo momento por outros semelhantes, que ao agir e também ser afetado por estes, surge a percepção dessa relação mútua. Portanto, é de extrema importância desenvolver a empatia no cuidado prestado a fim de não interferir bruscamente no vinculo construído entre o enfermeiro e a adolescente.

Fica evidenciado na categoria "ser adolescente" que no conceito pessoal de adolescência experienciado por cada jovem emergem os motivos porque, uma vez que faz referência a acontecimento passados, enquanto os motivos para estão diretamente relacionados a acontecimentos que ainda irão acontecer.

Quando perguntadas sobre o significado pessoal da maternidade, emergiu outra categoria.

\section{Conceito de Maternidade}

Apesar de subjetivo, a maternidade foi e continua sendo considerada por muitos, como uma das atividades da essência feminina, como um chamado ou predestinação.

“Ser mãe é algo especial!" (AP2);

"Ser mãe é dar conselho, estar sempre junto (com a filha), é acreditar que ela vai vencer" (AP3);

"A coisa mais importante da minha vida. Eu ser mãe, é tudo"(AP9);

"É uma responsabilidade e tanto. É uma criança cuidando de outra"(AP13);

“(Ser mãe é) Cumprir os deveres de casa, estar junto, servir” (AP14).

Não se pode negar os impactos e as consequências da maternidade marcados por alterações comportamentais e psicológicas de extrema importância para o desenvolvimento da mulher e que na maioria das vezes, esse mudanças tendem a ser positivas na perspectiva da adolescente.

“É viver uma experiência nova"(AP1);

"Hoje eu já sou uma mulher, porque agora eu tenho um filho. Agora eu tenho responsabilidades, já sou mãe"(AP11);

"Ser mãe transforma a vida de uma pessoa" (AP17). 
Diante de uma criança e uma nova vida, a maternidade precoce tem como sinônimo responsabilidade, mudanças e amadurecimento que muitas vezes não viriam sem o fenômeno da maternidade precoce, até mesmo pela pouca idade. Há uma unanimidade nos relatos com relação aos sentimentos envolvidos nessa etapa. A mudança mais expressiva imediatamente na visão dessas jovens é devido ao momento em que entendem a complexidade e a fragilidade do ser que até então não era conhecido para elas e que passa a ocupar o papel central em suas vidas, como nos relatos a seguir.

"É saber que agora eu tenho uma responsabilidade muito grande para se preocupar. Responsabilidade com o meu filho. O amor pelo meu filho. Carinho, atenção, afeto. Antes eu não tinha com o que me preocupar, agora eu tenho meu filho. Uma "pessoinha" que é indefesa" (AP9);

"Não sei explicar. A primeira vez que a vi foi... muito amor. (Maternidade) significa amor e mudança de vida... uma mudança boa" (AP10).

É inegável a mudança que uma criança gera na família, em especial na mãe, e essas mudanças são rápidas e na maioria das vezes, muitos benéficas e eficazes na perspectiva das jovens.

‘É estar com seu filho, dar amor, carinho... Eu amadureci mais rápido depois que tive filho" (AP2);

"Ser mãe é mudar de rumo... Antes eu era só adolescente, agora eu fiquei mãe, muda a vida" (AP3).

Nessa categoria é possível enxergar melhor e compreender que algumas expectativas de vida da adolescente não mudam após o nascimento dos filhos, como no relato abaixo.

"Agora ela (filha) se tornou uma parte da minha vida, então o que eu sonhava para o meu futuro, agora estou incluindo ela. Vai ser difícil continuar, mas se eu tiver força de vontade, é claro que eu consigo terminar meus estudos. Eu quero ser engenheira civil e tenho vontade de terminar tudo e seguir em frente, mesmo com ela" (AP5).

Não se pode negar as dificuldades que essas jovens mães enfrentam e enfrentaram pela pouca idade, diante da sociedade que cobra dessas mulheres uma posição quase que altiva e imediata diante de seus filhos e na criação dos mesmos. Porém, o sentimento de responsabilidade as movem a assumir a nova posição que por sua vez, gera respeito e mudanças positivas para as mesmas.

"Tenho minhas responsabilidades e olhar para esses rostinhos fofos... para mim são só responsabilidades. Não sei, algumas pessoas já me veem com outros olhos. Tem algumas pessoas que dizem que eu não sou a mesma pessoa de antes, estou diferente. Várias pessoas falam isso. Diferente no jeito de agir, nas coisas que você fazia e agora não faço mais"(AP4).

É importante ressaltar, que essa intersubjetividade está ligada ao sujeito, indivíduo que na maioria das vezes está inserido num contexto de agravantes sociodemográficos, 
bem como fatores culturais que alteram o significado da maternidade nos dias atuais.

Nessa categoria ficam evidenciados com maior frequência os motivos porque que estão relacionados ao conceito pessoal que as puérperas estabeleceram com as mudanças sofridas com a chegada da criança. Apesar das falas não estarem colocadas especificamente no passado, o sentido expresso nas mesma faz referência um pretérito não muito distante que claramente modificou a vida dessas jovens mães.

A maternidade é uma construção histórica e social, sendo entendida de diferentes maneiras, de acordo com os tempos e possibilidades, designando o lugar das mulheres na família e na sociedade (LAIXEN; QUADRADO, 2018).

A maternidade é um período de transformações importantes na vida da maioria das mulheres, independente da idade. Quando ocorre na adolescência, a gravidezé um desafio considerando, além do risco biológico, o risco psicossocial. Por outro lado, diante da desigualdade de gênero e de classe social, a gravidez pode ser uma tentativa da adolescente de encontrar um lugar social, configurando-se uma conjuntura crítica e subjetiva na sua vida (BRASIL, 2018).

Assim, a intersubjetividade como fenômeno de uma teoria fenomenológica da cultura tão explanada por Schutz (2012), se dá pela tipicialidade da experiência individual de mundo, tendo em vista que o conhecimento não é solipsista, ou seja, sem existência real. Todo conhecimento gerado e adquirido é transformado com o decorrer dos anos e por esse motivo é intersubjetivo (CASTRO, 2012).

\section{Sentimentos maternos}

Nessa categoria emersa nas falas, as puérperas demonstraram um misto de sentimentos investidos em seus filhos, dentre os quais, o sentimento de amor foi unanime nos relatos. Carinho e afeto também apareceram com muita frequência apesar de serem sinônimos. O que mostra certa confusão em classificar os sentimentos, como nos relator a seguir:

"Sinto muitas coisas: carinho, afeto, amor, nova família" (AP1);

"É um amor, um carinho enorme. É um sentimento que vai além de tudo. Quero dar afeto, mostrar carinho, compreensão, amor" (AP2);

"Sinto amor. Nossa! muito amor... fico nervosa. Quero dar o melhor para ela. Educação, carinho... quero dar uma vida melhor pra ela" (AP3);

"Eu sinto um amor grande demais, carinho. Eu tenho que cuidar bastante, dar muito carinho, atenção" (AP8).

Houveram relatos onde ficaram evidenciados sentimentos de medo com relação ao futuro profissional das crianças e preocupação com a vida profissional das jovens com a finalidade de ter condições financeiras para arcarem com a educação de seus filhos. Outro relato pertinente foi em relação a criação e educação no meio social dos filhos, conforme as falas abaixo. 
"Eu quero que ela seja uma pessoa bem-sucedida na profissão. E quero educála para isso. Não quero que ela siga meu exemplo. Tudo bem que os pais são espelho mas se eu tentar, eu acho que consigo" (AP5);

"Penso em poder dar uma vida boa pra ela, terminar os estudos, tudo por ela" (AP10);

"Sinto emoção e preocupação. Quero dar para ele tudo o que não tive" (AP11);

"Eu penso em como vai ser daqui pra frente, eu tenho essa preocupação em relação ao futuro, a criação dele" (AP17);

"Eu fico preocupada. Penso que agora eu tenho uma responsabilidade, que eu tenho que criar e educar" (AP18).

Como evidenciado, mesmo em uma gestação não planejada a preocupação com o sustento, estudo, trabalho e o futuro de modo geral estão presentes nas falas das gestantes puerperas participantes do estudo.

No contexto da gravidez na adolescência, percebe-se que a preocupação das adolescentes está em resolver suas necessidades mais imediatas, que são sobreviver e sustentar o filho (MIURA; TARDIVO; BARRIENTOS, 2018).

Os motivos mostram uma inquietude com o futuro e todas as possibilidades que cercam o fenômeno maternidade que as entrevistadas estão envolvidas, em especial com o futuro no âmbito profissional/social. Há também evidencias de que as entrevistadas vivenciam o momento com amor. Já os motivos porque aparecem nas referências ao passado, na tentativa de educarem os filhos para evitarem os acontecimentos considerados como errôneos ou desagradáveis na perspectiva das adolescentes.

A relação entre esses tipos de motivos serve de base para a discussão da natureza humana, sendo o sentido que o agente atribuiu aos seus atos, a preocupação central para os observadores sociais. Dessa forma, cada ação possui um sentido, sendo que a mesma é sempre situacional, compreendida pelo observador, através das tipificações e idealizações repetidas na vida do sentindo comum (SCHUTZ, 2012).

\section{Perspetivas e ansiedade com relação ao futuro dos filhos}

A preocupação com relação ao futuro dos filhos, não é um privilégio apenas das mães adolescentes. Além de considerar que a relação mãe-filho é de extrema importância, as jovens também têm expectativas quanto aos dias vindouros da criança. A garantia de acesso a uma educação de qualidade e a cultura está entre esperanças futuras conforme evidenciado nas falas a seguir:

"Dar uma boa educação para ela (filha)" (AP1);

"Com certeza, que ela esteja fazendo algum curso e tendo bons estudos e que a gente tenha condição de pagar tudo para ela. Eu penso em ela ter uma boa carreira, não desviar dos estudos de jeito nenhum" (AP5).

Além das expectativas apresentadas anteriormente há também um desejo de que as crianças não passem pelas dificuldades e restrições pelo quais as mães passaram, além do 
sentimento latente de proteção das dores e decepções da vida. Relatos que se confirmam abaixo:

"Quero o melhor pra ele! Toda mãe quer o melhor para seu filho...Quero um futuro melhor pra ele. Dar um estudo pra ele. Poder dar estudo, dar tudo o que não tive, tudo do melhor pra ele" (AP2);

"Estudar bem, ter uma vida melhor... Uma menina educada, cheia de amor para dar, que respeite todo mundo" (AP3);

"Pessoa honesta, que ele tenha os estudos melhores que os meus. Um indivíduo de bem. As pessoas olharem pra ele e ver nele uma pessoa honesta que gosta de ajudar o próximo" (AP17).

Porém, nessa categoria há uma projeção do futuro que era almejado pelas jovens e agora elas passam a sonhar para seus filhos, sobre a justificativa de um futuro melhor do que elas, a partir de então provavelmente terão, como mostrado a seguir.

"Estudar, ter uma profissão. Ser alguém na vida. Eu espero uma juventude boa. Ele ser alguém na vida. Quero que ele tenha respeito, atenção"(AP9);

"Dar educação, ser amiga dele e ensinar as coisas da vida. Quero que ele termine os estudos. Que ele saiba se relacionar bem com as pessoas"(AP11);

"Eu quero que ela tenha um futuro bom, que não pare os estudos, que faça uma faculdade para se formar naquilo que ela quer. Espero que ela seja muito inteligente e que possa seguir a vida dela diferente. Diferente da minha"(AP18).

Também há desejos de realização profissional independente da escolha, como exemplificado acima.

Há um monopólio profissional no Brasil por serem considerados profissões elitistas e poderem controlar mesmo que indiretamente as relações sociais, fatos que se diferem a vida cotidiana de um cidadão comum para um indivíduo tido como de elite. conforme falas a seguir:

"Eu quero que ele esteja estudando muito para ser advogado!"(AP4);

"O pai dela quer que ela seja advogada. Eu também. A mesma coisa. "Estudar bastante para chegar até onde o pai dela quer" (AP8);

"Que ele estude, seja alguém na vida. Seja médico, advogado ou algo importante" (AP13);

"Que ele seja uma pessoa de bem, estude, se forme para ser alguém na vida. Quero que ele seja Médico Veterinário"(AP15).

As questões sentimentais e referentes a situação conjugal futura dos filhos também foi explanada pelas entrevistadas. Porém, há um incentivo à união por parte da família de modo geral, e somente ao lado romântico do casamento, baseado nos atributos do cônjuge e ideia de estabilidade emocional, comportamental e sexual que o matrimonio traz consigo, descritos nas falas abaixo:

"Quero que ela tenha boas amizades, e que conheça a pessoa certa (para casar) e que seja uma boa menina..."(AP10). 
Por outro lado, há também quem defenda que um casamento precoce pode interferir na formação e desenvolvimento do filho.

Ao menos um sucesso que para as jovens, pelo menos por hora, não é viável; como pode ser observado no relato abaixo:

"Que ele estude, se forme, não case cedo"(AP16).

Sobre as ansiedades expressas pelas adolescentes puérperas, entre as mães de crianças do sexo masculino, o medo expresso é com a possibilidades de envolvimento com o tráfico de drogas, além do uso e consumo dessas substancias. Porém as mães de meninas, não expressaram essa ansiedade.

"Quero que ele não se envolva nesse mundo porque hoje em dia ter filho é tão bom mas com as coisas que esse mundo tá tendo. Drogas, essas coisas. Não quero isso para o meu filho" (AP4);

"Tem filho que escolhe mexer com porcaria (drogas). Muitas vezes é difícil para gente que é mãe ver" (AP7);

"Dar conselho pra ele não se envolver com porcaria (drogas)" (AP11).

Concomitante a essas afirmativas há adolescentes que temem pelas experiências vividas e para que as mesmas não se repitam com seu filhos, como nas falas abaixo:

"Antes de eu ter ele (filho), eu fumava demais, eu era demais. Aí eu tenho medo, porque os pais tem que ser exemplo" (AP6);

"Não quero que ele cometa os mesmos erros que eu. Não quero que ele se envolva com a bandidagem, não se envolva com coisas erradas... essas coisas"(AP13).

Apesar do fenômeno maternidade precoce não ser visto como negativo pelas as entrevistadas, algumas delas expressaram que tem preocupação de suas filhas também serem mães enquanto adolescentes, chegando a relatar que o evento em foi um erro. Nesse ponto então há uma controvérsia nas falas, como pode ser observado nas falas abaixo.

"Não cometer os mesmos erros que eu cometi, no caso, ter uma filha com 16 anos" (AP5);

"Penso para ela um futuro diferente do meu. Se prevenir mais pra não acabar como eu (mãe adolescente)... eu acho que foi um erro. Não ela, mas eu ter engravidado cedo demais" (AP10);

"Ensinar ela para não ser mãe nova como eu sou" (AP12);

"Que possa seguir a vida dela diferente da minha. Porque eu engravidei nova e isso não é bom" (AP18).

É importante ressaltar o contexto que essa adolescentes estão envolvidas: de pobreza, em uma comunidade com altos níveis de violência, sem muito acesso a formação escolar e por consequência mais dificuldade de inserção no mercado de trabalho. E por isso, os medos e ansiedades expresso nesse estudo são totalmente pertinentes. 
Sendo assim, buscar compreender o mundo ao qual a vida dos participantes pertence é fundamental para interpretar a origem das vivências, possibilitando assim, o reconhecimento do fenômeno.

Os motivos para ficam evidentes e emergem a partir do momento que a adolescente puérpera põe-se a pensar no futuro que ela considera ideal para seu filho, bem como nas ansiedades e medos expressos no mesmo relato.

Compreender o típico vivido das adolescentes puérperas e as vivências alcançadas sobre a maternidade precoce constitui-se de um constante movimento de revelar à luz do referencial teórico-filosófico de Alfred Schutz, (2012).

As expectativas para o futuro, discursados como motivos para,ou seja relacionados ao futuro, diferentemente melhor do que as adolescentes provavelmente terão, é um desejo que a maioria das mãe tem (SCHUTZ, 2012).

As profissões elitizadas e citadas pelas adolescentes puerperas tais como médico, advogado e engenheiro geralmente estão ligadas a uma boa condição de vida, garantia de sucesso profissional, com salários mais altos além do prestígio social. Por isso há uma preferência por essas categorias citadas pelos participantes.

Para as opiniões sobre o casamento e relacionamentos são construídas ao longo da vida e moldadas de acordo com a sociedade em que vivem e como são experenciadas (DIAS et al, 2013).

Nesse caso, autor argumenta que parte da perspectiva de que não contraindo matrimônio, a formação educacional ficaria em primeiro lugar, e o filho poderia ficar na casa dos pais até que a inserção no mercado de trabalho fosse uma fato, acarretando o que na visão das adolescentes, é tido como sucesso (PATIAS et al, 2011).

Cada ação possui um sentido, sendo que a mesma é sempre situacional, compreendida pelo observador, por meio das tipificações e idealizações repetidas na vida do sentido comum (SCHUTZ, 2012).

A maternidade precoce, em muitos casos reforça o ciclo de dependência dos familiares e impede o crescimento econômico da jovem, uma vez que a já referida baixa escolaridade/ atraso escolar põe em risco a colocação da mesma no mercado de trabalho e quando colocada, as baixas remunerações a farão ser sempre auxiliadas por familiares ou companheiro (GODINHO et. al, 2000).

Assim, para a adolescente quando começa sua relações conjugais oficializadas perante a lei ou não, idealiza também a gravidez (XIMENES et al, 2007), ou seja, fica complicado para essa adolescente entender o parto prematuro, o o parto vaginal, 0 aleitamento, a prematuridade quando ocorre.

$\mathrm{Na}$ abordagem fenomenológica, a ação social desses acontecimentos é compreendida como uma relação interpessoal que é estabelecida no mundo exterior e que proporciona o conhecimento intersubjetivo dos significados humanos (SODRÉ et al., 2010).

A vivência da adolescente em relação a maternidade precoce é subjetiva. A 
adolescente que tem a vivência da maternidade precoce, em seu universo, pertence a um contexto relacional. Sua ação sempre estará voltada para alguém uma vez que ela não vive só, mas sim de relacionamentos com outras pessoas.

Nesse contexto, o enfermeiro deve implementar novas propostas de intervenção e promoção da saúde, direcionar as atividades no período gravídico, estabelecer vínculos, e acompanhar suas necessidades (FONSECA, 2019).

\section{I CONSIDERAÇÕES FINAIS E IMPLICAÇÕES PARA ENFERMAGEM}

Este estudo mostrou através dos motivos porque, que as adolescentes puérperas entrevistadas são jovens de baixa renda, inseridas num contexto de vulnerabilidade social, todas pariram na ala dedicada a pacientes do Sistema Único de Saúde, que incentiva o parto normal.

Por vezes percebeu-se as dificuldades dessas jovens para atribuir significados aos pensamentos e sentimentos, não sabendo discursar sobre as perguntas norteadoras da pesquisa. Esse fato pode ser reflexo do atraso escolar e da baixa escolaridade, bem como do déficit escolar dessas adolescentes.

Compreendeu-se que a maternidade precoce é um profundo desafio para a política pública e para a ciência, porém consegue ainda ser mais complexo para a adolescente que a vivência. Percebeu-se que a maternidade proporciona experiências diversas e amadurecimento sem igual para a jovem e estas mudanças podem influenciar suas vivencias relacionadas a maternidade através dos motivos para e porque.

Por meio dos motivos para, foi possível compreender que as expectativas maternas postas sobre os filhos nada mais é que a projeção de um futuro que ela considera ideal e quer estender à criança por consequência.

O estudo evidenciou a necessidade de uma assistência não somente por parte dos profissionais de enfermagem mas também das equipes de apoio social e políticas de promoção a cidadania e fim de contribuir para o crescimento e desenvolvimento dessas crianças minimizando as vulnerabilidades e risco sociais, para pleno exercício dos direitos e deveres de um cidadão engajado na sociedade.

Vale ressaltar que em alguns relatos não foi encontrado na voz dada às adolescentes mãe de meninos, o medo da paternidade precoce no futuro, o que reforça o argumento amplamente discutido de que vivemos em um mundo machista, no qual para os homens não há estigmas nesse aspecto.

A partir do conhecimento da vivência da adolescente puérpera acerca da maternidade surge a necessidade de incremento de políticas públicas no sentido de atender a adolescente com deferência e qualidade para essa faixa etária principalmente.

Sendo assim, fica evidente que este estudo é de grande valia para a enfermagem e para todos os envolvidos no processo de cuidar, uma vez que trabalha na promoção de 


\section{REFERÊNCIAS}

ANDRADE, P.R.D.; OHARA, C.V.D.S.; BORBA, R.I.H.D.; RIBEIRO, C. Enfrentando uma experiência difícil mesmo com apoio: a adolescente menor vivenciando a maternagem. Revista Gaúcha de Enfermagem, 366(spe), p. 111-118, 2015.

BRASIL. Ministério da Saúde. Pré-natal e Puerpério: atenção qualificada e humanizada - manual ténico/Ministério da Saúde, Secretaria de Atenção à Saúde, Departamento de Ações Programáticas Estratégicas - Brasília: Ministério da Saúde, 2005. 158 p.

BRASIL. Ministério da Saúde. Sistema de informações sobre nascidos vivos [Internet]. Brasília; 2015. Disponível em: http://tabnet.datasus.

gov.br/cgi/deftohtm.exe?sinasc/cnv/nvuf.def. Acesso em 03 de junho 2021.

BRASIL. Ministério da Saúde. Proteger e cuidar da saúde de adolescentes na atenção básica / Ministério da Saúde, Secretaria de Atenção à Saúde, Departamento de Ações Programáticas e Estratégicas. - 2. ed. - Brasília: Ministério da Saúde, 2018. p.233

CASTRO, C.M.; WICH, P.; LIMA, A.M.J.; GUEDES, H.M. O estabelecimento do vínculo mãe/recémnascido: percepções maternas e da equipe de enfermagem. R. Enferm. Cent. O. Min.; v. 2, n 1, p.:6777, 2012. Doi: https://doi.org/10.19175/recom.v0i0.165

DIAS, A.C.G.; JAGER, M.E., PATIAS, N.D.; OLIVEIRA, C.T. Maternidade e casamento: o que pensam as adolescentes. Interacções. v. 25, p.90-112, 2013.

CABRAL, C.S. Gravidez na adolescência" e identidade masculina: repercussões sobre a trajetória escolar e profissional do jovem. In: Encontro Nacional de Estudos Populacionais, Anais,13, 2016, Ouro Preto, 1-26.

FONSECA, J.M. Assistência de enfermagem às adolescentes grávidas. Revista Científica Multidisciplinar Núcleo do Conhecimento. Ano 04, Ed. 09, v. 03, p. 92-114, 2019. Disponível em: https://www.nucleodoconhecimento.com.br/saude/adolescentes-gravidas. Acesso em 03 de junho 2021.

GODINHO, R.A.; SCHELP, J.R.B.; PARADA, C.M.G.L. BERTONCELLO, N.M.F. Adolescentes e grávidas: onde buscam apoio?. Rev.latino-am.enfermagem, Ribeirão Preto, v. 8, n 2, p. 25-32, 2000.

GRAÇA, E.M.; SANTOS, G.F. Metodologia do cuidar em enfermagem na abordagem fenomenológica. São Paulo: Revista da Escola de Enfermagem da USP, v. 43, n 1, p. 200-7, 2009.

GROSSMAN, E. A construção do conceito de adolescência no Ocidente. Revista Saúde \& Adolescência, v. 7, n 3, p. 47-51, 2010.

LAIXEN, J.; QUADRADO, R.P. Maternidade sem romantismos: alguns olhares sobre as maternidadese os sujeitos-mãe na contemporaneidade. Revista Latino-Americana de Estudos em Cultura e Sociedade. v.4, ed. especial, 2018.

LIMA, F.B.N.; LIRA, G.G.; MELO, R.A, MOLA, R.; FERNANDES, F.E.C.V. Maternidade: significados atribuídos por adolescentes primíparas. Rev enferm UFPE on line., v. 11, n 3, p.1163-70, 2017. 
LONGO, L.A.D.B. Juventude e contracepção: um estudo dos fatores que influenciam o comportamento contraceptivo das jovens brasileiras de 15 a 24 anos. In: Encontro Nacional de Estudos

Populacionais, Anais, 13, 2016, Ouro Preto, 1-27.

MESSIAS, C.M. O significado do ensino da consulta de enfermagem uma contribuição na perspectiva da abordagem sindrômica. 2013.110f. Tese (Doutorado em enfermagem). Escola de enfermagem Anna Nery, Universidade Federal do Rio de Janeiro. Rio de Janeiro. 2013.

MIURA, P.O; TARDIVO, L.S.P.C; BARRIENTOS, D.M.S. O desamparo vivenciado por mães adolescentes e adolescentes grávidas acolhidas institucionalmente. Ciênc. saúde colet. v. 23, n 5, 2018. https://doi.org/10.1590/1413-81232018235.14152016. Acesso em 03 de junh. 2021.

MOREIRA, T.M.M.; VIANA, D.S.; QUEIROZ, M.V.O.; JORGE, M.S.B. Conflitos vivenciados pelas adolescentes com a descoberta da gravidez. Revista da Escola de Enfermagem USP, v. 42, p.31220, 2008.

MUNSLINGER, I.M.; MARÇAL, S.S.; BORTOLI, C.F.C.; GUIMARÃES, K.B.A. Maternidade na perspectiva de mães adolescentes. Revista Brasileira em Promoção da Saúde 29 set Jul-Set 2016: Disponível em: http://www.redalyc.org/comocitar.oa?id=40849134007. Acesso em 22 de Junho de 2017.

OGIDO, R.; SCHOR, N. A jovem mãe e o mercado de trabalho. São Paulo: Saúde Soc., v. 21, n. 4, p.1044-1055, 2012.

PATIAS, N.D.; JAGER, M.E.; CHECHI, P.; DIAS, A.C.G. Construção histórico social da adolescência: implicações na percepção da gravidez na adolescência como um problema. Revista Contexto e Saúde, 10(20), 205-14, (2011). Disponível em: http://www1.unijui.edu.br/revistas/index.php/revistacontexto-e-saude-edicaoatual

SAWYER, S.M.; AZZOPARDI, P.S.; WICKREMARATHNE, D.; PATTON, G.C. The age of adolescence. The Lancet Child \& Adolescent Health, v 2, n. 3, p: 223-228, 2018.

SODRÉ, T.M. et al. Necessidade de cuidado e desejo de participação no parto de gestantes residentes em Londrina-Paraná. Texto \& Contexto Enfermagem, v.19, n. 3, 2010.

SCHUTZ, A. Sobre a fenomenologia e relações sociais. In: WAGNER, H.T.R (Org). (1979)

Fenomenologia e relações sociais: textos escolhidos de Alfred Schutz. Rio de Janeiro: Vozes, 2012.

XIMENES, N.F.R.G.; DIAS, M.S.A.; ROCHA, J.; CUNHA, I.C.K.O. Gravidez na adolescência: motivos e percepções de adolescentes. Rev Bras Enferm. v. 60, n 3, p.:279-85, 2007. 


\section{CONHECIMENTO DOS ENFERMEIROS DA ATENÇÃO BÁSICA SOBRE DEPRESSÃO PÓS- PARTO}

Data de aceite: $20 / 08 / 2021$

\section{Emmanuelle de Araújo Ewald}

Graduanda da nona fase do curso de Enfermagem da Universidade Regional de

Blumenau. FURB

Blumenau - SC

\section{Daniela Priscila Oliveira do Vale Tafner}

Enfermeira, doutoranda pela Universidade Federal de Santa Catarina - UFSC. Docente no curso de Enfermagem da Universidade Regional de Blumenau - FURB Blumenau - SC

RESUMO: Objetivo: Este capitulo tem como objetivo geral apresentar o conhecimento de enfermeiros da atenção básica sobre depressão pós-parto e como objetivos específicos identificar a fonte de conhecimento dos profissionais, reconhecer parâmetro para definir a presença da depressão e analisar a caracterização dos profissionais. Método: Pesquisa qualitativa descritiva, desenvolvida no município de Blumenau em três unidades de atenção básica, com a participação de quatro enfermeiras. A coleta de dados ocorre através de chamada telefônica utilizando questionário semiestruturado, os relatos foram gravados, transcritos e então realizada a análise, essa pesquisa foi aprovado no Comitê de Ética em Pesquisa da instituição ao qual foi realizado, pelo protocolo $n^{\circ} 4.580 .069$, CAAE 40735720.6.0000.5370. Resultados: Os resultados mostraram que a enfermagem possui um conhecimento superficial sobre o assunto, não reconhecendo a diferença entre depressão pós-parto e tristeza materna, seus sintomas e fatores de risco, se fazendo necessária uma educação continuada. Conclusão: Conclui-se que a depressão pós-parto é um problema de saúde pública que traz tantos prejuízos para a mulher, bebê e família, porém é pouco abordado e conhecido pela enfermagem, mesmo esses sendo a porta de entrada para o acolhimento é quem participa do diagnóstico e direciona essa mulher para o tratamento, a Escala de Depressão Pós-Parto de Edimburgo e Pré-Natal Psicológico são ferramentas que podem ser incorporadas pela enfermagem para proporcionar assim um cuidado integral, visando o cuidado a saúde fisiológica e mental.

PALAVRAS - CHAVE: Enfermagem; Depressão pós-parto; Gestantes; Puérperas; Atenção Básica

\section{KNOWLEDGE OF PRIMARY CARE NURSES ABOUT POSTPARTUM DEPRESSION}

ABSTRACT: Objetive: This article had as a general objetive to identifify the knowledge of nurses in primary care about 'postartum depression and as specific objetives to identify the source of knowlefge of professionals, recognize parameters to define the presence if depression and analyse the characterization of professionals.

Method: Descriptive qualitative research, deseloped in the city Blumenau in trhee primary care units, whit the participation or four nurses. Data collection takes place through a telefone call using a semi-structured questionnaire, the reports 
were recorded, transcribed na the analyzed. This research was approved by the research ethics committee of the institution to which it was carried out, under protocol $n^{\circ} 4.580 .069$, CAAE 407357200.6.0000.5370. Results: The results showed that nursing has a superficial knowledge on the subject, not recognizing the difference between postpartum depression and maternal sadness, its symptoms and risk factors, making continuing education necessary. Conclusion: It is concluded that postpartum depression is a public health problem that brings so much harm to the woman, baby and family, but it is little addressed and known by nursing, even though these are the gateway to welcoming, it is those who participate in the diagnosis and directs this woman to treatment, the Edinburgh Postpartum Depression Scale and Psychological Prenatal Care are tools that can be incorporated by nursing to provide comprehensive care, aiming at physiological and mental health care.

KEYWORDS: Nursing; Post partum depression; Puerperal; Primary care.

\section{INTRODUÇÃO}

De acordo com dados da Organização Mundial da Saúde (OMS) ${ }^{1}$ a depressão é uma doença que é muito comum pelo mundo que se estima que acomete mais de 300 milhões de pessoas, a depressão pode ocorrer em vários períodos da vida, sendo uns desses períodos no pós-parto, sendo conhecida como a depressão pós-parto ou depressão puerperal.

Conforme o Ministério da Saúde ${ }^{2}$ a depressão pós-parto é uma condição que se manifesta devido a várias mudanças que ocorrem no corpo e vida da mulher durante a gestação e após o parto, sendo elas associadas a fatores hormonais, emocionais, físicos, estilo de vida e histórico de transtornos psicológicos.

A depressão pós-parto é significante problema para a saúde pública pois é uma das principais complicações no pós-parto. Estimativas gerais mostram a prevalência de 10 a $15 \%$, porém esses números são encontrados em países desenvolvidos, em condições mais desfavoráveis essas porcentagens podem ser ainda maiores ${ }^{3}$.

A depressão pós-parto traz um impacto negativo não apenas na mulher, mas na sua família e no bebê, esse impacto negativo interfere na relação em um todo com a família, e principalmente na relação entre a mãe e o recém-nascido, que podem levar a consequências futuras ao longo do desenvolvimento da criança ${ }^{4}$. As consequências da depressão pós-parto podem trazer prejuízos no desenvolvimento cognitivo e emocional dos filhos e prejudicar a relação da mulher com o marido e familiares ${ }^{3}$.

Existe uma associação entre DPP e problemas posteriores do desenvolvimento das crianças, incluindo transtornos de conduta, comprometimento da saúde física, ligações inseguras e episódios depressivos. Os sintomas de depressão interferem em todas as relações interpessoais, especialmente no desenvolvimento da interação entre a mãe e seu bebê $^{5}$

Desta forma, o enfermeiro deve ter o conhecimento acerca da etiologia e os sinais 
associados a DPP, para tomar medidas preventivas contra a doença. Deve promover saúde mental da gestante de uma maneira em geral, cabem ao enfermeiro executar com qualidade e dedicação durante o pré-natal ${ }^{6}$.

Os profissionais da atenção básica em saúde, conhecendo os fatores de risco devem atuar de forma preventiva com as puérperas que realizaram o pré-natal, oferecendo as mesmas a consulta de puerpério. Os profissionais precisam estar atentos a possíveis episódios de depressão pós-parto, promovendo um tratamento precoce e prevenindo contra repercussões negativas no desenvolvimento do bebê e na saúde mental dessa puérpera ${ }^{7}$.

\section{METODOLOGIA}

Trata-se de uma pesquisa descritiva com abordagem qualitativa. Segundo Minayo, Deslandes e Gomes $^{8}$ a pesquisa qualitativa trabalha com significados, motivos, aspirações, crenças, valores e atitudes, respondendo questões muito únicas, num nível de realidade que não se pode ser quantificado.

O presente estudo foi realizado no município de Blumenau-SC. A coleta de dados foi realizada durante o mês de março e abril do ano de 2021, sendo os participantes da pesquisa quatro enfermeiros de unidades de atenção básica.

Devido ao momento de pandemia da Sars- CoV-2 as entrevistas foram realizadas por chamada telefônica utilizando questionário semiestruturado, os relatos foram gravados e posteriormente transcritos e então realizada a análise. Individualmente foi explicado sobre a pesquisa, garantindo ao participante anonimato, apresentado o Termo de Consentimento Livre e Esclarecido, respeitando a Resolução 466/2012 do Conselho Nacional de Saúde. Para manter o anonimato das participantes da pesquisa, elas receberam o codinome ENF 1, ENF 2, ENF 3 e ENF 4. O estudo foi aprovado no Comitê de Ética em Pesquisa da instituição ao qual foi realizado, pelo protocolo $n^{\circ}$ 4.580.069, CAAE 40735720.6.0000.5370.

A análise de conteúdo foi realizada através das informações obtidas nas entrevistas, foram transcritas na integra, os dados foram organizados, separados em categorias relacionando com os objetivos e utilizado a técnica de análise de conteúdo na perspectiva de Minayo $^{9}$ que traz que os pesquisadores buscam uma compressão dos significados no contexto das falas, ultrapassam apenas a parte descritiva da mensagem e vão para uma interpretação mais profunda mensagem. Para proceder com as análises, as categorias elencadas foram: Depressão pós-parto e a tristeza materna (baby blues); Pré-natal psicológico; Sinais e sintomas da depressão pós-parto; Fatores de risco da depressão pósparto; Avaliação psicológica; Papel da Enfermagem.

A presente capítulo tem como objetivo identificar o conhecimento de enfermeiros da atenção básica sobre depressão pós-parto. Em apoio, os objetivos específicos estão assim delineados: identificar a fonte de conhecimento dos profissionais, reconhecer parâmetro para definir a presença da depressão e analisar a caracterização dos profissionais. 


\section{RESULTADOS}

Perfil dos participantes.

\begin{tabular}{|lll|}
\hline PARTICIPANTE & GENERO & TEMPO DE FORMAÇÃO \\
\hline ENF 1 & FEMININO & 23 ANOS \\
\hline ENF 2 & FEMININO & 6 ANOS \\
\hline ENF 3 & FEMININO & 6 ANOS \\
\hline ENF 4 & FEMININO & 30 ANOS \\
\hline
\end{tabular}

Tabela 1: Gênero e tempo de formação de cada participante da pesquisa

Fonte: dados da pesquisadora

Buscando responder ao objetivo geral as participantes foram questionadas "Para você como enfermeiro da atenção básica em saúde o que é depressão pós-parto?" Todas as participantes tiveram respostas parecidas:

ENF 1 "Então, é uma patologia né(...)"

ENF 3 "É um transtorno psico, que pode surgir após o nascimento do bebê(...)"

ENF 4 “(...)seria um quadro né de múltiplos sintomas(...)”

Ao questionar se já ouviram falar em pré-natal psicológico, três relataram que não conheciam:

ENF 2: "eu não conheço, nunca ouvi falar e não conheço"

E uma que:

ENF 3: "Sim, é a integração da gestante, e o casal, a todo o processo gravídico."

Focando em atender ao segundo objetivo específico da pesquisa foi questionado as participantes "Qual a diferença da depressão pós-parto e o baby blues ou tristeza materna?" Três das participantes trouxeram que:

ENF 2: "(...)a depressão pós-parto no caso é considerada a doença, a tristeza materna ela não é considerada uma doença né, ela é considerada aquele momento que a parturiente tem por algum motivo que houve ela está com aquele período de tristeza (...)"

ENF 3: "Depressão pós-parto é um transtorno psicológico que acontece do nascimento até o $6^{\circ}$ mês de nascimento, já o Baby Blues são alterações hormonais que acontecem até 15 dias do puerpério e a tristeza materna mobiliza o emocional e o ambiente que se vive e pode durar até 2 semanas."

ENF 4: "É que assim ó a tristeza materna é uma coisa que passa mais rápido(...) a depressão pós-parto ela é uma coisa mais assim, mais intensa, uma apatia mais intensa assim da mãe(...)"

Uma das participantes trouxe que:

ENF 1: “(..) para mim quase não tem diferença nenhuma porque é tudo muito 
parecido(...)"

As participantes também foram questionadas a respeito dos sintomas da depressão pós-parto "Quais os sinais e sintomas que você busca em uma puérpera para suspeitar da depressão pós-parto?" Os principais sintomas que as entrevistadas trouxeram foi:

ENF 1: "essa tristeza(...)a gente observa o cuidado que ela tem com ela mesma, porque as vezes a depressão ta ligada com cuidado que ela tem que a gente acha que só porque ela ta cansada que ela não ta se cuidando(...) não tem vontade de se arrumar, de cuidar do filho(...)"

ENF 2: “(...)observa é a questão do vínculo né da mãe(...) é o vínculo da mãe com o bebê, então se você já vê que essa mãe ela não quer ter um vínculo, ela não quer amamentar, ela não quer trocar são coisas simples né que ela não quer fazer com o filho a gente já tem que desconfiar e seguindo também olhando a questão irritabilidade(...) nervosismo, insônia(...)"

ENF 3: "Baixa autoestima, desinteresse no bebê, não sente vontade de amamentar, tristeza, sentimento de culpa, falta de apetite, insônia, a puérpera não consegue ver o lado divertido da vida, não encara o futuro com alegria, se culpa pelas coisas sempre dá errado, ansiedade sem motivos, medo ou pânico sem motivo, sobrecarga das tarefas do dia a dia."

ENF 4: “(...)principalmente é a dificuldade que ela tem de expressar os seus sentimentos, a apatia, a dificuldade de enfrentar e expressar os sentimentos e a dificuldade de realizar os cuidados básicos com ela e com o bebê(...) ela fica mais apática, sem energia(...)ela não consegue desenvolver as tarefas de cuidado com a criança e com ela né"

As enfermeiras também foram questionadas em relação aos fatores de risco "Quais os fatores de risco da depressão pós-parto?" Uma das enfermeiras relacionou com fatores fisiológicos durante a gestação:

ENF 1: “(...)algumas situações fisiológicas dela que ela durante a gestação já apresenta(...)"

A segunda participante da pesquisa trouxe que os fatores de risco estão ligados a questões sociais:

ENF 2: “(...)condições financeiras, baixa escolaridade, questão do desemprego(...)"

E questões de saúde mental:

ENF 2: “(...)a saúde mental também, talvez se essa parturiente já teve casos de depressão na família, ou se ela mesma já teve caso de depressão ou ansiedade, ou de tristeza, ou algum trauma psicológico"

A terceira participante traz que os fatores de risco são:

ENF 3: "Os fatores de risco são violência doméstica, usuárias de drogas ilícitas, desemprego, histórico anterior de depressão, baixa escolaridade, não aceitação da gravidez(...)"

A quarta participante apresenta que os fatores de risco estão fortemente relacionados 
a falta de apoio familiar:

ENF 4: "(...) se essa mulher não tiver um apoio familiar, uma retaguarda né, ou se ela não tiver da família(...)"

Atendendo ao terceiro objetivo específico da pesquisa foi questionado "Você já ouviu falar sobre a avaliação psicológica da gestante e ou puérpera? Se sim, você realiza de que forma?" Uma das enfermeiras traz que já ouviu falar:

ENF 1: "Já ouvi falar(...) acho que só acabam fazendo quando tem alguns sinais que são mais alarmantes, que daí elas encaminham pra psicóloga."

Duas enfermeiras falaram que não conhecem essa avaliação,

ENF 2: "Eu não conheço essa avaliação psicológica da gestante(...) “

ENF 3: "Não(...)"

E uma relatou que:

ENF 4: "É na realidade assim, a gente é enfermeira não é psicóloga, né, então assim, o que a gente percebe, a gente não tem um instrumento né digamos assim para fazer essa avaliação, mas tu percebes o que, no atendimento o que a gente pode perceber e a mudança de comportamento, né, é a mudança de comportamento e daí é conversar pra tentar(...)"

Também foi questionado sobre quais condutas as enfermeiras tomavam "Qual a conduta que você adota no seu dia a dia quando percebe os sintomas de depressão pós-parto em uma mulher?" Três das enfermeiras relataram que ao perceber os sintomas encaminham para a psicóloga:

ENF 3: "Eu encaminharia para o setor de psicologia, para ajuda profissional(...)" Uma das enfermeiras disse que encaminharia para o médico:

ENF 4: "a gente conversa com o médico né, pra tentar fazer um encaminhamento" Uma das enfermeiras falou sobre os grupos que a gestante pode estar participando:

ENF 1: “(...)na nossa unidade nós temos alguns grupos, efetivamente não tão acontecendo agora no momento por causa da pandemia, mas se não nós temos a horta comunitária, tem o grupo de mulheres, tem o Taishi, tem o grupo de relaxamento, e a gente consegue encaixar elas nesses grupos, pra elas poderem ter algum suporte, e a ausculta né, porque muitas delas tem que ser escutadas."

E uma das participantes traz que:

ENF 3: “(...)agendaria consultas com mais frequência para a puérpera para acompanhar de perto todo o processo."

Relacionado ao primeiro objetivo específico foi questionado as participantes "Como e onde você aprendeu sobre a depressão pós-parto? E como esse conhecimento auxilia na sua prática?" Uma das enfermeiras relata que só teve contato com o assunto na faculdade:

ENF 1: "Nossa isso faz muito tempo, só na faculdade que a gente ouviu falar, depois não sei se é porque não é valorizado, mas não houver nenhuma capacitação enquanto profissional pra ta fazendo acompanhamento de depressão pras nossas mulheres(...)" 
Três enfermeiras relatam que aprenderam sobre o assunto ao longo da vivência:

ENF 4: “(...)na vivência também né, na vivência do dia a dia no atendimento né(...) “

Uma das enfermeiras traz que além da faculdade e da vivência, aprendeu sobre o assunto em artigos e outros materiais online:

ENF 2: “(...)aprendi bastante sobre a questão da depressão pós-parto em alguns protocolos de saúde da mulher principalmente ali do COREN, o COREN ele disponibiliza algum protocolo, e também artigo que eu li (...)"

\section{DISCUSSÃO DOS RESULTADOS}

\section{Depressão Pós-Parto e Tristeza Materna (Baby Blues)}

É possível perceber através da fala de algumas das participantes da pesquisa que existe uma certa dificuldade em diferenciar a depressão pós-parto e a tristeza materna. A depressão pós-parto afeta de 10 a $15 \%$ das mulheres no período do pós-parto, esse quadro tem início com maior incidência entre a quarta e a oitava semana após o parto, mas pode ocorrer em qualquer momento durante o primeiro ano de pós-parto. Os sintomas geralmente se manifestam em conjunto como irritabilidade, choro, sentimento de desamparo, falta de motivação e energia, desinteresse sexual, ansiedade, transtornos alimentares e do sono ${ }^{10}$.

O Baby Blues ou Tristeza Materna, diferente da depressão pós-parto, acomete certa de $80 \%$ das mulheres, por ser um assunto pouco comentado, essa porcentagem pode ser ainda maior. É um estado de humor depressivo que costuma aparecer a partir da primeira semana depois do parto, o quadro regride por si só por volta do primeiro mês quando a mulher tem apoio e as suas questões são elaboradas. Os sintomas geralmente são irritabilidade, mudanças bruscas de humor, tristeza, indisposição, insegurança, baixa autoestima e sensação de incapacidade de cuidar do bebê ${ }^{11}$.

O que difere a depressão pós-parto do Baby Blues ou Tristeza materna é a gravidade do quadro, como ele afeta no desenvolver de tarefas da mãe, se ele apresenta algum perigo para o seu bem-estar e o do bebê e o tempo que esses quadro de sintomas persiste na mulher ${ }^{11}$.

\section{Pré Natal Psicológico}

O Pré-Natal Psicológico (PNP) é uma forma de complemento ao pré-natal biomédico, com objetivo de prestar um atendimento psicológico para a gestante, trazer uma maior humanização ao processo gestacional e do parto e a integração dos familiares ao longo do período gravídico-puerperal, o programa visa essa integração através de grupos temáticos, que tem ênfase na preparação psicológica para a maternidade, paternidade e prevenção da depressão pós-parto ${ }^{12}$. O PNP é um programa de baixo custo que possibilita um cuidado integral para a mulher e para o bebê, previne doenças e promove a saúde ${ }^{13}$.

A realização de um acompanhamento psicológico durante a gestação contribui 
para uma vivência mais saudável e tranquila desse período para as gestantes, de forma que previne perturbações no processo de desenvolvimento gravídico e consequentes ocorrências patológicas, como por exemplo, as complicações no parto, distúrbios emocionais no pós-parto e até mesmo o parto prematuro que são todos fatores de risco para a depressão pós-parto ${ }^{14}$.

\section{Sinais e Sintomas da Depressão Pós-Parto}

Como é notável nas falas das enfermeiras, os sintomas da depressão pós-parto podem ser muitos, dentre eles, irritação, tristeza, insônia, cansaço excessivo, problemas de memória e concentração, falta de interesse em atividades que antes eram prazerosas, preocupação e cuidados exagerados com o bebê ou a falta de vínculo e desinteresse ${ }^{15}$.

Outros sintomas ainda podem ser, mudanças bruscas de humor, doenças psicossomáticas, desinteresse por atividades do dia a dia, sensação de incapacidade de cuidar do bebê, podendo chegar ao extremo de pensamentos suicidas e homicidas em relação ao bebêt1.

\section{Fatores de Risco da Depressão Pós-Parto}

Há diversos fatores de risco que estão sendo estudados e apresentam relação com a depressão pós-parto, dentre eles estão: mulheres que apresentam quadro de sintomas depressivos antes ou durante a gestação, mulheres que sofrem com a TPM, que tem histórico de problemas de infertilidade, dificuldades ao longo da gestação, que passaram por parto cesárea, primigestas, mulheres vítimas de carência social, mães solteiras, mulheres que passaram pelo processo de luto de pessoas importantes, mulheres que perderam filhos anteriormente, mães de bebês que apresentam alguma anomalia ou doença, mulheres que vivem em desarmonia conjugal ou que se casaram devido a gravide ${ }^{11}$, fatores esses que são lembrados pelas enfermeiras ao longo da entrevista.

Lima, Ravelli, Floriano e Vienscoski ${ }^{16}$ ainda trazem baixa escolaridade, baixa renda familiar como fatores de risco da depressão pós-parto. E por fim alguns outros fatores de risco podem ser privação de sono, apoio social inadequado, histórico de depressão e a ocorrência recente de uma grande mudança de vida como divórcio, morte, um novo emprego e mudança de cidade ${ }^{14}$.

\section{Avaliação Psicológica}

O quesito da avaliação psicológica não é um fator de muito conhecimento da parte da enfermagem, o que foi notório durante a fala das profissionais de enfermagem, porém existe materiais que podem auxiliar nessa questão.

A escala de Edimburgo foi traduzida e validada em diversos países, inclusive no Brasil, desenvolvido na Grã-Bretanha, e é utilizada como forma de rastreio e detecção da 
depressão pós-parto, essa ferramenta é em forma de questionário contém dez perguntas com quatro opções de resposta que são pontuadas de 0 a 3, de acordo com a presença ou intensidade do sintoma, a soma total do questionário vária de 0 a 30 pontos, as puérperas com pontuação igual ou superior a 12 pontos são consideras como grupo de risco para desenvolver a depressão pós-parto ${ }^{14}$, sendo uma ferramenta que poderia ser utilizada como forma de avaliação psicológica pela enfermagem.

A Escala de Depressão Pós-parto de Edimburgo é uma ferramenta alternativa que pode ser aplicada de forma fácil e rápida, de forma que é possível identificar sintomas de depressão pós-parto nas mulheres e a partir dos resultados realizar um encaminhamento para psicóloga e um acompanhamento pela equipe de enfermagem de forma mais precisa e direcionada, promovendo ações de prevenção e promoção a saúde mental para as gestantes e puérperas ${ }^{17}$.

\section{Papel da Enfermagem}

Como profissionais da saúde é necessitamos estar ciente das diferenças entre a Depressão pós-parto e a Tristeza materna (Baby Blues), conhecer os fatores de risco que aumentam a probabilidade da depressão pós-parto para que se possa intervir de forma precoce, o que causa uma melhora no prognostico ${ }^{11}$.

Profissionais da saúde além de reconhecer fatores de risco, sinais e sintomas da depressão pós-parto, precisam planejar e executar ações de prevenção, estabelecer um relacionamento seguro e de empatia com a gestante ou puérpera e a sua família, a atenção integral e humanizada precisa estar presente na implantação e execução de ações, utilizando as redes de apoio que estão disponíveis ${ }^{17}$.

Cabe ao enfermeiro o conhecimento sobre a depressão pós-parto, uma vez que esses profissionais são a porta de entrada para o acolhimento e encaminhamento adequado da puérpera ou gestante, tanto no promoção e prevenção da parte fisiológica como da parte da saúde mental, a consulta de pré-natal é o momento em que o enfermeiro e a paciente tem a oportunidade de criar vínculo, sendo extremamente importante a relação de confiança e segurança entre o paciente e o profissional, e pra que esses encaminhamentos para os profissionais que atendem as demandas de saúde mental ocorram, o profissional precisa conhecer sobre o assunto e estar habilitado para detectar os casos, visto que a enfermagem atua na prevenção de forma que busca minimizar possíveis riscos de ocorrer uma depressão pós-parto ${ }^{14}$.

Além do cuidado com a mãe, é necessária a atenção para o bebê que tendem a se fazerem ouvir por meio sintomas psicossomáticos iniciando um ciclo de adoecimentos, as somatizações dos recém-nascidos não podem ser subestimadas no que envolve a relação entre a mãe e o bebê, a somatização é a forma que o bebê sinaliza o seu desconforto psíquico, que se estabelece devido o desconforto das pessoas que cuidam dele, refletindo 
o desconforto psíquico da mãe na maioria das vezes ${ }^{11}$.

A detecção precoce da depressão pós-parto através do acompanhamento das gestantes e puérperas é uma forma de cuidado não apenas com a mulher, mas também das repercussões na interação entre mãe e filho e a sua família ${ }^{5}$.

\section{CONSIDERAÇÕES FINAIS}

A depressão pós-parto atualmente é um grande problema de saúde pública, que atinge várias mulheres, porém diversas vezes é um assunto negligenciado, tanto pela falta de políticas públicas específica, como pela falta de material que traga esse assunto à tona.

É possível perceber através da fala da maioria das entrevistadas que esse problema de saúde mental é pouco abordado e que não se tem incentivo para uma educação continuada, mesmo sendo este um problema de grande impacto na vida da mulher e a sua família e que pode trazer prejuízos ao longo do desenvolvimento dos seu bebê.

A enfermagem é a porta de entrada para o acolhimento dessa gestante ou puérpera, é um dos profissionais que a paciente tem mais contato e as vezes o único por um longo período e com quem cria mais vínculo devido ao pré-natal. Porém é possível notar que a enfermagem não reconhece como a sua participação no diagnóstico da depressão pós-parto é importante e acaba focando apenas o seu atendimento na parte fisiológica e deixando de lado a avaliação da saúde mental dessa mulher.

Também é notável que a enfermagem não tem total conhecimento sobre ferramentas de avaliação da depressão pós-parto, sendo que existe a escala conhecida como Escala de Depressão Pós-Parto de Edimburgo, sendo esse um instrumento validado no Brasil, e que pode ser aplicado de forma simples e rápida.

Tanto a Escala de Depressão Pós-Parto de Edimburgo como o Pré-Natal Psicológico podem ser incorporados pelos enfermeiros, auxiliando dessa forma no cuidado prestado pela enfermagem para as mulheres.

A extremamente importante que esse assunto seja mais comentado, evidenciado e aprofundado, incentivando os profissionais da saúde a conhecer mais sobre o assunto e aplicar esse conhecimento durante o atendimento com as gestantes ou puérperas, dessa forma promovendo um acolhimento de forma integral.

Uma limitação para realização para o desenvolvimento desta pesquisa foi a necessidade de realizar as entrevistas em forma de chamada telefônica devido a pandemia do Sars-CoV-2.

\section{CONFLITO DE INTERESSES}

Nenhum conflito financeiro, legal ou político envolvendo terceiros (governo, empresas e fundações privadas etc.) foi declarado para nenhum aspecto do trabalho submetido (incluindo, mas não se limitando a subvenções e financiamentos, participação em conselho 
consultivo, desenho de estudo, preparação de manuscrito, análise estatística etc.).

\section{REFERÊNCIAS}

1. Organização Mundial da Saúde. (OMS). Depressão. 2020. Disponível em: https://www.who.int/es/ news-room/fact-sheets/detail/depression. Acesso em: 01 jun. 2021.

2. BRASIL. MINISTÉRIO DA SAÚDE. (org.). Depressão pós-parto. 2021. Disponível em: https://www. gov.br/saude/pt-br/assuntos/saude-de-a-a-z-1/d/depressao-pos-parto. Acesso em: 26 maio 2021.

\section{Brunner MAC. PREVALÊNCIA DA DEPRESSÃO PÓS-PARTO ENTRE MULHERES ASSISTIDAS NO AMBULATÓRIO DE PÓS-NATAL DO INSTITUTO FERNANDES FIGUEIRA - FIOCRUZ. 2011. 77 f. Dissertação (Mestrado) - Curso de Pós-Graduação em Saúde da Criança e da Mulher, Instituto Fernandes Figueira - Fiocruz, Rio de Janeiro, 2011. Disponível em: https://teses.icict.fiocruz.br/pdf/ Maria_Brunner.pdf. Acesso em: 04 jun. 2021.}

4. Figueira P, Corrêa H, Malloy-Diniz L, Romano-Silva MA. Escala de Depressão Pós-natal de Edimburgo para triagem no sistema público de saúde. Rev. Saúde Pública, [s. I.], 2009. Disponível em: https://www.scielo.br/pdf/rsp/v43s1/744.pdf. Acesso em: 30 de maio de 2021

5. Schmidt E B, Piccoloto NM, Müller MC. Depressão pós-parto: fatores de risco e repercussões no desenvolvimento infantil. Psico-Usf, Porto Alegre, v. 10, n. 1, p. 61-68, jan. 2005. Disponível em: https://www.scielo.br/j/pusf/a/6HnH84JM9TGFPRG7hhhwwnD/?lang=pt\&format=pdf. Acesso em: 04 jun. 2021.

6. Silva DC. Depressão Pós-Parto: O Papel do Enfermeiro Durante o Pré-Natal. Revista Científica Multidisciplinar Núcleo do Conhecimento. Ano 03, Ed. 08, Vol. 07, pp. 138-162, agosto de 2018. Acesso em: 30 maio 2021

7. BRASIL. Ministério da Saúde. Secretária da Atenção A Saúde (org.). ATENÇÃO AO PRÉ-NATAL DE BAIXO RISCO. Brasília: Editora do Ministério da Saúde, 2012. 316 p. Disponível em: http://bvsms. saude.gov.br/bvs/publicacoes/cadernos_atencao_basica_32_prenatal.pdf. Acesso em: 01 jun. 2021.

8. Minayo MCS, Deslandes SF, Gomes R. Pesquisa Social: Teoria, método e criatividade. 28. ed. rev. Petrópolis, RJ: Vozes, 2009. Disponível em: http://www.mobilizadores.org.br/wp-content/ uploads/2015/03/MINAYO-M.-Cec\%C3\%ADlia-org.-Pesquisa-social-teoria-m\%C3\%A9todo-ecriatividade.pdf. Acesso em: 23 out. 2020.

9. Minayo MCS. O desafio do conhecimento: pesquisa qualitativa em saúde. $9^{\mathrm{a}}$ ed. rev. e aprimorada. São Paulo: Hucitec, 2006.

10. Schmidt EB, et al. Depressão pós-parto: fatores de risco e repercussões no desenvolvimento infantil. Psico-Usf, Porto Alegre-Rs, p. 61-65, 19 maio 2005. Disponível em: https://www.scielo.br/j/ pusf/a/6HnH84JM9TGFPRG7hhhwwnD/?lang=pt. Acesso em: 01 jun. 2021.

11. laconelli V. DEPRESSÃO PÓS-PARTO, PSICOSE PÓS-PARTO E TRISTEZA MATERNA. Revista Pediatria Moderna, Pinheiros, v. 41, n. 4, p. 1-6, jul. 2005. Disponível em: http://institutogerar.com.br/ wp-content/uploads/2017/03/dpp-psicose-pos-parto-e-tristeza-materna.pdf. Acesso em: 04 jun. 2021. 
12. Arrais AR, Mourão MA, Fragalle B. O pré-natal psicológico como programa de prevenção à depressão pós-parto. Saúde e Sociedade, [S.L.], v. 23, n. 1, p. 251-264, mar. 2014. FapUNIFESP (SciELO). http://dx.doi.org/10.1590/s0104-12902014000100020. Disponível em: https://www.scielosp. org/pdf/sausoc/2014.v23n1/251-264/pt. Acesso em: 04 jun. 2021.

13. Arrais AR, Araujo TCCF. Pré-Natal Psicológico: perspectivas para atuação do psicólogo em saúde materna no Brasil. Sociedade Brasileira de Psicologia Hospitalar, Rio de Janeiro, v. 19, n. 1, p. 103-116, jan. 2016. Disponível em: http://pepsic.bvsalud.org/pdf/rsbph/v19n1/v19n1a07.pdf. Acesso em: 04 jun. 2021.

14. Silva CRA, Pereira GM, Jesus NB, Aoyama EA, Souto GR. DEPRESSÃo PÓS-PARTO: A IMPORTÂNCIA DA DETECÇÃO PRECOCE E INTERVENÇÕES DE ENFERMAGEM. Revista Brasileira Interdisciplinar de Saúde, Brasília, v. 2, n. 2, p. 12-19, 2020. Disponível em: https:// revistarebis.rebis.com.br/index.php/rebis/article/view/82/115. Acesso em: 04 jun. 2021.

15. GOIÁS. SECRETÁRIA DE ESTADO DE SAÚDE DO GOVERNO DO ESTADO DE GOIÁS. (org.). Depressão pós-parto. 2019. Disponível em: https://www.saude.go.gov.br/biblioteca/7594depress\%C3\%A3o-p\%C3\%B3s-parto\#g-footer. Acesso em: 26 maio 2021.

16. Lima NC, Ravelli APX, Floriano LSM, Vienscoski SS. DEPRESSÃo PÓS-PARTO BASEADA NA

ESCALA DE EDIMBURGO. Revista Conexao Uepg, [S.L.], v. 12, n. 2, p. 268-277, 2016. Universidade Estadual de Ponta Grossa (UEPG). http://dx.doi.org/10.5212/rev.conexao.v.12.i2.0008. Disponível em: http://www.revistas2.uepg.br/index.php/conexao. Acesso em: 04 jun. 2021.

17. Boska GA, Wisniewski D, Lentsck MH. Sintomas depressivos no período puerperal: identificação pela escala de depressão pós-parto de Edinburgh. Journal Of Nursing And Health, S.L, v. 1, n. 1, p. 38-50, 30 abr. 2016. Disponível em: https://periodicos.ufpel.edu.br/ojs2/index. php/enfermagem/article/viewFile/5525/5327. Acesso em: 04 jun. 2021. 


\section{O CUIDADO DE ENFERMAGEM COMO FERRAMENTA METODOLÓGICANA IDENTIFICAÇÃO PRECOCE DE GESTANTES EM RISCÓ PARA A DEPRESSÃO PÓS-PARTO}

Data de aceite: $20 / 08 / 2021$

Data de submissão: 06/07/2021

Fernanda Alves Pinto

Graduanda em Enfermagem pela Pontifícia

Universidade Católica de Campinas.

Pontifícia Universidade Católica de Campinas

Hortolândia - São Paulo

https://orcid.org/0000-0001-8142-6377

Mayra Roberta Faria de Moraes

Graduanda em Enfermagem pela Pontifícia

Universidade Católica de Campinas.

Pontifícia Universidade Católica de Campinas

Paraisópolis - Minas Gerais

https://orcid.org/0000-0002-2473-9067

RESUMO: Durante o período gestacional, a mulher é submetida a diversas transformações, sendo as fisiológicas mais visíveis. Porém, as alterações emocionais devem ser intensamente rastreadas, pois a incidência de transtornos psicológicos neste período é frequente. Neste âmbito, o acometimento mental mais expressivo é a depressão pós-parto, que segundo estudos da Fundação Oswaldo Cruz, acomete cerca de 25\% das mães brasileiras. O objetivo deste estudo é observar como o cuidado de enfermagem pode atuar de forma terapêutica na prevenção de casos de depressão pós-parto, observando sempre locais onde o profissional está inserido com a gestante, desde consultas pré-natais, o trabalho de parto e puerpério. Para a realização deste trabalho, executou-se uma busca de artigos científicos nas bases de dados SCIELO e Biblioteca Virtual em Saúde, em português, publicados no período de 2001 a 2021 . O critério de inclusão foi estar em conformidade com o tema proposto, e disponível na íntegra. No total, foram obtidos 15 artigos, mas apenas 6 utilizados, por serem os que se enquadram nos objetivos deste estudo, tendo sido incluídos também documentos oficiais do Ministério da Saúde que se relacionavam ao tema. Após a leitura e análise dos artigos e considerando o cuidado de enfermagem como uma possível ferramenta terapêutica para a identificação da depressão pós-parto, observou-se que com a proximidade do profissional e paciente nas consultas prénatais, pode-se identificar gestantes que possuam situações de vulnerabilidade para a doença e realizar encaminhamento para profissionais especializados, e também oferecer ações educativas em grupos, a fim de discutir sinais e sintomas como formas de promoção da saúde.

PALAVRAS - CHAVE: "Ações Educativas", "Depressão", "Depressão pós-parto", "Enfermagem", "Pré-natal".

\section{NURSING CARE AS A}

METHODOLOGICAL TOOL IN THE EARLY IDENTIFICATION OF PREGNANT WOMEN AT RISK FOR POSTPARTUM DEPRESSION

ABSTRACT: During the gestational period, the woman undergoes several transformations, the physiological being more visible one. However, emotional changes must be intensely tracked, because of the psychological disorders in this 
period is frequent. In this context, the most expressive mental impairment is postpartum depression, which, according to studies by the Oswaldo Cruz Foundation, affects around $25 \%$ of Brazilian mothers. The goal/objective of this study is to observe how nursing care can act therapeutically in the prevention of cases of postpartum depression, always observing places where the professional is inserted with the pregnant woman, from antenatal and labor. To develop this work, a search for scientific articles was performed in the SCIELO and Virtual Health Library databases, in Portuguese, published in the period 2001 to 2021 . The inclusion criteria of this project was to be in accordance with the proposed theme, and available in the media.In total, 15 articles were obtained, but only 6 were used, as they fit the objectives of this study. Official documents from the Ministry of Health were also included.After reading and analyzing the articles and considering nursing care as a possible therapeutic tool for the identification of postpartum depression, it could be observed that with the proximity of the medical staff and the patient in antenatal appointments, it was possible to identify pregnant women who were vulnerable to the disease and make referrals to specialized doctors, and also offer educational activities in groups, in order to discuss signs and symptoms as ways of health increase.

KEYWORDS: "Educational Actions", "Depression", "Postpartum Depression", "Nursing", "antenatal".

\section{INTRODUÇÃO}

Durante o período gestacional, a mulher é submetida a diversas transformações, sendo as fisiológicas mais visíveis. Neste cenário, a equipe de enfermagem adquire um vínculo com essa gestante que será atendida pelo serviço de saúde, excepcionalmente se a gestação for de risco habitual, onde as consultas pré-natais ficam a cargo do enfermeiro, e durante a realização destas, além de realizado o acompanhamento do desenvolvimento do feto, há um espaço para sanar dúvidas e realizar orientações importantes sobre a fase. Através da educação em saúde, a enfermagem é capaz de preparar a futura mãe para que esta seja inserida no contexto da maternidade e que esteja preparada para lidar com os novos desafios. Entretanto, além das modificações fisiológicas, o profissional deve ser capacitado a realizar o rastreio de alterações emocionais expressivas, pois a incidência de transtornos psicológicos neste período é frequente. Neste âmbito, o acometimento mental mais expressivo é a depressão pós-parto, que segundo estudos da Fundação Oswaldo Cruz, acomete mais de 25\% das mães brasileiras. (LEONEL, 2016)

Em linhas gerais, a depressão é caracterizada como um transtorno afetivo que acompanha os seres humanos desde os primórdios da sociedade (VIANA, FETTERMANN \& CESAR, 2020). Por acometer um alto número de pessoas, gerando gastos públicos consideráveis, no Brasil, a doença é considerada um problema de saúde pública (VIANA, FETTERMANN \& CESAR, 2020). Excepcionalmente na realidade feminina, a depressão apresenta números maiores em acometimento, o que pode advir de cobranças sociais, como as relacionadas ao comportamento. Em um contexto de maternidade, o risco se 
agrava, pois surge a constante necessidade de estar disponível para desempenhar múltiplas tarefas, concomitantemente à questão psicológica de lidar com uma nova pessoa que será totalmente dependente dela. (VIANA, FETTERMANN \& CESAR, 2020).

$\mathrm{Na}$ depressão pós-parto, o aparecimento de sinais e sintomas se dá, geralmente, entre a quarta e a oitava semana do puerpério, mas não a caráter de regra, estes podem aparecer até os primeiros doze meses de vida do bebê, podendo persistir por mais de um ano. (SCHIMIDT, PICOLOTO \& MULLER, 2005). Caracterizada como leve e grave, a primeira ocorre nos primeiros dias após o parto e desaparecendo até o décimo quinto, trazendo sintomas como a irritabilidade e uma sensibilidade maior perante os elementos que compõem as emoções. Na forma grave, as mulheres mais suscetíveis e possivelmente acometidas são as que apresentam prolongamento dos sinais e sintomas e histórico de doenças psiquiátricas pregressas ou familiares (VIANA, FETTERMANN \& CESAR, 2020).

A puérpera também está sujeita a outros dois principais tipos de acometimentos mentais, o baby blues e a psicose puerperal. O primeiro, também conhecido como "melancolia da maternidade" geralmente ocorre enquanto a mulher ainda está inserida na unidade de saúde, ou quando acaba de voltar para casa, entre o segundo e o quarto dia após o parto. É um período caracterizado por emoções efêmeras, que possuem remissão espontânea. Já a psicose caracteriza-se por sintomas mais graves e intensos, incluindo delírios, que podem levar ao medo contínuo de situações que possam ferir a integridade do recém-nascido, a até mesmo a prática do infanticídio (SCHIMIDT, PICOLOTO \& MULLER, 2005). Contudo, não somente no diagnóstico definido de depressão pós-parto, o monitoramento e cuidado da enfermagem são incisivamente necessários também nestes casos, acionando ações multiprofissionais em todas as situações que apresentem grandes riscos.

Por fim, este trabalho desenvolvido em forma de revisão integrativa buscou abordar como o cuidado de enfermagem pode ser utilizado como uma ferramenta na identificação precoce de gestantes em risco para o desenvolvimento da depressão pósparto, contemplando todas as áreas em que o enfermeiro estará inserido com a mulher, e se atentando a todos os aspectos do cotidiano que são afetados e modificados perante a presença da doença.

\section{METODOLOGIA}

Para a realização deste trabalho, executou-se uma busca de artigos científicos nas bases de dados SCIELO e Biblioteca Virtual em Saúde, em português, publicados no período de 2001 a 2021. O critério de inclusão foi estar em conformidade com o tema proposto, e disponível na íntegra. No total, foram obtidos 15 artigos, mas apenas 9 utilizados, por serem os que se enquadram nos objetivos deste estudo, tendo sido incluídos também documentos oficiais do Ministério da Saúde que se relacionavam ao tema. 


\section{SINAIS E SINTOMAS}

A sintomatologia da depressão pós-parto pode ser entendida como psicossomática, pois além de afetarem mentalmente a mulher, os sintomas da doença trazem também prejuízos à fisiologia dos sistemas corporais. De maneira geral, alterações de sono, perda do apetite e cansaço são comuns no puerpério, mas quando estes são observados de maneira mais intensa e combinados com sentimento de culpa, desinteresse sexual, demonstrações de apatia frente a realização de atividades diárias, sentimento de incapacidade para lidar com a maternidade aliada a desesperança sobre aspectos de melhora, pensamentos suicidas (VIANA, FETTERMANN \& CESAR, 2020), e acometimentos corporais sem causa orgânica aparente (SCHIMIDT, PICOLOTO \& MULLER, 2005), há um risco aumentado para um posterior diagnóstico clínico de DPP.

De maneira geral, estes sintomas sempre irão se alinhar com o contexto da maternidade, destacando-se os episódios de preocupação excessiva com o bem-estar e saúde do bebê, onde o agravante é a desconexão com a realidade, em especial, a ocorrência de delírios. (SCHIMIDT, PICOLOTO \& MULLER, 2005)

Ainda sendo uma doença que tem seu acometimento exclusivo no puerpério, durante o pré-natal é possível realizar buscas por possíveis fatores predisponentes a desencadear a condição no futuro. No primeiro trimestre da gestação é comum que as pacientes apresentem sintomas depressivos ((DELL'OSBEL, GREGOLETTO \& CREMONESE, 2019), que podem estar associados desde uma gravidez indesejada, a falta de apoio familiar ou conjugal, ou a preocupação com as formas de enfrentamento a uma nova condição de vida (SCHIMIDT, PICOLOTO \& MULLER, 2005). Entretanto, mediante acompanhamento profissional, notase que ao decorrer da gravidez esses sintomas tomam proporções brandas.

Complementar a isso, no acompanhamento inicial da gestação é fundamental que o profissional realize uma coleta de dados detalhada sobre antecedentes familiares e pessoais de transtornos mentais, bem como o uso de medicações contínuas e também sobre as condições sociais da gestante. Este último fator deve ser observado tanto no âmbito familiar, quanto no financeiro, visto que a baixa classe econômica é um grande fator predisponente à DPP (ALOISE, FERREIRA \& LIMA, 2019), e o baixo apoio familiar pode intensificar alguns sintomas depressivos, como a solidão.

Contudo, ainda na atenção básica, mediante obtenção de conhecimento técnico e científico, e seguindo a primeira etapa do processo de enfermagem, através dos sinais relatados pela mulher e pelos sintomas observados, o enfermeiro deve ser capaz de identificar possíveis sinais que se relacionem a quadros de DPP, tomando as condutas de enfermagem cabíveis a cada caso e acionando a equipe multidisciplinar sempre quando necessário. 


\section{O IMPACTO SOBRE A CRIANÇA}

Não somente relacionada à saúde materna, a DPP também traz prejuízos ao lactente, e alguns dos exemplos vastamente observados dentre os casos é a deficiência que acomete o vínculo mãe-filho e danos causados à saúde e desenvolvimento da criança. Em seu primeiro ano de vida, por exemplo, ao ter sua provedora adoecida mentalmente, mesmo que fisicamente esta esteja presente, a criança terá de passar por uma perda emocional, pois à medida que surjam manifestações clínicas da doença, esta mãe estará cada vez mais distante afetivamente. (SCHWENGBER \& PICCININI, 2003)

Perante a nutrição do bebê, sabe-se que a amamentação reduz os níveis de mortalidade infantil em até $13 \%$, e concomitantemente diminui a ocorrência de alergias, infecções, diarreia, doenças respiratórias, diabetes mellitus tipo 2, dentre outras patologias (BRASIL, 2020). Porém, estudos comprovam que em situações em que a mãe está deprimida, os índices de aleitamento caem, ou são menores em tempo de oferta quando comparados aos de mães não deprimidas. (FIGUEIREDO \& ET AL, 2013)

Observa-se também a presença de distúrbios cognitivos e socioemocionais em filhos de mães acometidas pela depressão pós-parto. O prolongamento do quadro de DPP pode desencadear uma redução na afetividade com a pessoa que a criança provavelmente possuirá maior convívio, o que também concomitantemente poderá acarretar possíveis prejuízos intelectuais para a idade, visto que todo o desenvolvimento será prejudicado. (SCHIMIDT, PICOLOTO \& MULLER, 2005)

Neste cenário, o cuidado de enfermagem além de atuar na prevenção durante o prénatal, quando em casos de depressão já instalados, deve englobar todas as necessidades da criança, junto ao tratamento materno. O estímulo ao aleitamento deve ser algo frequente, pois além dos benefícios nutricionais para o lactente, a mãe pode ter um benefício em seu quadro clínico devido a ação hormonal envolvida. Ocitocina e prolactina, por exemplo, estão envoltos em processos fisiológicos antidepressivos e ansiolíticos, e há ainda a ação do cortisol, que por processos neuroendócrinos pode reduzir a sintomatologia depressiva no pós-parto. (FIGUEIREDO \& ET AL, 2013). O fortalecimento do vínculo entre mãe e filho também pode ser trabalhado pela enfermagem, com atenção principal ao momento da amamentação, mas não esquecendo a interação nas atividades diárias.

\section{CONSIDERAÇÕES FINAIS}

Com a realização deste estudo, foi possível identificar o papel do enfermeiro frente a gestantes e puérperas acometidas pela depressão pós-parto, e essencialmente no prénatal, aplicar o cuidado de enfermagem como uma ferramenta na prevenção de novos casos.

Os métodos utilizados podem ser de caráter terapêutico ou informativo. O primeiro acontecerá quando o enfermeiro realizar a coleta de dados e observar fatores de risco, como 
antecedentes predisponentes, ou sintomas depressivos já instalados. Nestes cenários, as ações irão variar a depender do grau de complexibilidade de cada caso e até quais pontos a conduta de enfermagem poderá intervir perante o respaldo legal, além de que, sabendo identificar estes fatores, o profissional saberá quando acionar a equipe multiprofissional.

Promover meios para que a gestante conheça a doença, seus sinais e sintomas e todos os fatores relacionados garante que esta possua recursos para a prática do autocuidado e para saber em quais momentos o auxílio profissional é necessário. Uma alternativa cabível neste método são as ações educativas, muito trabalhada por enfermeiros nos níveis de atenção à saúde, e que são grandes meios para se promover a educação para a população. Este método de educação em saúde consiste em integrar a equipe de saúde, os usuários e os representantes da população para definir ações conjuntas para resolver problemas e modificar situações.

Utilizada pela enfermagem na prevenção da depressão pós-parto, é fundamental que a ação educativa seja bem estruturada, para que as metas sejam alcançadas. Primeiramente, deve-se diagnosticar a suscetibilidade dessas gestantes, para assim delinear justificativa e objetivos para a ação. Recursos e um cronograma de atividades bem definido também são necessários, visto que para ser trabalhado de uma forma mais didática e informativa, apresentar a doença de forma esquematizada e lúdica pode transformar o aprendizado em algo leve. Por fim, é imprescindível que ao final da ação educativa, o enfermeiro faça a avaliação dos resultados obtidos, que poderão ser observados através da análise dos conhecimentos adquiridos pela gestante, e também pelo rastreio de puérperas acometidas que tenham passado pelo processo de educação em saúde e souberam identificar quando buscar ajuda profissional.

\section{REFERÊNCIAS}

ALOISE, Sarah Regina; FERREIRA, Alaidistania Aparecida; LIMA, Raquel Faria da Silva. Depressão Pós-Parto: Identificação De Sinais, Sintomas e Fatores Associados em Maternidade De Referência Em Manaus, Enferm. Foco 2019; 10 (3): 41-45. Disponível em: <https://pesquisa.bvsalud. org/portal/resource/pt/biblio-1049782>. Acesso em 01 de julho de 2021.

DELL'OSBEL, Rafaela Santi; GREGOLETTO, Maria Luisa de Oliveira; CREMONESE, Cleber. Sintomas depressivos em gestantes da atenção básica: prevalência e fatores associados, ABCS Health Sci. 2019; 44(3):187-194. Disponível em: <https://docs.bvsalud.org/ biblioref/2020/01/1047751/44abcs187.pdf>. Acesso em 05 de julho de 2021.

FIGUEIREDO, Bárbara; et al. Amamentação e depressão pós-parto: revisão do estado de arte, J Pediatr (Rio J). 2013;89(4):332-8. Disponível em <https://www.scielo.br/j/jped/a/ fXfSZDzc6cZDDTW5mPLrsbG/?format=pdf\&lang=pt>. Acesso em 04 de julho de 2021.

LEONEL, Felipe. Depressão pós-parto acomete mais de $25 \%$ das mães no Brasil, Portal Fiocruz, 2016. Disponível em: <https://portal.fiocruz.br/noticia/depressao-pos-parto-acomete-mais-de-25-dasmaes-no-brasil>. Acesso em 01 de julho de 2021. 
Ministério da Saúde lança campanha de incentivo à amamentação, Governo do Brasil, 2020. Disponível em: <https://www.gov.br/pt-br/noticias/saude-e-vigilancia-sanitaria/2020/08/ministerio-dasaude-lanca-campanha-de-incentivo-a-amamentacao>. Acesso em 04 de julho de 2021.

SCHMIDT, Eluisa Bordin; PICOLOTO, Neri Maurício; MULLER, Marisa Campio. Depressão Pós-Parto: Fatores de Risco e Repercussões no Desenvolvimento Infantil, Psico-USF, v. 10, n. 1, p. 61-68, jan./jun. 2005. Disponível em: <https://www.scielo.br/j/pusf/a/6HnH84JM9TGFPRG7hhhwwnD/?lang= pt>. Acesso em 01 de julho de 2021.

SCHWENGBER, Daniela Delias de Sousa; PICCININI, Cesar Augusto. 0 impacto da depressão pósparto para a interação mãe-bebê, Estudos de Psicologia 2003, 8(3), 403-411. Disponível em: <https:// lume.ufrgs.br/bitstream/handle/10183/23160/000436134.pdf?sequence=1\&isAllowed=y $>$. Acesso em 04 de julho de 2021.

VIANA, Mariana Delli Zotti Souza; FETTERMANN, Fernanda Almeida; CESAR, Mônica Bimbatti Nogueira. Estratégias de Enfermagem na Prevenção da Depressão Pós-Parto, Rev. Pesqui. (Univ. Fed. Estado Rio J., Online), 2020. Disponível em: <https://pesquisa.bvsalud.org/portal/resource/pt/ biblio-1116274>. Acesso em 01 de julho de 2021. 


\section{CAPÍTULO 12 \\ BENEFÍCIOS DO CONTATO PELE A PELE ENTRE MÃE E BEBÊ NA UTI NEONATAL}

Data de aceite: 20/08/2021

Data da submissão: 06/07/2021

Suellen da Rocha Lage Moraes Centro Universitário Santa Cruz de Curitiba UniSantaCruz Curitiba - Paraná http://lattes.cnpq.br/4956814912404355

\section{Bianca Aparecida do Prado} Centro Universitário Santa Cruz de Curitiba UniSantaCruz Curitiba - Paraná http://lattes.cnpq.br/0521690464858798

Isis Vanessa Nazareth

Universidade Federal do Rio de JaneiroCampus Professor Aluísio Teixeira -Macaé) Macaé- Rio de Janeiro http://lattes.cnpq.br/2055438097841567

Larissa Marcondes Centro Universitário Santa Cruz de Curitiba UniSantaCruz Curitiba - Paraná http://lattes.cnpq.br/8872918972882126

Gislayne Castro e Souza de Nieto Hospital Brígida Curitiba - Paraná http://lattes.cnpq.br/6780218366690273

RESUMO: Objetivo: evidenciar os benefícios do contato pele a pele entre mãe e bebê internado em Unidade de Terapia Intensiva Neonatal de uma maternidade da rede privada do município de Curitiba-PR. Método: pesquisa descritiva com abordagem qualitativa, com 21 participantes, sendo 10 mães e 11 recémnascidos e, a coleta de dados entre março e maio de 2021. Resultados informa- se que emergiram duas categorias analíticas: Contato pele a pele fortalecendo o vínculo entre mãe e bebê e favorecendo o Aleitamento Materno para Recém-nascido Prematuro na Unidade de Terapia Intensiva Neonatal e, Contato pele a pele benefícios neuropsicomotores ao Recémnascido Prematuro. Conclusão: com essa pesquisa pode-se comprovar os benefícios que o contato pele a pele traz para mãe e o recémnascido prematuro internado na Unidade de Terapia Intensiva Neonatal, contribuindo para implementação desta prática em outras Unidades de Terapia Intensiva Neonatal.

PALAVRAS - CHAVE Enfermagem Neonatal; Unidade de Terapia Intensiva Neonatal; Prematuro.

\section{BENEFITS OF SKIN-TO-SKIN CONTACT BETWEEN MOTHER AND BABY IN NEONATAL ICU}

ABSTRACT: Objective: evince the benefits of skin-to-skin contact between mother and baby admitted to the Neonatal Intensive Care Unit of a private maternity hospital in the city of Curitiba-PR. Method: descriptive research with a qualitative approach, with 21 participants, 10 mothers and 11 newborns, and data collection between March and May 2021. Results: it is reported that two 
analytical categories emerged Skin-to-skin contact strengthening the bond between mother and baby and favoring Breastfeeding for Premature Newborns in the Neonatal Intensive Care Unit and, Skin-to-skin contact, neuropsychomotor benefits to Premature Newborns. Conclusion: this research can prove the benefits that skin-to-skin contact brings to the mother and the premature newborn admitted to the Neonatal Intensive Care Unit, contributing to the implementation of this practice in other Neonatal Intensive Care Units.

KEYWORDS: Neonatal Nursing; Neonatal Intensive Care Unit; Premature.

\section{I INTRODUÇÃO}

A Unidade de Terapia Intensiva Neonatal (UTIN) é um serviço de internação responsável pelo cuidado integral ao recém-nascido $(R N)$ grave ou potencialmente grave, dotado de estruturas assistenciais que possuem condições técnicas adequadas à prestação de assistência especializada, incluindo instalações físicas, equipamentos e recursos humanos (BRASIL, 2017).

São considerados recém-nascidos prematuros (RNPT), os nascidos com idade gestacional menor que 37 semanas. Esses ainda podem ser divididos em subcategorias, a saber: Pré-termo tardio (entre 34 semanas e 36 semanas e 6 dias); Pré-termo moderado (entre 32 semanas e 33 semanas e 6 dias); Muito pré-termo, (28 semanas a 31 semanas e 6 dias) e Pré-termo extremo, menor que 28 semanas (SBP, 2019).

O ambiente da UTIN é muitas vezes estressante para os bebês e suas mães, pois em geral, trata-se de um ambiente muito iluminado e ruidoso. Além disso, as intervenções realizadas acabam sendo dolorosas e causando desconforto, como por exemplo, punção, aspiração de vias aéreas, troca de fralda e alimentação, o que demanda muita energia e uma demora para que o $\mathrm{RN}$ retorne ao estado de equilíbrio emocional e fisiológico de antes das intervenções (MOREIRA et al.,2003a).

Ao entrarem na UTIN pela primeira vez, as mães experimentam um misto de sensações, dentre as quais perplexidade e medo em face de uma realidade tão distante daquela idealizada inicialmente para o seu bebê. A separação pelo período de internação dificulta o estreitamento do vínculo materno e traz incertezas sobre a saúde do RN. Para minimizar o potencial estressor fisiológico e emocional, preconiza-se o contato pele a pele entre mãe e bebê o mais precocemente, com finalidade de desencadear uma série de sentimentos e comportamentos que beneficiam tanto a mãe quanto o bebê (MOREIRA et al., 2003b).

A partir deste levantamento elaborou-se um questionamento que pudesse nortear o estudo: Quais benefícios o contato pele a pele traz para mãe e bebê internado em uma Unidade de Terapia Intensiva Neonatal?

A fim de captar a realidade estudada tem-se por objetivo, evidenciar os benefícios do contato pele a pele entre mãe e bebê internado em Unidade de Terapia Intensiva Neonatal 
em uma maternidade da rede privada do município de Curitiba-PR. Sendo assim, esse presente estudo visa incentivar o contato pele a pele entre a mãe e o $\mathrm{RN}$, e identificar a sua contribuição para a saúde do RNPT e para o estreitamento do vínculo.

\section{I MÉTODO}

Trata-se de um estudo descritivo exploratório de natureza qualitativa. A pesquisa descritiva, "descreve" de maneira fiel uma realidade, sem necessariamente interferir sobre ela. Por conta disso, esta modalidade de pesquisa sempre vem acompanhada de especificações em termos de quem, o que, quando, onde, por que e como determinado fenômeno se apresenta na realidade. (MALHOTRA, 2012).

O presente estudo foi conduzido nas dependências da Unidade de Terapia Intensiva Neonatal de um hospital privado do município de Curitiba. Os sujeitos da pesquisa foram 10 mães, sendo uma, mãe de gemelar e, 11 RN's com idade gestacional abaixo de 37 semanas de gestação que realizaram contato pele a pele enquanto os mesmos se encontravam internados na UTIN.

Critérios de inclusão foram mães de bebês nascidos prematuros, de ambos os sexos, com permanência de internação igual ou superior a 7 dias na UTIN, com idade gestacional abaixo de 37 semanas e com convivência familiar. Os critérios de exclusão foram RNPT que apresentassem diagnóstico médico de doenças genéticas que comprometam o desenvolvimento neuropsicomotor uma vez que impossibilitaria a avaliação do seu desenvolvimento.

Para produção de dados foram elaborados três instrumentos. O primeiro foi um formulário com perguntas fechadas para caracterização das mães quanto ao perfil socioeconômico, o segundo constou com duas questões norteadoras da entrevista que foram gravadas por um aplicativo de áudio: "Você acha importante colocar o seu bebê em contato pele a pele junto com você durante a permanência dele na Unidade de Terapia Intensiva Neonatal?" E "Como você se sentiu quando seu bebê foi colocado em contato pele a pele com você? ". E, o terceiro para a coleta de dados dos RN's através dos prontuários. O período da coleta de dados ocorreu entre os meses de março a maio de 2021.

Os RN's foram colocados em contato pele a pele com suas mães por um tempo mínimo de 1 hora com auxílio de um colete que traz segurança e conforto para ambos, confeccionado em tecido Brin, de fácil retirada em casos de emergência com RN. O contato pele a pele ocorreu em dias alternados devido as condições de saúde que RNPT demandam e as medidas restritivas que vivenciamos devido a pandemia de COVID- 19.

As entrevistas ocorreram em uma sala reservada da UTIN, com tempo médio de 20 minutos. Os dados coletados foram analisados através da Análise de Conteúdo de Bardin. Esta é uma técnica caracterizada como um conjunto de técnicas de análise das comunicações, que pode expressar uma análise de significados a análise temática, como 
também uma análise dos significantes léxico e dos procedimentos. (BARDIN, 2010).

Após a coleta dos depoimentos, os mesmos foram transcritos em sua íntegra onde no primeiro momento foi realizado uma leitura flutuante, deixando-se impregnar pelo seu conteúdo. No segundo momento, foram realizadas leituras a fim de localizar as unidades de significados para a construção das categorias. Os dados dos RN's foram copilados e analisados através de tabelas, sendo utilizado o programa Microsoft Office Exce® para sua construção.

O estudo foi submetido ao Comitê de Ética do Hospital Paranaense de Otorrinolaringologia - IPO conforme a resolução 466/12 de Diretrizes e Normas Regulamentadoras da Pesquisa com Seres Humanos do Conselho Nacional de Saúde sendo aprovado com o parecer $n^{\circ} 4.576 .079$, sem ressalvas.

As mães selecionadas foram informadas sobre a pesquisa, seus objetivos e método, ficando livres para participarem ou não; podendo desistir de sua participação ou de seu RN em qualquer momento do estudo e sua negativa não teria danos na assistência prestada aos seus RN`s. Após esclarecimento e aceite, as participantes foram convidadas a assinar o Termo de Consentimento Livre e Esclarecido (TCLE). Afim de manter o anonimato das mães e seus respectivos RN's, utilizou-se a letra E para identificação das mães e RN para os recém-nascidos, seguido de números, E1 a E10 e RN1 a RN 11.

\section{I RESULTADOS}

Para melhor visualização e discussão dos dados, o Quadro 1 fornece a caracterização das mães contendo os seguintes tópicos: pseudônimo, idade, estado civil, religião, grau de instrução e antecedentes obstétricos. 


\begin{tabular}{|c|c|c|c|c|c|}
\hline Pseudônimo & \begin{tabular}{|l|} 
Idade \\
(anos)
\end{tabular} & $\begin{array}{c}\text { Estado } \\
\text { Civil }\end{array}$ & Religião & $\begin{array}{c}\text { Grau de } \\
\text { instrução }\end{array}$ & $\begin{array}{c}\text { Antecedentes } \\
\text { Obstétricos }\end{array}$ \\
\hline E1 & 35 & Casada & Católica & $\begin{array}{l}\text { Superior } \\
\text { completo }\end{array}$ & G1P0C0A0 \\
\hline E2 & 38 & Casada & Católica & $\begin{array}{l}\text { Superior } \\
\text { completo }\end{array}$ & G1P0C0A0 \\
\hline E3 & 27 & Casada & Católica & $\begin{array}{l}\text { Superior } \\
\text { completo }\end{array}$ & $\mathrm{G} 1 \mathrm{P} 0 \mathrm{C} 0 \mathrm{~A} 0$ \\
\hline E4 & 28 & $\begin{array}{l}\text { União } \\
\text { estável }\end{array}$ & Católica & $\begin{array}{c}\text { Superior } \\
\text { incompleto }\end{array}$ & G1P0C0A0 \\
\hline E5 & 29 & Casada & Católica & $\begin{array}{l}\text { Superior } \\
\text { completo }\end{array}$ & G1P0C0A0 \\
\hline E6 & 40 & Casada & Católica & $\begin{array}{l}\text { Superior } \\
\text { completo }\end{array}$ & $\mathrm{G} 2 \mathrm{P} 0 \mathrm{C} 1 \mathrm{~A} 0$ \\
\hline E7 & 30 & Casada & Católica & $\begin{array}{c}1^{\circ} \text { grau } \\
\text { incompleto }\end{array}$ & $\mathrm{G} 2 \mathrm{P} 1 \mathrm{C} 0 \mathrm{~A} 0$ \\
\hline E8 & 22 & $\begin{array}{l}\text { União } \\
\text { estável }\end{array}$ & Católica & $\begin{array}{c}\text { Superior } \\
\text { incompleto }\end{array}$ & G1P0A0C0 \\
\hline E9 & 28 & Casada & Católica & $\begin{array}{l}\text { Superior } \\
\text { completo }\end{array}$ & G1P0C0A0E 1 \\
\hline $\mathrm{E} 10^{*}$ & 32 & Casada & Espiritualista & $\begin{array}{l}\text { Superior } \\
\text { completo }\end{array}$ & G1P0C0A0 \\
\hline
\end{tabular}

Quadro 1 - Caracterização das mães, Curitiba, PR, 2021

${ }^{*}$ Gravidez de gemelar

Legenda: G- Gestação, P- Parto, C- Cesária, A- Aborto, E- gestação ectópica.

Fonte: Elaborada pelas autoras, 2021

O Quadro 2 fornece dados dos recém-nascidos internados na Unidade de Terapia Intensiva Neonatal como: data da internação na UTIN, motivo da internação, idade gestacional, dados de padrão ventilatório, dias de internamento. 


\begin{tabular}{|c|c|c|c|c|c|}
\hline Pseudônimo & $\begin{array}{c}\text { Data } \\
\text { internação } \\
\text { na UTIN }\end{array}$ & $\begin{array}{c}\text { Motivo do } \\
\text { internamento }\end{array}$ & $\begin{array}{c}\text { Idade } \\
\text { gestacional }\end{array}$ & $\begin{array}{c}\text { Padrão } \\
\text { ventilatório }\end{array}$ & $\begin{array}{c}\text { Dias de } \\
\text { internamento }\end{array}$ \\
\hline RN1 & $08 / 03 / 2021$ & $\begin{array}{c}\text { RNPT, AIG, DRP, } \\
\text { tocotraumatismo }\end{array}$ & 31 semanas & CPAP & 25 dias \\
\hline RN2 & $13 / 02 / 2021$ & RNPT, RCIU, DRP & 31 semanas & NIPPV & 34 dias \\
\hline RN3 & $23 / 03 / 2021$ & $\begin{array}{c}\text { RNPT, AIG, DRP } \\
\text { RN4 }\end{array}$ & $\begin{array}{c}28 \text { semanas+3 } \\
\text { dias }\end{array}$ & NIPPV & 19 dias \\
\hline RN5 & $06 / 04 / 2021$ & $\begin{array}{c}\text { RNPT Extremo, AIG, } \\
\text { Asfixia neonatal }\end{array}$ & $\begin{array}{c}30 \text { semanas+6 } \\
\text { dias }\end{array}$ & $\begin{array}{c}\text { Ventilação } \\
\text { mecânica }\end{array}$ & 29 dias \\
\hline tocotraumatismo, \\
RN6
\end{tabular}

Quadro 2 - Caracterização dos Recém-nascidos internados na Unidade de Terapia Intensiva Neonatal, Curitiba, PR, 2021.

Legenda: RNPT- Recém-nascido Prematuro; AIG-Adequado para idade gestacional; DRP- Distress respiratório; RCIU- Restrição de Crescimento Intrauterino; MBPN - Muito baixo peso ao nascer; PIG-

Pequeno para idade gestacional; NIPPV- Nasal Intermittent positive Pressure Ventilation.; CPAP-

Continous Positive Airway Pressure;

Fonte: Elaborada pelas autoras, 2021.

O Quadro 3 fornece dados dos RN's e o contato pele a pele como: pseudônimo, Período e frequência que foi realizado o contato pele a pele, Peso ao nascer, ao iniciar o contato pele a pele e na alta da UTIN. 


\begin{tabular}{|c|c|c|c|c|}
\hline Pseudônimo & $\begin{array}{c}\text { Período contato } \\
\text { pele a pele }\end{array}$ & Peso ao nascer & $\begin{array}{c}\text { Peso ao iniciar } \\
\text { contato pele a } \\
\text { pele }\end{array}$ & Peso de alta \\
\hline RN1 & 22 dias & $1300 \mathrm{~g}$ & $1330 \mathrm{~g}$ & $1960 \mathrm{~g}$ \\
\hline RN2 & 9 dias & $1100 \mathrm{~g}$ & $1525 \mathrm{~g}$ & $1750 \mathrm{~g}$ \\
\hline RN3 & 17 dias & $1225 \mathrm{~g}$ & $1225 \mathrm{~g}$ & $\begin{array}{c}1320 \mathrm{~g} \text { (transferência } \\
\text { UTI Pediátrica) }\end{array}$ \\
\hline RN4 & 60 dias & $825 \mathrm{~g}$ & $770 \mathrm{~g}$ & $2020 \mathrm{~g}$ \\
\hline RN5 & 23 dias & $1470 \mathrm{~g}$ & $1400 \mathrm{~g}$ & $1915 \mathrm{~g}$ \\
\hline RN6 & 15 dias & $1755 \mathrm{~g}$ & $1640 \mathrm{~g}$ & $1955 \mathrm{~g}$ \\
\hline RN7 & 11 dias & $1875 \mathrm{~g}$ & $1810 \mathrm{~g}$ & $1910 \mathrm{~g}$ \\
\hline RN8 & 9 dias & $1700 \mathrm{~g}$ & $1665 \mathrm{~g}$ & $1910 \mathrm{~g}$ \\
\hline RN9 & 14 dias & $1520 \mathrm{~g}$ & $1465 \mathrm{~g}$ & $1915 \mathrm{~g}$ \\
\hline RN10 & 10 dias & $1630 \mathrm{~g}$ & $1570 \mathrm{~g}$ & $1790 \mathrm{~g}$ \\
\hline RN11 & 9 dias & $1815 \mathrm{~g}$ & & $1935 \mathrm{~g}$ \\
\hline
\end{tabular}

Quadro 3 - Dados dos Recém-nascidos e contato pele a pele realizados na Unidade de Terapia Intensiva Neonatal, Curitiba, PR, 2021

Fonte: Elaborada pelas autoras, 2021.

\section{I DISCUSSÃO}

Contato pele a pele fortalecendo o vínculo entre mãe e bebê e favorecendo o Aleitamento Materno para Recém-nascido Prematuro na Unidade de Terapia Intensiva Neonatal

A relação entre mãe e bebê existe desde antes do nascimento, nas fantasias das mulheres, que são associadas com a possibilidade de gerar um filho. Essa fantasia criada do bebê imaginário acontece de acordo com cada casal e geralmente ocorre no segundo trimestre da gravidez. Por fim, com o nascimento diferente do bebê idealizado, causam medos, inseguranças e incertezas em relação ao bebê real. (ANTUNES, PATROCINIO, 2007; CARVALHO et al, 2017).

[...] você nunca vai estar preparado para sair do hospital sem teu filho, nunca vai estar preparada para deixá-lo tão pequeno com pessoas que você nunca viu na vida, você acredita que as pessoas sejam de bem, mas não é isso que você deseja. (E2). [...] o deixar o bebê aqui é um sofrimento antes da gente chegar em casa, estar em casa sem o bebê é um sofrimento (E5). 
A palavra vínculo, é muito utilizada para abordar o estabelecimento e o desenrolar da relação mãe e bebê. Durante a construção do vínculo, a mãe espera que seu filho supra seu desejo de ser mãe. Isto é possível pelas hipóteses que ela tece a respeito do suposto endereçamento de uma demanda de amor e reconhecimento. O contato pele a pele, possibilita a interação entre mãe e bebê de forma positiva, ainda no ambiente hospitalar, com maiores demonstrações de afeto, bem como maior estado de alerta dos bebês prétermo. Afora isso, as mães tendem a perceber seus bebês como menos vulneráveis e demonstram menores índices de depressão. (CARVALHO et al, 2017). A mãe E6, após uma perda neonatal prévia e a oportunidade de contato pele a pele com segundo filho ainda na UTIN, traz em sua fala o quanto foi importante esse contato para construção do vínculo e o sentir-se mãe.

[...]uma palavra que pode definir eu me senti mãe (risos), eu acho que foi um sentimento que vai além de falar palavras né? E contar o que realmente é que para mim, no meu caso foi um sentimento de renascimento, eu renasci por já ter perdido uma na UTI né, e não ter tido essa oportunidade de pegar ela no colo viva e bem. Então para mim, é um sentimento de renascimento, hoje eu sou uma nova mãe. (E6).

O contato pele a pele promove para as mães uma maior afetividade entre mãe e bebê, diminuição do estresse, redução da ansiedade, aumento na autonomia dos cuidados. Destarte, o contato pele a pele é uma forma de acolher a mãe, pois nessa etapa a mãe tem oportunidade de se aproximar das rotinas da UTIN e vencer os medos decorrentes da complexidade tecnológica e da dinâmica do serviço. Deve-se estimular o contato pele a pele a fim de diminuir essas incertezas maternas (CANTANHEDE et al., 2020; SANTOS et al., 2013).

"Eu me senti mãe porque até então eu só tinha visto ele pelo vidro, mas quando eu peguei, eu falei 'caraca', eu sou mãe, agora é minha vez né? Agora eu posso me acalmar. E a minha pressão estava alta até agora. E eu senti que quando eu comecei a pega- ló, minha pressão não aumentou demais, sempre tá alta, mas está estabilizando mais rápido do que quando eu não o pegava, e eu sinto que ele fica mais calminho no meu colo também" (E1)

[...] eu acho muito importante esse contato que a gente tem com o bebê, pele a pele né? Até pelo sentimento que isso traz para nós. A mãe que tem o bebê na UTI Neonatal, ela fica muito apreensiva, muito nervosa, muito insegura não sabe o que está acontecendo com o bebê o que vai acontecer daqui para a frente. Então esse contato pele a pele, traz maior segurança para a mãe, é um acalento na verdade, porque a gente fica mais segura, fica mais tranquila, fica mais feliz. Aquela sensação de choro interminável, ela acaba passando quando o bebê está em contato pele a pele conosco, é bem importante mesmo. (E5)."

[...]quando você colocou o canguru com ele em pele a pele o jeito que o canguru ficou é como se fosse minha barriga sabe? Tipo redondinho, assim, era isso que eu tinha de novo, tipo prótese de alguém amputado. Para mim isso foi como se devolvesse uma parte do meu corpo sabe, (choro), mesmo que tivesse uma muletinha que é colete estava de novo sabe (choro). Essa foi 
a sensação que eu tive de estar inteira de novo com meu bebê mesmo que tivesse o canguru. Mas era eu e ele tão perto tão próximos, voltei tão feliz que eu tive vontade de ficar daquele jeito para sempre. (E2).

A posição canguru consiste em manter o recém-nascido de baixo peso em contato pele a pele, na posição vertical, junto ao tórax dos pais. A equipe de saúde deve estar adequadamente treinada para orientar de maneira segura os pais a realizarem essa posição. (SBP,2021).

Além do estreitamento do vínculo, o contato pele a pele entre mãe e bebê contribui para aumento da produção do leite, favorecendo uma maior frequência, precocidade e duração da amamentação (SANTOS et al.,2012), o que corrobora com a fala de E3.

\begin{abstract}
"Olha, é uma sensação inexplicável. Primeiro, aquele sentimento de mãe. A questão do meu leite também eu senti aumento do meu leite, até de pegar ela no meu colo meu leite acabava vazando já. Então é inexplicável, é uma sensação de bem-estar, é ter seu pedacinho de volta. É inexplicável, ela me traz uma paz muito grande (choro), a sensação eu não consigo definir, é o que é mais próximo de paz, (choro), e é isso, ter ela no colo é essa sensação de paz e serenidade. " (E3)
\end{abstract}

Sabe-se que o objetivo do contato pele a pele é de aproximar a mãe e o bebê, tornando a progenitora uma "incubadora natural" e assim, aumentar o estímulo sensorial, o vínculo afetivo e aleitamento materno. (TONI, 2011).

\footnotetext{
"Bom, a primeira vez foi uma emoção gigantesca né? Veio uma emoção, veio um choro, o meu seio começou a vazar de leite, muito, muito, muito leite, foi engraçado né? Molhou toda minha blusa e foi uma emoção gigantesca. Foi assim, eu não sei nem explicar, é a melhor sensação do mundo, eu amei muito (risos) ". (E10).
}

De acordo com Scochi et al (2003), o contato pele a pele é mencionado como estratégia para o aumento da lactação materna, e proporcionar confiança nos cuidados do filho e para favorecer o estabelecimento do vínculo e apego.

\footnotetext{
"Eu achei super importante adorei o projeto. Minha filha evoluiu bastante, até na sucção ela melhorou bastante. Desde os dias em que eu a coloquei em contato pele a pele é um sentimento que eu não consigo explicar o que é, ter o seu filho em contato pele a pele com você é um sentimento bem inusitado é um sentimento de vitória e de conquista. " (E7).
}

\title{
Contato pele a pele e os benefícios neuropsicomotores ao Recém-nascidos Prematuros
}

A transição precoce ao ambiente extrauterino cria um desafio ao RNPT, que necessita se manter estável em um ambiente cheio de estímulos, sendo assim, a promoção de um ambiente mais estável a esses bebês é essencial para a facilitação do desenvolvimento normal do prematuro. Com isso, é de extrema importância estabelecer o contato pele a pele precoce entre mãe e bebê (BARRADAS et al.,2006), 
"Eu senti a recuperação dela acontecendo até de pegar ela no colo, até quando tirava ela do colo ela já acordava. Eu via diferença nela, do comportamento dela comigo, de esperteza sabe? Ela fica muito mais ativa após sair do colo. Uma das coisas que eu achei mais importante na pele a pele foi isso sentir ela mais acordada, a posição também, que ela fica aconchegante. Eu vi melhora no aspecto de firmeza dela no corpinho". (E3).

Para Passavante e Vasconcellos (2019) o contato pele a pele proporciona o contato íntimo com bebê, influenciando no tônus motor do recém-nascido, o contato interfere positivamente na organização e modulação do tônus do bebê, aumento de peso do RNPT e favorecendo a alta precoce.

"Então como ela nasceu prematura a gente fica com muito medo, e esse contato ajudou a diminuir o medo a gente fica mais tranquila com ela pertinho sentindo nossa pele, como se ela tivesse na barriga sabe? Para ela sentir isso e fiquei muito feliz, acho que ajudou muito na melhora dela para ela ir de alta assim tão rápido, e ela ganhou muito peso assim bem rápido isso ajudou bastante" (E8).

[...]o contato pele a pele eu te digo não é importante, é fundamental, é essencial, e a coisa mais maravilhosa que aconteceu comigo aqui e com ele. Porque ele melhorou muito, ele é um bebê que não teve problemas sabe, nada, ele precisava engordar ele é emocional sabe, entende? É só emocional, ele só precisa ficar comigo, eu tenho certeza que é só isso. Com sete dias ele estava sem CPAP, sem cheirinho, sem nada. Com sete dias de UTI com $1200 \mathrm{~g}$ estava respirando normal, um bebê saudável, que é pequeno, ele só precisava de mim entende, o pior momento daqui foi sair do hospital e chegar em casa sem ele. Então é fundamental esse pele a pele, eu acho que todas as mães deveriam ter o que eu tive esse prazer e essa evolução. (E2).

O efeito do contato pele a pele no desenvolvimento neuropsicomotor dos RNPT, se mostra bastante favorável em relação a posição em que se é colocado os recém-nascidos em contato pele a pele. A posição lateral e decúbito ventral adotadas promovem um desenvolvimento motor precoce, devido a flexão dos músculos extensores, favorecendo desenvolvimento, extensão ativa e flexão ativa, apresenta melhora em padrões de sono principalmente sono profundo, melhora de padrões respiratórios. O contato pele a pele é considerado uma estratégia fundamental para o desenvolvimento neuropsicomotor dos RNPT internados em UTI Neonatal. (ZIRPOLI et al; 2019.)

\section{I CONCLUSÃO}

O nascimento prematuro, a hospitalização do recém-nascido na Unidade de Terapia Intensiva Neonatal, e a separação de forma tão inesperada que acontece com a mãe e o bebê, podem dificultar o início do vínculo entre eles, tendo em vista que a mãe não estava preparada com tantos acontecimentos em relação ao nascimento do seu filho de forma tão repentina e imatura.

O propósito deste estudo, foi evidenciar os benefícios da realização do contato 
pele a pele entre mãe e bebê na Unidade de Terapia Intensiva Neonatal. Observando as análises descritas acima, percebeu -se que as participantes expressaram seus sentimentos em relação a hospitalização do seu bebê e aos benefícios que elas puderam perceber em relação ao contato pele a pele.

Evidenciou-se durante as entrevistas, momentos de choro e tristeza na fala das mães em relação a separação que aconteceu durante a internação do seu bebê na UTIN. $\mathrm{E}$, em relação ao contato pele a pele, se mostraram felizes, seguras, por poder partilhar desse momento tão íntimo com seu bebê, e diante disso tornar -se mãe no contexto da prematuridade.

Em relação aos benefícios, evidenciou-se que o contato pele a pele favoreceu o vínculo entre mãe e bebê, uma vez que as mães trouxeram falas como renascimento, surgimento de uma nova mãe, segurança em relação aos cuidados com seu bebê, acalento e se sentiram completas. Já em relação aos benefícios relacionados a amamentação as mães relataram um aumento na produção do leite, após a realização do contato pele a pele. Em relação a evolução neuropsicomotora dos prematuros, as mães relataram melhora no tônus do recém-nascido, melhora de padrão respiratório, ganho de peso e favoreceu a alta mais rápida dos seus bebês o que pode ser visto com o acompanhamento do peso e período de internação coletados no prontuário do RNPT.

Ressalta-se que a equipe multiprofissional é fundamental na realização desse passo tão importante que é o contato pele a pele, pois é a prestadora do cuidado ao recémnascido e quem acolhe e orienta os pais nessa fase tão delicada, avalia o RNPT e o estado emocional das mães nessa fase cheia de emoções, que é o nascimento de um filho prematuro.

Após a realização desse estudo se faz necessário dar continuidade a pesquisas sobre o tema, buscando entender a importância e a necessidade da implementação de contato pele a pele dentro das UTIN e o quanto é benéfico a humanização para o cuidado com a mãe e bebê que vivenciam o nascimento prematuro.

\section{REFERÊNCIAS}

ANTUNES, M. S. D. C., PATROCINIO, C. A malformação do bebê: vivências psicológicas do casal. Psicologia, Saúde \& Doenças, 8(2), 239-251.2007 Disponível em: http://www.mec.pt/scielo. php?pid=S164500862007000200007\&script=sci_arttext\&tln g=em Acesso em 25 mai.2021.

BARDIN, Laurence. Análise de conteúdo. 4. ed. Lisboa: Edições 70, 2010.

BRASIL. Ministério da Saúde. Secretaria de Atenção à Saúde. Departamento de Ações Programáticas Estratégicas. Atenção humanizada ao recém-nascido: Método Canguru: manual técnico / Ministério da Saúde, Secretaria de Atenção à Saúde, Departamento de Ações Programáticas Estratégicas. - 3. ed. - Brasília: Ministério da Saúde, 2017. Disponível em:<https://bvsms.saude.gov. br/bvs/publicacoes/atencao_humanizada_metodo_canguru_manual_3ed.pdf > Acesso em 25 mai. 2021. 
BRASIL. Resolução $n^{\circ}$ 466, de 12 de dezembro de 2012. Dispõe sobre diretrizes e normas regulamentadoras de pesquisas envolvendo seres humanos. Diário Oficial [da] República Federativa do Brasil, Brasília, DF, 13 jun. 2013. Disponível em: <https://conselho.saude.gov.br/ resolucoes/2012/Reso466.pdf Acesso em: 25 mai. 2021.

BARRADAS et al. Premature, Kangaroo Mother Care, positioning, neuromotor development. J Pediatr (Rio J). 2006;82(6):475-80. Disponível em: <https://www.scielo.br/j/jped/a/ fFrWbnQKJ98dzJjswcNX8gn/?lang=pt\&format=pdf Acesso em 25 mai.2021.

CARVALHO, L. et al, As reações psicológicas dos pais frente à hospitalização do bebê prematuro na UTI neonatal, Rev. SBPH vol.20 no. 2, Rio de Janeiro - jul./dez.2017. Disponível em: <http://pepsic. bvsalud.org/pdf/rsbph/v20n2/v20n2a07.pdf> Acesso em 25 mai.2021.

CANTANHEDE et al., Experiências das mães no cuidado ao recém-nascido prematuro no método canguru. Revista Cogitare Enfermagem, V25, 2020. Disponível em: <https://revistas.ufpr.br/cogitare/ article/view/67416/pdf > Acesso 25 mai.2021.

MALHOTRA, Naresh K. Pesquisa de marketing: uma orientação aplicada. 6. ed. Porto Alegre: Bookman, 2012.

MOREIRA, MEL., et al. Conhecendo uma UTI neonatal. Rio de Janeiro: Editora FIOCRUZ, 2003a. Disponível em: <http://books.scielo.org/id/rqhtt/pdf/moreira-9788575413579-05.pdf > Acesso em 25 mai. 2021.

MOREIRA, MEL., et.al. Quando a vida começa diferente: o bebê e sua família na UTI neonatal. Rio de Janeiro: Editora FIOCRUZ, 2003b. Disponível em: <https://static.scielo.org/scielobooks/rqhtt/pdf/ moreira-9788575413579.pdf > Acesso em 25 mai.2021.

PASSAVANTE. E; VASCONCELOS. R, Impactos psicológicos na relação mãe-bebê frente à hospitalização na unidade de cuidado intermediário neonatal canguru. Repositório institucional, Faculdade pernambucana de saúde, 2019. Disponível em: <http://tcc.fps.local:80/handle/fpsrepo/603> Acesso em 30 mai.2021.

SANTOS, T.A.S., et.al. Práticas favorecedoras do aleitamento materno ao recém-nascido prematuro internado na unidade de terapia intensiva neonatal, R. Enferm. Cent. O. Min. VOL. 2, NO. 3, 2012. Disponível em:<http://www.seer.ufsj.edu.br/index.php/recom/article/view/220 Acesso em 30 mai.2021.

SANTOS. L.M, et al. Percepção materna sobre o contato pele a pele através da posição canguru. Revista de Pesquisa Cuidado é Fundamental Online, vol. 5, núm. 1, março, 2013, Rio de Janeiro. Disponível em: <https://www.redalyc.org/pdf/5057/505750897031.pdf> Acesso em 25 mai. 2021.

SOCIEDADE BRASILEIRA DE PEDIATRIA, Departamento Científico de Neonatologia, Mês da Prevenção da Prematuridade, 2019. Disponível em: <https://www.sbp.com.br/fileadmin/user_upload/ DocCientNeonatolSBP_Prematuridade_18112019_1_.pdf> Acesso em 25 mai. 2021.

SOCIEDADE BRASILEIRA DE PEDIATRIA, Departamento Cientifico de Neonatologia, Método Canguru: atenção humanizada ao recém-nascido de baixo peso, 2021, Disponível em: <https:// www.sbp.com.br/especiais/pediatria-para-familias/cuidados-com-o-bebe/metodo-canguru-atencaohumanizada-ao-recem-nascido-de-baixo-peso/Acesso em 26 jun.2021. 
SCOCHI CGS, et.al. Incentivando o vínculo mãe-filho em situação de prematuridade: as intervenções de enfermagem no hospital das clínicas de Ribeirão Preto. Rev Latino-am Enfermagem 2003 julho-agosto; 11(4):539-43. <https://www.scielo.br/j/rlae/a/ PyTz7CXJYqrzSfxsTTwsRKn/?lang=pt\&format=pdf Acesso em 25 mai.2021.

TONI. M.M. Avalição neuropsicomotora em prematuros internados na UTI Neonatal do Hospital Materno Infantil Santa Catarina do município de Criciúma -SC, antes e após a aplicação do método mãe canguru. Criciúma, novembro, 2011. Disponível em: <http://repositorio.unesc.net/ bitstream/1/337/1/Morgana\%20Martins\%20De\%20Toni.pdf > Acesso em 25 maio.2021

ZIRPOLI B.D, et al. Benefits of the Kangaroo Method: An Integrative Literature Review. Rev Fund Care Online. 2019. Disponível em: <http://www.seer.unirio.br/index.php/cuidadofundamental/article/ view/6541/pdf Acesso em 04.jul.2021. 


\section{HIPOTERMIA TERAPÊUTICA EM RECÉM-NASCIDOS COM ASFIXIA PERINATAL: ASSISTÊNCIA DE ENFERMAGEM}

Data de aceite: $20 / 08 / 2021$

Data de submissão: 06/08/2021

Michelle Cristine de Oliveira Minharro

Faculdade Marechal Rondon

São Manuel - São Paulo

http://lattes.cnpq.br/1658599597609935

Débora Fernanda Colombara

Faculdade Marechal Rondon

São Manuel - São Paulo http://lattes.cnpq.br/6112680125473901

Simone Buchignani Maigret

Faculdade Marechal Rondon

São Manuel - São Paulo http://lattes.cnpq.br/4801471366767637

RESUMO: A encefalopatia hipóxico-isquêmico (EHI) é uma manifestação clínica da asfixia perinatal, ocorre quando há falta de oxigênio e de perfusão para o feto intra-útero, durante o trabalho de parto e após o nascimento por complicações hemodinâmica, elevando os índices de morbimortalidade neonatal, estimase que cerca de $60 \%$ dos recém-nascidos (RN) afetados por essa condição adquirem sequelas graves ou morrem. Objetivo: Identificar na literatura existente os cuidados de enfermagem ao recém-nascido submetidos a hipotermia terapêutica na Unidade de Terapia Intensiva Neonatal. Metodologia: Trata-se de um estudo de revisão de literatura com abordagem qualitativa. A amostra foi formada por artigos relacionados diretamente com neonatos que sofreram injúria hipóxica-isquêmica tratados com hipotermia terapêutica e submetidos aos cuidados integrais da enfermagem. Resultados: Dentre os cuidados de enfermagem destacam-se cuidados com a qualidade da assistência, monitorização rigorosa, cuidados com a pele e extremidades, sedação, garantia de conforto durante sua aplicabilidade, humanização no atendimento, oferecendo assim uma assistência embasada cientificamente. Conclusão: Pesquisadores destacam benefícios ao aderir o tratamento, comprovando que a hipotermia terapêutica é segura e eficaz reduzindo as complicações e mortalidade entre os recém-nascidos, além de ser um procedimento de baixo custo sendo considerado um tratamento promissor com desfechos positivos na qualidade de vida.

PALAVRAS - CHAVE: "Hipotermia Induzida", "Hipóxia-Isquemia Encefálica", "Enfermagem" e "Recém-nascido"

\section{THERAPEUTIC HYPOTHERMIA IN NEWBORNS WITH PERINATAL ASPHYXIA: NURSING CARE}

ABSTRACT: Hypoxic-ischemic encephalopathy (HIE) is a clinical manifestation of perinatal asphyxia, occurs when there is a lack of oxygen and perfusion to the fetus in the uterus, during labor and after birth due to hemodynamic complications, increasing morbidity and mortality rates neonatal, it is estimated that about $60 \%$ of newborns (NB) affected by this condition acquire severe sequelae or die. Objective: To identify, in the existing literature, nursing care for newborns in therapeutic hypothermia in the Neonatal Intensive Care Unit. Methodology: 
This is a literature review study with a qualitative approach. The sample consisted of articles directly related to newborns who suffered hypoxic-ischemic injury treated with therapeutic hypothermia and comprehensive nursing care. Results: Among the nursing care, care with the quality of care, rigorous monitoring, skin and extremity care, sedation, guarantee of comfort during its applicability, humanization without care are highlighted, thus offering a scientifically based care. Conclusion: Researchers highlight the benefits of adhering to treatment, proving that therapeutic hypothermia is safe and effective as complications and mortality among newborns, in addition to being a low-cost procedure and considered a promising treatment with positive outcomes in the quality of life of treatment.

KEYWORDS: "Induced Hypothermia", "Hypoxia-cerebral ischemia", "Nursing" and "Newborn"

\section{I INTRODUÇÃO}

A encefalopatia hipóxico-isquêmico (EHI) é uma manifestação clínica da asfixia perinatal, ocorre quando há falta de oxigênio e de perfusão para o feto intra-útero, durante o trabalho de parto e após o nascimento por complicações hemodinâmica, elevando os índices de morbimortalidade neonatal, estima-se que cerca de $60 \%$ dos recém-nascidos (RN) afetados por essa condição adquirem sequelas graves ou morrem. (CUNHA, et al, 2018)

A EHI ocorre em duas fases, na primeira fase o cérebro respondetransformando-se em metabolismo anaeróbico, e na segunda fase que se iniciade 6 a 15 horas depois do insulto hipóxico, ocorre o acúmulo de neurotransmissores excitatórios e apoptose neuronal, quando iniciada acarreta danos irreversíveis ao sistema nervoso central. (SACCO, 2016; SILVA, et al, 2017)

Esta técnica vem sendo utilizada desde a década passada sendo indicada para recém-nascido com idade gestacional de 35 semanas ou mais, alguns estudos mostram a redução de $19 \%$ no risco de morte e acometimento neurológico, além de aumentar em 53\% a sobrevida sem paralisia cerebral. (LEMYRE, 2018)

O sucesso do tratamento de hipotermia terapêutica depende da identificação precoce do quadro de asfixia, devendo ser iniciada na primeira fase em até 6 horas de vida, neste momento temos a janela terapêutica sendo uma possibilidade de interromper esse processo de deterioração neuronal. (MAGALHÃES, et al, 2015)

A estratégia neuroprotetora da hipotermia terapêutica envolve a interrupção de alguns mecanismos de lesão irreversível, inibindo a cascata inflamatória, reduz a produção de espécies reativas de oxigênio, redução da taxa metabólica com redução do consumo de oxigênio e produção de gás carbônico.(SILVEIRA, 2015)

Observar esses neonatos é um grande desafio, a enfermagem tem papel fundamental no tratamento sendo executor direto do procedimento, somos responsáveis pela monitorização contínua destes $\mathrm{RN}$, durante todas as fasesde indução, manutenção e reaquecimento, portanto a participação daenfermagem é essencial para que haja êxito no tratamento, para garantir os resultados esperados é indispensável que a utilização 
da sistematização da assistência de enfermagem (SAE) e processo de enfermagem (PE) permite a atuação de forma planejada visando garantir a segurança e qualidade do serviço prestado. (SANTOS, et al, 2019)

Sendo assim justifica-se a escolha do tema por tamanha relevância, dando publicidade ao tratamento de hipotermia terapêutica e fazer que o mesmo seja mais utilizado, esmiuçar os cuidados de enfermagem durante o protocolo de hipotermia terapêutica baseando-se na literatura existente.

\section{I OBJETIVO}

Identificar na literatura existente os cuidados de enfermagem ao recém-nascido submetidos a hipotermia terapêutica na Unidade de Terapia Intensiva neonatal.

\section{I MÉTODO}

A revisão integrativa possibilita gerar novas perspectivas sobre um tema, oferece aos profissionais o acesso rápido aos resultados relevantes quefundamentam as condutas ou a tomada de decisão, além de verificar lacunas do conhecimento.(POLIT \& BECK, 2011)

A construção da presente revisão integrativa foi guiada por seis momentos: identificação do tema e elaboração da questão de pesquisa, estabelecimento de critérios de exclusão e inclusão, definição das informações a serem extraídas dos estudos selecionados/ categorização dos estudos, avaliação dos estudos incluídos na revisão, interpretação e síntese dos resultados, e, por último a apresentação da revisão.(MENDES, 2008)

Trata-se de um estudo de revisão de literatura de caráter integrativo com abordagem qualitativa. A amostra será formada por artigos relacionados diretamente com neonatos que sofreram injúria hipóxica-isquêmica tratados com hipotermia terapêutica e submetidos aos cuidados integrais da enfermagem, mediante a leitura exploratória dos mesmos. Descritores (DeCS): "Hipotermia Induzida", "Hipóxia-Isquemia Encefálica", "Enfermagem"e "Recémnascido" sendo cruzados em dupla ou trio. A busca foi realizada na Biblioteca Virtual em Saúde nas bases de dados LiLacs, BDENF e MEDLINE. Como critério de inclusão: artigos científicos disponíveis na íntegra, publicados entre 2016 a 2021 na língua portuguesa e inglesa. Critérios de exclusão: artigos científicos indisponíveis na íntegra, publicados anteriormente ao ano de 2016 que não correspondiam com o tema abordado.

Os resultados obtidos foram 26 artigos, utilizando-se os critérios de exclusão e inclusão citados acima, diante disto selecionou-se 5 artigos que correspondem com a temática abordada.

E como pergunta norteadora usou-se: Como devem ser os cuidados de enfermagem a um recém-nascido com asfixia perinatal submetido ao tratamento de hipotermia terapêutica? 


\section{I RESULTADOS}

Os 5 estudos selecionados estão apresentados na Tabela 1, segundoautor, título do artigo, periódico e país em que foi realizado o estudo.

\begin{tabular}{|c|c|c|c|c|}
\hline No & Autor/Ano & Título & Periódico & Local de Estudo \\
\hline 1 & $\begin{array}{c}\text { Ibrani D, } \\
\text { Molacavage S. } \\
2018\end{array}$ & $\begin{array}{l}\text { The six-hour window: how the } \\
\text { community hospital nursery } \\
\text { can optimize outcomes of the } \\
\text { infant with suspected hypoxic- } \\
\text { ischemic encephalopathy. }\end{array}$ & $\begin{array}{l}\text { Springer } \\
\text { Publishing } \\
\text { Company. }\end{array}$ & $\begin{array}{l}\text { Seattle, } \\
\text { Washington } \\
\text { Tacoma. }\end{array}$ \\
\hline 2 & $\begin{array}{c}\text { Leite PNM, Teixeira } \\
\text { RB, da Silva GD, } \\
\text { Reis AT, Araújo M. } \\
2020\end{array}$ & $\begin{array}{l}\text { Hipotermiaterapêutica na } \\
\text { encefalopatia hipóxico- } \\
\text { isquêmica neonatal: revisão } \\
\text { integrativa. }\end{array}$ & $\begin{array}{l}\text { Revista } \\
\text { Enfermagem } \\
\text { UERJ }\end{array}$ & $\begin{array}{l}\text { Universidade } \\
\text { Estadual do Rio } \\
\text { de Janeiro, Rio } \\
\text { janeiro. }\end{array}$ \\
\hline 3 & $\begin{array}{l}\text { Craig A, James C, } \\
\text { Bainter J, Lucas FL, } \\
\text { Evans S, Glazer } \\
\text { J,Thibeau S. } \\
2017 .\end{array}$ & $\begin{array}{l}\text { Survey of neonatal intensive } \\
\text { care unit nurse attitudes } \\
\text { toward therapeutichypothermia } \\
\text { treatment. }\end{array}$ & $\begin{array}{l}\text { Advances in } \\
\text { Neonatal }\end{array}$ & $\begin{array}{l}\text { San Diego, } \\
\text { Califórnia. }\end{array}$ \\
\hline 4 & $\begin{array}{c}\text { Corrêa LVO, } \\
\text { Silveira RSD, } \\
\text { Mancia JR,Corrêa } \\
\text { NL, Reinhardf } \\
\text { IMDS, LunardiVL, } \\
\text { Ciconet RM. } \\
2018 .\end{array}$ & $\begin{array}{l}\text { Hipotermia terapêutica: efeitos } \\
\text { adversos, complicações e } \\
\text { cuidados de enfermagem. }\end{array}$ & $\begin{array}{c}\text { Enfermagem em } \\
\text { Foco. }\end{array}$ & $\begin{array}{l}\text { Rio Grande do } \\
\text { Sul. }\end{array}$ \\
\hline 5 & $\begin{array}{c}\text { Browning B. } \\
\text { Page KE, Kuhn } \\
\text { RL, Diliberto MA, } \\
\text { Deschenes J, Taillie } \\
\text { E, Pemberton VL. } \\
2016 .\end{array}$ & $\begin{array}{l}\text { Nurses' attitudes toward } \\
\text { clinical research: experience } \\
\text { of the therapeutic hypothermia } \\
\text { after pediatric cardiac arrest } \\
\text { trials. }\end{array}$ & $\begin{array}{l}\text { Pediatric Critical } \\
\text { Care Medicine. }\end{array}$ & $\begin{array}{c}\text { Arizona, } \\
\text { Filadélfia, } \\
\text { Nova York, } \\
\text { Washington, } \\
\text { detroit, Salt Lake } \\
\text { City }\end{array}$ \\
\hline
\end{tabular}

Quadro 1- Sintese dos artigos selecionados para o estudo segundo autor e ano de publicação, título, periódico e local de estudo.

Nesta revisão integrativa foram analisados 5 artigos que atenderam aos critérios estabelecidos. Todos publicados no período entre os anos de 2016 a 2021.

Quanto à indexação dos artigos nas bases de dados, 20\% (1) estão na LILACS, $60 \%$ (3) na Medline, 20\% (1) BDENF. Nas demais bases, Embase, Cochrane, Web of Science, Pubmed, Scielo, CINAHL e Scopus não foram encontrados artigos que respondessem à questão da revisão.

Quanto ao país de origem, 40\% (2) dos artigos foram desenvolvidos no Brasil, $60 \%$ (3) na América do Norte.

Sobre o delineamento de pesquisa dos artigos selecionados encontrou-se $20 \%$ (1) estudo de coorte, $20 \%$ (1) pesquisa quantitativa, $20 \%$ (1) revisão de literatura e $40 \%$ (2) pesquisa qualitativa.

O Quadro 2 apresenta uma síntese dos estudos incluídos na revisão. 


\begin{tabular}{|c|c|c|c|c|c|}
\hline $\mathbf{N}^{\circ}$ & Autor & Delineamento & Participantes & Objetivo & Resultados \\
\hline 1 & $\begin{array}{c}\text { Ibrani D, } \\
\text { Molacavage } \\
\text { S. } \\
2018\end{array}$ & $\begin{array}{l}\text { Pesquisa } \\
\text { qualitativa. }\end{array}$ & Enfermeiros & $\begin{array}{l}\text { Ensinar enfermeiras } \\
\text { neonatais sobre } \\
\text { reanimação e } \\
\text { cuidados } \\
\text { pós-reanimação de } \\
\text { um bebê em riscode } \\
\text { EHI. }\end{array}$ & $\begin{array}{l}\text { Contribui com base } \\
\text { na literatura definição, } \\
\text { etiologia, fases da } \\
\text { lesão, diagnóstico, } \\
\text { tiposde resfriamento, } \\
\text { ressuscitação, } \\
\text { tratamento para } \\
\text { encefalopatia hipóxico- } \\
\text { isquêmico, treinamento } \\
\text { para equipe e apoio } \\
\text { familiar. }\end{array}$ \\
\hline 2 & $\begin{array}{l}\text { Leite PNM, } \\
\text { Teixeira RB, } \\
\text { da Silva GD, } \\
\text { Reis AT, } \\
\text { Araújo M. } \\
2020\end{array}$ & $\begin{array}{l}\text { Revisão da } \\
\text { literatura }\end{array}$ & Enfermeiros & $\begin{array}{l}\text { Identificar evidências } \\
\text { acerca do uso } \\
\text { seguro da hipotermia } \\
\text { terapêutica em } \\
\text { recém-nascidos. }\end{array}$ & $\begin{array}{l}\text { As indicações para } \\
\text { inclusão noprotocolo, } \\
\text { evidência em qual } \\
\text { momento deve iniciar a } \\
\text { terapêutica e oscuidados } \\
\text { essenciais da equipe } \\
\text { multiprofissional }\end{array}$ \\
\hline 3 & $\begin{array}{c}\text { Craig A, } \\
\text { James C, } \\
\text { Bainter } \\
\text { J, Lucas } \\
\text { FL, Evans } \\
\text { S, Glazer } \\
\text { J,Thibeau S. } \\
2017 .\end{array}$ & $\begin{array}{l}\text { Pesquisa } \\
\text { quantitativa- } \\
\text { qualitativa }\end{array}$ & Médicos & $\begin{array}{l}\text { Avaliar as atitudes } \\
\text { do enfermeiro da } \\
\text { UTIN quanto ao } \\
\text { fornecimento de HT } \\
\text { no quediz respeito } \\
\text { às percepções sobre } \\
\text { dor/ sedação do } \\
\text { bebê e necessidade } \\
\text { de educação da } \\
\text { enfermagem e dos } \\
\text { pais, tomada de } \\
\text { decisão sobreo início } \\
\text { da HTe barreiras para } \\
\text { o melhor cuidado. }\end{array}$ & $\begin{array}{l}\text { Este artigo colaborou: } \\
\text { metodologia para } \\
\text { aplicação da terapia de } \\
\text { hipotermia induzida com } \\
\text { qualidade e segurança } \\
\text { da assistência para } \\
\text { o recém-nascido que } \\
\text { sofreu insulto } \\
\text { hipóxico-isquêmico }\end{array}$ \\
\hline 4 & $\begin{array}{c}\text { Corrêa LVO, } \\
\text { Silveira } \\
\text { RSD, Mancia } \\
\text { JR, Corrêa } \\
\text { NL, Reinhardf } \\
\text { IMDS, Lunardi } \\
\text { VL, Ciconet } \\
\text { RM. } \\
2018 .\end{array}$ & $\begin{array}{l}\text { Pesquisa } \\
\text { qualitativa }\end{array}$ & Enfermeiros & $\begin{array}{c}\text { Conhecer os } \\
\text { efeitos adversos } \\
\text { e complicações } \\
\text { vivenciadas pela } \\
\text { equipe de saúde e } \\
\text { conhecer os cuidados } \\
\text { de enfermagem } \\
\text { realizados durante } \\
\text { a aplicação } \\
\text { da hipotermia } \\
\text { terapêutica. }\end{array}$ & $\begin{array}{l}\text { Evidencia do baixo custo } \\
\text { de ser aplicada, sendo } \\
\text { necessários que a equipe } \\
\text { seja qualificada, adesão } \\
\text { do tratamento, trazendo } \\
\text { a efetividade dos } \\
\text { cuidados de enfermagem } \\
\text { aospacientes submetidos } \\
\text { a hipotermia terapêutica. }\end{array}$ \\
\hline 5 & $\begin{array}{c}\text { Browning B. } \\
\text { Page KE, } \\
\text { Kuhn RL, } \\
\text { Diliberto MA, } \\
\text { Deschenes } \\
\text { J, Taillie E, } \\
\text { Pemberton } \\
\text { VL. } \\
2016 .\end{array}$ & $\begin{array}{l}\text { Método coorte } \\
\text { transversal. }\end{array}$ & $\begin{array}{c}\text { Equipe } \\
\text { Multidisciplinar }\end{array}$ & $\begin{array}{c}\text { Compreenderos } \\
\text { fatores queafetam } \\
\text { as atitudes dos } \\
\text { enfermeiros em } \\
\text { relaçãoaos ensaiosde } \\
\text { hipotermiaterapêutica } \\
\text { após parada } \\
\text { cardíaca pediátrica e } \\
\text { associação com taxas } \\
\text { de abordagem. }\end{array}$ & $\begin{array}{l}\text { Corrobora trazendo a } \\
\text { relação multidisciplinar, } \\
\text { percepções e abordagem } \\
\text { dosprofissionais da área, } \\
\text { e importância científica } \\
\text { relevante a temática. }\end{array}$ \\
\hline
\end{tabular}

Quadro 2 - Descrição dos estudos incluídos na revisão segundo autores, ano de publicação, delineamento, participantes, objetivo e contribuições 
A lesão cerebral causada inicialmente pela asfixia neonatal é decorrente da falha do sistema de trocas gasosas podendo evoluir para encefalopatia hipóxico-isquêmico, a hipóxia leva a diminuição do débito cardíaco fetal que por sua vez diminui o fluxo sanguíneo para o cérebro. Alesão cerebral ocorre em duas fases distintas, a primeira acontece no momento do evento quando ocorre a falha no fornecimento do oxigênio e glicose ao cérebro e a segunda fase acontece 6 a 15 horas após o insulto hipóxico inicial. O diagnóstico e tratamento precoces são fundamentais para minimizar efeitos lesivos, a intervenção preferida é a hipotermia terapêutica, a mesma proporciona uma redução do metabolismo cerebral interrompendo a cascata inflamatória, diminuindo ou sanando as lesões irreversíveis cerebrais.(IBRANI, 2018)

Diante disto para que o recém-nascido seja incluso neste tratamento é imprescindível o preenchimento de alguns critérios como: idade gestacional igual ou maior que 36 semanas, cuja o apgar menor ou igual a 5 no $10^{\circ}$ minuto de vida, agravantes perinatais como prolapso de cordão, descolamento prematuro de placenta (DPP), ressuscitação prolongada minutosapós o nascimento, apresentar manifestações neurológicas neonatais tais como: convulsões, coma ou hipotonia moderados ou grave antes das 6 horas de vida, acidose grave $\mathrm{pH}<7,0$ ou $\mathrm{BE}<-16$ dentro de 1 hora após o nascimento, essa amostra sanguínea pode ser coletada do cordão umbilical, arterial ou venosa. (LEITE, 2020)

Para a aplicação da técnica HT a troca multidisciplinar pode contribuir significativamente para a qualidade e segurança da assistência ao recém-nascido que sofreu insulto hipóxico-isquêmico, Estudos comprovam que os efeitos do tratamento foram melhores quando iniciados precocemente, sendo assim deve se iniciar em até 6 horas após o nascimento, devido a janelaterapêutica e o período de latência a técnica consiste em baixar a temperatura central entre 33 a $34^{\circ} \mathrm{C}$ durante um período de 72 horas, o recomendado pararealização do tratamento é utilizar equipamentos de resfriamento servocontrolados apropriados para essa clientela. (CRAIG, et al, 2017)

Por se tratar de uma terapia complexa, o paciente submetido a este tratamento requer atenção constante da enfermagem, que executa cuidados específicos para alcançar a melhora clínica, sendo essencial uma equipe devidamente qualificada e engajada. (CORRÊA, et al, 2018)

Quanto aos cuidados de enfermagem devemos cuidar dos materiais que será utilizado na indução a terapia, monitorização frequente dos sinais vitais variando os protocolo que cada instituição segue, atenção com a pele e extremidades evitando as queimaduras, foi evidenciado que a Hipotermia terapêutica causa vasoconstrição periférica tornando propício a lesões desse tipo, essa situação exige avaliação do enfermeiro regularmente sendo indispensável que o gelo esteja envolvido em compressas e ou lençol sendo rodiziado com maior frequência. (CORRÊA, et al, 2018)

Cabe ao enfermeiro realizar os procedimentos de sondagem nasogástrica, sondagem vesical, instalação do termômetro esofágico e de pressão arterial média, 
gasometria arterial amostra pode ser coletada do cateter umbilical, restrição da dieta devido a efeitos adversos da terapia sobre o sistema gastrointestinal, avaliação constante do nível de sedação com foco em evitar qualquer desconforto gerado pelo tratamento, manipulação deverá ser mínima evitando o excesso de movimentação desnecessária reduzindo assim fatores estressantes.(CORRÊA, et al, 2018)

Browning (2016) traz que cabe ao enfermeiro supervisionar todos os procedimentos realizados, incluindo o gerenciamento do controle da temperatura, equipamentos utilizados, registros dos sinais vitais frequentes, exames laboratoriais e relatar efeitos adversos.

\section{5 | DISCUSSÃO}

No estudo realizado por Ibrani e Molacavage (2018), o paciente com asfixia perinatal e encefalopatia hipóxico-isquêmico moderado a grave requer uma abordagem precisa e cuidadosa que começa no centro obstétrico e continua até a unidade de terapia intensiva neonatal. Corroborando com esse pensamento Leite et al. (2020) acreditam que a Hipotermia induzida deve ser fornecida em Unidade de terapia intensiva diante da necessidade de assistência integral e vigilância cuidadosa dos recém-nascidos submetidos a esta terapia. A hipotermia terapêutica é mais eficaz quando instituída na fase latente, antes na segunda falha, deverá ser aplicada este tratamento apenas em recém-nascido que preencherem a alguns critérios de inclusão.

Segundo os estudos de Craig, et al. (2017) evidência que o ideal para este tratamento, é iniciar precocemente em até 6 horas após o nascimento, sugere também que a manutenção da temperatura corporal centraldeve ser $33^{\circ}$ a $34^{\circ} \mathrm{C}$ por 72 horas , seguida por um período de reaquecimento de 6 a 12 horas 0,2 a $0,5^{\circ} \mathrm{C}$, além disso observou-se de maneira geral o papel que a enfermagem exerce é fundamental e indispensável, o cuidado rigoroso prestado quando qualificado possibilita a implementação segura e eficaz da terapia.

É reafirmado por Corrêa, et al (2021) destacando aimportância da assistência de enfermagem sendo o executor direto dos procedimentos, e responsáveis por garantir conforto, segurança e qualidade doserviço prestado.

Browning, et al (2016) acrescenta que os cuidados oferecidos são de alta complexidade, cabe ao enfermeiro supervisionar todos os procedimentos, registros, exames e gerenciamento sendo prioridade que os profissionais da saúde estejam cientes de sua propedêutica.

\section{6 | CONCLUSÃO}

Este estudo de revisão se propôs a pesquisar e reunir dados da literatura existente mais recentes e relevantes sobre a hipotermia induzida, fazendo com que os profissionais da área possam através deste artigo sanar algumas dúvidas e obter informações importantes 
sobre a terapêutica.

Grandes pesquisadores destacam benefícios ao aderir o tratamento, comprovando que a hipotermia terapêutica é segura e eficaz reduzindo as complicações e mortalidade entre os recém-nascidos, além de serum procedimento de baixo custo sendo considerado um tratamento promissor com desfechos positivos na qualidade de vida.

Diante disso, é evidente a relevância da atuação da enfermagem sendo essencial para sucesso do tratamento, devemos manter a equipe de enfermagem capacitada e embasada cientificamente, para desempenhar a assistência adequada e segura deste paciente identificando possíveis riscos.

Sugere-se que novos estudos sejam realizados, trazendo visibilidade para o tratamento gererando novas evidências voltadaspara prática do enfermeiro.

\section{REFERÊNCIAS}

Browning B., et al. Nurses' attitudes toward clinical research: experienceof the therapeutic hypothermia after pediatric cardiac arrest trials. Pediatric Critical Care Medicine. 17(3): 121-129, 2016.

Cunha CR, Viana LM, Souza CV, Mangueira MA, Lima FP. Therapeutichypothermia in newborns with hipoxic-ischemic encephalopathy: Integrative review. Rev Soc Bras Enf Ped. 18(1):37-42, 2018.

Craig A, James C, Bainter J, Lucas FL, Evans S, Glazer J, Thibeau S. Survey of neonatal intensive care unit nurse attitudes toward therapeutichypothermia treatment. Advances in Neonatal Care. 17(2): 123-130, 2017.

Corrêa LVO, Silveira RSD, Mancia JR, Corrêa NL, Reinhardf IMDS, LunardiVL, Ciconet RM. Hipotermia terapêutica: efeitos adversos, complicações e cuidados de enfermagem. Enfermagem em Foco. 9(4): 55-59, 2018.

Ibrani $D$, Molacavage $S$. The six-hour window: how the community hospital nursery can optimize outcomes of the infant with suspected hypoxic-ischemic encephalopathy. Springer Publishing Company. 37(3): 155-163, 2018.

Lemyre B, Chau V. Hypothermia for newborns with hypoxic-ischemic encephalopathy. Paediatrics \& Child Health, 23(4): 285-291,2018.

Leite PNM, Teixeira RB, da Silva GD, Reis AT, Araújo M. Hipotermiaterapêutica na encefalopatia hipóxico-isquêmica neonatal: revisão integrativa. Revista Enfermagem UERJ. 28: 42281,2020.

Magalhães, M, et al. Hipotermia corporal neuroprotetora em recém-nascidos com encefalopatia isquêmica hipóxica: experiência de três anos em um hospital universitário terciário. Um estudo observacional retrospectivo. São Paulo Medical Journal. 133(4): 314-319, 2015.

Mendes KDS, Silveira RCCP GC. Revisão integrativa: método depesquisa. Texto Contexto.

Enfermagem. 17 (4):758-764, 2008.

Polit DF, Beck CT HB. Fundamentos de pesquisa em enfermagem:métodos, avaliação e utilização.

Porto Alegre: Artmed; 2011. 
Sacco L. Amplitude-integrated electroencephalography interpretationduring therapeutic hypothermia: an educational program and novel teaching tool. Neonatal Network. 35(2):78-86, 2016.

Santos APA, et al. A atuação do enfermeiro na Hipotermia Terapêuticaem UTI neonatal. A Produção do Conhecimento nas Ciências da Saúde 4. Atena Ed. 1;388-416, 2019. DOI: 10.22533/ at.ed.0191903041

Silva GD da, et al. Resfriamento para recém-nascidos com encefalopatiahipóxico-isquêmica. Rev. enferm. UFPE on line. 11(4):1804-1805, 2017.

Silveira RC, Procianoy RS. Hypothermia therapy for newborns withhypoxic ischemic encephalopathy. J Pediatr (Rio J). 91(6):78-83, 2015. 


\section{CAPÍTULO 14 \\ MANEJO NÃO-FARMACOLOGICO DA DOR EM RECEM-NASCIDO SOB CUIDADOS INTENSIVOS}

Data de aceite: 20/08/2021

Data de submissão: 06/07/2021

Nanielle Silva Barbosa

Enfermeira. Pós-graduanda do Programa de Residência Multiprofissional em Saúde da Família e Comunidade pela Universidade Estadual do Piauí

Teresina-Piauí http://lattes.cnpq.br/1573380751471631

\section{Stefânia Araújo Pereira}

Enfermeira pela Universidade Estadual do

Piauí

Teresina-Piauí

http://lattes.cnpq.br/4338446793621509

\section{José Francisco Ribeiro}

Enfermeiro. Mestre em Ciências e Saúde pela Universidade Federal do Piauí

Teresina-Piauí

http://lattes.cnpq.br/3875070789775588

Ana Caroline Escórcio de Lima

Enfermeira pela Universidade Estadual do

Piauí

Teresina-Piauí

http://lattes.cnpq.br/8452505065233066

Amanda Karoliny Meneses Resende

Enfermeira pela Universidade Estadual do Piauí. Residência em Enfermagem Obstétrica pela Universidade Federal do Piauí. Mestranda em Enfermagem pela Universidade Federal do

Piauí

Teresina-Piauí

http://lattes.cnpq.br/3126388137953689
Marianna Soares Cardoso Acadêmica de Enfermagem pela Universidade

Estadual do Piauí

Teresina-Piauí

http://lattes.cnpq.br/5516909164192129

Emanuelle da Costa Gomes

Acadêmica de Enfermagem pela Universidade

Estadual do Piauí

Teresina-Piauí

http://lattes.cnpq.br/3305440783709593

lara Lima de Andrade Ferreira

Acadêmica de Enfermagem pela Universidade

Estadual do Piauí

Teresina-Piauí

http://lattes.cnpq.br/3811801035486659

Juliete Machado Aguiar Bandeira

Acadêmica de Enfermagem pela Faculdade

Estácio/CEUT

Teresina-Piauí

http://lattes.cnpq.br/8503779230375544

Geovana Marques Teixeira

Graduanda em Enfermagem pela Universidade

Estadual do Piauí

Teresina-Piauí

http://lattes.cnpq.br/4212932932624348

Maria Erislâine de Carvalho Rodrigues Acadêmica de Enfermagem pela Faculdade

Estácio/CEUT

Teresina-Piauí

http://lattes.cnpq.br/7520702024627543

Palloma Ohana de Meneses Moura Lima Graduanda em Enfermagem pela Universidade

Estadual do Piauí

Teresina-Piauí

http://lattes.cnpq.br/7215400541456127 
RESUMO: INTRODUÇÃO: a Unidade de Terapia Intensiva Neonatal teve um avanço do conhecimento científico, tecnológico e inovações terapêuticas, no entanto, há o aumento da manipulação e procedimentos invasivos. Se por um lado, tais tratamentos clínicos mantem os neonatos, por outro lado, ocasionam muitas vezes dor e sofrimento. OBJETIVO: analisar as evidências científicas acerca do manejo não-farmacológico da dor em recém-nascidos sob cuidados intensivos. MÉTODO: trata-se de uma revisão integrativa com levantamento realizado entre Setembro e Novembro de 2018. Aplicou-se a combinação dos descritores: "recém-nascido", "manejo da dor" e "cuidados críticos" à base de dados Literatura LatinoAmericana e do Caribe em Ciências da Saúde, Medical Literature Analysis and Retrieval Sistem Online, Cummulative Index to Nursing and Allied Health Literature e SCOPUS. Para extração de dados foi utilizado instrumento elaborado pelos autores. Classificou-se o nível de evidência. RESULTADOS E DISCUSSÃO: 12 produções foram incluídas como amostra, destacando a importância da avaliação da dor e exemplos de métodos não-farmacológicos de manejo. CONSIDERAÇÕES FINAIS: o manejo da dor em neonatos não é fácil. Os profissionais de saúde tem um significativo potencial para a prevenção de complicações clínicas ocasionadas pela da dor e desenvolvimento de estratégias que utilizem métodos não-farmacológicos.

PALAVRAS - CHAVE: Neonato; Dor; Cuidados Críticos.

\section{NON-PHARMACOLOGICAL MANAGEMENT OF PAIN IN NEWBORN UNDER INTENSIVE CARE}

ABSTRACT: INTRODUCTION: the Neonatal Intensive Care Unit had an advance in scientific and technological knowledge and therapeutic innovations, however, there is an increase in manipulation and invasive procedures. If, on the one hand, such clinical treatments keep newborns, on the other hand, they often cause pain and suffering. OBJECTIVES: to analyze the scientific evidence about the non-pharmacological management of pain in newborns under intensive care. METHOD: this is an integrative review with a survey conducted between September and November 2018. The combination of descriptors: "newborn", "pain management" and "critical care" was applied to database of Latin American and Caribbean Health Sciences Literature, Medical Literature Analysis and Retrieval System Online, Cumulative Index to Nursing and Allied Health Literature and SCOPUS. For data extraction, an instrument developed by the authors was used. The level of evidence was rated. RESULTS AND DISCUSSION: 12 productions were included as a sample, highlighting the importance of pain assessment and examples of non-pharmacological management methods. FINAL CONSIDERATIONS: pain management in neonates is not easy. Health professionals have a significant potential for preventing clinical complications caused by pain and developing strategies that use non-pharmacological methods.

KEYWORDS: Newborn; Pain; Critical Care.

\section{I INTRODUCÃO}

A Unidade de Terapia Intensiva Neonatal (UTIN) teve um avanço do conhecimento científico, tecnológico e inovações terapêuticas, corroborado na sobrevida dos neonatos 
de alto risco, no entanto há o aumento da manipulação e procedimentos invasivos. Se por um lado, tais tratamentos clínicos mantem os neonatos, por outro lado, ocasionam muitas vezes dor e sofrimento (KEGLER et al., 2016; BRASIL, 2014).

\section{A Joint Commission on Accreditation of Healthcare Organizations (JCAHO)} reconhece a dor como o quinto sinal vital, procurando assegurar que todos tenham acesso às intervenções para seu controle da mesma forma que se dá o tratamento imediato das alterações dos demais sinais (SBED, 2016).

A dor gera desconforto, estresse e irritabilidade especialmente em unidades de internação neonatal. Os fatores contextuais a dor do neonato englobam: maturidade, estado de saúde, ambiente, equipe que presta cuidados, além de experiência anterior com a dor ou a duração da hospitalização (MELO; CARDOSO, 2017; CIGNACCO et al., 2017).

Pesquisa realizada no Brasil, em unidades de cuidados intensivos e intermediário neonatal de média complexidade, constatou que de 32 recém-nascidos, durante sete dias de hospitalização, foram submetidos a 1.316 procedimentos potencialmente dolorosos, uma média de 5,9 procedimentos por recém-nascido (BONUTTI et al., 2017).

A dor aguda mal administrada ou subtratada deve ser considerada um evento adverso, pois é possivelmente evitável e pelas consequências deletérias do ponto de vista comportamental e fisiológico. Portanto, há necessidade urgente de estabelecer tratamentos seguros e eficazes para seu alívio em neonatos (BRENN et al., 2016; QIU et al., 2017).

O manejo não farmacológico tem sido ressaltado para a analgesia nos procedimentos invasivos de intensidade leve a moderada. Traz como benefício, baixo risco para o neonato e baixo custo operacional nos cuidados críticos. Os mais utilizados são: sucção não nutritiva, glicose à $25 \%$ e o posicionamento. O uso combinado desses, principalmente em prematuros, reduz as reações de estresse e dor. Quando aliados à terapia farmacológica, tornam menos agressivo o tratamento em recém-nascidos (MORAES et al., 2016; COSTA et al., 2016).

Considerando a importância da realização de estudos que permitam um conhecimento amplo e mais aprofundado sobre o tema, esta revisão traz como objetivo analisar as evidências científicas acerca do manejo não farmacológico da dor em recém-nascido sob cuidados intensivos, contribuindo para o planejamento de estratégias e ações de cuidado adequadas, minimizando problemas decorrentes de uma assistência desqualificada ao paciente neonatal.

\section{I METODO}

Estudo de revisão integrativa da literatura construída com base em seis etapas de investigação (MENDES; SILVEIRA; GALVÃO, 2008).

Para a elaboração da questão de pesquisa foi utilizada a estratégia PICo (P: recémnascido; I: manejo da dor; Co: cuidados intensivos), resultando na questão: quais as 
evidências científicas relacionadas às intervenções não farmacológicas no manejo da dor em recém-nascido sob cuidados intensivos (LOCKWOOD et al., 2017).

A pesquisa foi realizada por dois revisores, simultaneamente e de forma independente, no período de Setembro a Novembro de 2018 nas bases de dados: Literatura Latino-Americana e do Caribe em Ciências da Saúde (LILACSIBVS), Cummulative Index to Nursing and Allied Health Literature (CINAHL), Medical Literature Analysis and Retrieval Sistem Online (MEDLINE/PUBMED) e SCOPUS. Os descritores selecionados, "recém-nascido", "manejo da dor" e "cuidados intensivos", encontram-se inseridos nos vocabulários Descritores em Ciências da Saúde (DeCS), list CINAHL e Medical Subject Headings (MeSH). Estes foram combinados com os operadores "AND" e "OR".

Foram utilizados como critérios de inclusão: estudos primários desenvolvidos com seres humanos, ensaios clínicos randomizados controlados individuais, estudos com delineamento de pesquisa quase experimental e estudos transversais e longitudinais. Os critérios de exclusão englobaram as produções duplicadas, estudos de revisão, teses, dissertações, editoriais e opinião de especialista.

No primeiro momento, foi realizada busca nas bases seguida pela exclusão dos duplicados. Por conseguinte, título e resumo, para inclusão dos estudos primários pertinentes, foram revisados. No terceiro momento, de forma independente, houve a leitura do texto completo dos artigos. As discordâncias foram resolvidas por meio de discussão e avaliação com um terceiro revisor. Esse processo resultou na filtragem e seleção de 12 produções para amostra.

Para extração de dados relevantes utilizou-se instrumento elaborado pelos autores contendo informações acerca do ano de publicação, país de origem, área de atuação dos autores, detalhamento do método (tipo de estudo, amostra, cenário), intervenção e avaliação da intervenção. Foi classificado o nível de evidência de acordo com as orientações do Oxford Centre for Evidence-based Medicine (DURIEUX; VANDENPUT; PASLEAU, 2013).

Os dados foram analisados de forma descritiva e os resultados apresentados e discutidos em três categorias temáticas que levaram em consideração a similaridade de informações que respondiam ao problema deste estudo.

\section{I RESULTADOS E DISCUSSÃO}

O ano de publicação dos artigos variou entre 2006 e 2018, sendo que o ano de 2016 obteve maiores publicações, quatro (33,3\%), seguindo de 2018 e 2012 com quatro $(33,3 \%)$ publicações. Quanto ao local da pesquisa, houve predomínio do Brasil com oito $(66,6 \%)$ artigos. Artigos da área de atuação em Enfermagem com 11 (91,6\%) produções. Maiores informações encontram-se apresentadas na Tabela 1 abaixo: 


\section{Autores/ \\ Área de atuação/ Intervenção \\ Avaliação da intervenção}

A1

Costa et al./

Enfermagem/

Brasil/2017

A2

Soares et al./

Enfermagem/

Brasil/2016

A3

Oliveira et al./

Enfermagem/

Brasil/2016

A4

Kegler et al./

Enfermagem/

Brasil/2016

A5

Amaral et al./

Enfermagem/

Brasil/2014

A6

Santos; Ribeiro; Santana/

Enfermagem/

Brasil/2012

A7
Glicose oral, sucção nãonutritiva e posicionamento

Glicose a $25 \%$,sucção não-nutritiva e contenção com lençol

Diminuição de ruído e luminosidade, aleitamento materno, posicionamento, soluções adocicadas, enrolamento,sucção não-nutritiva, contenção facilitada e música

Glicose a $25 \%$, sucção não-nutritiva e enrolamento

Sucção não-nutritiva, gota de sacarose, enrolamento, posicionamento, manuseio, diminuição de ruídos e luminosidade

Contenção, diminuição dos ruídos e da iluminação, sucção não-nutritiva, mudança de decúbito $e$ ninho

Sucção não-nutritiva, diminuição dos ruídos e da iluminação, posicionamento e manuseio
Os participantes $(68,6 \%)$ relataram que a glicose oral é efetiva no alivio da dor. A sucção não-nutritiva foi citada por $58,8 \%$ como medida analgésica. $56,9 \%$ constataram a eficácia do podicionamento no manejo da dor.

Os métodos eram realizados antes e após os procedimentos por $100 \%$ das enfermeiras e $96,7 \%$ dos técnicos de enfermagem.

A posição canguru (76,9\%), o aleitamento materno $(73,1 \%)$ e solução adocicada $(69,2 \%)$ são evidentes no manejo da dor neonatal. O colo $(76,9 \%)$ e posicionamento $(69,2 \%)$ eram realizados na promoção do conforto.

Ao submeterem o neonato ao procedimento da PICC foi percebido que apresentavam uma resposta dolorosa diminuída comparado ao que não está fazendo uso dessa prática analgésica.

O posicionamento (13,9\%) proporcionava um conforto durante o procedimento.

A sucção não-nutritiva $(11,20 \%)$ melhorou os parâmetros fisiológicos e comportamentais alterados pela dor.

No manejo da dor e desconforto dos recém-nascido utilizava-se o método rolamento mais sucção não-nutritiva, resultando no conforto no útero artificial $e$ alivio da dor.

Se inicia o tratamento da dor nas ações e atitudes de humanização com métodos não-farmacológicos de manejo. 
Scochi et al./ Enfermagem/ Brasil/2006

A9

Peng et al./ Enfermagem /Taiwan/ 2018

A10 Hsieh et al./
Enfermagem
/Taiwan/ 2018

A11

\section{Neshat et al./} Enfermagem /Irã/ 2016

Cignacco et al./

A12 Enfermagem /Suíça/ 2012
Mudança de decúbito, sucção não-nutritiva, ninho, diminuição dos ruídos, iluminação e toque e contanto pele a pele

\section{Sucção combinada + leite materno, aconchego e dobradinha}

Leite materno, $10 \%$ de água dextrose (D10W) e água destilada (placebo)

Odor do leite materno e de baunilha

Sacarose oral
Tanto a manipulação quanto os estímulos ambientais foram reduzidos para amenizar o desconforto nas unidades.

A combinação dos métodos foi efetiva na redução do escore da dor leve dos prematuros e na redução do escore da dor moderada e intensa no procedimento do calcanhar. As dobradinhas ajudaram na recuperação da dor.

O leite materno é mais eficaz no alivio da dor que a D10W no procedimento do calcanhar e prematuros e ainda auxilia no crescimento e desenvolvimento do recém-nascido.

O odor do leite materno pode reduzir a frequência cardíaca durante e após a punção venosa. $O$ odor de baunilha não teve efeito significativo.

A sacarose foi efetiva no alívio da dor, mesmo em prematuros $<32$ semanas de idade gestacional com exposições repetidas à dor e permanece eficaz nas tentativas do procedimento de calcanhar.

Tabela 1- Distribuição das referências por ano de publicação, país de origem, autores, área de atuação, intervenção testada e avaliação. Teresina, Brasil, 2018

Fonte: Dados da pesquisa, 2018

Em relação síntese metodológica, prevaleceu o estudo quantitativo com oito $(66,6 \%)$. Sete $(66,6 \%)$ foram classificados como nível de evidência $2 B$, conforme Tabela 2 : 
Estudo quantitativo, transversal, avaliativo, tipo inquérito, Conhecimento, profissionais de enfermagem. hospital público, com a participação de 26 profissionais de enfermagem.

Estudo qualitativo, descritivo exploratório, construindo a partir do banco de dados de um projeto e de entrevistas semiestruturadas, com a participação 17 profissionais de enfermagem.

Estudo quantitativo, descritivo exploratório, realizado na UTIN e na participação de 33 técnicos de enfermagem e 9 enfermeiros.

Estudo qualitativo, descritivo, realizando na UTIN de um hospital público. A6 Realizou-se entrevista por meio de um questionário semiestruturado com 05 enfermeiras e 05 técnicos de enfermagem.

Estudo qualitativo, descritivo, realizado na UTIN de um hospital público. Com a participação de 25 profissionais de enfermagem.

Estudo qualitativo, descritivo, na UCIN de um hospital público. Realizouse entrevista semiestruturada com participando 17 profissionais de enfermagem.

Estudo quantitativo, prospectivo, randomizado controlado que foi usado para comparar os efeitos do uso combinado de sucção + leite materno, sucção + leite materno + aconchego e cuidados rotineiros nos escores de dor e risco de dor antes, durante e após procedimentos. Inclusos 109 prematuros com idade gestacional média de 31,21 $\pm 2,87$ semanas.

Estudo quantitativo, prospectivo, randomizado controlado, utilizando métodos como leite materno, água dextrose (D10W), água destilada (placebo)e nada no grupo controle. Inclusos 20 recém-nascidos prematuros.

Estudo quantitativo, prospectivo, randomizado controlado, utilizando

A11 odor do leite materno e odor de baunilha durante e após punção venosa.

Inclusos 135 bebês prematuros divididos em três grupos de controle.

Um estudo quantitativo, multicêntrico, randomizado controlado, utilizando

A12 a sacarose e a contenção facilitadora durante procedimentos em recémnascidos prematuros. Inclusos 71 recém-nascidos prematuros subdivididos em 3 grupos de intervenção.

Tabela 2 - Sumarização das publicações conforme detalhamento do método e classificação do nível de evidência. Teresina, Brasil, 2018.

Fonte: Dados da pesquisa, 2018 


\subsection{O reconhecimento de situações dolorosas nos cuidados críticos}

A Unidade de Terapia Intensiva Neonatal (UTIN) possui um número elevado de procedimentos dolorosos, sendo necessário suporte diagnóstico e terapêutico mais avançado. A identificação da dor é fundamental, mas a ausência do autorrelato pelo neonato dificulta a avaliação e manejo adequado. Dessa maneira, é essencial que os profissionais utilizem instrumentos validados para a mensuração da dor (SPOSITO et al., 2017).

Acredita-se que os recém-nascidos pré-termo possuem maior sensação dolorosa do que $o$ a termo. Nessas situações, as dores intensas devem ser manejadas com agentes farmacológicos prescritos como o uso de analgésicos não-opíodes e os procedimentos leves e intermediários com métodos não farmacológicos (AMARAL et al., 2014).

Entre os procedimentos mais comuns na UTIN estão a punção venosa, intubação, aspiração, drenagem torácica, passagem de sonda e CPAP nasal e não invasivos como manipulação excessiva, toque brusco, posição desconfortável e retirada de esparadrapo (SCOCHI et al., 2006).

Algumas situações são vistas como causadoras de desconforto e estresse ao neonato como abertura da portinhola da incubadora, ruídos e conversas altas na enfermaria. Visto a isso, há necessidade de verificar o ambiente na avaliação clínica de parâmetros sugestivos ao processo doloroso (SANTOS; RIBEIRO; SANTANA, 2012).

Os indicadores comportamentais da dor são: o choro, atividade motora e mímica facial e os indicadores fisiológicos, a frequência cardíaca, respiratória, pressão arterial e saturação de oxigênio. A avaliação ocorre concomitante com os parâmetros fornecendo informações mais confiáveis e válidas (KEGLER et al., 2016).

A exposição repetida a estímulos dolorosos pode ter efeitos deletérios no crescimento e desenvolvimento. Enquanto que a sua redução promove a homeostase e estabilidade clínica, essenciais para o cuidado e suporte aos neonatos imaturos na UTIN. Possíveis complicações podem ser evitadas através da prevenção da causa da dor (ZARGHAMBOROUJENI; ELSAGH; MOHAMMADIZADEH, 2017).

Os instrumentos utilizados na avaliação da dor ou estresse nas UTINs podem ser uni ou multidimensionais, contribuindo no julgamento clínico, reconhecendo potenciais entre a resposta a dor e a sensibilidade. Os profissionais reconhecem a importância da utilização desses instrumentos, mas há uma discrepância entre a utilização e conhecimento da sua existência e limitações quanto ao seu registro e intervenção (HALL; KANWALJEET, 2014).

Um pacote de medidas é fundamental para o aperfeiçoamento na formação, avaliação, gestão e manejo da dor no neonato, priorizando os imaturos por sua resposta a dor ser inespecífica, apresentarem maiores co-morbilidades e instabilidade clínica, incorporando em tais planos a equipe multidisciplinar, neonatologistas e enfermeiros (COLLADOS-GÓMEZ ET AL., 2018). 


\subsection{Manejo da dor com o método não-farmacológico}

No Brasil, um estudo demostrou que de 663 procedimentos dolorosos apena 162 tiveram condutas para alívio da dor. Outro, identificou que os neonatos criticamente doentes são submetidos a vários procedimentos potencialmente dolorosos e recebem manejo inadequado (KEGLER et al., 2016; SILVA, 2017).

O uso dos métodos não-farmacológicos destaca-se como estratégia terapêutica na redução dos danos causados ao recém-nascido pois previne o processo doloroso, a desorganização do neonato, estresse e a agitação. Os mais citados foram redução de ruídos e iluminação (84,6\%), posição canguru $(76,9 \%)$, colo $(76,9 \%)$, aleitamento materno $(73,1 \%)$, posicionamento $(69,2 \%)$, soluções adocicadas $(69,2 \%)$, sucção não-nutritiva $(57,5 \%)$, contenção facilitada (38,5\%), música $(34,6 \%)$ e leite materno $(26,9 \%)$ (NOBREGA et al., 2018; OLIVEIRA et al., 2016).

Em relação aos ruídos, destacam-se o choro do neonato, atividades e a comunicação dos profissionais, barulho da água no circuito do ventilador, incubadora aberta e os alarmes dos equipamentos. A redução da iluminação pode ser feita através de estratégias como cobrir a incubadora, proporcionando o ciclo natural de sono e vigília (SANTOS; RIBEIRO; SANTANA, 2012).

O toque brusco, a manipulação excessiva, posição desconfortável e retirada de esparadrapo ocasiona estresse e sofrimento, deve-se evitar manipular desnecessariamente na troca de fralda e administração de medicação. Tanto a inserção de dispositivos quanto a manutenção acarreta dor e incomodo devido a sua manipulação. Medidas como criações de rotina são necessárias para o bem-estar do neonato (SPOSITO et al., 2017; SCOCHI et al., 2006).

A realização do método canguru apresenta efeitos anestésicos em procedimentos invasivos, reduz o estresse, facilita sucção, favorece o neuropsicomotor e fisiológico do neonato, evolução do seu quadro clínico e aumenta a chances de alta na UTIN (OLIVEIRA et al., 2016).

Ao investigar a sucção do leite materno ou dextrose (glicose + agua destilada), na redução da dor na punção do calcanhar, constatou-se que substancias adocicadas combinada ou não reduzem a dor e que o leite materno deve ser a primeira escolha. Somente água destilada não possui efeitos significativos, necessitando de mais estudos. A partir de uma análise de um estudo com glicose a $25 \%$, foi perceptível que as alterações dos parâmetros estavam ligadas diretamente à intensidade da dor durante o procedimento executado (HSIEH et al., 2016).

Um estudo randomizado controlado realizado em três UTINs na Suíça, tendo a sacarose combinada e a contenção facilitada realizadas nos prematuros na fase crítica dos primeiros 14 dias de internação, mostrou efeitos aditivos no manejo da dor e na recuperação de punção no calcanhar (CIGNACCO et al., 2017). 
Outro estudo expôs um grupo de neonatos ao odor do leite materno e odor de baunilha, obtendo um efeito sedativo não-farmacológico com odor do leite materno que reduz a frequência cardíaca durante e após a punção venosa. Já o odor de baunilha, não teve efeito significativo (ANDREAZZA et al., 2018).

Uma das limitações deste estudo relaciona-se ao número restrito de publicações com acesso ao texto completo, a falta do Decs ou palavra-chave não-farmacológicos e muitos direcionados ao tratamento farmacológico. Frente a isso, recomenda-se a necessidade de novas pesquisas mais aprofundadas sobre o tema.

A contribuição advinda deste estudo se dá pela união e organização dos dados existentes sobre o manejo da dor com o método não-farmacológico nos cuidados intensivos ao neonato, principalmente na validação dos dados da eficácia das intervenções e como é imprescindível o profissional ter evidencias que embase a pratica clinica.

\section{I CONSIDERAÇÕES FINAIS}

O manejo da dor em neonatos não é fácil devido suas peculiaridades o que leva a neonatologia a ser indispensável para o cuidado. Os profissionais de saúde tem um significativo potencial para a prevenção de complicações clínicas ocasionadas pela da dor e desenvolvimento de estratégias que utilizem métodos não-farmacológicos.

É necessário investimentos em educação e formação especializada, ampliando os conhecimentos, percepções e sentimentos dos profissionais para lidar com situações relacionadas ao comportamento ocasionado pela dor. Portanto, instiga-se a realização novos estudos neste âmbito a fim de ampliar a base de evidências, expandindo discussões sobre uso da tecnologia terapêutica na terapia intensiva neonatal, reconhecimento da dor com um sinal vital, escalas de avaliação, protocolos a fim de contribuir no cuidado destinado a aliviar a dor e reduzir sequelas e tempo de internação, proporcionado uma assistência de melhor qualidade aos neonatos.

\section{REFERÊNCIAS}

AMARAL, J. B. et al. Equipe de enfermagem diante da dor do recém-nascido pré-termo. Esc Anna Nery, v. 18, n. 2, p. 241-6, 2014.

ANDREAZZA, M. G. et al. Percepção da dor em neonatos pela equipe de enfermagem de unidade de terapia intensiva neonatal. Revista Brasileira de Pesquisa em Saúde, v. 19, n. 4, p. 133-9, 2018.

BONUTTI, D. P. et al. Dimensionamento dos procedimentos dolorosos e intervenções para alívio da dor aguda em prematuros. Rev. Latino-Am. Enfermagem, v. 25, e2917, 2017.

BRASIL. Ministério da Saúde. Secretaria de Atenção à Saúde. Departamento de Ações Programáticas Estratégicas. Atenção à saúde do recém-nascido: guia para os profissionais de saúde. Brasília, 2014. 
BRENN, B. R. et al. Toward Better Pain Management: The Development of a "Pain Stewardship Program" in a Tertiary Children's Hospital. Hospital pediatrics, v. 6, n. 9, p. 520-8, 2016.

CIGNACCO, E. et al. Individual contextual factors in the validation of the Bernese pain scale for neonates: protocol for a prospective observational study. BMC Pediatr, v. 17, n. 1, p. 171, 2017.

COLLADOS-GÓMEZ, L. et al. Percepción del personal de enfermería sobre el manejo del dolor en neonatos. Enfermería Intensiva, v. 29, n. 1, p. 41-7, 2018.

COSTA, K. F. S. F. et al. Rede de descanso e ninho: comparação entre efeitos fisiológicos e comportamentais em prematuros. Revista Gaúcha de Enfermagem, v. 37, n. esp, e62554, 2016.

DURIEUX, N.; VANDENPUT, S.; PASLEAU, F. Médecine factuelle: la hiérarchisation des preuves par le Centre for Evidence-Based Medicine d'Oxford. Rev Med Liège, v. 68, n. 12, p. 644-49, 2013.

HALL, R. W.; KANWALJEET, J. S. A. Management of pain in newborns. Clin Perinatol, v. 41, n. 4, p. 895-924, 2014.

$\mathrm{HSIEH}, \mathrm{K} . \mathrm{H}$. et al. The analgesic effect of non-pharmacological interventions to reduce procedural pain in preterm neonates. Pediatrics \& Neonatology, v. 59, n. 1, p. 71-6, 2016.

KEGLER, J. J. et al. Manejo da dor na utilização do cateter central de inserção periférica em neonatos. Escola Anna Nery, v. 20, n. 4, e20160099, 2016.

LOCKWOOD, C. et al. Chapter 2: Systematic reviews of qualitative evidence. In: Aromataris E, Munn Z (Editors). Joanna Briggs Institute Reviewer's Manual. The Joanna Briggs Institute, 2017. Disponível em: https://wiki.joannabriggs.org/display/MANUAL/JBI+Reviewer\%27s+Manual

MELO, G. M.; CARDOSO, M. V. L. M. L. Medidas não farmacológicas em recém-nascidos pré-termo submetidos à punção arterial. Revista Brasileira de Enfermagem, v. 70, n. 2, p. 317-25, 2017.

MENDES, K. D. S.; SILVEIRA, R. C. C. P.; GALVÃO, C. M. Revisão integrativa: método de pesquisa para a incorporação de evidências na saúde e na enfermagem. Texto contexto - enferm, v. 17, n. 4, 758-64, 2008.

MORAES, A. P. S. et al. Medidas não farmacológicas no manejo da dor em recém-nascido: cuidado de enfermagem. Rev Rene, v. 17, n. 3, p. 435-42, 2016.

NESHAT, $\mathrm{H}$. et al. Effects of breast milk and vanilla odors on premature neonate's heart rate and blood oxygen saturation during and after venipuncture. Pediatrics \& Neonatology, v. 57, n. 3, p. 225-31, 2016.

NOBREGA, A. S. M. et al. Tecnologias de Enfermagem no Manejo da Dor em Recém-Nascidos na Unidade De Terapia Intensiva Neonatal. Enferm. Foco, v. 9, n. 2, p. 66-72, 2018.

OLIVEIRA, I. M. et al. Conhecimento e atitude dos profissionais de enfermagem sobre avaliação e tratamento da dor neonatal. Revista Eletrônica de Enfermagem, v. 18, e1160, 2016. 
QIU, J. et al. Effect of combined music and touch intervention on pain response and $\beta$-endorphin and cortisol concentrations in late preterm infants. BMC Pediatr, v. 17, p. 38, 2017.

SANTOS, L. M.; RIBEIRO, I. S.; SANTANA, R. C. B. Identificação e tratamento da dor no recémnascido prematuro na Unidade de Terapia Intensiva. Rev. Bras. Enferm, v. 65, n. 2, p. 269-75, 2012.

SBED. Sociedade Brasileira Para Estudo Da Dor. $5^{\circ}$ Sinal Vital. Capítulo Brasileiro da Internacional Association for the Study of Pain - IASP. 2016. Disponivel em: http://www.sbed.org.br/materias. php?cd_secao=65.

SCOCHI, C. G. S. et al. A dor na Unidade Neonatal sob a perspectiva dos profissionais de enfermagem de um hospital de Ribeirão Preto-SP. Rev. Bras. Enferm, v. 59, n. 2, p. 188-94, 2006.

SILVA, L. A. Dor neonatal e o neurocomportamento de recém-nascidos pré-termo. Fundação Oswaldo Cruz, Instituto Nacional de Saúde da Mulher da Criança e do Adolescente Fernandes Figueira. Dissertação (Mestrado em Ciências), Rio de Janeiro, 2017. Disponível em: https://www.arca.fiocruz.br/ handle/icict/25236

SPOSITO, N. P. B. et al. Avaliação e manejo da dor em recém-nascidos internados em uma Unidade de Terapia Intensiva Neonatal: um estudo transversal. Revista Latino-Americana de Enfermagem, v. 25, e2931, 2017.

ZARGHAM-BOROUJENI, U. M.; ELSAGH, U. M.; MOHAMMADIZADEH, H. The effects of massage and breastfeeding on venipuncture pain response among hospitalized neonates. J Nurs Obstetrícia Res, v. 22, n. 4, p. 308-12, 2017. 


\section{CAPÍTULO 15 \\ CATETERISMO VENOSO PERIFÉRICO EM RECÉM-NASCIDOS EM UTI NEONATAL: UM LEVANTAMENTO BIBLIOMÉTRICO}

Data de aceite: $20 / 08 / 2021$

Data da submissão: 26/05/2021

Higor Pacheco Pereira Mestrando em Enfermagem pelo Programa de Pós-Graduação em Enfermagem da

Universidade Federal do Paraná. Curitiba - Paraná https://orcid.org/0000-0001-5112-1118

\section{Débora Maria Vargas Makuch}

Mestre em Ensino nas Ciências da Saúde. Docente da Faculdades Pequeno Príncipe.

Curitiba - Paraná. http://orcid.org/0000-0001-7060-4414

Izabela Linha Secco

Doutoranda em Enfermagem pelo Programa de Pós-Graduação em Enfermagem da Universidade Federal do Paraná. Curitiba - Paraná. http://orcid.org/0000-0003-0930-2139

\section{Andrea Moreira Arrué}

Pós-Doutoranda plo Programa de PósGraduação em Enfermagem da Universidade

Federal do Paraná.

Curitiba - Paraná https://orcid.org/0000-0001-5391-324X

Mitzy Tannia Reichembach Professora associada ao departamento de Enfermagem da Universidade Federal do

Paraná.

Curitiba - Paraná. http://orcid.org/0000-0001-5380-7818
PALAVRAS - CHAVE: Cateterismo venoso periférico, recém-nascido, unidade de terapia intensiva neonatal.

KEYWORDS: Catheterization Peripheral; Infant Newborn; Intensive Care Units Neonatal.

\section{INTRODUÇÃO}

A Unidade de terapia intensiva neonatal (UTIN) é um espaço dedicado à assistência a recém-nascido (RN) em estado de saúde grave, altamente críticos e vulneráveis, onde é necessário o uso de cuidados de enfermagem especiais e contínuos de alta complexidade, emprego de tecnologias e procedimentos invasivos (BOMFIM; PASSOS; SILVA, 2017).

É fundamental que o enfermeiro necessite de conhecimento científico, habilidade técnica, atenção, percepção e sensibilidade no cuidar, para garantir uma assistência segura, humanizada e identificar as necessidades apresentadas pelo RN (BORGHESAN et al., 2017).

Para o sucesso na terapia intravenosa a ser administrada no $\mathrm{RN}$ são fatores determinantes: o tipo de cateter e a gravidade da condição clínica apresentada (SOUZA et al., 2016). Dentre as modalidades de cateteres destaca-se o cateter central de inserção periférica (CCIP), comumente utilizados em $\mathrm{RN}$ à termo e prematuros a fim de terapia 
intravenosa prolongada e uso de nutrição parenteral e são a maioria das linhas centrais inseridas nas UTINs (YU et al., 2018).

\section{OBJETIVO}

Identificar publicações que versam sobre o uso de cateter venoso periférico em recém-nascidos na UTIN.

\section{MÉTODO}

Trata-se de um estudo bibliométrico, descritivo. Realizou-se recorte temporal, sobre o que versam as publicações referente ao uso de cateter venoso periférico em recémnascidos na UTIN, entre janeiro de 2010 a maio de 2019. Utilizou-se o portal da Biblioteca Virtual em Saúde (BVS) com a seguinte estratégia de busca: ("Catheterization Peripheral") AND ("Infant Newborn") AND ("Intensive Care Units Neonatal"). O estudo não envolveu sujeitos, pois incorporou os resultados de estudos primários.

\section{RESULTADOS}

Obteve-se um total de 117 publicações, sendo Texto completo disponível $(n=77$, $65 \%)$, Base de dados internacionais $(n=104,88 \%)$, Base de dados especializadas $(n=13$, $11 \%)$. Base de dados MEDLINE ( $n=87,74 \%)$, LILACS $(n=17,14 \%)$, BDENF-Enfermagem $(n=14,11 \%)$. Quanto ao Assunto principal das publicações foram encontrados "cateterismo periférico" ( $n=96,82 \%)$, "cateterismo venoso central" $(n=47,40 \%)$, "unidades de terapia intensiva neonatal" ( $n=40,34 \%)$, "enfermagem neonatal" $(n=17,14 \%)$, "recém-nascido prematuro" ( $n=16,13 \%)$, "infecções relacionadas a cateter" e "cateteres venosos centrais" $(n=12,10 \%$ respectivamente). Quanto ao tipo de estudo, predominaram estudo de coorte $(n=10,8 \%)$, relatos de casos $(n=5,4 \%)$, ensaio clínico controlado e revisões sistemáticas avaliadas $(n=2,1,5 \%)$. Dentre os Países/regiões que mais publicaram sobre o assunto destaca-se América do Norte ( $n=10,8 \%)$, Ásia $(n=9,7 \%)$, América do Sul $(n=5,4 \%)$, Brasil $(n=4,3 \%)$, Europa $(n=3,2 \%)$, Oceania $(n=2,1,5 \%)$. Há o predomínio do idioma inglês $(n=85,72 \%)$, seguido por português $(n=27,23 \%)$ e espanhol $(n=4,3 \%)$. De acordo com o recorte temporal estabelecido pelos autores obtiveram-se em 2012 ( $n=13,11 \%), 2014$ ( $n=12,10 \%), 2010$ e 2013 ( $n=10,8 \%$ respectivamente), 2011, 2016 e 2017 ( $n=8,6 \%$, respectivamente), $2018(n=2,1 \%)$ e $2019(n=1,0,5 \%)$.

\section{DISCUSSÃO}

A análise bibliométrica das publicações demonstrou predominância de estudos internacionais oriundos da América do Norte no idioma inglês. Com relação ao tipo de 
estudo, $10 \%$ foram estudos com nível 1 de evidência o que contribui para a prática baseada em evidência, o que permite a instrumentalização da prática profissional no contexto do cuidado. Observa-se um declínio na última década quanto ao número de publicações sobre a temática. Destaca-se também como um limitante na pesquisa o termo "cateter venoso central de inserção periférica" não ser um Descritor em Ciências da Saúde (DECS), o que impossibilita filtrar com mais precisão os artigos que englobem essa temática na referida pesquisa.

\section{CONSIDERAÇÕES FINAIS}

Espera-se incentivar os profissionais a realizarem pesquisas envolvendo a temática, buscando um cuidado baseado em evidência a fim de melhorar a competência clínica profissional, a tomada de decisão, a utilização racional de recursos, incorporação de novas tecnologias no cuidado ao recém-nascido, capacitação das equipes em UTIN, o que certamente contribuirá para a excelência na assistência segura ao paciente.

\section{REFERÊNCIAS}

BONFIM, J. M. S.; PASSOS, L. DOS S.; SILVA, J. C. DA. Cateter central de inserção periférico: desafios e estratégias de enfermagem na manutenção do dispositivo. Cuidarte Enfermagem, v. 11, n. 1, p. 131-137, jan. jun. 2017. Disponível em: < http://www.webfipa.net/facfipa/ner/sumarios/ cuidarte/2017v1/18\%20Artigo\%20Cateter_central\%20de\%20inser\%C3\%A7\%C3\%A30\%20 perif\%C3\%A9rico\%20PICC.pdf>. Acesso em 25 mai. 2021.

BORGHESAN, N. B. A. et al. Cateter venoso central de inserção periférica : práticas da equipe de enfermagem na atenção intensiva neonatal. Revista Enfermagem UERJ, v. 25, n. 28143, p. 1-7, dez. 2017. DOI. 10.12957/reuerj.2017.28143. Disponível em:<https://www.e-publicacoes.uerj.br/index. php/enfermagemuerj/article/view/28143>. Acesso em 25 mai. 2021.

SOUZA, R. R. B. DE et al. O conhecimento do enfermeiro sobre cateter central de inserção periférica : estudo descritivo. Online braz j nurs, v. 15, n. 1, p. 21-31, 2016. DOI. 10.17665/16764285.20165298. Disponível em: <file:///C:/Users/Usuario/Downloads/O_conhecimento_do_enfermeiro_ sobre_cateter_central.pdf>. Acesso em: 25 mai. 2021.

YU, X. et al. Risk Factors Related to Peripherally Inserted Central Venous Catheter Nonselective Removal in Neonates. BioMed Research International, v. 2018, p. 1-6, 30 maio 2018. DOI. 10.1155/2018/3769376. Disponível em: < https://www.ncbi.nlm.nih.gov/pmc/articles/PMC5998161/pdf/ BMRI2018-3769376.pdf>. Acesso em: 25 mai. 2021. 


\section{ALÉM DA TEORIA A PRÁTICA HUMANISTA: O USO DE BINQUEDOS TERAPÊUTICOS NA ASSISTÊNCIA PEDIÁTRICA}

Data de aceite: $20 / 08 / 2021$

Data da submissão: 22/06/2021

Ana Flávia da Silva Ribeiro

Faculdade Estácio de Teresina

Teresina - Piauí https://orcid.org/0000-0001-7171-6506

Ana Karina Viana Pereira

Faculdade Estácio de Teresina

Teresina - Piauí https://orcid.org/0000-0001-9201-4474

Andréa Veruska de Souza Almeida

Faculdade Estácio de Teresina

Teresina - Piauí https://orcid.org/0000-0003-0806-1054

Anna Thereza Ribeiro Pindaíba Moura

Faculdade Estácio de Teresina

Teresina - Piauí

https://orcid.org/0000-0003-3040-8106

Maria Luiza Visgueira da Silva

Faculdade Estácio de Teresina

Teresina - Piauí

https://orcid.org/0000-0003-2427-8333

Shavia Ravenna Silva Andrade

Faculdade Estácio de Teresina

Teresina - Piauí

https://orcid.org/0000-0002-5976-2523

Maria Tamires Alves Ferreira

Faculdade Estácio de Teresina

Teresina - Piauí

http://lattes.cnpq.br/4183905820785710
RESUMO: INTRODUÇÃO: A prática de brincar no ambiente hospitalar simboliza o meio de comunicação possível e apropriado da equipe de enfermagem em pediatria. Assim, são adotadas medidas da brinquedoterapia afim de reduzir danos à saúde e integridade da criança. OBJETIVO: Busca explanar a importância do brinquedo terapêutico na assistência à criança hospitalizada. METODOLOGIA: Trata-se de uma pesquisa bibliográfica realizada através do portal MEDLINE (Medical Literature Analysis and Retriebal Sistem), LILACS (Literatura LatinoAmericana e do Caribe em Ciências da Saúde) e BDENF (Base de Dados em Enfermagem) disponíveis no Portal Regional da Biblioteca Virtual em Saúde (BVS) e Pubmed. Os critérios de inclusão foram artigos publicados em recorte temporal de dez anos, no idioma português. RESULTADOS/DISCUSSÃO: Após a análise dos artigos foi possível agrupar as ideias principais em núcleos, sendo eles: Percepção do cliente pediátrico quanto ao uso do Brinquedo Terapêutico; A humanização da assistência com o Brinquedo Terapêutico a partir dos pais/ responsáveis; vivenciando estratégias de cuidado de enfermagem ao paciente pediátrico; Barreiras encontradas na implementação da prática humanizada do Brinquedo Terapêutico. CONCLUSÃO: Assim, observa-se similaridade na implementação de brinquedos terapêuticos ou outras práticas humanistas pelos profissionais para o enfrentamento da dor, embora reconheçam as diversas barreiras encontradas para utilização de tal prática. Contudo, a arte do brincar tornase um processo que reduz o estresse, dor e sofrimento durante a hospitalização. 
PALAVRAS - CHAVE: Jogos e Brinquedos; Criança hospitalizada; Enfermagem Pediátrica.

\section{BEYOND THEORY TO HUMANISTIC PRACTICE: THE USE OF THERAPEUTIC TOYS IN PEDIATRIC CARE}

ABSTRACT: INTRODUCTION: The practice of playing in the hospital environment symbolizes the possible and appropriate means of communication of the nursing team in pediatrics. Thus, play therapy measures are adopted in order to reduce damage to the child's health and integrity. OBJECTIVE: To explain the importance of therapeutic play in assisting hospitalized children. METHODOLOGY: This is a bibliographic search carried out using MEDLINE (Medical Literature Analysis and Retrieval System), LILACS (Latin American and Caribbean Literature on Health Sciences) and BDENF (Nursing Database) available at the Regional Portal of the Virtual Health Library (VHL) and Pubmed. Inclusion criteria were articles published over a ten-year period, in Portuguese. RESULTS/DISCUSSION: After analyzing the articles, it was possible to group the main ideas into cores, as follows: Perception of the pediatric client regarding the use of the Therapeutic Toy; The humanization of assistance with the Therapeutic Toy from the parents/guardians; Experiencing nursing care strategies to the pediatric patient; Barriers found in the implementation of the humanized practice of the Therapeutic Toy. CONCLUSION: Thus, it is observed similarity in the implementation of therapeutic toys or other humanistic practices by professionals for coping with pain, although they recognize the various barriers encountered for the use of such practice. However, the art of play becomes a process that reduces stress, pain and suffering during hospitalization.

KEYWORDS: Games and Toys; Hospitalized Child; Pediatric Nursing.

\section{INTRODUÇÃO}

A infância consiste em um período da vida de grande desenvolvimento e crescimento humano. No Brasil, as patologias de origem gastrointestinais, respiratórias e infecciosas, além de acidentes domésticos e de trânsito, são as principais causas de hospitalização que acometem crianças menores de cinco anos (OLÍMPIO et al., 2018).

Percebe-se que a rotina hospitalar pode desencadear conturbações emocionais na criança, como medo, ansiedade e diversas frustrações que comprometem a sua qualidade de vida, tendo em vista que por ser fonte de estresse evidenciado por ambiente e pessoas desconhecidas além de procedimentos dolorosos, gera mudanças na rotina e afastamento de familiares (NICOLINO et al., 2015; SILVEIRA, LIMA, PAULA, 2018).

A hospitalização infanto-juvenil, por ser uma condição nova e desafiadora, na maioria dos casos, requer da equipe prestadora de cuidados intervenções que minimizem o sofrimento da criança ou adolescente sujeito. Nesse sentido, o trabalho multidisciplinar deve ser realizado a partir de uma abordagem que considere a criança/adolescente como um ser em desenvolvimento e com necessidades individuais e características (CHEROBIN, ADAMOLI, 2015; MOREIRA-DIAS, SILVA, 2018).

Sendo assim, a prática de brincar é algo que favorece o elo de ligação da criança 
com a imaginação, permitindo olhar leve com sentimento de conforto e bem-estar. A brinquedoterapia consiste em uma intervenção terapêutica em uso para reduzir danos à saúde e integridade da criança afim de promover reciprocidade entre paciente e equipe multiprofissional oferecendo benefício na cessação de sentimentos negativos (SANTOS et al., 2020).

Além do mais, o brincar no ambiente hospitalar representa um meio de comunicação possível nos serviços de saúde tendo em vista que proporciona compreender e atender as necessidades das crianças e contribui para os profissionais de saúde na transformação do cenário hospitalar em um espaço mais humanizado (RIBEIRO et al., 2020).

Em Sousa et al. (2015), é perceptível que a brinquedoteca é tida como ambiente preferido para a permanência da criança durante a internação $(96,9 \%)$, vista como local mais adequado, por promover novas experiências, bem como amenizar os efeitos negativos e difíceis da hospitalização, auxilia no desenvolvimento incentivando a aprendizagem através do oferecimento de atividades pedagógicas, bem como o desencadeamento de habilidades físicas e psicológicas, despertando novos interesses.

Para esse fim, a equipe deve aderir a meios estratégicos e eficazes de comunicação, através do lúdico e do recreativo, com o objetivo de estreitar laços com a criança e, facilitar a aceitação do tratamento, adquirir confiança e permitir a vivência típica da idade da qual possui (MOREIRA-DIAS, SILVA, 2018).

Conforme disposto na Resolução n 546/2017 do Conselho Federal de Enfermagem (COFEN), em seu artigo 10: "Compete à Equipe de Enfermagem que atua na área pediátrica, a utilização da técnica do brinquedo/brinquedo terapêutico, na assistência à criança e família hospitalizadas", e em seu artigo 20: "A utilização da técnica do brinquedo/ brinquedo terapêutico deverá contemplar as etapas do Processo de Enfermagem (...)", fazse necessário discutir sobre as perspectivas do enfermeiro quanto à utilização do BT nas suas intervenções.

Nesta perspectiva, justifica-se o interesse em desenvolver esse estudo para identificar na literatura evidências científicas sobre a importância do brinquedo terapêutico na assistência à criança hospitalizada.

\section{METODOLOGIA}

O presente estudo trata-se se uma revisão integrativa desenvolvida em seis etapas: elaboração da questão norteadora, levantamento de dados, coleta de dados, filtragem de arquivos e levantamento de informações, resultados obtidos e discussões para a construção deste artigo.

A primeira refere-se à elaboração da questão norteadora: Qual a importância do brinquedo terapêutico na assistência à criança hospitalizada? Na segunda etapa, fez-se o levantamento bibliográfico nas bases de dados MEDLINE (Medical Literature Analysis 
and Retriebal Sistem), LILACS (Literatura Latino-Americana e do Caribe em Ciências da Saúde) e BDENF (Base de Dados em Enfermagem), disponíveis no Portal Regional da Biblioteca Virtual em Saúde (BVS), e no Pubmed (National Library of Medicine - NLM).

Para tal, utilizaram-se os Descritores em Ciências da Saúde (DeCS e MeSH) "Jogos e brinquedos", "Criança hospitalizada" e "Enfermagem pediátrica" e, "Games and toys", "Child hospitalized", "Pediatric nursing" e, entre eles, o operador booleano AND, obtendose 166 publicações. Foram adotados os critérios de inclusão: artigos publicados nos últimos dez anos (2010 a 2020) e disponíveis na íntegra com temática referente ao uso do brinquedo terapêutico pela Enfermagem. Dessa forma, foi implementado uma estratégia de busca nas bases de dados, detalhado no QUADRO 1.

\begin{tabular}{|c|c|}
\hline Base de Dados & Estratégia de Busca \\
\hline MEDLINE (Pubmed) & $\begin{array}{c}(\text { Games and toys) AND (Child hospitalized)) AND } \\
\text { (Pediatric nursing) }\end{array}$ \\
\hline BDENF, LILACS E MEDLINE via BVS & $\begin{array}{c}\text { ("Jogos e brinquedos" AND "Criança } \\
\text { hospitalizada" AND "Enfermagem pediátrica") }\end{array}$ \\
\hline
\end{tabular}

QUADRO 1: Estratégias de busca.

A terceira etapa se deu a partir da coleta de dados. O instrumento utilizado para descrição dos estudos elencado na busca foi composto das seguintes informações: título do artigo, ano de publicação, nome do periódico, autoria e principais achados. Na quarta etapa, relativa à análise dos dados obtidos, foram levados em consideração aqueles extraídos dos critérios de inclusão, previamente citados. A filtragem resultou em 56 artigos, no entanto, foram excluídos documentos sem relação com o tema (14); documentos em outros formatos, como revisões da literatura (1), teses (2) e relatos de experiência (1); documentos de acesso restrito (6); e repetidos (7). Desse modo, a nossa busca final obteve 25 artigos para a realização do estudo como demonstra o fluxograma na figura 1.

A análise dos resultados evidenciados foi realizada de forma descritiva, sendo apresentada a síntese de cada estudo incluído na revisão integrativa e comparações entre as pesquisas incluídas, destacando diferenças e semelhanças. 


\begin{tabular}{|c|c|c|c|c|}
\hline \multicolumn{5}{|c|}{ Coleta de dados } \\
\hline \multicolumn{5}{|c|}{ Total de 166 artigos encontrados } \\
\hline LILACS & BDENF & MEDLINE (BVS) & \multicolumn{2}{|r|}{ MEDLINE (Pubmed) } \\
\hline \multirow[t]{2}{*}{36} & 40 & 87 & & 03 \\
\hline & & & \multicolumn{2}{|c|}{$\begin{array}{l}\text { Após critério de inclusão } \\
\text { e exclusão }(\mathrm{n}=56)\end{array}$} \\
\hline \multicolumn{5}{|c|}{ Após nova análise para exclusão (56 artigos) } \\
\hline LILACS & BDE & MEDLINE & & MEDLINE (Pubmed) \\
\hline 24 & 22 & 07 & & 03 \\
\hline
\end{tabular}

Excluídos artigos que fugiram da temática (14), em outro formato (4), acesso restrito (6), repetidos (7).

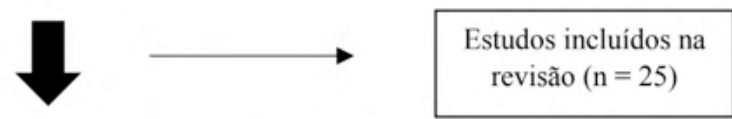

\begin{tabular}{c|c|c}
\hline LILACS & BDENF & MEDLINE (Pubmed) \\
\hline 11 & 13 & 1 \\
\hline
\end{tabular}

Figura 1: Fluxograma da seleção de artigos.

\section{RESULTADOS}

Obteve-se um total de 25 artigos na qual foi possível analisar como torna-se diferencial a implementação de novas estratégias que adotem a humanização no cuidado pediátrico e assim contribuir para a redução dos impactos negativos gerados pela hospitalização.

Quanto ao período do estudo, a maioria era do ano de 2016 (18,6\%), 14,8\% de cada um dos anos 2014, 2019 e 2020, 7,4\% correspondente aos anos 2011, 2012, 2013, 2018 cada, e os demais anos de 2015 e 2017 correspondem a 3,7\% dos artigos. Além disso, notou-se a prevalência de estudos do tipo descritivo com abordagem qualitativa, totalizando 18 artigos $(66,6 \%)$, estudo exploratório $(22,2 \%)$ e demais de caráter fenomelógico $(11,1)$. (QUADRO 02)

Os periódicos evidenciados consistem em: Journal of reserach: fundamental care. Online (2); Psico-USF (1); Revista Gaúcha de Enfermagem (3); Escola Anna Nery (2); Revista Mineira de Enfermagem (1); Revista de enfermagem da UFPE online (4); Revista Baiana de Enfermagem (1); Online Brazilian Journal of Nursing (1); Cogitare Enfermagem (1); Ciência Cuidado e Saúde (1); Health Sci Inst. (1); Acta Paulista de Enfermagem (2); Revista Brasileira de Enfermagem (1); Revista Escola de Enfermagem USP (2); Revista Pesquisa: cuidado é Fundamental Online (2), sendo a Revista de Enfermagem da UFPE o periódico em maior evidencia entre os estudos.

Através dos estudos foi possível analisar como o uso de atividades que estimulem o humor, transmitem felicidade e permitem a liberação de sentimentos assim como realizar 
dinamicamente as implementações assistenciais direcionadas para o tratamento das complicações na saúde evidenciadas pelas crianças. Sabendo ainda que os profissionais de saúde possuem dificuldade em manter relação inicial com esse público, o uso dessa prática humanista favorece positivamente o vínculo tanto com o paciente como com a família, e ainda que seja comprovada por estudos sua eficácia, muitas instituições têm certa dificuldade de realizar a adesão e ter profissionais capacitados para a aplicação da técnica.

\begin{tabular}{|c|c|c|c|}
\hline TíTULO & ANO & MÉTODO & PERIÓDICO \\
\hline $\begin{array}{l}\text { Dificuldades da enfermagem na } \\
\text { utilização do lúdico no cuidado à } \\
\text { criança com câncer hospitalizada }\end{array}$ & 2014 & $\begin{array}{l}\text { Pesquisa descritiva, com } \\
\text { abordagem qualitativa }\end{array}$ & $\begin{array}{l}\text { Journal of reserach: } \\
\text { fundamental care. online }\end{array}$ \\
\hline $\begin{array}{c}\text { Cuidado lúdico à criança } \\
\text { hospitalizada: perspectiva do } \\
\text { familiar cuidador e equipe de } \\
\text { enfermagem }\end{array}$ & 2014 & $\begin{array}{c}\text { Pesquisa exploratória, } \\
\text { descritiva de caráter } \\
\text { qualitativa }\end{array}$ & $\begin{array}{l}\text { Journal of reserach: } \\
\text { fundamental care. online }\end{array}$ \\
\hline $\begin{array}{l}\text { Palhaços de hospital como } \\
\text { estratégia de amenização da } \\
\text { experiência de hospitalização } \\
\text { infantil }\end{array}$ & 2014 & $\begin{array}{l}\text { Pesquisa de caráter } \\
\text { qualitativo. }\end{array}$ & Psico-USF \\
\hline $\begin{array}{c}\text { Contribuição do brinquedo } \\
\text { terapêutico estruturado em } \\
\text { um modelo de cuidado de } \\
\text { enfermagem para crianças } \\
\text { hospitalizadas }\end{array}$ & 2016 & $\begin{array}{c}\text { Trata-se de uma Pesquisa } \\
\text { Convergente Assistencial } \\
\text { (PCA), de abordagem } \\
\text { qualitativa }\end{array}$ & $\begin{array}{l}\text { Revista Gaúcha de } \\
\text { Enfermagem }\end{array}$ \\
\hline $\begin{array}{l}\text { Lúdico no cuidado à criança } \\
\text { e ao adolescente com câncer: } \\
\text { perspectivas da equipe de } \\
\text { enfermagem }\end{array}$ & 2016 & $\begin{array}{c}\text { Pesquisa descritiva } \\
\text { exploratória de abordagem } \\
\text { qualitativa }\end{array}$ & Esc. Anna Nery \\
\hline $\begin{array}{c}\text { A ludoterapia e a criança } \\
\text { hospitalizada na perspectiva dos } \\
\text { pais }\end{array}$ & 2016 & $\begin{array}{l}\text { Trata-se de pesquisa } \\
\text { qualitativa, descritiva }\end{array}$ & Rev Min Enferm \\
\hline $\begin{array}{l}\text { Brincando para continuar a } \\
\text { ser criança e libertar-se do } \\
\text { confinamento da hospitalização } \\
\text { em precaução. }\end{array}$ & 2018 & Pesquisa qualitativa & Escola Anna Nery \\
\hline $\begin{array}{l}\text { Percepção dos acompanhantes } \\
\text { das crianças hospitalizadas } \\
\text { acerca do brinquedo terapêutico. }\end{array}$ & 2018 & $\begin{array}{l}\text { Estudo qualitativo, } \\
\text { de campo, descrito e } \\
\text { exploratório }\end{array}$ & $\begin{array}{l}\text { Rev enferm UFPE on } \\
\text { line }\end{array}$ \\
\hline $\begin{array}{l}\text { O brincar e a criança } \\
\text { hospitalizada: visão de } \\
\text { enfermeiras. }\end{array}$ & 2016 & $\begin{array}{l}\text { Estudo exploratório com } \\
\text { abordagem qualitativa }\end{array}$ & $\begin{array}{l}\text { Revista Baiana de } \\
\text { Enfermagem }\end{array}$ \\
\hline
\end{tabular}




\begin{tabular}{|c|c|c|c|}
\hline $\begin{array}{c}\text { Brinquedo terapêutico na } \\
\text { administração de medicação } \\
\text { endovenosa em crianças: estudo } \\
\text { exploratório }\end{array}$ & 2016 & $\begin{array}{l}\text { Estudo exploratório, } \\
\text { qualitativo. }\end{array}$ & $\begin{array}{c}\text { Online Brazilian Journal } \\
\text { of Nursing }\end{array}$ \\
\hline $\begin{array}{l}\text { Validação de conteúdo para } \\
\text { construção de sítio virtual sobre } \\
\text { uso do brinquedo na enfermagem } \\
\text { pediátrica }\end{array}$ & 2013 & $\begin{array}{l}\text { Pesquisa exploratória, } \\
\text { quantitativa e qualitativa. }\end{array}$ & Cogitare Enfermagem \\
\hline $\begin{array}{l}\text { Protocolo de desinfecção de } \\
\text { brinquedos em unidade de } \\
\text { internação pediátrica: vivência } \\
\text { acadêmica de enfermagem }\end{array}$ & 2013 & $\begin{array}{c}\text { Pesquisa exploratória e } \\
\text { descritiva. }\end{array}$ & Ciênc. Cuid. Saúde \\
\hline $\begin{array}{l}\text { O Brinquedo Terapêutico e o } \\
\text { lúdico na visão da equipe de } \\
\text { enfermagem }\end{array}$ & 2012 & $\begin{array}{l}\text { Pesquisa descritiva e } \\
\text { qualitativa, através de uma } \\
\text { revista semiestruturada. }\end{array}$ & Health Sci Inst. \\
\hline $\begin{array}{l}\text { Uso rotineiro do brinquedo } \\
\text { terapêutico na assistência } \\
\text { a crianças hospitalizadas: } \\
\text { percepção de enfermeiros }\end{array}$ & 2012 & $\begin{array}{l}\text { Estudo descritivo- } \\
\text { exploratório, de } \\
\text { abordagem quantitativa. }\end{array}$ & $\begin{array}{l}\text { Acta Paulista de } \\
\text { Enfermagem }\end{array}$ \\
\hline $\begin{array}{c}\text { Percepção das crianças acerca } \\
\text { da punção venosa por meio do } \\
\text { brinquedo terapêutico }\end{array}$ & 2020 & Abordagem qualitativa & Acta Paul Enfermagem \\
\hline $\begin{array}{c}\text { Compreendendo a sessão de } \\
\text { brinquedo terapêutico dramático: } \\
\text { contribuição para a enfermagem } \\
\text { pediátrica }\end{array}$ & 2020 & Estudo qualitativo & Rev. Bras. Enferm \\
\hline $\begin{array}{c}\text { A percepção do escolar sobre a } \\
\text { hospitalização: } \\
\text { Contribuições para o cuidado de } \\
\text { enfermagem }\end{array}$ & 2011 & Abordagem qualitativa & Rev Esc Enferm USP \\
\hline $\begin{array}{c}\text { Utilizando o brinquedo } \\
\text { terapêutico instrucional durante } \\
\text { a admissão de crianças no } \\
\text { hospital: percepção da família }\end{array}$ & 2020 & Pesquisa fenomelógica & $\begin{array}{l}\text { Revista Gaúcha de } \\
\text { Enfermagem }\end{array}$ \\
\hline $\begin{array}{l}\text { The therapeutic play in nursing } \\
\text { graduation: from theory to } \\
\text { practice }\end{array}$ & 2019 & Estudo qualitativo & $\begin{array}{l}\text { Revista de Pesquisa: } \\
\text { Cuidado é Fundamental } \\
\text { Online }\end{array}$ \\
\hline $\begin{array}{l}\text { Play as a care strategy for } \\
\text { children with cancer }\end{array}$ & 2015 & $\begin{array}{l}\text { Estudo descritivo de } \\
\text { caráter exploratório }\end{array}$ & $\begin{array}{l}\text { Revista Gaúcha de } \\
\text { Enfermagem }\end{array}$ \\
\hline $\begin{array}{l}\text { Compreendendo a sensibilização } \\
\text { do enfermeiro para o uso do } \\
\text { brinquedo terapêutico na prática } \\
\text { assistencial à criança }\end{array}$ & 2011 & Interacionismo simbólico & Rev Esc Enferm USP \\
\hline
\end{tabular}




\begin{tabular}{|c|c|c|c|}
\hline $\begin{array}{c}\text { Utilização do lúdico no cenário da } \\
\text { hospitalização pediátrica }\end{array}$ & 2019 & $\begin{array}{c}\text { Estudo qualitativo, } \\
\text { descritivo e exploratório }\end{array}$ & $\begin{array}{c}\text { Rev. Enferm UFPE } \\
\text { online }\end{array}$ \\
\hline $\begin{array}{c}\text { Estratégias lúdicas no cuidado } \\
\text { de enfermagem à criança } \\
\text { hospitalizada }\end{array}$ & 2019 & $\begin{array}{c}\text { Estudo qualitativo, } \\
\text { descritivo. }\end{array}$ & $\begin{array}{c}\text { Rev. Enferm UFPE } \\
\text { online }\end{array}$ \\
\hline $\begin{array}{c}\text { O brincar de irmãos de crianças } \\
\text { hospitalizadas após visita } \\
\text { hospitalar }\end{array}$ & 2019 & $\begin{array}{c}\text { Estudo qualitativo } \\
\text { de abordagem } \\
\text { fenomenológica. }\end{array}$ & $\begin{array}{c}\text { Rev. Enferm UFPE } \\
\text { online }\end{array}$ \\
\hline $\begin{array}{c}\text { A percepção do enfermeiro sobre } \\
\text { o brincar e o impacto dessa } \\
\text { prática na assistência pediátrica }\end{array}$ & 2020 & $\begin{array}{c}\text { Pesquisa descritiva, } \\
\text { exploratória e com } \\
\text { abordagem qualitativa. }\end{array}$ & $\begin{array}{c}\text { Rev. Pesqui: cuid. } \\
\text { Fundam. Online }\end{array}$ \\
\hline
\end{tabular}

QUADRO 2: Quanto ao título, ano, método e periódico.

\section{DISCUSSÕES}

Após a análise dos artigos foi possível agrupar as ideias principais em três categorias temáticas: (1) percepção do cliente pediátrico quanto ao uso do Brinquedo Terapêutico; (2) a humanização da assistência com o Brinquedo Terapêutico a partir dos pais/responsáveis; (3) vivenciando estratégias e dificuldades de cuidado em enfermagem com uso do brinquedo terapêutico.

\section{Percepção do cliente pediátrico quanto ao uso do Brinquedo Terapêutico}

Tendo em vista que o processo de hospitalização pediátrica acarreta fatores de estresse na criança, faz-se necessário a discussão sobre mudança na abordagem clínica adotada. Dessa forma, a arte do brincar, mediante execuções de técnicas e momentos de lazer na brinquedoteca, facilita não só o tratamento da criança, como atua de forma significativa no crescimento e desenvolvimento (CASTRO, REZENDE., 2012; DEPIANTI et al, 2014; DEPIANTI, MELO, RIBEIRO, 2018; SILVA et al., 2018; CALEFFI et al., 2016; OLIVEIRA et al., 2016; SANTOS et al., 2020)

Nesse contexto, a hospitalização pode repercutir negativamente na saúde mental das crianças e deve ser entendida como um processo que tem diferentes impactos no comportamento de cada uma, uma vez que isso depende de fatores como idade, a forma de abordagem realizada pelo profissional e a assistência prestada. O uso do Brinquedo Terapêutico (BT) na assistência ao paciente pediátrico é percebido pelas próprias crianças como um meio de minimizar a tensão criada pela mudança de ambiente causada pela hospitalização (SOUZA et al., 2012; SILVA et al., 2019; RIBEIRO et al., 2020).

Em seu estudo, Souza e Lapa (2011) relatam, a partir da visão dos pacientes, que mesmo os hospitais gerais ou pediátricos dispondo de práticas humanistas, ainda é raro que as instituições gerais incentivem os profissionais a aderirem às atividades lúdicas e recreativas na assistência prestada às crianças. Mesmo em hospital pediátrico, o lúdico 
ainda é pouco realizado, e isso distancia ainda mais a criança do que antes era sua rotina, e essa realidade pode ser percebida por ela como uma consequência tão ruim quanto estar sujeita aos procedimentos dolorosos (SOUZA, LAPA, 2011; FRANCISCHINELLI, ALMEIDA, FERNANDES, 2012; LIMA, SANTOS, 2015; MARQUES et al., 2016).

Assim como o brincar, o humor acrescenta muitos benefícios quando utilizado para a diversão das crianças hospitalizadas. Nessa perspectiva, muitas instituições recebem ações voluntárias na qual utilizam de fantasias para gerar distração nas crianças e amenizar o medo dos procedimentos e adaptação no ambiente hospitalar, assim permite interação e expressão dos sentimentos, ao mesmo tempo que estimula propagação de alegria (CAIRES et al., 2014).

\section{A humanização da assistência com o Brinquedo Terapêutico a partir da visão dos pais/responsáveis}

Quando uma criança precisa ser hospitalizada, o responsável legal por ela passa à condição de acompanhante e a conviver com a rotina hospitalar, presenciando procedimentos dolorosos, lidando com a própria angústia e a do filho por estarem em um ambiente que, em muitos casos, remete ao sofrimento ou por não saberem quando tal situação findará. Nesses casos, o BT vira peça-chave na humanização do serviço, uma vez que elimina a tensão criada pelas intervenções hospitalares e, consequentemente, reduz a barreira entre profissional e paciente, e entre profissional e familiar.

Os responsáveis pais e familiares do paciente pediátrico perceberm no BT um meio de transmitir segurança e conforto para a criança ao facilitar a aceitação do tratamento, principalmente na realização dos cuidados de enfermagem. Também segundo os autores, na visão dos pais, o uso do BT pela equipe de enfermagem significa respeito e consideração pela criança, estimulação da sua capacidade física e uma tentativa de diminuir a hostilidade que o ambiente parece transmitir. Além disso, para eles, o brincar ajuda a criança no entendimento em relação aos procedimentos realizados e à necessidade da internação (FIORETI et al., 2016; SILVA et al., 2018; ARANHA et al., 2020).

Outros estudos abordam que a utilização do brinquedo terapêutico no preparo da punção venosa promove maior bem-estar e serenidade a criança, além de proporcionar aceitação e compreensão do procedimento, pois passa a compreender melhor o procedimento e se torna mais colaborativa quando se permite que ela visualize e manuseie o instrumento. Com isso, o enfermeiro consegue detectar informações e equívocos acerca de receios e fantasias irreais do paciente pediátrico. Dessa forma, o profissional de saúde propicia um tratamento menos traumático, reduz o sofrimento causado pelas enfermidades e colabora para a recuperação da criança (LIMA, SANTOS, 2015; BARROSO et al., 2020).

Em concomitância com tais estudos, observa-se o setting intitulado como um local/espaço para brincadeira, na qual é induzida por irmãos e familiares, de forma que fortaleçam laços e se mantenham unidas no processo de hospitalização, bem como integrar 


\section{Vivenciando estratégias e dificuldades de cuidado em enfermagem com uso do brinquedo terapêutico}

Maia, Ribeiro e Borba (2011), ao descreverem a sensibilização do enfermeiro para o uso do BT na prática assistencial em pediatria, encontraram nos participantes do estudo unanimidade no que se refere aos benefícios que esse instrumento traz à criança, ao familiar e ao próprio enfermeiro.

O primeiro contato do enfermeiro com o brinquedo terapêutico, na maioria dos casos, acontece ainda na faculdade. O Conselho Regional de Enfermagem de São Paulo (COREN$\mathrm{SP}$ ) recomenda a inserção desse instrumento nos cursos de graduação, propondo que seja conteúdo obrigatório na grade curricular dos Cursos de Graduação em Enfermagem. Essa proposta vem sendo adotada pelos enfermeiros docentes, que buscam possibilitar que 0 aluno conheça e vivencie essa prática, com o objetivo de torná-la cada vez mais comum no ambiente hospitalar (MAIA, RIBEIRO, BORBA, 2011; BARROSO et al., 2019).

Sabe-se que, por mais que existam capacitações, respaldo legal e interesse em utilizar o BT, muitas vezes o enfermeiro, ou outro profissional, não possui incentivo por parte da instituição ou da própria equipe. $\mathrm{O}$ uso desse objeto é muito comum em hospitais pediátricos, no entanto, em hospitais gerais, como aqueles especializados em cardiologia, poucos são os profissionais com alguma formação em pediatria, fato que acaba se tornando um empecilho e até desestímulo para aqueles que a possuem e desejam colocá-la em prática (MAIA, RIBEIRO, BORBA, 2011; SANTOS et al., 2020).

No entanto, ainda que haja benefícios com a prática do cuidado lúdico, resultados do estudo mostram que existem fatores que causam restrição ao uso, uma vez que existe alta incidência de contaminação e infecção cruzada por meio do brinquedo o que aumenta a necessidade de limpeza e fiscalização (NICOLA, et al., 2014; RIBEIRO et al., 2020; SILVA et al., 2019).

A carência de recursos nas instituições hospitalares para a adesão da brinquedoteca, falta de preparo da equipe e rápida rotina dos profissionais são algumas outras barreiras evidenciadas na adoção dessa prática. Sendo assim, sabendo que é importante buscar novas estratégias facilitadoras do cuidado pediátrico, outras ações podem contribuir como o ato de contar histórias e cantar, no intuito de estimular a imaginação, a expressão dos sentimentos, e cessar as conturbações geradas pela hospitalização (NICOLA, et al., 2014; RIBEIRO et al., 2020; SILVA et al., 2019).

Em contrapartida a isso, estudos como de Paula et al(2019), demonstram que mesmo com a falta de insumos adequados e as diversas barreiras aqui citadas, estes utilizam de materiais hospitalares dispostos no posto como (seringas, luvas, esparadrapo, papel, caneta) durante a realização de procedimentos. Apontou-se, ainda que além de diversas estratégias lúdicas, os profissionais ainda procuram utilizar roupas/jalecos coloridos e com 
desenhos, para desmitificar a ideia de que o ambiente hospitalar é algo assustador.

\section{CONSIDERAÇÕES FINAIS}

A hospitalização na medida que é um processo gerador de estresse, dor e sofrimento tanto para as crianças para os pais destas ela também pode promover novas vivências e aprendizados. Assim, destaca-se os benefícios da implementação de brinquedos terapêuticos ou outras práticas humanistas pelos profissionais para o enfrentamento da dor e estresse da hospitalização, embora reconheçam as diversas barreiras encontradas para utilização de tal prática.

Reitera-se assim, que essa prática humanista constitui um recurso de comunicação importante no âmbito hospitalar. Entretanto, reforça-se a importância da capacitação de profissionais para melhor adequação dos mesmos na prestação da assistência de enfermagem.

\section{REFERÊNCIAS}

ARANHA, BF, et al. Utilizando o brinquedo terapêutico instrucional durante a admissão de crianças no hospital: percepção da família. Revista Gaúcha de Enfermagem, v. 41, 2020. http://dx.doi. org/10.1590/1983-1447.2020.20180413

Barroso, MC, et al. Percepção das crianças acerca da punção venosa por meio do brinquedo terapêutico. Acta Paulista de Enfermagem, v. 33, 2020.

BARROSO, MCCS, et al. The therapeutic play in nursing graduation: from theory to practive. Revista de Pesquisa: Cuidado é Fundamental Online, v. 11, n. 4, p. 1043-1047, 2019. DOI: 10.9789/21755361.2019.v11i4.1043-1047.

CAIRES, S; ESTEVES, CH; CORREIA, S. Palhaços de hospital como estratégia de amenização da experiência de hospitalização infantil. Psico-USF, Bragança Paulista, v. 19, n. 3, p. 377-386, set./dez. 2014.

CALEFFI, CCF, et al. Contribuição do brinquedo terapêutico estruturado em um modelo de cuidado de enfermagem para crianças hospitalizadas. Revista Gaúcha de Enfermagem, v. 37, n. 2, 2016. http:// dx.doi.org/10.1590/1983-1447.2016.02.58131

CASTRO, AR; REZENDE, MA. Validação de conteúdo para construção de sítio virtual sobre uso do brinquedo na enfermagem pediátrica. Cogitare Enferm. 2013 Abr/Jun; 18(2):261-7. Disponível em: http://www.revenf.bvs.br/scielo.php?script=sci_arttext\&pid=S1414-85362013000200008.

CHEROBIN, IA; ADAMOLI, AN. Conhecimento da equipe multiprofissional sobre Crianças com Câncer: Percepções da Equipe Multidisciplinar. Revista Brasileira de Cancerologia, v. 64, n. 3, p. 311-318, 2018.

DANTAS, FA, et al. Brinquedo terapêutico na administração de medicação endovenosa em crianças: estudo exploratório. Online Braz. J. Nurs. (Online), v. 15, n. 3, p. 454-465, 2016. 
DEPIANTI, JRB, et al. Dificuldades da enfermagem na utilização do lúdico no cuidado à criança com câncer hospitalizada. J. res.: fundam. Care. online. Jul./set. v. 6, n. 3, p. 1117-1127, 2014.

DEPIANTI, JRB.; DE LIONE MELO, L; RIBEIRO, CA. Brincando para continuar a ser criança e libertarse do confinamento da hospitalização em precaução. Escola Anna Nery, v. 22, n. 2, 2018.

FIORETI, FCCF; MANZO, BF; REGINO, AEF. A ludoterapia e a criança hospitalizada na perspectiva dos pais. REME - Revista Mineira de Enfermagem, p. 1-6, 2016.

FRANCISCHINELLI, AGB.; ALMEIDA, FA; FERNANDES, DM. Uso rotineiro do brinquedo terapêutico na assistência a crianças hospitalizadas: percepção de enfermeiros. Acta Paulista de Enfermagem. Disponível em: https://doi.org/10.1590/S0103-21002012000100004 .

LIMA, KYN.; SANTOS, VEP. Play as a care strategy for children with câncer. Revista Gaúcha de Enfermagem, v. 36, n. 2, p. 76-81, 2015. DOI: http://dx.doi.org/10.1590/19831447.2015.02.51514

MAIA, EBS.; RIBEIRO, CA; BORBA, RIH. Compreendendo a sensibilização do enfermeiro para o uso do brinquedo terapêutico na prática assistencial à criança. Revista Esc. Enferm. USP, v. 45, n. 4, p. 839-846, 2011.

MARQUES, EP, et al. Lúdico no cuidado à criança e ao adolescente com câncer: perspectiva da equipe de enfermagem. Escola Anna Nery, v. 8, 2016. https://doi.org/10.5935/1414-8145.20160073

MELO, LL; PEDROSO, GER.; GARCIA, APRF. O brincar de irmãos de crianças hospitalizadas após visita hospitalar. Rev enferm UFPE on line, v. 13, p. 1-8, 2019. DOI: https://doi.org/10.5205/19818963.2019.240898

MOREIRA-DIAS, PL.; SILVA, IP. A Utilização do Brinquedo durante o Tratamento multidisciplinar da unidade de pediatria de um hospital da Serra gaúcha. Ciências e Artes. v. 1, n. 1. 2018.

NICOLA, GDO, et al. Cuidado lúdico à criança hospitalizada: perspectiva do familiar cuidador e equipe de enfermagem. J. res.: fundam. Care. Online. Abr./jun. 6(2):703-715 2014.

NICOLINO, TNA, et al. Contação de história na unidade pediátrica: percepção de acompanhantes de crianças hospitalizadas. Revista de Enfermagem da UFSM, v. 5, n. 1, p. 32-39, 2015. DOI: $10.5902 / 2179769213204$

OLÍMPIO, ACS, et al. Perfil clínico-epidemiológico de internamentos na unidade pediátrica de um hospital público cearense. REME - Revista Mineira de Enfermagem, v. 22, 2018. DOI: http://www. dx.doi.org/10.5935/1415-2762.20180044

OLIVEIRA, JD, et al. O brincar e a criança hospitalizada: visão de enfermeiras. Revista Baiana de Enfermagem, v. 30, n. 4, 2016.

PAULA, GK, et al. Estratégias lúdicas no cuidado de enfermagem à criança hospitalizada. Rev enferm UFPE on line, v. 13, p. 1-11, 2019. DOI: https://doi.org/10.5205/1981-8963.2019.238979.

RIBEIRO, AMN, et al. A percepção do enfermeiro sobre o brincar e o impacto dessa prática na assistência pediátrica. Rev. Pesqui: cuid. Fundam. Online, v. 12, p. 1017-1021, 2020. DOI: http:// dx.doi.org/0.9789/2175-5361.rpcfo.v12.7415 
SANTOS, GM, et al. A Influência do Brinquedo Terapêutico no Cuidado à Criança em Ambiente Hospitalar. Revista Brasileira Interdisciplinar de Saúde [Internet]. V. 2, n. 2, p. 40-45, 2020.

SANTOS, VLA, et al. Compreendendo a sessão de brinquedo terapêutico dramático: contribuição para a enfermagem pediátrica. Revista Brasileira de Enfermagem, v. 73, n. 4, 2020. http://dx.doi. org/10.1590/0034-7167-2018-0812

SILVA, MKCO, et al. A utilização do lúdico no cenário da hospitalização pediátrica. Rev enferm UFPE on line, v. 13, p. 1-7, 2019. DOI: https://doi.org/10.5205/1981-8963.2019.238585

SILVA, SRM et al. Percepção dos acompanhantes das crianças hospitalizadas acerca do brinquedo terapêutico. Rev. Enferm. UFPE online, p. 2703-2709, 2018.

SILVEIRA, KA.; LIMA, VL.; PAULA, KP. Estresse, dor e enfrentamento em crianças hospitalizadas: análise de relações com o estresse do familiar. REV. SBPH, Rio de Janeiro, v. 21, n. 2, p. 5-21, 2018. Disponível em <http://pepsic.bvsalud.org/scielo.php?script=sci_arttext\&pid=S1516$08582018000200002 \&$ Ing=pt\&nrm=iso >. Acessado em: 07 de set. 2020.

SOUSA, LC, et al. O brincar no contexto hospitalar na visão dos acompanhantes de crianças internadas. Rev. bras. crescimento desenvolv. hum., São Paulo, v. 25, n. 1, p. 41-49, 2015. Disponível em: http://dx.doi.org/10.7322/JHGD.96766. Acesso em 07 set. 2020.

SOUZA, LP, et al. O Brinquedo Terapêutico e o lúdico na visão da equipe de enfermagem. Health Sci Inst, v. 30, n. 4, p. 354-358, 2012.

SOUZA, TV.; LAPA, DF. A percepção do escolar sobre a hospitalização: contribuições para o cuidado de enfermagem. Rev. Esc. Enferm USP, v. 45, n. 4, p. 811-817, 2011. 


\section{ASSISTÊNCIA DE ENFERMAGEM NO CUIDADO À CRIANÇA COM CARDIOPATIA CONGÊNITA}

Data de aceite: 20/08/2021

Data de submissão: 06/07/2021

Michelle Cristine de Oliveira Minharro

Faculdade Marechal Rondon

São Manuel - São Paulo

http://lattes.cnpq.br/1658599597609935

Nathalia Domingues de Oliveira

Faculdade Marechal Rondon

São Manuel - São Paulo

http://lattes.cnpq.br/6212170052140124

Thalita Luiza Madoglio

Faculdade Marechal Rondon

São Manuel - São Paulo

http://lattes.cnpq.br/6114621334335015

RESUMO: Cardiopatia congênita é caracterizada pela irregularidade da estrutura e/ou da função cardiocirculatória, baseada na malformação embrionária ou pela ausência da estrutura de forma biológica, acarretando desenvolvimento insuficiente e incompleto desde a geração. Existem dois tipos desta cardiopatia: acianótica e cianótica, sendo a primeira a mais comum, e a segunda de gravidade maior, por se tratar da diminuição da concentração da hemoglobina no sangue arterial. Em ambas $70 \%$ das crianças não chegam aos 18 anos de idade. Nosso objetivo é expor através de uma revisão de literatura, benefícios na qualidade de vida advindos da assistência humanizada do enfermeiro com essas crianças. A revisão ocorreu de janeiro a março de 2021, realizada na BVS, selecionando as bases: Lilacs, Bdenf e Medline; artigos encontrados na íntegra na língua inglesa e portuguesa, relacionados ao tema e publicados entre 2016-2021. Foram encontrados 26 artigos, excluídos 22 e selecionados quatro. De acordo com o autor Lima et. al (2018) quando o enfermeiro consegue diagnosticar casos reais e de risco, traçar cuidados específicos, e acolher os pais, há diminuição da ansiedade, melhora no prognóstico, diminuição e prevenção de possíveis complicações. Segundo HOM et. al (2016) e Silva et. Al (2017), agravos da doença é prevenido com adequado e precoce diagnostico. Por fim Magalhães et. Al (2016) afirma que o cuidado de enfermagem humanizado aumenta sobrevida da criança. Concluímos que o cuidado de enfermagem deve ser científico, técnico e humanizado para atender as demandas da doença e proporcionar melhor qualidade de vida ao cliente/família.

PALAVRAS-CHAVE: "cuidados de enfermagem", "cardiopatia", "cuidado da criança”, "enfermagem neonatal".

NURSING CARE IN THE CARE OF CHILDREN WITH CONGENITAL HEART DISEASE

ABSTRACT: Congenital heart disease is characterized by irregularity of the structure and/ or cardiocirculatory function, based on embryonic malformation or by the absence of the structure in a biological way, causing insuficiente and incomplete development from generation. There are two types of this heart disease: acyanotic and cyanotic, the first being the most common, and the second more severe, as it is a reduction 
in the concentration of hemoglobina in the arterial blood. In both, $70 \%$ of children do not reach 18 years of age. Our objective is to expose, through a literature review, benefits in the quality of life arising from the humanized care provided by nurses to these children. The review took place from January to March 2021, carried out at the BVS, selecting the bases: Lilacs, Bdenf and Medline; articles found in full in English and Portuguese, related to the topic and published between 2016-2021. 26 articles were found, 22 were excluded and four were selected. According to the author Lima et al. (2018) when the nurse is able to diagnose real and risk cases, outline specific care, and welcome the parentes, there is a reduction in anxiety, improvement in the prognosis, reduction and prevention of possible complications. According to Hom et al. (2016) and Silva et al (2017), disease aggravations are prevented with adequate and early diagnosis. Finally, Magalhães et al (2016) states that humanized nursing care increases child survival. We conclude that nursing care must be scientific, technical and humanized to meet the demands of the disease and provide a better quality of life for the cliente/family.

KEYWORDS: "nursing care", "cardiopathy", "child care", "neonatal nursing".

\section{I INTRODUÇÃO}

Cardiopatia congênita é caracterizada pela irregularidade da estrutura e/ou da função cardiocirculatória, baseada na malformação embrionária ou pela ausência da estrutura de forma biológica, gerando um desenvolvimento insuficiente e incompleto desde a concepção. Existem fatores de risco que aumentam a incidência da patologia, tais eles: histórico familiar e fatores maternos que possuam doenças crônicas como diabetes e fenilcetonúria mal controlada, etilismo, exposição a toxinas ambientais, etc. (BELO; OSELAME; NEVES. 2016)

Clinicamente essa patologia é classificada como acianótica e cianótica, onde as cardiopatias acianóticas correspondem mais frequentemente a: comunicação interatrial (CIA), comunicação interventricular (CIV), defeito no septo atrioventricular total (DSAVT) ou parcial (DSAVP) (muitas vezes associado com a síndrome de Down), estenose aórtica, persistência do canal arterial (PCA) e a coarctação da aorta (CoA). As cardiopatias cianóticas possuem um potencial de gravidade maior comparado às acianóticas, pois há uma diminuição na concentração de hemoglobina no sangue arterial; tetralogia de Fallot (T4F) é a que mais ocorre, em um porcentual maior entre todas as cardiopatias. (ARAGÃO et al. 2013)

Dentre as anomalias congênitas, a cardiopatia é considerada a mais comum, correspondendo de 3-5\% de óbitos no período neonatal. Nos Estados Unidos da América (EUA) $44,5 \%$ das crianças com essa cardiopatia chegam ir a óbito ainda no seu primeiro ano de vida. Já na América Latina é a segunda maior causa de óbitos em crianças menores de um ano e no Brasil é a principal causa de morte, chegando a 30\%. Em média, 70\% de crianças com cardiopatias congênitas graves não chegam aos 18 anos de idade, e a prevalência vem aumentando de 6 para 9 em cada 1.000 recém-nascidos vivos. 
(CAPPELLESSO; AGUIAR. 2017)

A intervenção cirúrgica dentro do primeiro ano de vida da criança portadora de cardiopatia congênita complexa possibilita uma maior sobrevida e aumento da qualidade de vida, a qual inclui aspectos como melhora da capacidade funcional, estado emocional, suporte familiar, estilo de vida e o próprio estado de saúde. Decorrente esse procedimento aumenta a rigorosidade da adequada assistência da enfermagem a esse grupo. (CARLANTÔNIO; SANTIAGO; RIBEIRO; ARCOVERDE. 2015)

O cuidado da enfermagem às crianças portadoras dessa afecção é primordial desde a suspeita do diagnóstico, salientando a importante detecção precoce dos sinais que se caracterizam a descompensação, para dar embasamento aos cuidados, os quais podem levar a melhores condições favoráveis à possíveis cirurgias de correção. (SILVA. 2005)

Após análise dos dados acima torna-se evidente a importância de uma assistência qualificada e exemplar da enfermagem, uma vez que essa prevalência vem aumentando, a necessária especialização do cuidado voltada à essa patologia cresce concomitantemente. Portanto com essa revisão da literatura ressaltamos a notabilidade da assistência de um enfermeiro a crianças com cardiopatia congênita, identificando cuidados humanizados.

\section{I OBJETIVO}

Identificar através da literatura científica o cuidado prestado pelo enfermeiro a criança com cardiopatia congênita.

\section{I MÉTODO}

A revisão integrativa possibilita gerar novas perspectivas sobre um tema, oferece aos profissionais o acesso rápido aos resultados relevantes que fundamentam as condutas ou a tomada de decisão, além de verificar lacunas do conhecimento. (POLIT, 2011)

A construção da presente revisão integrativa foi guiada por seis momentos: identificação do tema e elaboração da questão de pesquisa, estabelecimento de critérios de exclusão e inclusão, definição das informações a serem extraídas dos estudos selecionados/ categorização dos estudos, avaliação dos estudos incluídos na revisão, interpretação e síntese dos resultados, e, por último a apresentação da revisão. (MENDES, 2008)

Utilizou-se o método de estudo revisão integrativa com enfoque no Cuidado de enfermagem em crianças com cardiopatia congênita. A revisão ocorreu de janeiro a março de 2021, a pesquisa foi realizada na Biblioteca Virtual da Saúde (BVS) e os artigos selecionados foram da base de dados científicos Lilacs, Bdenf e Medline. Com o uso de descritores: "cuidados de enfermagem", "cardiopatia", "cuidado da criança", "enfermagem neonatal".

Critérios de inclusão: artigos encontrados na íntegra; em língua portuguesa e inglesa, artigos relacionados ao tema e artigos publicados entre 2016 à 2021. Critérios 
de exclusão: artigos que fugiram ao tema proposto, artigos que não compreendiam aos descritores e artigos que foram publicados até o ano de 2016.

E como pergunta norteadora usou-se: Qual o papel do enfermeiro no cuidado com crianças portadoras de cardiopatia congênitas?

\section{I RESULTADOS}

Os quatro estudos selecionados estão apresentados a seguir na Tabela 1.

\begin{tabular}{|c|c|c|c|c|}
\hline No & Autor/Ano & Título & Periódico & $\begin{array}{c}\text { Local de } \\
\text { Estudo }\end{array}$ \\
\hline $\mathbf{1}$ & $\begin{array}{c}\text { Lima TG, Silva } \\
\text { MA, Siqueira } \\
\text { SMC. } \\
2018\end{array}$ & $\begin{array}{c}\text { Diagnóstico e cuidados de enfermagem } \\
\text { ao neonato com cardiopatia congênita }\end{array}$ & $\begin{array}{c}\text { Rev. Soc. Cardiol } \\
\text { Estado de São Paulo. }\end{array}$ & $\begin{array}{c}\text { Salvador-BA, } \\
\text { Brasil. }\end{array}$ \\
\hline $\mathbf{2}$ & $\begin{array}{c}\text { Magalhães SS, } \\
\text { Queiroz MVO, } \\
\text { Chaves EMC. } \\
2016\end{array}$ & $\begin{array}{c}\text { Cuidados da enfermagem neonatal ao } \\
\text { bebê com cardiopatia congênita }\end{array}$ & $\begin{array}{c}\text { Online Brazilian } \\
\text { Journal of Nursing. }\end{array}$ & $\begin{array}{c}\text { Rio de Janeiro, } \\
\text { Brasil. }\end{array}$ \\
\hline $\mathbf{3}$ & $\begin{array}{c}\text { Hom LA, Martin } \\
\text { GR. } \\
2016\end{array}$ & $\begin{array}{c}\text { Newborn Critical Congenital Heart } \\
\text { Disease Screening Using Pulse } \\
\text { Oximetry: Nursing Aspects. }\end{array}$ & $\begin{array}{c}\text { American Journal of } \\
\text { Perinatology }\end{array}$ & $\begin{array}{c}\text { Washington, } \\
\text { EUA. }\end{array}$ \\
\hline $\mathbf{4}$ & $\begin{array}{c}\text { Silva WLAV, } \\
\text { Barros ATL, } \\
\text { Santos RD, Silva } \\
\text { LA, Miranda LN. } \\
2017\end{array}$ & $\begin{array}{c}\text { Cirurgias cardíacas: assistência } \\
\text { de enfermagem a portadores de } \\
\text { cardiopatia no período perioperatório }\end{array}$ & $\begin{array}{c}\text { Ciências Biológicas e } \\
\text { de Saúde Unit. }\end{array}$ & $\begin{array}{c}\text { Alagoas, Brasil. } \\
\end{array}$ \\
\hline
\end{tabular}

Tabela 1. Artigos selecionados para o estudo segundo autor e ano de publicação, título, periódico e local de estudo.

Nesta revisão integrativa foram analisados quatro artigos que atenderam aos critérios estabelecidos. Todos de autoria de enfermeiros e publicados no período entre os anos de 2016 à 2021.

Quanto ao país de origem, 3 (75\%) foram desenvolvidos no Brasil e 1 (25\%) nos Estados Unidos da América (EUA).

Sobre o delineamento de pesquisa dos artigos selecionados encontrou-se 3 revisões integrativas da literatura (75\%) e 1 estudo de rastreamento (25\%).

O Quadro 2 apresenta uma síntese dos estudos incluídos na revisão. 


\begin{tabular}{|c|c|c|c|c|c|}
\hline $\mathrm{N}^{\mathrm{O}}$ & Autor & Delineamento & Participantes & Objetivo & Resultados \\
\hline 1 & $\begin{array}{c}\text { Lima TG, Silva } \\
\text { MA, Siqueira } \\
\text { SMC. } \\
2018\end{array}$ & $\begin{array}{l}\text { Revisão } \\
\text { Integrativa }\end{array}$ & Enfermeiro & $\begin{array}{c}\text { Descrever os } \\
\text { diagnósticos e } \\
\text { os cuidados de } \\
\text { enfermagem ao } \\
\text { neonato com } \\
\text { cardiopatia congênita. }\end{array}$ & $\begin{array}{c}\text { No que diz respeito à } \\
\text { assistência de enfermagem ao } \\
\text { RN } \\
\text { portador de cardiopatia } \\
\text { congênita é necessário } \\
\text { que os enfermeiros tenham } \\
\text { competência técnica e científica, } \\
\text { no sentido de avaliar o } \\
\text { neonato e traçar diagnósticos e } \\
\text { cuidados, com a finalidade de } \\
\text { resolver problemas e prevenir a } \\
\text { ocorrência de agravos. }\end{array}$ \\
\hline 2 & $\begin{array}{c}\text { Magalhães } \\
\text { SS, Queiroz } \\
\text { MVO, Chaves } \\
\text { EMC. } \\
2016\end{array}$ & $\begin{array}{l}\text { Revisão } \\
\text { Integrativa }\end{array}$ & Enfermeiro & $\begin{array}{l}\text { Buscar evidências } \\
\text { disponíveis na } \\
\text { literatura sobre } \\
\text { os cuidados de } \\
\text { enfermagem aos } \\
\text { recém-nascidos com } \\
\text { cardiopatia congênita } \\
\text { em unidades } \\
\text { neonatais. }\end{array}$ & $\begin{array}{c}\text { A enfermagem, na atualidade, } \\
\text { está envolvida diretamente } \\
\text { nesse tipo de triagem, podendo } \\
\text { desenvolvê-la nos serviços de } \\
\text { saúde. Daí a importância de } \\
\text { conhecer estudos que abordem } \\
\text { esta atividade como importante } \\
\text { campo de atuação da } \\
\text { enfermagem neonatal. Precisa, } \\
\text { portanto, ter a compreensão do } \\
\text { desenvolvimento da atividade e } \\
\text { habilidades envolvidas em sua } \\
\text { execução. }\end{array}$ \\
\hline 3 & $\begin{array}{l}\text { Hom LA, } \\
\text { Martin GR. } \\
2016\end{array}$ & $\begin{array}{l}\text { Estudo de } \\
\text { rastreamento }\end{array}$ & Enfermeiro & $\begin{array}{l}\text { Contribuir com o } \\
\text { desenvolvimento das } \\
\text { melhores práticas } \\
\text { para implementação } \\
\text { e fornecer educação } \\
\text { às famílias sobre } \\
\text { o rastreamento do } \\
\text { CCHD }\end{array}$ & $\begin{array}{c}\text { A função da enfermagem } \\
\text { frequentemente inclui a } \\
\text { implementação de iniciativas } \\
\text { de melhoria de qualidade } \\
\text { de acompanhamento para } \\
\text { garantir que ocorra uma triagem } \\
\text { sistemática e precisa }\end{array}$ \\
\hline 4 & $\begin{array}{l}\text { Silva WLAV, } \\
\text { Barros ATL, } \\
\text { Santos RD, } \\
\text { Silva LA, } \\
\text { Miranda LN. } \\
2017\end{array}$ & $\begin{array}{l}\text { Revisão } \\
\text { Integrativa }\end{array}$ & Enfermeiro & $\begin{array}{c}\text { Identificar a } \\
\text { assistência de } \\
\text { enfermagem aos } \\
\text { portadores de } \\
\text { cardiopatia no período } \\
\text { perioperatório. E } \\
\text { com isso responder } \\
\text { à seguinte questão } \\
\text { de pesquisa: qual } \\
\text { a assistência de } \\
\text { enfermagem no } \\
\text { período perioperatório } \\
\text { em paciente } \\
\text { cardíaco? }\end{array}$ & $\begin{array}{c}\text { A conduta do enfermeiro } \\
\text { diante de pacientes com } \\
\text { indicações cirúrgicas cardíacas, } \\
\text { deverá conter a promoção } \\
\text { da saúde, atendimento } \\
\text { humanizado, qualificado e } \\
\text { seguro, desempenhar a função } \\
\text { de educador, realizar um } \\
\text { planejamento da capacitação } \\
\text { da equipe de enfermagem para } \\
\text { que ocorra uma sistematização } \\
\text { da equipe. }\end{array}$ \\
\hline
\end{tabular}

Quadro 2 - Descrição dos estudos incluídos na revisão segundo autor, ano de publicação, delineamento, participantes, objetivo e resultados.

\section{5 | DISCUSSÃO}

Destaca-se a necessária habilidade e conhecimento dos enfermeiros em saber diagnósticos reais e de risco para pacientes com cardiopatia congênita, como exemplo 
dos mais pertinentes, respectivamente: hipertermia, padrão do sono perturbado, padrão respiratório ineficaz e risco para diminuição do débito cardíaco, risco para alteração no volume de líquidos e risco para infecção. Ainda segundo Lima, Silva, Siqueira (2018), quanto aos cuidados, o enfermeiro deve portar competências técnicas e científicas à monitorização do paciente, manutenção de cateteres, dispositivos e suporte ventilatório, controle da dor, aspiração do tubo orotraqueal e das vias aéreas superiores, etc. $\mathrm{O}$ autor também ressalta a importância do acolhimento dos pais nos cuidados, pois a ação promove vínculo, minimizando a ansiedade e melhorando o prognóstico do recém-nascido (RN). Uma vez que um RN sob internação, com esta doença, está propenso a evoluir com outros problemas, exigindo então do profissional a resolução humanizada e prevenção de ocorrência de agravos.

De acordo com Hom, Martin (2016), a doença cardíaca congênita (DCC) é o defeito congênito mais comum, ocorrendo em cerca de 1 em cada 100 bebês, com aproximadamente $30 \%$ desses casos sendo as formas mais graves. Diante disso concorda com a extrema importância do diagnóstico precoce, indica que o mesmo seja realizado através de uma triagem adequada e também conta com o auxílio dos familiares nesse processo de detecção da doença. Esta triagem é de responsabilidade da enfermagem e tem como objetivo permitir a intervenção antes da alta do hospital, antes mesmo que o bebê sofra de insuficiência cardíaca e danos permanentes aos órgãos ou morte.

Segundo Silva et al (2017), a enfermagem deve estar apta para ensinar a família e o paciente como lidar com essa situação (com intuito de também humanizar o cuidado, por haver um comprometimento emocional, que pode prejudicar no processo de tratamento) trabalhando e desenvolvendo ações que ajudarão o paciente, ou seja, a intervenção de enfermagem é uma ferramenta principal para recuperação dos hábitos do conjunto paciente/família. Por conseguinte, os cuidados de enfermagem devem ser orientados por uma metodologia científica que atende plenamente as necessidades do paciente.

Em concordância Magalhães, Queiroz, Chaves (2016), ressalva a importância da identificação e síntese desse conhecimento teórico e prático do cuidado profissional para com o bebê. Porém o mesmo demonstra certa preocupação sobre a escassez de conteúdo na literatura sobre o tema, trazendo em discussão um aumento necessário do envolvimento do enfermeiro na aprimoração do cuidado de enfermagem a essas crianças, a fim de aperfeiçoar a prática clínica com evidências.

\section{I CONCLUSÃO}

Diante do exposto, concluímos a importância da enfermagem no diagnóstico precoce, na necessidade de possuir profissionais capacitados, com conhecimentos sobre os cuidados nas intervenções com as crianças portadoras de DCC - ambos com embasamento técnico e científico e nos benefícios da ajuda familiar na detecção desta doença e a participação 
no cuidado à criança. Com isso, vimos que dispõe um cuidado humanizado e holístico, favorece maior vínculo paciente/família, diminui ansiedade, melhora no prognóstico do RN, e prevê aparição de agravos, danos e sequelas permanentes à vida dos envolvidos.

Entretanto, por se tratar de um problema de saúde pública no Brasil e no mundo, se faz necessário novas pesquisas referentes ao tema, com enfoque no cuidado específico, pois a literatura ainda é escassa em relação ao tema.

\section{REFERÊNCIAS}

Aragão JA, Mendonça MP, Silva MS, Moreira AN, Aragão MECS, Reis FP. O perfil epidemiológico dos pacientes com cardiopatias congênitas submetidos à cirurgia no hospital do coração. $R$. Bras. Ci. Saúde, 17(3):263-268, 2013.

Belo WA, Oselame GB. Neves EB, Perfil clínico-hospitalar de crianças com cardiopatia congênita. Cad. Saúde Colet., Rio de Janeiro, 24(2):216-220, 2016.

Cappellesso VR, Aguiar AP. Cardiopatia congênita em crianças e adolescente: caracaterização clínico-epidemiológica em um hospital infantil de Manaus-AM. O Mundo da Saúde, São Paulo, 41(2):144-153; 2017.

Carlantônio, LFMD, Santiago, LC, Ribeiro, RV, \& Arcoverde, KVPTS. An integrative review about the pediatric heart transplant and the aspects of quality of life. J. res.: fundam. care. Online, 7(3):28052814; 2015. https://doi.org/10.9789/2175-5361.2015.v7i3.2805-2814.

Hom LA, Martin GR. Newborn Critical Congenital Heart Disease Screening Using Pulse Oximetry: Nursing Aspects. Am J Perinatol; 33(11):1072-5; 2016. https://doi: 10.1055/s-0036-1586108.

Lima TG, Silva MA, Siqueira SMC. Diagnósticos e cuidados de enfermagem ao neonato com cardiopatia congênita. Rev Soc Cardiol Estado de São Paulo; 28(1):101-9; 2018. http://dx.doi. org/10.29381/0103-8559/20182801101-9

Magalhães SS, Queiroz MVO, Chaves EMC. Cuidados da enfermagem neonatal ao bebê com cardiopatia congênita: revisão integrativa. Online braz. J. nurs (online); 15(4): 724-734, 2016.

Silva WLA, Barros ATL, Santos RD, Silva LA, Miranda LN. Cirurgias cardíacas: assistência de enfermagem a portadores de cardiopatia no período perioperatório. Ciências Biológicas e de Saúde Unit Alagoas; 4(2): 323-336, 2017.

SILVA, V. M. Caracterização de diagnósticos de enfermagem em crianças com cardiopatias congênitas: estudo num hospital especializado em doenças cardiopulmonares. 2005. $119 \mathrm{f}$. Dissertação (Mestrado em Enfermagem) - Faculdade de Farmácia, Odontologia e Enfermagem, Universidade Federal do Ceará, Fortaleza, 2005. 


\section{CAPÍTULO 18 \\ DA ROBOTIZAÇ̃̃O À HUMANIZAČ̃̃O: A ENFERMAGEM NA HOSPITALIZACCÃO DA CRIANÇA VÍTIMA DE MAUS-TRATOS}

Data de aceite: 20/08/2021

\section{Sabi Barbosa Moraes}

Acadêmica de Enfermagem no IBMR- Instituto Brasileiro de Medicina e Reabilitação

\section{Webster de Oliveira Leite}

Acadêmica de Enfermagem no IBMR- Instituto Brasileiro de Medicina e Reabilitação

\section{Viviane de Melo Souza}

Mestre em Enfermagem pela Faculdade de Enfermagem/UERJ. Docente do curso de graduação da IBMR e UNIABEU

\section{Eric Rosa Pereira4}

Doutorando em Saúde Pública pela ENSP/ FIOCRUZ. Mestre em Enfermagem pela Escola de Enfermagem Anna Nery/UFRJ. Docente universitário das faculdades UNIABEU e Fundação Técnico Educacional Souza Marques

RESUMO: Objetivo: Analisar os cuidados de enfermagem às crianças vítimas de maus tratos em ambiente hospitalar. Método: Trata-se de uma análise sistematizada, de abordagem qualitativa, realizada sob consulta nas bases de dados Scientific Electronic Library Online Scientific Electronic Library Online e Biblioteca Virtual em Saúde onde foram encontrados 14 artigos para composição da revisão integrativa. Resultados: Diante da análise dos estudos, revelou-se uma interação científica entre profissionais da equipe de Enfermagem, Psicologia e Assistência social na construção dos materiais utilizados; a sua maioria em pósgraduação. A Revista Gaúcha de Enfermagem foi a que mais publicou artigos e o ano de 2010 o de maior número de publicações sobre o tema. Não foram feitas menções ao tema em 2017. A região Sul, com destaque à cidade de Porto Alegre, foi a que mais desenvolveu estudos, a região Sudeste teve participação expressiva e as regiões Norte e Nordeste não produziram sobre o tema em questão. Sobre abuso, os físicos, sexuais e por negligência foram os mais abordados no estudo. Conclusão: Para que os profissionais da saúde sejam cada vez mais humanizados e menos mecanizados numa assistência à crianças violentadas, é preciso protocolos específicos de assistência, maior interação e continuidade entre a equipe multidisciplinar, e mais valorização do profissional de Enfermagem que é o profissional que faz parte constantemente de todo processo de hospitalização.

PALAVRAS - CHAVE: Maus-tratos infantis; Hospitalização; Enfermagem; Cuidados de enfermagem; Cuidado da criança.

ABSTRACT: Objective: To analyze nursing care for child victims of abuse in a hospital setting. Method: This is a systematic analysis, with a qualitative approach, carried out under consultation in the databases Scientific Electronic Library Online Scientific Electronic Library Online and Virtual Health Library where 14 articles were found for the composition of the integrative review. Results: In view of the analysis of the studies, it was revealed a scientific interaction between professionals from the Nursing, Psychology and Social Assistance team in the construction of the 
materials used; the majority in graduate school. Revista Gaúcha de Enfermagem was the one that published the most articles and the year 2010 was the one with the largest number of publications on the topic. No mention was made of the theme in 2017. The South region, with emphasis on the city of Porto Alegre, was the one that developed the most studies, the Southeast region had an expressive participation and the North and Northeast regions did not produce on the subject in question. About abuse, physical, sexual and negligence were the most addressed in the study. Conclusion: For health professionals to be increasingly humanized and less mechanized in assisting abused children, specific care protocols are needed, greater interaction and continuity between the multidisciplinary team, and more appreciation for the nursing professional who is the professional who it is constantly part of the entire hospitalization process.

KEYWORDS: Child abuse; Hospitalization; Nursing; Nursing care; Child care.

\section{I INTRODUÇÃO}

O presente estudo tem por objetivo analisar os cuidados de enfermagem às crianças vítimas de maus tratos em ambiente hospitalar.

Por muito tempo, as crianças foram tratadas como adultos em miniatura, onde não existia um olhar específico voltado às suas necessidades e peculiaridades. A infância não era tratada como parte de um ciclo vital, parte esta que necessita de uma abordagem especializada, com necessidades singulares. (Ariés ${ }^{1}, 2011$ ).

No século XIX, ainda com índices de mortalidade infantil elevados, os números indicavam que as medidas apresentavam pouco sucesso. As mudanças começaram a ser percebidas somente quando a sociedade tomou consciência da situação da criança e os serviços públicos deram início ao trabalho efetivo de elaboração de políticas e investimentos na saúde materno-infantil. (Victora², 2001).

\footnotetext{
Com vistas a mudar a assistência à saúde da criança no país e em busca do cuidado integral, por volta dos anos de 1980, identificou-se como necessidade o acompanhamento do processo de crescimento e desenvolvimento de todas as crianças. Assim, o Ministério da Saúde elaborou o Programa de Assistência Integral à Saúde da Mulher e da Criança (PAISMC), no qual os serviços deveriam estar preparados para resolver todos os problemas que poderiam afetar a saúde materno-infantil. (Araújo et $\mathrm{al}^{3,1002-3}, 2014$ ).
}

Em 1984, o PAISMC foi desintegrado e dividido em Programa de Assistência Integral à Saúde da Mulher (PAISM) e o Programa de Assistência Integral à Saúde da Criança (PAISC). Nele, a criança tornou-se o público-alvo nas estratégias de políticas públicas. Suas ações eram voltadas ao acompanhamento do crescimento e desenvolvimento infantil, incentivando o aleitamento materno, o controle e doenças diarreicas e de infecções respiratórias agudas. (Araújo et $\mathrm{al}^{3}, 2014$ ).

Pela Lei $n^{\circ} 8069$, de 13 de julho de 1990, foi aprovado o Estatuto da Criança e do Adolescente (ECA) onde esses, a partir daí, passam a ser assegurados com amplos 
direitos de proteção da integridade física e psicológica, lazer e bem-estar; devendo ser amparados pela família, comunidade e pelo Estado. (Brasil $\left.{ }^{4}, 1990\right)$.

Art. $4^{\circ}$ É dever da família, da comunidade, da sociedade em geral e do poder público assegurar, com absoluta prioridade, a efetivação dos direitos referentes à vida, à saúde, à alimentação, à educação, ao esporte, ao lazer, à profissionalização, à cultura, à dignidade, ao respeito, à liberdade e à convivência familiar e comunitária.

Art. $5^{\circ}$ Nenhuma criança ou adolescente será objeto de qualquer forma de negligência, discriminação, exploração, violência, crueldade e opressão, punido na forma da lei qualquer atentado, por ação ou omissão, aos seus direitos fundamentais.

Segundo o artigo 18, cabe a todos o cuidado da honra e da dignidade da criança e do adolescente, onde todos têm a responsabilidade de guardá-los e protegê-los, seja qual for a situação que os coloquem em risco. "Art. 18. É dever de todos velar pela dignidade da criança e do adolescente, pondo-os a salvo de qualquer tratamento desumano, violento, aterrorizante, vexatório ou constrangedor". ${ }^{4}$

Exposição à violência, tratamento desumano, aterrorizante, vexatório ou constrangedores são alguns dos exemplos dos riscos à dignidade, onde poderão ser expostos. (Brasil $\left.{ }^{4}, 1990\right)$.

Art. 70-A. A União, os Estados, o Distrito Federal e os Municípios deverão atuar de forma articulada na elaboração de políticas públicas e na execução de ações destinadas a coibir o uso de castigo físico ou de tratamento cruel ou degradante e difundir formas não violentas de educação de crianças e de adolescentes, tendo como principais ações: (Incluído pela Lei $n^{\circ} 13.010$, de 2014)

O Artigo 70 A determina que todas as esferas governamentais mais o Distrito Federal deverão de forma continuada atuar na prevenção do uso de castigo físico ou de tratamento cruel ou degradante através da elaboração de políticas públicas que vise a prevenção dessas ações. A promoção de campanhas, a formação continuada, a capacitação dos profissionais de saúde, a criação de atividades sobre a reflexão, debate e orientação sobre ao uso de castigo físico são algumas das principais ações previstas no artigo. (Brasil ${ }^{4}$, 1990).

Art. 86. A política de atendimento dos direitos da criança e do adolescente far-se-á através de um conjunto articulado de ações governamentais e não governamentais, da União, dos estados, do Distrito Federal e dos municípios.

Art. 87. Inciso III - serviços especiais de prevenção e atendimento médico e psicossocial às vítimas de negligência, maus-tratos, exploração, abuso, crueldade e opressão.

No Artigo 87 trata-se do dever do poder público em planejar e implementar variados tipos de programas e projetos para garantir proteção para as crianças e adolescentes vítimas de maus tratos, exploração, abuso, crueldade, crianças desaparecidas; visando 
com isso a proteção integral da criança e do adolescente. (José, Amorim5 , 2010).

Criada em 2003 pelo Ministério da Saúde, a Política Nacional de Humanização (PNH) está inserida no contexto do SUS, atuando de forma efetiva e direta nos seus princípios, qualificando-o através da valorização dos usuários, trabalhadores e gestores no processo de saúde. Para que se estabeleça o efetivo processo de humanização, deve haver uma maior valorização no que tange a relação da vida com o cuidado, aprimorando as relações interpessoais entre os profissionais em si e profissionais com os clientes, estabelecendo assim uma relação de cuidado entre profissionais e clientes. (Brasill, 2003).

Em 2015, o Ministério da Saúde institui a Política Nacional de Atenção Integral à Saúde da Criança (PNAISC), onde sintetiza os eixos de ação que compõem a atenção integral à saúde da criança, com objetivo de promover e proteger a saúde da criança e o aleitamento materno. Essa política aponta estratégias e dispositivos para a articulação das ações e serviços de saúde, mediante a atenção e cuidados integrais reintegrados da gestação aos nove anos de vida, em especial a primeira infância e à população de maior vulnerabilidade, objetivando a redução da mortalidade, num ambiente digno e que favoreça seu desenvolvimento. (Brasil7, 2015).

\footnotetext{
Os princípios norteadores do cuidado à criança abrangem práticas e ações intersetoriais permitindo que cada profissão atue desenvolvendo ações que incluem: o acesso universal, o acolhimento, a assistência integral, a equidade, a participação da família, contribuindo, assim, para um modelo de assistência que favoreça o acompanhamento e a aproximação das famílias e das crianças junto às equipes de saúde, na construção do vínculo terapêutico e de um atendimento mais humanizado (Monteiro et al8, 3-9, 2012).
}

Conforme a Sociedade Brasileira de Pediatria ${ }^{9}$ (2001), crianças e adolescentes são uma população cujos direitos básicos, como o acesso à escola, à saúde e os cuidados necessários para seu desenvolvimento, são muitas das vezes violados.

Podemos caracterizar como maus-tratos ou abuso quando um sujeito em condições de superioridade (idade, força, posição social ou econômica, inteligência, autoridade) que comete pela ação, omissão, supressão ou transgressão danos físicos, psicológicos ou sexuais, contrariando à vontade da vítima ou por consentimento obtido a partir de indução ou sedução enganosa. (Deslandes $\left.{ }^{10}, 1994\right)$.

Os maus-tratos são divididos em: físicos (síndrome do bebê sacudido e síndrome da criança espancada), psicológico, sexual, negligência e Síndrome de Munchausen por procuração, que é a condição na qual a criança recebe cuidados conforme sinais e sintomas inventados ou provocados pelos seus responsáveis. ${ }^{9}$

Desde 2011, os profissionais da área da saúde são obrigados a notificar qualquer caso de violência doméstica, sexual e/ou outras violências. (Brasil $\left.{ }^{11}, 2017\right)$. No Estatuto da Criança e do Adolescente os Art.13 e Art. 245 reforça a obrigatoriedade da notificação ao conselho tutelar em casos de suspeita ou confirmação de maus-tratos, professores e responsáveis pelo ensino pré-escolar ou creche e fundamental não se excluem dessa 
obrigação. (Brasil $\left.{ }^{4}, 1990\right)$.

$\mathrm{O}$ atendimento às vítimas de maus-tratos encontra-se pouco estruturado, sendo insuficiente para a demanda que chega aos serviços de saúde. Muitas das vezes, aquele profissional que recebe a criança vítima de maus tratos, não é capacitado para uma abordagem holística necessária para identificar os sinais de violência sendo necessário elucidar e sensibilizar os profissionais para a temática em questão. ${ }^{9}$

"A atitude dos profissionais frente à abordagem dos maus-tratos cometidos contra a criança e o adolescente se encontra intimamente relacionada com a visibilidade ou não que o problema assume em seu cotidiano. "(Gomes et $\mathrm{al}^{12}$, 2002).

As dificuldades que os profissionais da saúde lidam com a violência contra a criança e o adolescente são apresentadas basicamente em duas temáticas distintas: o desajuste em delimitar um problema, onde são diversos os impeditivos encontrados para lidar com as situações de violência, tais como o despreparo da equipe e a falta de apoio das instituições, deixando os profissionais preocupados e com sentimento de impotência frente a uma situação de emergência; e a dificuldade em desarticular a rede de serviço onde muitas das vezes reflete a falta de interação entre os profissionais da saúde e os órgãos competentes. (Nunes, Sarti, Ohara $\left.{ }^{13}, 2009\right)$.

É fundamental que a equipe de enfermagem saiba identificar e reconhecer os sinais de alerta a fim de detectar a violência, uma vez que são esses profissionais que terão contato inicial com a criança. (Ângelo et $\mathrm{al}^{14}, 2013$ ).

A criança acometida por maus-tratos necessita de atendimento multidisciplinar, pois muitas vezes sofre com diferentes tipos de agressões, seja física ou mental, as quais necessita de profissionais de várias especialidades diferentes (médicos, enfermeiros, psicólogos, assistentes sociais) visando acolhimento de forma global. Esses profissionais interligam-se, buscando entender o contexto geral, identificando fatores de risco à criança e adolescente, como agressões intra e extradomiciliares, opressões, vulnerabilidade metabólica, social e psicológica (Laurez ${ }^{15}$, 2009).

Segundo dados da Fundo das Nações Unidas para a Infância (UNICEF) ${ }^{16}$ (2017), "300 milhões de crianças com idade entre 2 e 4 anos são diariamente sujeitas a punições físicas e psicológicas graves, infligidas por pais e cuidadores". Somente no estado do Rio de Janeiro em 2018 foram notificados 7.507 casos de violência contra crianças menores de 10 anos. (Brasil $\left.{ }^{17}, 2018\right)$. É evidente a necessidade de uma discussão mais ampla sobre o ECA e sua aplicabilidade no dia a dia.

\section{2 | MÉTODO}

Trata-se de uma Revisão Integrativa estabelecendo uma criteriosa avaliação, viabilizando a sistematização do conhecimento científico, levando ao pesquisador a problemática abordada e permitindo que o mesmo observe a evolução desta temática. 
Com isso, possibilitando um apanhado do conhecimento, bem como a aplicabilidade de resultados significativos na prática de enfermagem. (Mendes, Silveira, Galvão18, 2008).

A presente revisão é desenvolvida através de seis etapas: identificação do tema e seleção da hipótese ou questão norteadora da pesquisa; estabelecimento de critérios para inclusão e exclusão de estudos; definição das informações a serem extraídas dos estudos selecionados; avaliação dos estudos incluídos na revisão; interpretação dos resultados e apresentação da revisão e síntese do conhecimento. (Mendes, Silveira, Galvão ${ }^{18}$, 2008). A amplitude do assunto a ser estudado irá determinar o mecanismo de amostragem. É fundamental que a quantidade de estudos a ser pesquisada seja suficiente para a construção da revisão, pois um estudo muito amplo pode dificultar a observação de ideias e uma busca muito superficial, limitar a construção da mesma. Esse processo de busca por artigos que fundamentam a revisão é feito em bases de dados que servem como referências padronizadas para pesquisas. (Mendes, Silveira, Galvão'18, 2008).

Definiu-se então como questão norteadora: "Como podemos melhorar os cuidados de enfermagem frente à criança hospitalizada vítima de maus-tratos? "

Nessa revisão, foram utilizados artigos completos e disponíveis entre os anos 2009 até 2019 no idioma português, aplicando como base de dados da Scientific Electronic Library Online (SCIELO) e Biblioteca Virtual em Saúde (BVS). Foram excluídos materiais que não responderam à questão do estudo, bem como dissertações, monografias, revisões de literatura, catálogos, estudo de casos, teses e cartas ao editor.

$\mathrm{Na}$ triagem dos artigos, foram utilizados os descritores: "maus-tratos infantis", "cuidados de enfermagem", "cuidado de enfermagem", "cuidado da criança", "violência", "enfermagem", "criança institucionalizada" e "hospitalização". Utilizamos a palavra "AND" entre os descritores no sistema de busca como operador booleano. A maioria dos descritores foi empregada em pares a fim aumentar o campo de busca. A consulta às bases de dados foi realizada durante o mês de outubro de 2020 e finalizada em novembro do mesmo ano.

$\mathrm{Na}$ primeira busca na BVS foram utilizados os descritores "maus-tratos infantis" e "cuidados de enfermagem" e selecionadas as bases de dados LILACS, MEDLINE e BDENF-Enfermagem, encontrando 18 artigos. Durante a coleta foram considerados como critérios de inclusão: texto completo, ano de publicação e idioma português. Após a leitura dos títulos e sinalizando duplicidade, excluímos 11 artigos, restando 5 artigos para serem utilizados na íntegra.

$\mathrm{Na}$ segunda busca foram utilizados os descritores "maus-tratos infantis" e "Hospitalização" utilizando a mesma base de dados e os mesmos critérios de inclusão, onde restou 1 artigo que contemplou o tema da revisão. Já na terceira busca, com os descritores "cuidado da criança" e "maus-tratos infantis" foram utilizadas as mesmas bases de dados e os mesmos critérios, restando 2 artigos que abordaram o tema.

$\mathrm{Na}$ busca seguinte, utilizamos os descritores "cuidado da criança", "violência" e "enfermagem" seguindo os mesmos critérios, encontrando 37 artigos, excluindo 33 com 
leitura do título e duplicidade, sendo 4 artigos utilizados. Para finalizar a busca com os descritores "criança institucionalizada" e "maus-tratos infantis", conforme os critérios anteriores, foram encontrados 6 artigos, sendo 1 artigo aproveitado e 5 excluídos.

No Scielo quando empregamos os descritores "maus-tratos infantis" e "cuidado de enfermagem" emergiram um total de 6 artigos; destes, 5 foram excluídos pelo título por não abordarem a temática proposta e/ou por duplicidade, restando apenas 1 artigo para compor esse estudo. Num segundo momento, utilizamos os descritos "maus-tratos infantis" e "hospitalização", seguindo os mesmos critérios, não foi contemplou nenhum artigo para temática do estudo.

Em seguida ao usar os descritores "cuidado da criança" e "maus-tratos infantis", utilizando os mesmos filtros, localizamos 8 artigos que foram descartados por não contemplarem o estudo e por estarem duplicados. Seguidamente, utilizando "cuidado da criança", "violência" e "enfermagem" localizamos 2 artigos, também descartados por repetição. Por último, utilizando "criança institucionalizada" e "maus-tratos infantis", sempre seguindo os mesmos critérios de inclusão e exclusão nenhum artigo foi localizado.

Para melhor compreensão dos estudos incluídos foi realizado um fluxograma exemplificando os resultados obtidos através do levantamento bibliográfico realizado nas bases de dados citadas.

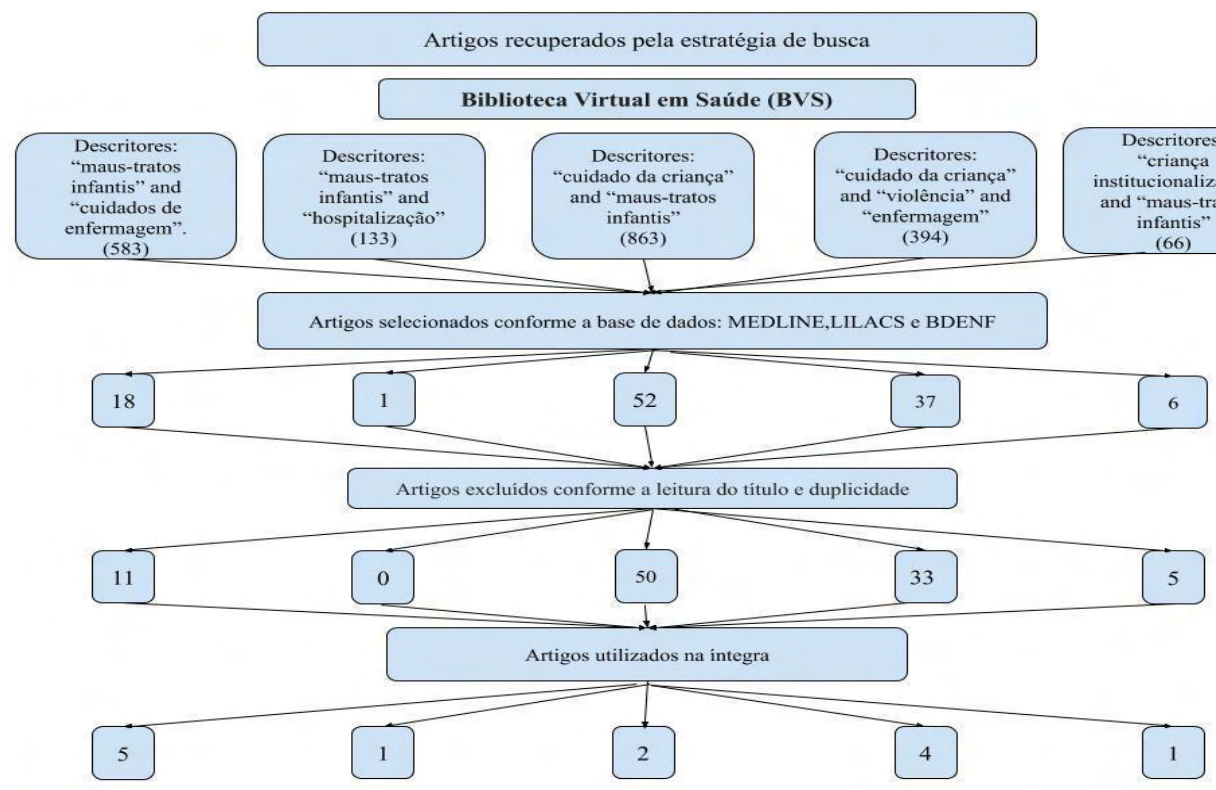

Fluxograma 1 - Artigos recuperados na BVS

Fonte: Os autores (2021) 


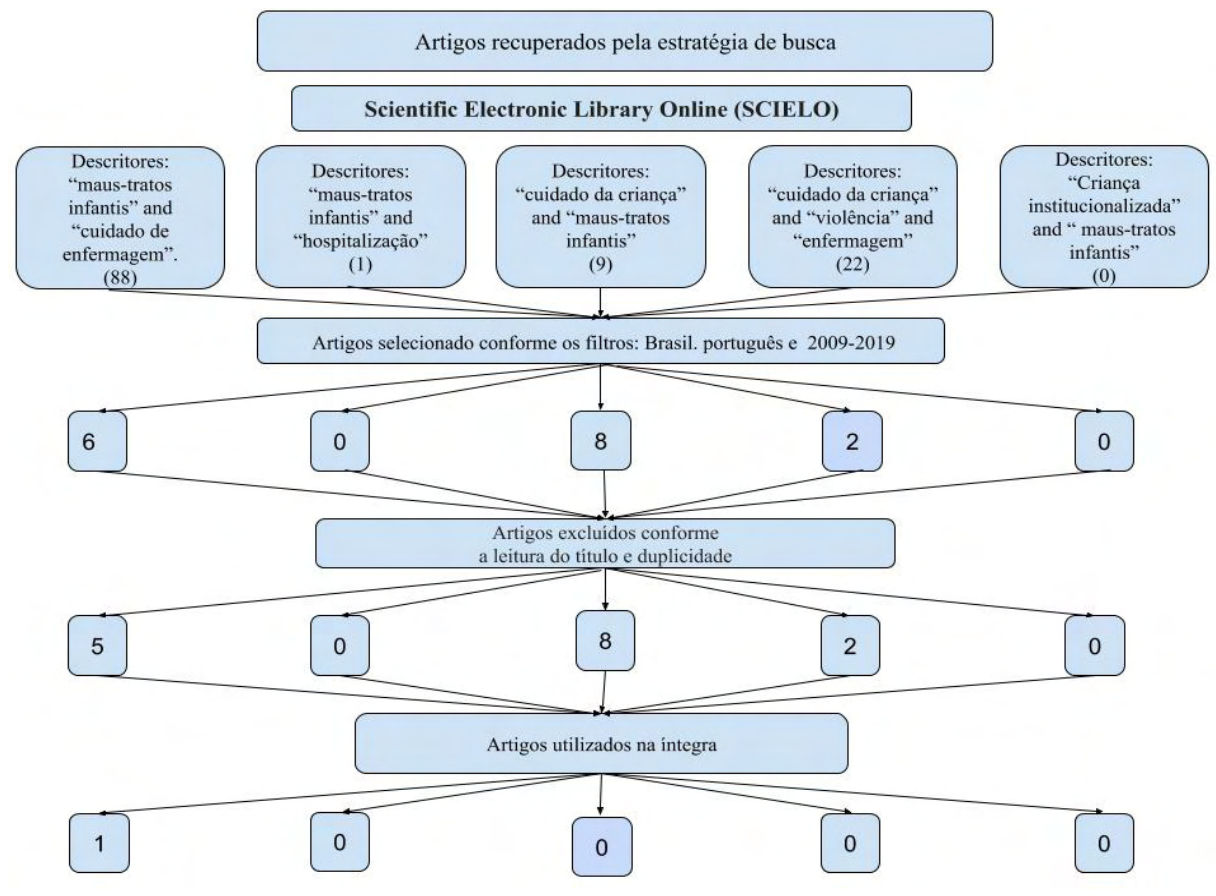

Fluxograma 2 - Artigos recuperados na SCIELO

Fonte: Os autores (2021)

Sendo assim, tivemos nesta busca de literatura o total de 14 artigos.

\section{I RESULTADOS}

Diante dos resultados obtidos nessa pesquisa, através da análise de estudos, foram evidenciadas características importantes nessa abordagem metodológica. O idioma nativo prevalente utilizado foi a Língua Portuguesa, exceto em 2 artigos, que são da Colômbia e do Chile, todos os demais foram publicados no Brasil no período de 2009 a 2019. Na construção desse estudo, participaram profissionais da equipe da Enfermagem, Psicologia e Assistente social, sendo em sua maioria, profissionais de Enfermagem em pós-graduação Strict Sensu (mestrado e doutorado).

Quanto à abordagem metodológica, a grande maioria dos estudos utilizou abordagem qualitativa.

Métodos qualitativos: fenomenologia e compreensão. Analisam o comportamento humano, do ponto de vista do ator, utilizando a observação naturalista e não controlada; são subjetivos e estão perto dos dados (perspectiva de dentro, insider), orientados ao descobrimento; são exploratórios, descritivos e indutivos; são orientados ao processo e assumem uma realidade dinâmica; são holísticos e não generalizáveis. (Serapioni ${ }^{19}{ }^{191}$, 2000). 
Em nossa análise, foram colocados os resultados apresentados no apêndice deste trabalho, que compreendem e abordam características dos estudos, assim como os dados relacionados com os maus-tratos infantis contemplados nos artigos analisados.

Quanto à revista que mais publicou sobre o assunto, destacou-se Revista Gaúcha de enfermagem $(21,4 \%)$ e sobre período de publicação, 2010 foi o ano em que houve maior número de publicações sobre o tema $(28,6 \%)$. Não foram verificados artigos publicados no ano de 2017. A maioria dos estudos foi desenvolvida na região Sul, com destaque para cidade de Porto Alegre/RS. Entretanto, destaca-se a considerável quantidade de produções da região Sudeste, ressaltando, ainda, a ausência de pesquisas realizadas nas regiões Norte e Nordeste do país.

Quanto às formas de maus-tratos infantis expressas nos trabalhos estudados, as violências físicas, sexuais e por negligência foram igualmente evidenciadas com $25,6 \%$ cada uma, num total de $76,8 \%$ dos estudos. A violência de natureza psicológica foi evidenciada em $23,2 \%$ do estudo.

\section{4 | DISCUSSÃO}

As dificuldades do enfermeiro diante dos maus tratos infantis e suas consequências teóricas e práticas no cuidado à criança hospitalizada.

O ambiente familiar deveria ser um local de amparo e proteção para as crianças e os adolescentes, porém isso não se confirma na prática clínica nem nos estudos analisados, pois é no próprio lar que eles estão expostos e possuem maior risco de sofrer maus-tratos. Estudos indicam que uso abusivo de álcool e drogas é o maior motivador de violência intrafamiliar, o que muitas das vezes resultam na institucionalização da criança. (Gabatz et $\left.\mathrm{al}^{20}, 2010\right)$.

Segundo um estudo realizado em uma UTI de serviço público de saúde foi evidenciado que $50 \%$ das hospitalizações de crianças ocorreram por meio de abuso físico e $36,4 \%$ por negligência. Isso demonstra o despreparo da família em lidar com suas necessidades, como também o uso da força física como método educativo. O familiar que deveria ser a proteção desses seres totalmente indefesos é o responsável pela sua hospitalização, visto que em $77,3 \%$ dos casos são eles os agressores. (Santome et $\mathrm{al}^{21}$, 2018).

A violência possui um aspecto cíclico, deixando marcas físicas, psicológicas e emocionais. Na criança isso é potencializado, pois ela ainda está no seu processo de desenvolvimento biopsicossocial que acarretará em transformações moleculares e neurobiológicos refletindo na sua maioridade, podendo tornar-se um futuro agressor. (De Oliveira et $\left.\mathrm{al}^{22}, 2010\right)$.

Um estudo demonstrou a atitude acolhedora da enfermagem frente à criança vítima de maus-tratos por familiares, no qual suas ações estavam centradas na criação de um ambiente protetor com conforto, carinho e segurança; onde a intensificação da vigilância 
era realizada como forma de suprir suas carências emocionais naquele momento porque se acredita que a ausência de tal ato pode ocasionar sequelas irreversíveis. Atitudes como deixar as portas e as cortinas abertas permitindo sua visualização, transmitem uma sensação de segurança, já que revelam que ela não se encontra sozinha e que nenhum ato contra sua integridade poderá ser realizado. (Angelo et $\mathrm{al}^{14}, 2013$ ).

A enfermagem vem se revelando cada vez mais atuante no processo de pesquisa e cuidados específicos relacionados ao atendimento às crianças vítimas de maus-tratos. $\mathrm{Na}$ assistência, os profissionais que compreendem o mecanismo do processo diante de um fenômeno tão impactante, podem refletir melhor sobre o tipo de assistência humanizada que têm realizado, podendo assim, buscarem cada vez mais essa especialização técnica e principalmente um olhar mais acolhedor.

"Conforme o protocolo da Secretaria Municipal de saúde, as crianças vitimizadas devem ser encaminhadas para hospitais de referência até 12 anos de idade. Porém muitos casos são encaminhados diretamente pelos familiares aos hospitais. "A enfermagem só terá contato com a criança vítima de violência sexual após ser atendida pelo médico de plantão e o perito do Instituto Médico Legal-IML. Como essa questão envolve não somente a criança e sua família, mas toda sua rede social, também é necessário acionar o conselho tutelar. (Woiski, Rocha ${ }^{23}, 2010$ ).

O cuidado de enfermagem numa situação de abuso sexual infantil conta, obviamente, com ações técnicas, porém necessita de uma grande entrega humanizada dos profissionais, o que está diretamente ligado a um preparo psicológico porque mesmo que indiretamente, acaba havendo um envolvimento emocional. A equipe relata a necessidade de uma capacitação e especialização voltada especificamente aos cuidados dessa vítima, pois muitas das vezes o atendimento se dá de forma empírica. De um modo geral, sobre crianças vítimas de maus-tratos, os enfermeiros sentem a real necessidade de um protocolo mais específico e voltado às necessidades de cada criança, tornando a assistência mais individualizada e agregadora no processo de hospitalização. Os profissionais não relatam um processo de enfermagem como método direcionador na sua assistência. (Woiski, Rocha $\left.{ }^{23}, 2010\right)$.

É comprovado que o vínculo, o acolhimento e a humanização da assistência melhoram o processo terapêutico e a relação entre profissionais e as crianças vítimas de maus-tratos. (Ciuffo, Rodrigues, Tocantins ${ }^{24}$, 2014).

Consideramos que diante de todas as formas de abuso, a violência sexual é a que mais leva sequelas para a vida da vítima, porque além de afetar o físico, afeta seu emocional de forma onde, muitas vezes ela levará marcas por toda sua vida. Para que as ações humanizadas do enfermeiro voltadas às crianças violentadas tenham motivações despertas, é preciso que ele tenha conhecimento das situações de violência vividas, a fim tocar-Ihes com propriedade sobre tal vivência, transmitindo segurança sobre sua assistência pautada no acolhimento. (Freitas, Moura, Monteiro ${ }^{25}, 2016$ ). 
Durante um estudo aplicado em crianças vítimas de maus-tratos, foi realizada uma abordagem que conectou as vítimas aos enfermeiros através da expressão de seus sentimentos e suas experiências. O método, chamado de Brinquedo Terapêutico, no caso específico de crianças vítimas de maus-tratos, Brinquedo Terapêutico Dramático, pois trabalha diretamente com a descarga emocional das crianças e através dele elas conseguem mostrar a violência sofrida de forma lúdica, dramatizando o ocorrido, fazendo assim com que os profissionais envolvidos compreendam as situações vivenciadas por elas em seu cotidiano, podendo então dar o melhor cuidado e atenção necessários para essa criança. (Giacomello, Jorgino, Melo ${ }^{26}, 2011$ ).

Grandes são as dificuldades encontradas na assistência pela equipe de enfermagem ao deparar com um caso de maus-tratos infantis. Muitas delas acontecem pela falta de qualificação desses profissionais, falta de capacitação e pela ausência de uma maior articulação com a equipe multiprofissional que dá assistência a essa criança, onde muitas das vezes o enfermeiro se vê sozinho diante de um quadro que necessita de uma atenção especializada e de uma continuidade no atendimento. Tais dificuldades contribuem e muito para o enfraquecimento do enfrentamento da violência e dos maus-tratos infantis. Com isso, revela-se grande necessidade de um protocolo de atendimento e assistência para esses casos específicos porque "a partir do momento que um serviço estabelece um protocolo de atendimento, o profissional se sente seguro e respaldado para então tomar as medidas cabíveis durante o processo". (Thomazine, De Oliveira, Viera ${ }^{27}, 2009$ ).

Esse protocolo para ser funcional é essencial que seja revisto, qualificado e alinhado por toda equipe envolvida no processo de cuidado dessa criança hospitalizada, para que haja uma maior interação acessível às demandas específicas de cada instituição e consequentemente de cada equipe envolvida na assistência. Quando se fala na necessidade de um protocolo, é de um protocolo adaptado às necessidades da assistência a essa criança. Não agrega ao trabalho um protocolo pronto sem especificidade, que não aborda a rotina e os problemas de cada instituição. (Camargo ${ }^{28}, 2015$ ).

Muitas foram as dificuldades encontradas por enfermeiros no atendimento à criança vítima de maus-tratos. Em relação aos pais e familiares, as dificuldades relacionadas à assistência estão ligadas à pobreza, à ignorância dos pais e à desinformação, à falta de educação e aos problemas socioculturais. Eles entendem que o próprio familiar muitas das vezes tenta esconder que há um problema de maus-tratos em casa, necessitando com isso de maior atenção a essa família, que muitas das vezes é vítima também. Essa tentativa de esconder a violência intrafamiliar revela o medo das consequências, não sabendo que ao revelar, poderão contar com o serviço de uma equipe multidisciplinar a fim de ajudarem nesse processo, minimizando os efeitos e consequências da violência na vida da criança e dessa família. (Thomazine, De Oliveira, Viera ${ }^{27}, 2009$ ).

Outra grande dificuldade relatada pelos profissionais é a leitura em conjunto com uma equipe multidisciplinar dessa criança vitimizada. Encontrar sinais camuflados de 
maus-tratos e negligência numa criança durante a assistência é um desafio diário durante a hospitalização da mesma. O profissional precisa estar atendo aos movimentos, olhares, reações atípicas diante de algum familiar específico, postura, modo de falar dessa criança que, muita das vezes não consegue se expressar com palavras por incapacidade, medo, coação ou insegurança. (Thomazine, De Oliveira, Viera ${ }^{27}, 2009$ ).

São diversos os aspectos que devem ser analisados na hospitalização de uma criança vítima de maus tratos, além dos cuidados aos ferimentos físicos, quando existirem, o enfermeiro precisa estar atento ao lado emocional dessa criança, ofertando carinho, amor, atenção e acolhimento a fim de não tornar essa assistência mecanizada, porque embora seja necessária toda parte técnica no tratamento, uma criança vítima de maus tratos sente tanta dor física quanto emocional. A diferença que faz no atendimento de quem está diariamente na sua assistência é exatamente na possibilidade de poder acolher essa criança de modo que ela se sinta protegida.

É necessário encarar a violência como um problema que impacta a vida da vítima e de sua família, acarretando graves problemas psicológicos e na saúde dessa criança, gerando consequências no seu desenvolvimento psicológico e cognitivo.

Um ponto que despertou surpresa em nossa análise é que num dos estudos, onde foram selecionados 13 enfermeiros que atuam nas unidades de pronto atendimento no Paraná, muitos deles não consideravam negligência como forma de violência. Por questões como essas, que é de grande importância a necessidade de esclarecimento, de treinamento e protocolos para lidar com esse tipo específico de atendimento. Para que haja uma assistência mais humanizada e acolhedora a essa vítima, a equipe de saúde precisa estar além de capacitada, interligada, trabalhando em conjunto e ciente de todos os aspectos que envolvem uma situação de maus tratos a fim de compreender o axioma de cada família, podendo então trabalhar melhor as emoções e os sentimentos que surgem, possibilitando um tratamento mais cuidadoso e digno à criança e a essa família. (Amaral et $\left.\mathrm{al}^{29}, 2013\right)$.

Muito se fala sobre sentimentos, emoções e sequelas das vítimas de maus-tratos, mas precisamos também falar da grande carga emocional que os enfermeiros que lidam com essas vítimas estão sujeitos. Mesmo esses profissionais dominando toda técnica do cuidado, precisamos falar de valorização do seu trabalho, valorização da sua saúde mental e valorização da sua remuneração. Fala-se muito em treinamento, protocolos e capacitação, mas pouco se investe na saúde mental desses profissionais tão necessários na assistência de uma criança violentada.

Mesmo com todo conhecimento científico, ao se depararem com as dificuldades que emergem no encontro com uma criança vítima de maus-tratos, os enfermeiros precisam lidar com seus próprios sentimentos de dor e sofrimento, o que se não for muito bem canalizado, pode interferir na relação terapêutica. É necessário que esse profissional não se engesse, tornando esse cuidado mecanizado, contribuindo para falta de humanização na 
assistência, o que acaba limitando uma resposta acolhedora diante de um acontecimento traumático, logo devemos enfatizar a importância do seu cuidado e como isso reflete na ponta, uma vez que é a equipe de enfermagem que passará a maior parte do tempo ao lado dessas vítimas.

O estudo ressaltou a importância da qualificação do enfermeiro no atendimento a essas crianças na busca por identificação por sintomas para reconhecer uma provável reincidência de abuso. Destaca-se a urgência de uma equipe multidisciplinar para atuar em diferentes segmentos do cuidado, indagando a importância do suporte de uma rede de apoio social extra-hospitalar para prover a atenção psicossocial da qual ela possui direito. (Saraiva et $\mathrm{al}^{30}, 2012$ ).

Infelizmente lidar com essa realidade tem se mostrado uma rotina no atendimento hospitalar, o enfermeiro encontra embates diários, que é preciso dotar de uma maturidade emocional para enfrentar tais situações, onde são muitos os sentimentos que afloram diante da criança vítima de violência. Podemos dizer que a angústia dos enfermeiros diante do sofrimento de crianças violentadas ultrapassa a dimensão profissional porque interfere diretamente em seus valores morais, pessoais e profissionais. (Lamb et al ${ }^{31}, 2019$ ).

Com isso, o processo de cuidado de uma criança vítima de maus-tratos se torna um constante desafio para os enfermeiros na assistência hospitalar por englobar aspectos biopsicossociais que vão além da lesão física. Além disso, quando o profissional trata diretamente de uma criança abusada, além de prestar assistência e oferecer um tratamento humanizado e acolhedor, ele também precisa lidar com seus próprios sentimentos e emoções que vão aparecendo conforme vai cuidando, confrontando muitas das vezes com suas pré concepções, saberes e conceitos como pessoa. (Amaral et al ${ }^{29}, 2013$ ).

Ter empatia, prover afeto e acolher são cuidados inseparáveis da prática do enfermeiro em crianças vítimas de maus-tratos. Isso torna-se primordial, onde o principal objetivo é minimizar os traumas já sofridos por elas. O caminho que deve ser percorrido para que as crianças tenham de fato todos os cuidados e a assistência que elas realmente necessitam ainda é longo nas unidades hospitalares, pois além de apresentarem baixas condições estruturais, falta de recursos humanos e materiais, salienta-se que seja essencial uma mudança estrutural no atendimento à criança, a começar na porta de entrada com o acolhimento e reconhecimento dos sinais de violência, dar ênfase para a notificação do abuso, aprimorar o cuidado, promover, instruir a vítima e a família, aperfeiçoar os registros e traçar uma estratégia de cuidado com ações interdisciplinares e no final organizar os serviços de referência e contra referência. (Cocco et $\mathrm{al}^{32}, 2010$ ).

\section{I CONCLUSÃO}

Ao final do estudo entendemos que o objetivo proposto foi alcançado. Grandes foram as dificuldades em encontrar estudos que abordassem as condutas dos profissionais 
de enfermagem na hospitalização de crianças violentadas; e a falta de estudos que evidenciam protocolos específicos de atendimento abordando da triagem à hospitalização da criança nos gerou surpresa, preocupação e de certo modo até desolação por vermos o quanto a enfermagem ainda está desassistida em todos os aspectos num assunto de tamanha importância. Não se obteve artigos que tivessem um fluxo de atendimento pautado na continuidade da assistência entre uma equipe multidisciplinar. Entende-se que uma assistência que requer um cuidado holístico não pode estar segregada, é preciso um trabalho em conjunto para o melhor resultado, tratamento, cuidado e proteção dessa criança.

Um enfermeiro na hospitalização de uma criança que foi violentada precisa não só de conhecimento e suporte técnico, como precisa ter a sua disposição um serviço de acolhimento para que ele tenha condição de acolher. Lidar com tamanha violência em pacientes tão vulneráveis requer equilíbrio emocional. Percebe-se uma classe que desempenha um trabalho tão importante, ainda ter problemas relativos à desvalorização no cenário de atuação. Entre tantos aspectos que deveriam estar estipulados em protocolos voltados especificamente para a hospitalização de uma criança vítima de maus tratos também está relacionada à melhores condições de trabalho de quem está diariamente lhe prestando assistência.

É preciso educação sobre saúde mental para os profissionais envolvidos no processo, é preciso acolhimento e é preciso autonomia para esses que estão na ponta da assistência diária na hospitalização com seu cuidado técnico, seu acolhimento e sua empatia.

\section{REFERÊNCIAS}

1 Ariés p. História social da criança e da família. 2. Ed. Rio de janeiro: livros técnicos e científicos; 2011.

2 Victora cg. Intervenções para reduzir a mortalidade infantil pré-escolar e materna no brasil. Rev. Bras. Epidemiol. [Internet] 2001 abr [acesso em 2020 nov 25]; 4(1):3-69. Disponível em: http://www. Scielo.Br/scielo.Php?Script=sci_arttext\&pid=s1415-790x2001000100002\&lng=en\&nrm=iso. Doi: https:// doi.Org/10.1590/S1415-790x2001000100002.

3 Araujo jp, da silva rm, collet n, neves et, tos br, vieira cs. História da saúde da criança: conquistas, políticas e perspectivas. Rev. Bras. Enferm. [Internet]. 2014 Dez [acesso em 2020 nov 25]; 67(6):1000-1007. Disponível em http://www.Scielo.Br/scielo.Php?Script=sci_arttext\&pid=s003471672014000601000\&lng=en\&nrm=iso. Doi: https://doi.Org/10.1590/0034-7167.2014670620.

4 Brasil. Lei federal $n^{\circ} 8.069$, De 13 de julho de 1990. Dispõe sobre o estatuto da criança e do adolescente e dá outras providências. Diário oficial da união. 1990 Jul 13.

5 José $\mathrm{m}$, amorim i. Estatuto da criança e do adolescente anotado e interpretado. Curitiba: ministério público do estado do paraná; 2010. 
6 Ministério da saúde (br). Humanizasus: política nacional de humanização. Brasília: ministério da saúde; 2003.

7 Ministério da saúde (br). Secretaria de atenção à saúde, departamento de ações pragmáticas e estratégicas. Brasília: ministério da saúde; 2015.

8 Monteiro ai, lima ky, santos ad, teixeira gb, macêdo ip. Humanização do atendimento à criança na atenção básica: visão dos profissionais. Rev ren. 2012; 13(4):724-33.

9 Brasil. Sociedade brasileira de pediatria. Escola nacional de saúde pública, brasil. Ministério da justiça. Guia de atuação frente a maus-tratos na infância e adolescência: orientação para pediatras e demais profissionais de saúde. 2. Ed. Rio de janeiro; 2001.

10 Deslandes sf. Prevenir a violência: um desafio para profissionais de saúde. Rev. Latino am. Enfermagem [internet]. 1995 Jul [acesso em 2020 nov 25]; 3(2):207-208. Disponível em: https://www. Redalyc.Org/articulo.Oa?ld=5057/505750818009.

11 Ministério da saúde (br). Informações em saúde: epidemiológicas e morbidade. Datasus [internet]. 2017 [Acesso em 2020 nov 25]. Disponível em: http://tabnet.Datasus.Gov.Br/cgi/tabcgi.Exe?Sinannet/ cnv/violerj.Def.

12 Gomes $r$, junqueira mf, silva co, junger wl. Abordagem dos maus-tratos contra a criança e o adolescente em uma unidade pública de saúde. Ciênc. Saúde coletiva. 2002;7(2):275-83.

13 Nunes cb, sarti ca, ohara, cv. Health care professionals' approaches to address family violence against children and teenagers. Acta paul. Enferm. [Internet]. 2009 [Acesso em 2020 nov 30]; 22:903-908. Disponível em: http://www.Scielo.Br/scielo.Php?Script=sci_arttext\&pid=s010321002009000700012\&lng=en\&nrm=iso. Doi: https://doi.Org/10.1590/S0103-21002009000700012.

14 Angelo m, prado si, cruz ac, ribeiro mo. Vivências de enfermeiros no cuidado de crianças vítimas de violência intrafamiliar: uma análise fenomenológica. Texto contexto enferm. 2013 Jul-set; 22(3):585-92.

15 Laurez fv. Manual para atendimento às vítimas de violência na rede de saúde pública do distrito federal. 2. Ed. Brasília: secretaria de estado de saúde do distrito federal; 2009.

16 A familiar face: violence in the lives of children and adolescentes. Unicef [internet]. Nov 2017 [acesso em 2020 nov 25]. Disponível em: https://www.Unicef.Org/publications/files/violence_in_the_lives_of_ children_and_adolescents.Pdf.

17 Ministério da saúde (br). Informações em saúde: epidemiológicas e morbidade. Datasus [internet]. 2018 [Acesso em 2020 nov 25]. Disponível em: http://tabnet.Datasus.Gov.Br/cgi/tabcgi.Exe?Sinannet/ cnv/violerj.Def.

18 Mendes kd, silveira rc, galvao cm. Revisão integrativa: método de pesquisa para a incorporação de evidências na saúde e na enfermagem. Texto contexto enferm [internet]. 2008 Out-dez [acesso em 2020 nov 25]; 17(4):758-764. Disponível em: http://www.Scielo.Br/scielo.Php?Script=sci_ arttext\&pid=s0104-07072008000400018\&Ing=e\&nrm=iso. Doi: https://doi.Org/10.1590/S010407072008000400018. 
19 Serapioni m. Métodos qualitativos e quantitativos na pesquisa social em saúde: algumas estratégias para a integração. Ciênc. Saúde coletiva [internet]. 2000 [Acesso em 2020 nov 25]; 5(1):187-192.

Disponível em: http://www.Scielo.Br/scielo.Php?Script=sci_arttext\&pid=s1413-81232000000100016\&lng =en\&nrm=iso. Doi: https://doi.Org/10.1590/S1413-81232000000100016.

20 Gabatz ri, de mello ps, neves et, terra mg. Fatores relacionados à institucionalização: perspectivas de crianças vítimas de violência intrafamiliar. Rev. Gaúcha enferm. [Internet]. 2010 Dez [acesso em 2020 nov 25]; 31(4):670-677. Disponível em http://www.Scielo.Br/scielo.Php?Script=sci_ arttext\&pid=s1983-14472010000400009\&Ing=en\&nrm=iso. Doi: http://dx.Doi.Org/10.1590/S198314472010000400009.

21 Santome Im, leal sm, mancia jr, gomes am. Crianças hospitalizadas por maus-tratos em uti de serviço público de saúde. Rev. Bras. Enferm. [Internet]. 2018 [Acesso em 2020 nov 2020]; 71(3):1420-1427. Disponível em: http://www.Scielo.Br/scielo.Php?Script=sci_arttext\&pid=s003471672018000901420\&lng=pt\&nrm=iso. Doi: https://doi.Org/10.1590/0034-7167-2017-0502.

22 De oliveira ga, antunes $\mathrm{cp}$, da silva Ir, de luca nm, silva md. A criança vítima de violência doméstica: limites e desafios para a prática de enfermagem. Rev. Pesqui. Cuid. Fund. Onl. 2010; 2(2):902-912.

23 Woiski ro, rocha dl. Cuidado de enfermagem à criança vítima de violência sexual atendida em unidade de emergência hospitalar. Esc. Anna nery [internet]. 2010 Mar [acesso em 2020 nov 25]; 14(1):143-150. Disponível em: http://www.Scielo.Br/scielo.Php?Script=sci_arttext\&pid=s141481452010000100021\&lng=en\&nrm=iso. Doi: http://dx.Doi.Org/10.1590/S1414-81452010000100021.

24 Ciuffo II, rodrigues bm, tocantins fr. Interdisciplinary action of nurses to children with suspected sexual abuse. Invest educ enfermería [internet]. 2014 Fev [acesso em 2020 nov 25]; 32(1):112-118. Disponível em https://revistas.Udea.Edu.Co/index.Php/iee/article/view/18576/16348.

25 Freitas rj, moura na, monteiro ar. Violência contra crianças/adolescentes em sofrimento psíquico e cuidado de enfermagem: reflexões da fenomenologia social. Rev. Gaúcha enferm. [Internet]. 2016 Abr [acesso em 2020 nov 25]; 37(1):1-4. Disponível em: http://www.Scielo.Br/scielo.Php?Script=sci_ arttext\&pid=s1983-14472016000100702\&lng=pt\&nrm=iso. Doi: http://dx.Doi.Org/10.1590/19831447.2016.01.52887

26 Giacomello kj, de lione $\mathrm{ml}$. Do faz de conta à realidade: compreendendo o brincar de crianças institucionalizadas vítimas de violência por meio do brinquedo terapêutico. Ciênc. Saúde coletiva [internet]. 2011 [Acesso em 2020 nov 25]; 16(1):1571-1580. Disponível em: http://www.Scielo.Br/ scielo.Php?Script=sci_arttext\&pid=s1413-81232011000700093\&lng=pt\&nrm=iso. Doi: http://dx.Doi. Org/10.1590/S1413-81232011000700093.

27 Thomazine am, de oliveira br, viera cs. Atenção a crianças e adolescentes vítimas de violência intrafamiliar por enfermeiros em serviços de pronto-atendimento. Revista eletrônica de enfermagem [internet]. 2009 Dez [acesso em 2020 nov 25]; 11(4):830-40. Disponível em: https://revistas.Ufg.Br/fen/ article/view/33237.

28 Camargo d. Processo participativo entre profissionais de saúde para integrar o atendimento à criança vítima de violência. Pesqui. Prát. Psicossociais [internet]. 2015 Dez [acesso em 2020 nov 25]; 10(2):340-353. Disponível em: http://pepsic.Bvsalud.Org/scielo.Php?Script=sci_arttext\&pid=s1809$89082015000200011 \&$ lng =pt\&nrm=iso. 
29 Amaral Iv, de amorim ga, figueiredo sv, gomes il. Significado do cuidado às crianças vítimas de violência na ótica dos profissionais de saúde. Rev. Gaúcha enferm [internet]. 2013 Dez [acesso em 2020 nov 25]; 34(4):146-152. Disponível em: http://www.Scielo.Br/scielo.Php?Script=sci_ arttext\&pid=s1983-14472013000400019\&Ing=en\&nrm=iso. Doi: https://doi.Org/10.1590/S198314472013000400019.

30 Saraiva rj, rosas amt, valente gs, de oliveira vl. Qualificação do enfermeiro no cuidado a vítimas de violência doméstica infantil. Cienc. Enferm [internet]. 2012 Abr [acesso em 2020 nov 25]; 18(1):17-27. Disponível em: https://scielo.Conicyt.Cl/scielo.Php?Script=sci_arttext\&pid=s071795532012000100003\&lng=es\&nrm=iso. Doi: http://dx.Doi.Org/10.4067/S0717-95532012000100003.

$31 \mathrm{Lamb}$ fa, beck cl, coelho, ap, vasconcelos ro. Trabalho de enfermagem em pronto socorro pediátrico: entre o prazer e o sofrimento. Cogitare enferm. [Internet]. 2019 Ago [acesso em 2020 nov 25]; 24:1-11. Disponível em: http://www.Revenf.Bvs.Br/scielo.Php?Script=sci_arttext\&pid=s1414$85362019000100308 \&$ Ing=pt\&nrm=iso. Doi: http://dx.Doi.Org/10.5380/Ce.V24i0.59396.

32 Cocco m, da silva eb, jahn, ad, poll ad. Violência contra crianças e adolescentes: estratégias de cuidado adotadas por profissionais de saúde. Cienc., Cuid. Saúde [internet]. 2010 Set [acesso em 2020 nov 25]; 9(2):292-300. Disponível em: http://periodicos.Uem.Br/ojs/index.Php/cienccuidsaude/article/ view/8061/6108. Doi: 10.4025/Cienccuidsaude.V9i2.8061. 


\section{ANÁLISE DOS PRINCIPAIS FATORES DE RISCO PARA O SURGIMENTO DO CÂNCER DE COLO DO ÚTERO}

Data de aceite: 20/08/2021

Data de submissão: 12/07/2021

Rafaela Alves de Oliveira

Bacharel em Enfermagem, Centro Universitário de Ciências e Tecnologia do Maranhão UNIFACEMA, Caxias/MA.

Bentinelis Braga da Conceição

Bacharel em Enfermagem, Centro Universitário de Ciências e Tecnologia do Maranhão UNIFACEMA, Caxias/MA.

Barbara Maria Rodrigues dos Santos Graduanda em Enfermagem, Universidade Federal do Piauí-UFPI, Teresina/PI.

Nariane Morais do Nascimento Silva Graduanda em Enfermagem, Universidade Anhanguera - Uniderp, Caxias/Ma.

Adriano Nogueira da Cruz

Bacharel em Enfermagem, Universidade Estadual do Maranhão - UEMA, Caxias/MA.

Islaila Maria Silva Ferreira

Graduanda em Enfermagem, Universidade Federal do Piauí - UFPI, Teresina/PI.

Ana de Cássia Ivo dos Santos Bacharel em Enfermagem, Universidade Federal do Piaul - UFPI, Parnaíba/PI.

Mariana Teixeira da Silva

Bacharel em Enfermagem, Universidade Federal do Piauí - UFPI, Picos/PI.

Layane Mayhara Gomes Silva Bacharel em Enfermagem, Centro Universitário de Ciências e Tecnologia do Maranhão UNIFACEMA, Caxias/MA
Maria da Cruz Alves da Silva Bacharel em Enfermagem, Universidade Estadual do Piauí - UESPI.

Brendon Nathanaell Brandão Pereira Centro Universitário UNINOVAFAPI Teresina/PI.

Maria Eugênia Lopes Mendes Instituto Federal do Piauí, Teresina/PI.

Zaíne Araújo Gonçalves

Bacharel em Enfermagem, Universidade Estadual do Piauí - UFPI, Teresina/PI.

Adriana dos Passos Silva Bacharel em Enfermagem, Faculdade IESM, Timon/MA.

RESUMO: Objetivo: Analisar os principais fatores de risco para o surgimento do câncer de colo do útero. Métodos: Trata-se de uma pesquisa bibliográfica do tipo revisão integrativa da literatura, onde formulou-se a seguinte questão não-clínica: "Quais os principais fatores de risco para o surgimento do câncer de colo do útero?". Resultados: Os seis estudos incluídos nesta revisão estavam nos idiomas português (50\%) e inglês (50\%). A maioria das publicações foram concentradas no ano de 2014 (2/33,3\%), e houve predomínio de estudos realizados no Brasil (3/50\%). O nível de evidência maior foi 3 (50\%) e o grau de recomendação foi A (100\%). Os principais fatores de risco para o surgimento do câncer de colo do útero após a análise dos artigos selecionados foram: a infecção pelo Papiloma Vírus Humano (HPV), o uso dos métodos 
contraceptivos orais, o tabagismo, a multiparidade, os múltiplos parceiros e a iniciação sexual precoce. Considerações finais: A equipe de enfermagem é responsável por realizar medidas de prevenção, juntamente com a população feminina, por meio do desenvolvimento de estratégias que busquem minimizar os fatores de risco para o surgimento do câncer de colo do útero, contribuindo para a melhoria da qualidade de vida das mulheres e diminuindo os números de casos de neoplasias.

PALAVRAS - CHAVE: Câncer de colo do útero; Fatores de risco; Mulheres.

\title{
ANALYSIS OF THE MAIN RISK FACTORS FOR THE APPEARANCE OF CERVICAL CANCER
}

\begin{abstract}
Objective: To analyze the main risk factors for the onset of cervical cancer. Methods: This is a bibliographical research of the type integrative review of the literature, where the following non-clinical question was formulated: "What are the main risk factors for the appearance of cervical cancer?". Results: The six studies included in this review were Portuguese (50\%) and English (50\%). Most of the publications were concentrated in the year 2014 (2 / 33.3\%), and there were predominant studies conducted in Brazil (3/50\%). The highest level of evidence was $3(50 \%)$ and the degree of recommendation was $A(100 \%)$. The main risk factors for the development of cervical cancer following the analysis of selected articles were: Human Papilloma Virus (HPV) infection, use of oral contraceptive methods, smoking, multiparity, multiple partners, and early sexual initiation. Final considerations: The nursing team is responsible for carrying out prevention measures, together with the female population, through the development of strategies that seek to minimize the risk factors for the onset of cervical cancer, contributing to the improvement of quality reduction in the number of cases of neoplasms.
\end{abstract}

KEYWORDS: Cervical cancer; Risk factors; Women.

\section{INTRODUÇÃO}

O câncer de colo uterino (CCU) é a segunda causa de morte por câncer entre mulheres no mundo, com maior incidência nos países em desenvolvimento. No Brasil representa o terceiro mais comum tipo de neoplasia maligna que acomete mulheres com vida sexual ativa depois do câncer de pele não-melanoma e do câncer de mama (FERNANDES et al., 2009).

Essa neoplasia tem causa multifatorial e, se não diagnosticada e tratada precocemente, poderá evoluir para o carcinoma invasivo (ANJOS et al., 2010). A mortalidade registrada no ano de 2009, decorrente desse câncer, foi de 5.063 óbitos, porém, quando o diagnóstico e o tratamento são realizados precocemente pode-se atingir um alto percentual de cura (PINHO; JODAS; SCHOCHI, 2012).

O Ministério da Saúde aponta que o exame do Papanicolau tem uma alta eficácia na detecção das lesões precursoras do câncer invasivo e que, se detectadas precocemente, podem ser curadas em $100 \%$ dos casos, portanto recomenda o início do rastreamento para o CCU aos 25 anos de idade para as mulheres que já iniciaram atividade sexual. O intervalo 
entre os exames deve ser de três anos, após dois exames negativos, com intervalo anual e devem ser feitos até os 64 anos e serem interrompidos após esta idade (BRASIL, 2011).

Com isso, a questão problematizadora desta revisão foi: Quais os principais fatores de risco para o surgimento do câncer de colo do útero? Para tal, este estudo teve como objetivo analisar os principais fatores de risco para o surgimento do câncer de colo do útero

\section{METODOLOGIA}

Trate-se de uma pesquisa bibliográfica do tipo revisão integrativa da literatura. De acordo com Ercole, Melo e Alcoforado (2014), a revisão integrativa de literatura é um método que tem como finalidade sintetizar resultados obtidos em pesquisas de maneira sistemática, ordenada e abrangente, mediante diferentes metodologias. É denominada integrativa porque fornece informações mais amplas sobre um assunto, constituindo um corpo de conhecimento e podendo ser direcionada para a definição de conceitos, revisão de teorias ou análise metodológica dos estudos.

Sua elaboração inclui: definição do objetivo; estabelecimento de critérios de inclusão e exclusão para a seleção da amostra; definição das informações a serem extraídas dos artigos selecionados; análise, e discussão dos resultados. Para orientar este estudo, formulou-se a seguinte questão não-clínica (PICo): Quais os principais fatores de risco para o surgimento do câncer de colo do útero?

A estratégia PICo, que representa um acrônimo para Paciente $(P)$, Intervenção (I), Contexto (Co), foi utilizada para a construção da questão norteadora desta revisão integrativa da literatura. Para a localização dos estudos relevantes, que respondessem à pergunta de pesquisa, utilizou-se de descritores indexados nos idiomas português, inglês e espanhol. Os descritores foram obtidos a partir do Medical Subject Headings (MESH) e dos Descritores em Ciências da Saúde (DeCS).

A coleta de dados foi realizada por meio de busca eletrônica nas seguintes bases de dados: Bireme (Biblioteca Virtual de Saúde - BVS) e PubMed da National Library of Medicine

Os critérios de inclusão definidos foram: estudos primários, disponíveis em sua totalidade, publicados nos últimos cinco anos, de 2013 até 2018, nos idiomas Português, Espanhol e Inglês. Foram excluídos da busca inicial capítulos de livros, resumos, textos incompletos, teses de doutorado, dissertações de mestrados, monografias e relatos técnicos.

Utilizaram-se os seguintes bancos com seus respectivos descritores: 


\begin{tabular}{|c|c|c|c|}
\cline { 2 - 4 } \multicolumn{1}{c|}{} & Elementos & Mesh & Decs \\
\hline P & "Mulheres" & "Women" & "Mulheres" \\
\hline I & "Câncer de colo do útero" & $\begin{array}{c}\text { "Cervical Neoplasm, } \\
\text { Uterine" }\end{array}$ & $\begin{array}{c}\text { "Neoplasias do Colo do } \\
\text { Útero" }\end{array}$ \\
\hline Co & "Fatores de risco" & "Risk Factors" & "Fatores de risco" \\
\hline
\end{tabular}

Quadro 1 - Elementos da estratégia PICo e descritores utilizados. Caxias, Ma, 2018.

Os termos utilizados durante a pesquisa foram classificados e combinados nos bancos de dados, resultando em estratégias específicas de cada base:

\begin{tabular}{|c|c|c|c|}
\hline Base de dados & Estratégia de busca & Resultados & Selecionados \\
\hline $\begin{array}{c}\text { Bireme } \\
\text { (descritores } \\
\text { Decs) }\end{array}$ & 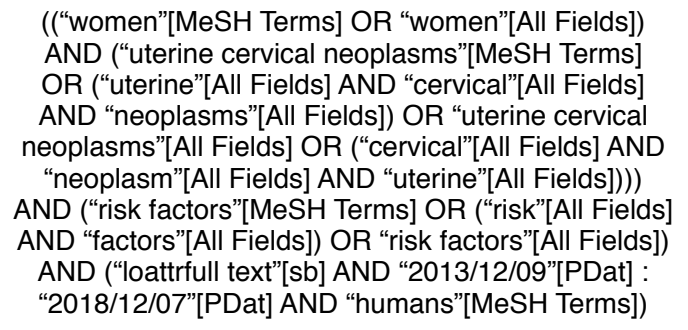 & 2.780 & 3 \\
\hline $\begin{array}{l}\text { PubMed } \\
\text { (descriptors } \\
\text { MeSH) }\end{array}$ & $\begin{array}{c}\text { ((Women) AND Cervical Neoplasm, Uterine) AND } \\
\text { Risk Factors AND free full text[sb] AND “last } 5 \\
\text { years"[PDat((Women) AND Cervical Neoplasm, } \\
\text { Uterine) AND Risk Factors AND ((Women) AND } \\
\text { Cervical Neoplasm, Uterine) AND Risk Factors } \\
\text { ((Women) AND Cervical Neoplasm, Uterine) AND Risk } \\
\text { Factors }\end{array}$ & 4.373 & 3 \\
\hline
\end{tabular}

Quadro 2 - Estratégias de busca utilizadas nas bases de dados Bireme e PubMed. Caxias, Ma, 2018.

Os estudos foram pré-selecionados segundo os critérios de inclusão e exclusão e de acordo com a estratégia de funcionamento e busca de cada base de dados, conforme fluxograma descrito na Figura 1. 
Questão norteadora: Quais os principais fatores de risco para o surgimento do câncer de colo do útero?

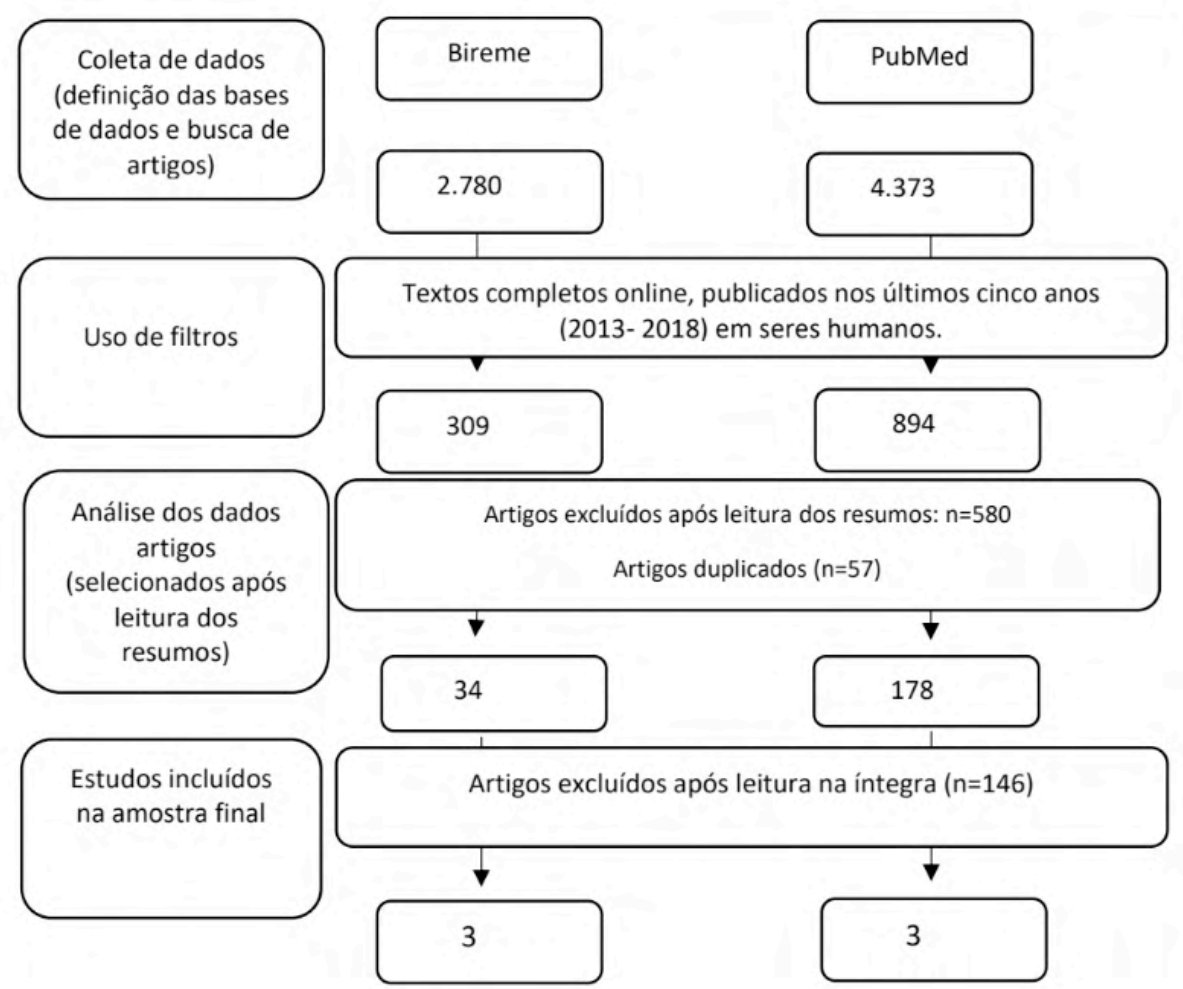

Figura 1: Fluxo do processo de seleção dos estudos para a revisão integrativa. Caxias, MA, 2018. $(n=6)$.

\section{RESULTADOS}

Os seis estudos incluídos nesta revisão estavam nos idiomas português $(50 \%)$ e inglês (50\%). A maioria das publicações foram concentradas no ano de 2014 (2/33,3\%), e houve predomínio de estudos realizados no Brasil (3/50\%). O nível de evidência maior foi $3(50 \%)$ e o grau de recomendação foi A (100\%). A principal linha de pesquisa investigada nessa temática versou sobre os principais fatores de risco para o surgimento do câncer de colo do útero (Quadro 3).

Os estudos identificaram a infecção pelo Papiloma Vírus Humano (HPV), o uso de métodos contraceptivos orais, o tabagismo, a multiparidade, os múltiplos parceiros e iniciação sexual precoce (Quadro 4). 


\begin{tabular}{|c|c|c|c|c|c|c|}
\hline Autores & Título & $\begin{array}{l}\text { Base/Ano de } \\
\text { publicação }\end{array}$ & País & $\begin{array}{c}\text { Delineamento da } \\
\text { pesquisa }\end{array}$ & $\begin{array}{l}\text { Nível de } \\
\text { evidência }\end{array}$ & $\begin{array}{l}\text { Grau de } \\
\text { recomendação }\end{array}$ \\
\hline $\begin{array}{l}\text { ANJOS, S. J. S. } \\
\text { B. et al. }\end{array}$ & $\begin{array}{l}\text { Fatores de risco } \\
\text { para o câncer de } \\
\text { colo do útero em } \\
\text { mulheres reclusas }\end{array}$ & Bireme/2013 & Brasil & $\begin{array}{l}\text { Estudo descritivo } \\
\text { de coorte } \\
\text { transversal com } \\
\text { abordagem } \\
\text { quantitativa }\end{array}$ & 3 & A \\
\hline $\begin{array}{l}\text { BARASUOL, } \\
\text { M. E. C.; } \\
\text { SCHMIDT, } \\
\text { D. B. }\end{array}$ & $\begin{array}{l}\text { Neoplasia do colo } \\
\text { do útero e seus } \\
\text { fatores de risco: } \\
\text { revisão integrativa }\end{array}$ & Bireme/2014 & Brasil & $\begin{array}{l}\text { Revisão } \\
\text { sistemática }\end{array}$ & 1 & A \\
\hline $\begin{array}{c}\text { AMARAL, } \\
\text { M. S.; } \\
\text { GONÇALVES, } \\
\text { A. G.; } \\
\text { SILVEIRA, L. } \\
\text { C. G. }\end{array}$ & $\begin{array}{l}\text { Prevenção do } \\
\text { câncer de colo de } \\
\text { útero: a atuação } \\
\text { do profissional } \\
\text { enfermeiro nas } \\
\text { unidades básicas } \\
\text { de saúde }\end{array}$ & Bireme/2017 & Brasil & $\begin{array}{l}\text { Revisão } \\
\text { sistemática }\end{array}$ & 1 & A \\
\hline $\begin{array}{l}\text { THAKUR, A. } \\
\text { et al. }\end{array}$ & $\begin{array}{l}\text { Risk factors for } \\
\text { cervical cancer } \\
\text { among rural women } \\
\text { in a mountainous } \\
\text { state: A case- } \\
\text { control study }\end{array}$ & $\begin{array}{l}\text { Pubmed/ } \\
2015\end{array}$ & Índia & Caso controle & 4 & A \\
\hline $\begin{array}{l}\text { OPOKU, C. U. } \\
\text { et al. }\end{array}$ & $\begin{array}{l}\text { Perception and risk } \\
\text { factors for cervical } \\
\text { cancer in women in } \\
\text { northern Ghana }\end{array}$ & $\begin{array}{l}\text { Pubmed/ } \\
2016\end{array}$ & África & $\begin{array}{c}\text { Estudo de } \\
\text { coorte, com } \\
\text { uma abordagem } \\
\text { quantitativa }\end{array}$ & 3 & A \\
\hline TAO, L. e at. & $\begin{array}{l}\text { Prevalence and risk } \\
\text { factors for cervical } \\
\text { cancer: a screening } \\
\text { program for cervical } \\
\text { cancer in Beijing }\end{array}$ & Cinhal/2014 & China & $\begin{array}{c}\text { Estudo de } \\
\text { coorte, com } \\
\text { uma abordagem } \\
\text { quantitativa }\end{array}$ & 3 & A \\
\hline
\end{tabular}

Quadro 3 - Distribuição das publicações incluídas segundo os autores, título, base de dados e ano de publicação, país onde o estudo foi realizado, delineamento da pesquisa, nível de evidência e grau de recomendação. Caxias, MA, 2018.

\begin{tabular}{|c|c|c|c|}
\hline Autores & Objetivo principal & Perfil amostral & Principais resultados \\
\hline $\begin{array}{l}\text { ANJOS, S. J. } \\
\text { S. B. et al. }\end{array}$ & $\begin{array}{c}\text { Identificar os fatores } \\
\text { de risco para o } \\
\text { desenvolvimento do } \\
\text { câncer de colo uterino em } \\
\text { mulheres reclusas. }\end{array}$ & $\begin{array}{c}\text { A seleção da amostra do } \\
\text { estudo ocorreu de acordo } \\
\text { com a disponibilidade de } \\
\text { presidiárias no momento } \\
\text { da coleta, totalizando } 36 \\
\text { reclusas. }\end{array}$ & $\begin{array}{l}\text { Referente aos riscos para o câncer } \\
\text { cervical, } 16 \text { mulheres }(44,5 \%) \text { eram } \\
\text { tabagistas, } 24(70,5 \%) \text { já fizeram uso do } \\
\text { contraceptivo oral por um tempo médio } \\
\text { de } 46 \text { meses, } 4(66,6 \%) \text { apresentaram } \\
\text { coitarca com idade inferior a } 15 \text { anos; } \\
26(72,2 \%) \text { faziam uso de preservativo, } \\
\text { porém } 10(38,4 \%) \text { o usavam raramente. }\end{array}$ \\
\hline $\begin{array}{l}\text { BARASUOL, } \\
\text { M. E. C.; } \\
\text { SCHMIDT, } \\
\text { D. B. }\end{array}$ & $\begin{array}{l}\text { Avaliar as evidências } \\
\text { disponíveis na literatura } \\
\text { a respeito dos fatores de } \\
\text { risco para a neoplasia de } \\
\text { colo do útero, visando obter } \\
\text { maior conhecimento sobre } \\
\text { a doença, seus fatores de } \\
\text { risco e políticas públicas } \\
\text { relacionadas. }\end{array}$ & $\begin{array}{c}\text { Dezoito (18) artigos } \\
\text { atenderam aos critérios de } \\
\text { elegibilidade desta revisão e } \\
\text { compuseram a amostra final. }\end{array}$ & $\begin{array}{l}\text { São conhecidos os diversos fatores } \\
\text { de risco para o desenvolvimento } \\
\text { desse tumor, sendo este relacionado à } \\
\text { infecção pelo papiloma vírus humano } \\
\text { (HPV), tabagismo, iniciação sexual } \\
\text { precoce, multiplicidade de parceiros, } \\
\text { multiparidade, uso de contraceptivos } \\
\text { orais, baixa ingestão de vitaminas e } \\
\text { coinfecção por agentes infecciosos } \\
\text { como HIV e Chlamydia trachomatis. }\end{array}$ \\
\hline
\end{tabular}




\begin{tabular}{|c|c|c|c|}
\hline $\begin{array}{l}\text { AMARAL, } \\
\text { M. S.; } \\
\text { GONÇALVES, } \\
\text { A. G.; } \\
\text { SILVEIRA, L. } \\
\text { C. G. } \\
\end{array}$ & $\begin{array}{l}\text { Analisar a importância do } \\
\text { enfermeiro na prevenção } \\
\text { do câncer de colo do útero } \\
\text { e sua atuação profissional } \\
\text { no contexto da estratégia } \\
\text { de saúde da família. }\end{array}$ & $\begin{array}{l}\text { A busca foi conduzida na } \\
\text { Biblioteca Virtual em Saúde } \\
\text { (BVS). De acordo com a } \\
\text { temática encontrou-se } 17 \\
\text { artigos. }\end{array}$ & $\begin{array}{c}\text { O profissional enfermeiro é o principal } \\
\text { responsável dentro da atenção primária } \\
\text { na prevenção desta doença por ser } \\
\text { capaz de analisar as dificuldades } \\
\text { encontradas para a realização do } \\
\text { exame citopatológico. }\end{array}$ \\
\hline $\begin{array}{l}\text { THAKUR, A. } \\
\text { et al. }\end{array}$ & $\begin{array}{l}\text { Estudar os fatores comuns } \\
\text { associados com colo do } \\
\text { câncer. }\end{array}$ & $\begin{array}{l}226 \text { casos recém- } \\
\text { diagnosticados, confirmados } \\
\text { histopatologicamente de } \\
\text { câncer de colo do útero } \\
\text { realizado no Regional } \\
\text { Cancer Center, Himachal } \\
\text { Pradesh, no período de julho } \\
\text { de } 2008 \text { a outubro de } 2009 \text {. }\end{array}$ & $\begin{array}{l}\text { Os fatores encontrados foram: idade } \\
\text { ao nascimento do primeiro filho, } \\
\text { espaçamento entre dois filhos, idade } \\
\text { no casamento, alfabetização, status } \\
\text { socioeconômico, multiparidade e falta } \\
\text { de higiene genital. }\end{array}$ \\
\hline $\begin{array}{l}\text { OPOKU, C. U. } \\
\text { et al. }\end{array}$ & $\begin{array}{l}\text { Avaliar a percepção do } \\
\text { risco de câncer do colo } \\
\text { do útero e a existência } \\
\text { de fatores de risco para } \\
\text { o câncer do colo do útero } \\
\text { com base em cinco fatores } \\
\text { de risco conhecidos entre } \\
\text { mulheres que frequentam } \\
\text { o Hospital Tamale em } \\
\text { Tamale, Gana. }\end{array}$ & $\begin{array}{l}\text { Composta por } 300 \\
\text { mulheres entrevistadas por } \\
\text { meio de um questionário } \\
\text { semiestruturado. }\end{array}$ & $\begin{array}{l}61 \% \text { das mulheres relataram que não } \\
\text { tinham risco pessoal para o câncer do } \\
\text { colo do útero. } 27 \% \text { estavam em relações } \\
\text { poligâmicas. } 2 \text { mulheres tiveram } \\
\text { um total de } \geq 5 \text { parceiros sexuais } \\
\text { durante a sua vida. } 23 \% \text { disseram que } \\
\text { seu parceiro atual teve pelo menos } \\
2 \text { partições sexuais em sua vida, e } \\
\text { daqueles, }(61 \%) \text { pensaram que não } \\
\text { estavam em risco de câncer cervical. } \\
46 \% \text { dos entrevistados relataram não ter } \\
\text { nenhum dos riscos listados no estudo. } \\
23 \% \text { dos entrevistados relataram ter um } \\
\text { fator de risco, enquanto } 21 \% \text { tinham } \\
\text { dois fatores de risco e } 11 \% \text { tinha três ou } \\
\text { mais fatores de risco. }\end{array}$ \\
\hline TAO, L. e at. & $\begin{array}{l}\text { Investigar a prevalência } \\
\text { de neoplasia cervical } \\
\text { e examinar os fatores } \\
\text { associados a lesões } \\
\text { intraepiteliais cervicais } \\
\text { de alto grau (HSIL) entre } \\
\text { mulheres que participam } \\
\text { de um programa de } \\
\text { rastreamento do câncer do } \\
\text { colo do útero em Pequim. }\end{array}$ & $\begin{array}{l}\text { As mulheres com idades } \\
\text { entre } 25 \text { e } 65 \text { anos foram } \\
\text { examinadas usando o teste } \\
\text { citológico ThinPrep e o } \\
\text { exame ginecológico. }\end{array}$ & $\begin{array}{c}\text { Entre } 728.704 \text { mulheres rastreadas, a } \\
\text { prevalência de neoplasia intra-epitelial } \\
\text { cervical (NIC) I, II, III foi de } 50,2,34,0 \text { e } \\
36,4 \text { por } 100.000 \text {, respectivamente. A } \\
\text { prevalência de câncer do colo do } \\
\text { útero foi de } 12,2 \text { por } 100.000 \text {. Os } \\
\text { fatores de risco para HSIL incluíram } \\
\text { estar na faixa etária de } 46 \text { a } 55 \text { anos, } \\
\text { sangramento após a relação sexual e } \\
\text { presença de infecção por Trichomonas } \\
\text { vaginalis, inflamação cervical e verrugas } \\
\text { genitais. O nível de educação superior } \\
\text { foi considerado protetor. }\end{array}$ \\
\hline
\end{tabular}

Quadro 4 - Publicações incluídas segundo o nome dos autores, objetivo principal, perfil amostral e principais resultados. Caxias, MA, 2018.

Os estudos abordaram os principais fatores de risco para o surgimento do câncer de colo do útero, onde foram elencados diversos desses fatores, tais como a infecção 'pelo Papiloma Vírus Humano (HPV), o uso de métodos contraceptivos orais, tabagismo, multiparidade, múltiplos parceiros e iniciação sexual precoce. 


\section{INFECÇÃO PELO PAPILOMA VÍRUS HUMANO (HPV)}

O Papiloma Vírus Humano é membro da família Papovavirida, formada por aproximadamente cerca de 100 tipos de vírus, sendo que aproximadamente 50 acometem a mucosa genital. Os vírus são classificados conforme o risco oncogênico, no qual são classificados em alto risco ou baixo risco, existindo pelo menos 13 vírus HPV nessa classe, dentre os quais os tipos 16 e 18 são os que estão mais presentes nos casos de câncer de colo do útero (BARASUOL; SCHMIDT, 2014). O HPV apresenta um papel crucial no surgimento do câncer de colo do útero e nas suas lesões precursoras, sendo considerado como um dos principais fatores de risco para o desenvolvimento da neoplasia (TAO et al., 2014).

Apesar da prevalência da infecção por HPV não seja conhecida em Gana, há uma estimativa de que cerca de $21,5 \%$ das mulheres na população geral na África Ocidental abrigam a infecção por HPV cervical (OPOKU et al., 2016).

A infecção pelo vírus HPV é uma das principais causas da carcinogênese cervical, mas não é a causa suficiente. Grande parte da população feminina que é infectada pelo vírus não desenvolvem o carcinoma cervical invasivo, apenas uma proporção de mulheres em quem a infecção é persistente e que possuem vários outros fatores relacionados persistentes (THAKUR et al., 2015).

\section{MÉTODOS CONTRACEPTIVOS ORAIS}

A pesquisa realizada pelos autores corroborou com o estudo em relação ao fator de risco referente a utilização dos métodos contraceptivos orais, pois obteve-se uma amostra significativa de 70,5\% (24) dos participantes que fizeram uso por um tempo médio de 46 meses. A utilização de métodos contraceptivos orais durante 5 anos ou mais pode duplicar o risco para o câncer cervical, seno assim é necessário que a realização de uma avaliação do custo-benefício desse método contraceptivo para a promoção da saúde sexual e reprodutiva da mulher. Além disso, as mulheres devem conhecer todas as possibilidades de contracepção disponíveis para que as mesmas possam ter autonomia na escolha de acordo com suas necessidades (ANJOS et al., 21013).

\section{TABAGISMO}

Em uma pesquisa realizada com 36 mulheres, 16 (44,5\%) afirmaram ter hábitos tabagistas. Com relação a dependência da nicotina, os autores perceberam que quanto maior o uso da mesma, maior a suscetibilidade para o desenvolvimento de lesões cancerígenas (ANJOS et al., 2013).

Ao avaliar a região do epitélio cervical de mulheres fumantes e não fumantes, percebe-se uma rápida diminuição nas células de Langherans, uma vez que o tabaco é considerado responsável pela diminuição do número e das funções dessas células. As 
células de Langherans são responsáveis pela defesa do tecido epitelial e, com a diminuição dessas células, ocorre a facilitação da instalação de lesões virais as quais são consideradas o primeiro estágio no processo de carcinogênese (BARASUOL; SCHMIDT, 2014).

\section{MULTIPARIDADE}

Alta paridade em mulheres com mais de 3filhos é um dos fatores de risco significativo. Em uma análise combinada de estudos de caso-controle em mulheres HPV-positivas, encontraram o risco de se tornar duas vezes maior com o número de gestações. A paridade é provavelmente um bom marcador de ambiente hormonal durante os anos férteis das mulheres, bem como um marcador de traumas cervicais repetidos que predispõem à infecção (THAKUR et al., 2015).

De acordo com a pesquisa realizada pelos autores a maioria das mulheres da pesquisa apresentaram alterações na citologia e eram multíparas. Pode-se relacionar a multiparidade e neoplasia cervical com mecanismos biológicos, tais como hormonais, nutricionais e imunológicos. Este achado justifica, constata e afirma a relação entre a doença com os seus fatores de risco, relembrando que a incidência de câncer cervical aumenta à medida que houver iniciação sexual precoce e, consequentemente, menor a idade da primeira gestação, multiparidade e múltiplos parceiros (BARASUOL; SCHIMIDT, 2014).

\section{MÚLTIPLOS PARCEIROS}

A multiplicidade de parceiros é um fator predisponente, pois facilita o aumento de infecções sexualmente transmissíveis. A maior incidência de lesões cervicais por HPV em mulheres cujo número de parceiros sexuais sem uso de preservativo é maior que dois (THAKUR et al., 2015).

Observou-se também no estudo realizado por Tao et al., (2014) que as mulheres que apresentam lesões por HPV, em sua maioria, tiveram ao menos uma relação sexual sem o uso do preservativo. O outro estudo demonstrou uma associação entre proteção contra infecção por HPV e uma relação conjugal considerada estável.

Em uma pesquisa realizada por Barasuol e Schmidt (2014) dentre as mulheres que apresentaram alterações na citologia, foi relatado que a maioria possuía mais de um parceiro sexual e, na mesma pesquisa, as mulheres que possuíram um único parceiro sexual apresentaram uma baixa frequência de lesões em relação às demais.

\section{INICIAÇÃO SEXUAL PRECOCE}

De acordo com Opoku et al. (2016) a sexarca antes dos 18 anos se classifica como precoce, pois nesta idade a cérvice ainda não está completamente formada e os níveis 
hormonais ainda se encontram desestabilizados. No estudo feito por Barasuol e Schmidt (2014) a faixa etária mais acometida pela neoplasia do colo do útero é de 25 a 60 anos. As jovens vão se constituindo em uma população vulnerável, justamente pelo início da vida sexual precoce, o que as deixa cada vez mais perto de agravos relacionados à saúde reprodutiva e sexual.

Observou-se no mesmo estudo que a maioria das participantes possuem o fator de risco para neoplasia de colo de útero relacionado ao início precoce da atividade sexual, levando em consideração que a maioria das entrevistadas tiveram sua sexarca entre 8 e 15 anos (BARASUOL; SCHIMIDT, 2014).

\section{BUNDLES DE INTERVENÇÕES}

Elencou-se um conjunto de cinco intervenções de enfermagem necessárias para a prevenção dos principais fatores de risco para o surgimento do câncer de colo do útero.

\begin{tabular}{|l|c|}
\hline \multicolumn{1}{|c|}{ INTERVENÇÕES } & $\begin{array}{c}\text { NÍVEL DE } \\
\text { EVIDÊNCIA }\end{array}$ \\
\hline Desenvolver mais programas de prevenção & I \\
\hline Realizar exames de Papanicolau & I \\
\hline Atualizar a equipe de enfermagem sobre as técnicas do exame citopatológico & I \\
\hline Disponibilizar mais informações acerca da importância da prevenção do CCU & I \\
\hline Implantar novas políticas públicas relacionadas à saúde da mulher & IV \\
\hline
\end{tabular}

Quadro 5 - Bundles de Intervenções para a prevenção dos principais fatores de risco para o surgimento do CCU. Caxias-MA, 2018.

\section{DISCUSSÃO}

Com o aumento dos números de casos de CCU há uma necessidade de implantar mais ações que facilitem a prevenção desses fatores. Portanto ao analisar os resultados dos estudos, foram escolhidos 5 (cinco) intervenções para compor o bundle. Desta forma o bundle constitui-se pelas seguintes intervenções e níveis I e IV: Desenvolver mais programas de prevenção; Realizar exames de Papanicolau; Atualizar a equipe de enfermagem sobre as técnicas do exame citopatológico; Disponibilizar mais informações acerca da importância da prevenção do CCU; E implantar novas políticas públicas relacionadas à saúde da mulher.

\section{DESENVOLVER MAIS PROGRAMAS DE PREVENÇÃO}

Os programas de prevenção são baseados na realização do exame citológico como umas das principais formas de detectar lesões precursoras, com o objetivo de tratá-las, 
controlando assim o desenvolvimento deste tipo de câncer (ANJOS et al., 2013). Em um programa nacional de combate ao $\mathrm{CCU}$ é fundamental apresentar quatro elementos importantes em sua realização, tais como a detecção precoce, a prevenção primária, o diagnóstico/tratamento e os cuidados paliativos, sendo a deteç̧ão precoce a modalidade mais eficaz na redução do CCU (AMARAL; GONÇALVES; SIQUEIRA, 2017).

\section{REALIZAR EXAMES DE PAPANICOLAU}

A principal estratégia de rastreamento aconselhada no Brasil pelo Ministério da Saúde é o exame citopatológico, direcionado principalmente a mulheres com idades entre 25 a 64 anos, com vida sexual ativa. É fundamental garantir a integralidade, a organização e a qualidade dos programas de rastreamento, assim como o seguimento das pacientes ao programa (AMARAL; GONÇALVES; SIQUEIRA, 2017).

\section{ATUALIZAR A EQUIPE DE ENFERMAGEM SOBRE AS TÉCNICAS DO EXAME CITOPATOLÓGICO}

Os profissionais de saúde necessitam buscar novas estratégias e técnicas de exames preventivos, principalmente o citopatológico, para facilitar a detecção precoce de fatores que facilitam o desenvolvimento do $\mathrm{CCU}$, sendo fundamental ainda a motivação das mulheres para comparecerem as palestras educativas nas unidades de saúde, pois nelas são abordados temas sobre o rastreamento, fatores de risco, promoção de saúde, voltada para a educação em saúde na qualidade de vida (AMARAL; GONÇALVES; SIQUEIRA, 2017).

\section{DISPONIBILIZAR MAIS INFORMAÇÕES ACERCA DA IMPORTÂNCIA DA PREVENÇÃO DO CCU}

Apesar de muitas mulheres realizarem o exame preventivo, ainda existem uma boa parte da população feminina que alegam desconhecer a finalidade da coleta do exame citopatológico, já outras nunca se submeteram ao exame por medo, vergonha ou questões culturais. O enfermeiro deve realizar ações educativas com as mulheres da comunidade através de palestras, transmitindo o máximo de informações possíveis para que as pacientes possam conscientizar não só a si como também a seus parceiros, pois o câncer de colo do útero quando detectado precocemente tem $100 \%$ de cura (AMARAL; GONÇALVES; SIQUEIRA, 2017). 


\section{IMPLANTAR NOVAS POLÍTICAS PÚBLICAS RELACIONADAS À SAÚDE DA MULHER}

Diante do aumento dos números de casos de mulheres com CCU, é fundamental a implantação de novas políticas públicas de forte coordenação intersetorial que visem a realização de programas de rastreamento de baixo custo para detectar casos em estágios iniciais e campanhas preventivas utilizando os recursos de saúde disponíveis no nível de base (THAKUR et al., 2015). Porém, é necessário um maior aperfeiçoamento das políticas de saúde já existentes para que todos tenham acesso a prevenção e controle da doença, bem como para que os profissionais tenham maior conhecimento sobre o assunto e possam ir ao encontro das propostas destas políticas de saúde, facilitando a qualidade de vida da população feminina (BARASUOL; SCHMIDT, 2014).

\section{CONSIDERAÇÕES FINAIS}

Após a análise dos artigos, concluiu-se que dentre os principais fatores de risco para o surgimento do câncer de colo do útero está a infecção pelo Papiloma Vírus Humano (HPV), os métodos contraceptivos orais, o tabagismo, a multiparidade, os múltiplos parceiros e a iniciação sexual precoce. As intervenções do bundles trazem medidas que versam sobre ações preventivas que envolvem o desenvolvimento de mais programas de prevenção, a realização de exames de Papanicolau, a atualização da equipe de enfermagem sobre as técnicas do exame citopatológico, a disponibilização de mais informações acerca da importância da prevenção do CCU e a implantação de novas políticas públicas relacionadas à saúde da mulher.

A equipe de enfermagem é responsável por realizar medidas de prevenção, juntamente com a população feminina, por meio do desenvolvimento de estratégias que busquem minimizar os fatores de risco para o surgimento do câncer de colo do útero, contribuindo para a melhoria da qualidade de vida das mulheres e diminuindo os números de casos de neoplasias.

\section{REFERÊNCIAS}

AMARAL, M. S.; GOLÇAVES, A. G.; SILVEIRA, L. C. G. Prevenção do câncer de colo de útero: a atuação do profissional enfermeiro nas unidades básicas de saúde. Revista Científica FacMais, v. 8 , n. 1, 2017.

ANJOS, S. J. S. B et al. Fatores de risco para câncer de colo do útero segundo resultados de IVA, citologia e cervicografia. Rev. Esc. Enferm., v. 44, n. 4, p. 912-920, 2010.

BARASUOL, M. E. C.; SCHMIDT, D. B. Neoplasia do colo do útero e seus fatores de risco: revisão integrativa. Revista Saúde e Desenvolvimento, v. 6, n. 3, 2014. 
BRASIL. Ministério da Saúde (MS). Instituto Nacional de Câncer (Inca). Estimativa 2012: incidência de câncer no Brasil. Rio de Janeiro, 2011.

ERCOLE, F. F.; MELO, L. S.; ALCOFORADO, C. L. G. C. Revisão Integrativa versus Revisão Sistemática. Rev. Min. Enferm., v. 18, n. 1, p. 1-260, 2014.

FERNANDES, J. V et al. Conhecimento, atitudes e práticas do exame de Papanicolau por mulheres, Nordeste do Brasil. Rev. Saúde Pública, São Paulo, v. 43, n. 5, p. 851-858, 2009.

MENDONÇA, V. G. et al. Mortalidade por câncer do colo do útero: características sociodemográficas das mulheres residentes na cidade de Recife, Pernambuco. Rev. Bras. Ginecol. Obstet., v. 30, n. 5, p. 248-255, 2008.

OPOKU, C. A. et al. Knowledge, Attitude and Practices of Women in Maldives Related to the Risk Factors, Prevention and Early Detection of Cervical Cancer. Asian Pacific Journal of Cancer Precention, v. 15, 2014.

PINHO, M. C. V.; JODAS, D. A.; SCHOCHI, M. J. Câncer de colo de útero e mama: concepção dos gestores do Sistema Único de Saúde. Av. Enferm., v. 2, p. 87-96, 2012.

SANTOS, U. M.; SOUZA, S. E. B. Papanicolau: diagnóstico precoce ou prevenção do câncer cervical uterino? Rev. Baiana de Saúde Pública, v. 37, n. 4, p. 941-951, 2013.

TAO, L. et al. Prevalence and risk factors for cervical neoplasia:a cervical cancer screening program in Beijing. BMC Public Health, v. 14, 2014.

THAKUR, A. et al. Risk factors for cervical cancer among rural women in a mountainous state: A casecontrol study. Public. Health, v. 58, p. 45-48, 2015. 


\section{CAPÍTULO 20}

\section{CÂNCER DE MAMA E COMPROMETIMENTO DA QUALIDADE DE VIDA DE MULHERES MASTECTOMIZADAS}

Data de aceite: 20/08/2021

Data de submissão: 06/08/2021

Camilla Pontes Bezerra Universidade Federal de São Paulo, Escola Paulista de Enfermagem São Paulo - São Paulo http://lattes.cnpq.br/0240028136282226

Suyane Pinto de Oliveira Bilhar Universidade de Fortaleza, Curso de Bacharelado em Enfermagem Fortaleza - Ceará http://lattes.cnpq.br/2841250973685480

Júlio César Lira Mendes Universidade de Fortaleza, Curso de Bacharelado em Enfermagem Fortaleza - Ceará http://lattes.cnpq.br/1330099366328762

Francisca Glaucineide Mendonça Vieira Faculdade Metropolitana da Grande Fortaleza, Curso de Enfermagem Fortaleza - Ceará http://lattes.cnpq.br/8707117911037826

Maria Janaides Alves da Silva Centro Universitário Estácio do Ceará, Curso de Bacharelado em Enfermagem Fortaleza - Ceará http://lattes.cnpq.br/9701101109377392

Keila Patrícia Bezerra Centro Universitário Estácio do Ceará, Curso de Bacharelado em Enfermagem

Fortaleza - Ceará http://lattes.cnpq.br/3495297571775535
Carlos Jerson Alencar Rodrigues Centro Universitário Estácio do Ceará, Curso de Bacharelado em Enfermagem

Fortaleza - Ceará http://lattes.cnpq.br/6912265642344914

Isabelle dos Santos de Lima Faculdade Católica Rainha do Sertão, Curso de Bacharelado em Enfermagem Fortaleza - Ceará http://lattes.cnpq.br/7327055259803080

Deuza Maria Pinheiro de Oliveira Faculdade Integrada da Grande Fortaleza, Curso de Enfermagem Fortaleza - Ceará http://lattes.cnpq.br/4113745662214907

Erinete Melo da Silva Freire Centro Universitário Estácio do Ceará, Curso de Bacharelado em Enfermagem Fortaleza - Ceará http://lattes.cnpq.br/6023459528782036

Maria Claumyrla Lima Castro Universidade de Fortaleza, Curso de Bacharelado em Enfermagem Fortaleza - Ceará http://lattes.cnpq.br/1500594608056399

Pâmella de Castro Duarte Pordeus Prefeitura Municipal de Caucaia

RESUMO: O carcinoma mamário no Brasil é o que mais causa mortes entre as mulheres, sendo sua incidência alta. $O$ diagnóstico deste tipo de câncer pode ser feito através do autoexame das mamas, da mamografia e ultrassonografia. 0 
diagnóstico de câncer de mama causa um efeito devastador na vida de uma mulher. Sabese que o medo de morrer é a questão principal, e a busca pelo tratamento adequado e cura são constantes. Assim, esse trabalho teve como objetivo avaliar a qualidade de vida de mulheres mastectomizadas por câncer de mama. Trata-se de um estudo descritivo, com análise qualitativa dos resultados, realizado no período de agosto a outubro de 2018 , em um programa de responsabilidade social de uma universidade privada de Fortaleza-Ceará. Foi utilizada a entrevista estruturada para coleta de dados. A qualidade de vida de mulheres mastectomizadas é influenciada por vários fatores biopsicossociais e ambientais. A descrição verbal das entrevistadas sugere dificuldades em aceitar o câncer de mama. Verificaram-se nos relatos que logo ao saberem sobre o diagnóstico de câncer houve piora na qualidade de vida, porém a superação da doença foi presente no decorrer do tratamento. Conclui-se que a qualidade de vida das pacientes mastectomizadas está, portanto, diretamente relacionada ao fator psicológico e aceitação de si mesma. Os indicadores de qualidade de vida poderão auxiliar na prática clínica, nortear estratégias de intervenção terapêutica, avaliar sucesso da intervenção após cirurgia e tratamento oncológico, além de criar parâmetros para definição de ações no sentido de promoção de saúde individual ou coletiva.

PALAVRAS - CHAVE: Neoplasias da mama. Enfermagem. Qualidade de vida.

\title{
BREAST CANCER AND COMPROMISED QUALITY OF LIFE IN MASTECTOMIZED WOMEN
}

\begin{abstract}
Breast cancer in Brazil is the cause of most deaths among women, with a high incidence. The diagnosis of this type of cancer can be done through breast self-examination, mammography and ultrasound. The diagnosis of breast cancer has a devastating effect on a woman's life. It is known that the fear of dying is the main issue, and the search for adequate treatment and cure is constant. Thus, this study aimed to assess the quality of life of women who underwent mastectomy for breast cancer. This is a descriptive study, with qualitative analysis of results, carried out from August to October 2018, in a social responsibility program of a private university in Fortaleza-Ceará. A structured interview was used for data collection. The quality of life of women with mastectomies is influenced by several biopsychosocial and environmental factors. The verbal description of the interviewees suggests difficulties in accepting breast cancer. It was verified in the reports that as soon as they learned about the cancer diagnosis, there was a worsening in their quality of life, but the overcoming of the disease was present during treatment. It is concluded that mastectomized patients' quality of life is, therefore, directly related to psychological factor and self-acceptance. Quality of life indicators can help in clinical practice, guide therapeutic intervention strategies, assess the success of the intervention after surgery and cancer treatment, in addition to creating parameters for defining actions to promote individual or collective health.
\end{abstract}

KEYWORDS: Breast Neoplasms. Nursing. Quality of Life.

\section{I INTRODUÇÃO}

O câncer de mama é o câncer mais frequente na população feminina no mundo, com 1,38 milhões de casos novos diagnosticados em 2008. Cerca de $75 \%$ dos casos novos de 
câncer de mama ocorrem nos países em desenvolvimento. Também é a principal causa de morte por câncer na população feminina, com mais da metade das mortes ocorrendo nos países em desenvolvimento. No Brasil, as neoplasias são a segunda causa de morte na população feminina e o câncer de mama constitui uma das principais causas de morte por câncer na população feminina entre 20 e 69 anos. A taxa de incidência é quase o dobro da taxa do segundo câncer mais incidente (câncer do colo do útero). As estimativas de casos novos para 2010 são de cerca de 50 mil casos, com aproximadamente 18 mil ocorrendo nas capitais (INSTITUTO NACIONAL DO CÂNCER, 2011a).

Internacionalmente, tem-se observado, em alguns países desenvolvidos, como é o caso dos Estados Unidos, Canadá, Reino Unido, Holanda, Dinamarca e Noruega, um aumento da incidência do câncer de mama acompanhado de uma redução da mortalidade por esse câncer, o que está associado à detecção precoce por meio da introdução da mamografia para rastreamento e à oferta de tratamento adequado. Em outros países, como no caso do Brasil, a elevação da incidência tem sido acompanhada do aumento da mortalidade, o que pode ser atribuído, principalmente, a um retardamento no diagnóstico e na instituição de terapêutica adequada (INSTITUTO NACIONAL DO CÂNCER, 2004).

O carcinoma mamário é provavelmente o câncer mais temido pelas mulheres, devido à sua alta frequência e, sobretudo pelos efeitos psicológicos que afetam a percepção da sexualidade e a própria imagem pessoal. Ele é relativamente raro antes dos 35 anos de idade, mas acima desta faixa etária sua incidência cresce rápida e progressivamente (FUNDAÇÃO CENTRO DE CONTROLE DE ONCOLOGIA DO ESTADO DO AMAZONAS, 2005).

Segundo o Instituto Nacional de Câncer (2011b), o câncer é um dos problemas de saúde públicos mais complexos que o sistema de saúde brasileiro enfrenta. Evidencia-se que pelo menos um terço dos casos novos de câncer que ocorre anualmente no mundo poderia ser prevenido.

Dentre as neoplasias malignas, o câncer de mama, tem se mostrado o responsável pelos maiores índices de mortalidade no mundo, tornando-se uma das grandes preocupações em saúde pública, no que diz respeito à saúde da mulher (DUARTE; ANDRADE, 2003).

Segundo o relatório do World Cancer Research Fund International (2018) e do American Institute for Cancer Research, cerca de 30\% dos casos de câncer de mama podem ser evitados por meio da prevenção adequando alimentação e nutrição adequadas, atividade física regular e manutenção do peso ideal. Em outubro de 2010, o Instituto Nacional do Câncer lançou suas recomendações para reduzir a mortalidade por câncer de mama no Brasil, destacando a importância da amamentação, da prática de atividades físicas e do controle do peso, e da ingesta de álcool, como formas de prevenir o câncer de mama. A redução da indicação de reposição hormonal na menopausa nos Estados Unidos, na década de 2000, acompanhou-se de uma redução importante na incidência desse câncer nas mulheres com mais de 50 anos (INSTITUTO NACIONAL DO CÂNCER, 2012). 
O diagnóstico deste tipo de câncer, de acordo com Veronesi (2002), pode ser feito através do auto-exame das mamas, da mamografia e da ultrassonografia. O diagnóstico precoce do câncer é de grande importância, pois tenta evitar a disseminação das células malignas pelo corpo.

O exame clínico da mama (ECM) é parte fundamental da propedêutica para o diagnóstico de câncer. Deve ser realizado como parte do exame físico e ginecológico, e constitui a base para a solicitação dos exames complementares. Como tal, deve contemplar os seguintes passos para sua adequada realização: inspeção estática e dinâmica, palpação das axilas e palpação da mama com a paciente em decúbito dorsal.

A mulher, quando é diagnosticada com câncer de mama, se envolve em três etapas: o recebimento do diagnóstico de ser portadora da doença, a realização de um tratamento longo e agressivo, e a aceitação de um corpo marcado por uma nova imagem com a necessidade de aceitação e convivência com a mesma (VIEIRA; LOPES; SHIMO, 2007).

Diante do diagnóstico, o médico, dependendo do tipo histológico, tamanho e localização do tumor, idade, vai escolher o tipo de cirurgia ideal para aquela paciente em específico. A cirurgia no câncer de mama tem por objetivo promover o controle local, com a remoção de todas as células malignas presentes junto ao câncer primário; proporcionar maior sobrevida, orientar a terapia sistêmica, definir o estadiamento cirúrgico da doença e identificar grupo de maior risco de metástase à distância (CAMARGO; MARX, 2000).

São diversos os tipos de procedimentos cirúrgicos: os conservadores (tumorectomia e quadrantectomia ou segmentectomia) e os radicais denominados mastectomias radicais modificadas: tipo Patey e de Madden e a mastectomia radical de Halsted.

Sabe-se que aproximadamente $50 \%$ das mulheres sobreviverão por, pelo menos, quinze anos após o diagnóstico e deverão ajustar-se às sequelas cirúrgicas, devido ao aumento das taxas de detecção precoce e à melhoria nos tratamentos oferecidos (HUGUET et al., 2009).

Um diagnóstico como o do câncer de mama causa um efeito devastador na vida de uma mulher. Sabe-se que o medo de morrer é a questão principal, e a busca pelo tratamento adequado e pela cura são uma constante. Após a fase aguda do tratamento, aos poucos, há uma predisposição a se retornar à qualidade de vida de antes do diagnóstico, ou mesmo a ocorrerem mudanças positivas na qualidade de vida, com oportunidade de crescimento pessoal. Em grande parte dos casos a vida passa a ter um maior sentido e há a reestruturação de prioridades (HUGUET et al., 2009).

Qualidade de vida tem uma diversidade potencial de condições que afetam: a percepção do indivíduo, seus sentimentos e comportamentos relacionados ao seu funcionamento diário, incluindo a sua condição de saúde e intervenção médicas (HUGUET et al., 2009).

Com base nas considerações apresentadas, cabe aqui levantar a questão da presente pesquisa: Como é a qualidade de vida de mulheres mastectomizadas por câncer de mama? 
Como a qualidade de vida para as mulheres que vivem com essa doença por muitos anos se torna importante e fundamental para viverem melhor, surgiu o interesse de estudar como é a qualidade de vida dessas mulheres mastectomizadas por câncer de mama.

A relevância do estudo encontra-se na necessidade de aprofundar a discussão sobre a qualidade de vida de mulheres mastectomizadas por câncer de mama num projeto de responsabilidade social do Centro Universitário Estácio do Ceará (FIC), Programa de Assistência à Mulher Mastectomizada (PROAMMA), prestado gratuitamente à sociedade e o impacto que o tratamento de câncer de mama, causa na qualidade de vida dessas mulheres. Além disso, esperamos trazer contribuições ao debate sobre as dificuldades dessas mulheres, no que se refere à qualidade de vida.

\section{I OBJETIVO}

Avaliar a qualidade de vida de mulheres mastectomizadas por câncer de mama.

\section{I METODOLOGIA}

Trata-se de um estudo descritivo. A pesquisa descritiva tem o objetivo de descrever as características de uma população ou um fenômeno, além de identificar se há relação entre as variáveis analisadas. O questionário e a observação são seus principais instrumentos (MASCARENHAS, 2012).

Quanto à abordagem, é qualitativa. Na pesquisa qualitativa, o pesquisador fica à vontade para desenhar o estudo da forma que julgar mais viável. Porém, é importante ressaltar que a pesquisa deve apresentar uma estrutura sólida e coerente, capaz de receber a aprovação dos membros da comunidade científica (MASCARENHAS, 2012).

O estudo foi realizado em um PROAMMA, um projeto de responsabilidade social do Centro Universitário Estácio do Ceará prestado gratuitamente à sociedade, que consiste em favorecer a criação de estratégias que possibilitem o diagnóstico precoce de câncer de mama, e dar assistência àquelas com a confirmação do diagnóstico, propiciando a promoção da saúde e melhorando a qualidade de vida, durante o período de agosto a outubro de 2018.

A amostragem foi constituída por mulheres mastectomizadas vítimas do câncer de mama que participam do PROAMMA. Foram utilizados como critérios de inclusão dos sujeitos na pesquisa: ter idade igual ou maior de 18 anos, concordância e assinatura do TCLE.

A técnica de coleta de dados utilizada foi a entrevista estruturada ou livre. Esta é uma entrevista que não requer um roteiro prévio de perguntas, sendo composta apenas de estímulos iniciais, ditados pelo pesquisador, com fins de orientação do pesquisado. 0 entrevistado é livre para conduzir o processo, enquanto o entrevistador foca sua atenção na coleta de dados mediante comunicação ativa e organização do fluxo de informações 
relativas às variáveis investigadas (MOURA; FERREIRA, 2005).

As entrevistas foram gravadas, mediante a autorização das participantes. A mesma teve natureza interativa, permitindo tratar de temas complexos, face a face de maneira metódica, permitindo proporcionar resultados satisfatórios e informações necessárias (LAKATOS; MARCONI, 2004).

Após a entrevista, os conteúdos das falas foram transcritos e analisados com base nas questões norteadoras e depois selecionadas por temáticas oriundas da análise das transcrições. As informações obtidas por meio das entrevistas foram submetidas à técnica de análise de conteúdo como forma de organização dos dados, que segundo Bardin (2011) é um conjunto de técnicas de análise das comunicações, visando, por procedimentos sistemáticos e objetivos de descrição do conteúdo das mensagens, obter indicadores quantitativos ou não, que permitam a inferência de conhecimentos relativos às condições de produção/recepção (variáveis inferidas) das mensagens.

Uma das características que define a análise de conteúdo é a busca do entendimento da comunicação entre as pessoas, apoiando-se no (re) conhecimento do conteúdo das mensagens. Esta análise não quer saber apenas "o que se diz", mas "o que se quis dizer" com tal manifestação.

A análise foi realizada com base na literatura pertinente à qualidade de vida das mulheres mastectomizadas por câncer de mama e vivência dos pesquisadores no PROAMMA, cenário do estudo.

Inicialmente a coordenadora do projeto foi informada sobre a pesquisa e o consentimento se deu por meio de apresentação de ofício, folha de rosto da pesquisa e carta de apresentação da pesquisa, com os devidos tópicos que iriam ser abordada durante a entrevista, anexada.

Como exigido, o estudo foi submetido via online à Plataforma Brasil e encaminhado a um Comitê de Ética e Pesquisa para análise dos preceitos ético-legais (autonomia, não maleficência, beneficência e justiça) recomendados na Resolução $n^{\circ}$ 466/2012 sobre pesquisas envolvendo seres humanos do Conselho Nacional de Saúde - Ministério da Saúde (BRASIL, 2012).

Foi elaborado um Termo de Consentimento Livre e Esclarecido; que foi entregue à mulher, a fim de se obter a concordância e assinatura da participante. Também lhes asseguramos a privacidade e a proteção da identidade, a liberdade de se recusar a participar ou retirar o seu consentimento, em qualquer fase da pesquisa, sem penalização alguma. A fim de não identificar as participantes do estudo decidimos substituir seus nomes por tipos de flores.

\section{I RESULTADOS E DISCUSSÃO}

Participaram do estudo seis mulheres de idade entre cinquenta e setenta e cinco 
anos. Destas, três eram casadas, duas separadas e uma viúva, ambas católicas. Em relação à ocupação, uma realizava atividade como técnica de segurança do trabalho; três delas eram donas de casa; uma era comerciante e a outra aposentada. A renda familiar variou entre um e três salários mínimos do ano vigente, seja por sua atividade laboral ou renda disponibilizada pelos filhos.

$\mathrm{Na}$ entrevista foram feitas perguntas relacionadas às seguintes temáticas: qualidade psicológica, imagem corporal, atividade sexual, relação marital, convívio familiar e amigos, atividade laboral, atividade de vida e reconstrução da mama.

Sendo assim, as categorias temáticas que surgiram na pesquisa, após análise criteriosa das falas, foram: "Mastectomia: aspectos psicólogos e adaptação psicossocial"; "Qualidade de vida" e "Reconstrução da mama", que serão apresentadas a seguir.

\subsection{Mastectomia: aspectos psicológicos e adaptação psicossocial}

Esta categoria temática teve como objetivo entender o sentimento, o impacto psicológico da doença, perda de parte do corpo e mudança na vida destas mulheres.

Os primeiros meses de reabilitação de uma mastectomia são caracterizados pelo movimento de reorganização para uma reinserção no mundo individual, social e espacial, visto que a mutilação dela decorrente favorece o surgimento de muitas questões na vida das mulheres, especialmente aquelas relacionadas à imagem corporal (BERVIAN; GIRARDONPERLINI, 2006; FERREIRA; MAMEDE, 2003).

A forma como a mulher percebe e lida com essa nova imagem e como isso afeta sua existência, são pontos cruciais para um entendimento da nova dinâmica que a vida dessas mulheres assume como podemos perceber nas falas a seguir.

A princípio saber que era portadora de câncer de mama, uma doença tão invasiva, e que o tratamento era a retirada da mama, no primeiro momento, me deixou bastante deprimida e sem saber o que pensar e fazer, é como nascer de novo, plantar uma semente de vida. Entretanto após a mastectomia, e iniciarem os tratamentos quimioterápico e radioterápico, me senti mais forte e com esperança renovada de vida e com a sensação de que Deus está sempre conosco (ORQUÍDEA)

É mudança de vida, não esperava que aquilo acontecesse comigo, mas depois do resultado do câncer de mama e de que teria que realizar a mastectomia, não houve revolta e, sim, conformação, a vida transcorreu normal (ROSA DÁLIA).

O resultado de que estava com câncer de mama e teria que retirar a mama, mudou por completo a minha vida social e familiar, tornei-me mais estressada e grosseira, dificultando me relacionar com amigos e família, evitando dialogar em relação à doença e os fatores desencadeadores desta mudança de vida (ROSA).

Eu fiquei sensível, mas acho que são os 50 anos que estão chegando. Depois do câncer, a gente fica mais chorosa (MARGARIDA).

Um dos principais fatores que influenciam na imagem corporal da mulher é caracterizado pelos parâmetros que a sociedade impõe para a identificação do corpo 
perfeito, do corpo feminino. A sociedade valoriza o corpo perfeito como essencial na atração sexual, e isso pode ser observado nos meios de comunicação, no qual são utilizados corpos esculturais para vender os mais variados produtos, além do aumento significativo do número de cirurgias plásticas para implante de silicone. Nesse aspecto, a mastectomia pode provocar consequências importantes na vida da mulher em razão das modificações estéticas decorrentes, e assim, desencadear novas reações relacionadas ao próprio corpo e às demais pessoas (PRADO, 2002).

Percebemos que todas as pacientes ficaram emocionalmente abaladas, por não terem conhecimento suficiente em relação à doença e desconhecimento do tratamento adequado ou por medo da necessidade de submeter-se ao procedimento cirúrgico. As pacientes demonstraram seus sentimentos de forma diferente, umas mais agressivas e outras mais sensíveis. Em alguns momentos a sensibilidade das pacientes, ao recordarem do momento em que receberam o diagnóstico, veio à tona através de um suspiro ou de lágrimas nos olhos. Pudemos constatar, portanto, que todas passaram por dificuldade para lidar com o diagnóstico do câncer.

\subsection{Qualidade de vida}

Esta categoria temática buscou entender a vida destas mulheres, mudanças positivas e negativas, superação da doença e suas perdas, assim como a caracterização de suas vidas no momento atual.

A Organização Mundial de Saúde (OMS) define qualidade de vida como a "percepção do indivíduo de sua posição na vida no contexto da cultura e sistemas de valores nos quais ele vive e em relação aos seus objetivos, expectativas, padrões e preocupações" (SALES et al., 2001, p. 264). A qualidade de vida pode ser avaliada do ponto de vista do paciente, referindo-se à apreciação dos pacientes e satisfação com o seu nível funcional, comparado com o que ele percebe como sendo possível ou ideal (CELLA; CHERIN, 1988 citados por SALES et al., 2001).

Dessa forma, a avaliação da qualidade de vida dessas mulheres inclui os funcionamentos físico, psicológico, social, sexual e espiritual, nível de independência, ambiente e crenças pessoais, como percebemos nas falas abaixo:

Passei a valorizar mais o sentido da vida, o amor, a família, fortifiquei a minha religiosidade. E como falei anteriormente, é como nascer de novo, então a vida nova nos torna seres humanos melhores. Minha vida hoje tem mais sentido e as pequenas coisas, hoje tem mais valor. Os valores de cada um de nós está no interior de nossa alma e como a desenvolveram em prol de nossa vida e do outro. Quero dizer que mediante a doença, temos que ser forte, ter equilíbrio emocional e psicológico, a cabeça movimenta o corpo, adoece outros órgãos. Fé e esperança e Deus acima de tudo e presença da família, valorizando a vida em todos os momentos, e hoje sou muito feliz (ORQUÍDEA).

Minha vida tornou-se melhor, hoje valorizo a vida como se cada minuto fosse o último e sou feliz assim (ROSA DÁLIA). 
Ainda não sei descrever de forma concreta a melhora de vida, me sinto bem quando estou junto da família e amigos que participam deste projeto, mas algumas vezes acho que a vida perdeu o sentido (ROSA).

Pra mim está ótimo, que eu estou aproveitando bastante, vou pra festa, vou passear, faço parte do programa, já trabalhei, cuidei dos filhos, agora tenho que usufruir, tem males que vem para o bem (DAMA DA NOITE).

Esses grupos que a gente faz parte, levanta muito o astral da gente, é muito bom, toda mulher que passa por isso, devia se engajar num grupo, eu participo de vários grupos como, Amigas do Peito, Toque de Vida. Passei a gostar mais de mim, me achar mais bonita, desfilo de maiô, camisola, fiz ensaio fotográfico, pelo Toque de Vida (MARGARIDA).

A única limitação que tenho é sensibilidade do braço direito, aí recorri ao Proamma, fiz drenagem linfática, seis meses depois da cirurgia (GIRASSOL).

Percebemos que todas as pacientes após o acometimento da doença deram mais valor aos pequenos detalhes do seu cotidiano, tais como: vida, família, amigos e lazer. Dedicam seu tempo livre a momentos prazerosos participando, inclusive, de grupos de apoio recompensando assim o tempo em que estiveram psicologicamente abaladas no período em que estiveram debilitadas devido ao câncer de mama.

\subsection{A reconstrução da mama}

Esta categoria temática visou descrever a negatividade, anseios e dificuldades relacionadas à cirurgia de reconstrução da mama.

Reconstruir a mama pode representar a preservação da auto-imagem da mulher, melhor qualidade de vida e, portanto, um processo de reabilitação menos traumático. Inúmeros recursos de cirurgia plástica estão à disposição para amenizar os sentimentos pela alteração física provocada pela mastectomia (MESSA, 2001; PRADO, 2002).

As mulheres apresentaram diferentes opiniões e sentimentos acerca da cirurgia de reconstrução mamária:

Optei por fazer a reconstrução da mama, mas ainda não consegui realizar, mas continuo com esperança que conseguirei (ORQUÍDEA).

A cirurgia reconstrutora da mama, em minha opinião, é mais um sofrimento, e então, optei por não realizar (ROSA DÁLIA).

Não quis realizar a cirurgia de reparação da mama, por escolha própria, me sinto bem como estou hoje (ROSA).

Como é que faz mulher? Desde que me liberaram que estou atrás, mas faz muitos anos isso. Acho que é devido a idade né?!. No hospital que fiz a cirurgia fui atrás, já posso fazer a reconstituição, mas a doutora olhou para mim simplesmente e disse "pra quê?", aí já percebi a dificuldade que vinha na frente (DAMA DA NOITE).

A opção pela reconstrução mamária tem mostrado uma melhoria na adaptação da imagem corporal, bem como contribuído para restabelecer o equilíbrio psicológico que é 
perdido no momento do diagnóstico e da perda da mama. A reconstrução mamária é um procedimento cirúrgico, cujas diferentes técnicas permitem ao cirurgião plástico criar uma mama similar em forma, textura e característica da mama extraída, que pode ser realizado no mesmo ato cirúrgico da mastectomia ou tardiamente (AZEVEDO; LOPES, 2010).

Consideramos parte importante do tratamento de mulheres mastectomizadas vítimas do câncer de mama, tendo em vista a análise das falas das entrevistadas e o conteúdo emocional desprendido ao verbalizarem sua vontade, anseios e dificuldades relacionados a reconstrução cirúrgica da mama. Entendemos, ao confrontar as falas das entrevistadas com as literaturas associadas ao estudo, que a reconstrução da mama é um fator de alta relevância, influenciando de formal crucial para a qualidade de vida biopsicossocial e emocional destas mulheres.

\section{I CONSIDERAÇÕES FINAIS}

Os resultados observados neste estudo sugerem que a qualidade de vida de mulheres mastectomizadas acometidas pelo câncer de mama está associada a vários fatores como atividade laboral, atividade sexual, alterações na qualidade do sono, renda familiar, percepção do significado de ter saúde e valorização de alguns sentimentos relacionados ao valor da vida no seu dia a dia.

No estudo observou-se, segundo relato verbal das pacientes, uma piora na qualidade de vida das mulheres, que de alguma forma, tiveram alteração na atividade laboral, desencadeando, a princípio, um sentimento de impotência, mais superado durante os tratamentos quimioterápicos.

Outro achado relevante observado neste estudo, está relacionado à reconstrução cirúrgica da mama. Uma porcentagem das entrevistadas relatou a negação ao procedimento, e verbalizou a não interferência na qualidade de vida, entretanto, outras entrevistadas relatam a procura da cirurgia de reconstrução da mama, mas relatam dificuldades relacionadas à equipe médica e rede hospitalar referenciada.

Concluímos que os achados deste estudo sugerem que a qualidade de vida de mulheres mastectomizadas por câncer de mama, são influenciados por vários fatores biopsicossociais e ambientais, mas a descrição verbal das entrevistadas sugere dificuldades maiores em aceitar o câncer de mama e, consequentemente, afetando de forma positiva na qualidade de vida destas pacientes. Esta descrição das entrevistadas de que, inicialmente houve piora na qualidade de vida e, consequentemente, superação da doença ao decorrer do tratamento, implica que a qualidade de vida das pacientes mastectomizadas depende muito mais do fator psicológico e aceitação de si mesma.

Os resultados deste estudo podem contribuir para complementar o conhecimento de profissionais de saúde sobre aspectos relacionados à vida das pacientes mastectomizadas após alta do tratamento, auxiliando no manejo de pacientes e familiares a compreenderem 
possíveis dificuldades emocionais e sociais, após mastectomia e tratamento coadjuvante. Também servindo como material de leitura de apoio para mulheres mastectomizadas.

Sugerem-se futuros estudos que venham a complementar esta pesquisa e possam auxiliar no que se refere à qualidade de vida de mulheres acometidas com o câncer de mama e submetida à mastectomia.

\section{REFERÊNCIAS}

AZEVEDO, R. F.; LOPES, R. L. M. Revisando as contribuições da reconstrução mamária para mulheres após a mastectomia por câncer. Rev. enferm. UERJ, Rio de Janeiro, v. 18, n. 2, p. 298-303, abr./jun. 2010. Disponível em: http://www.facenf.uerj.br/v18n2/v18n2a22.pdf.

BARDIN, L. Análise de conteúdo. Lisboa: Edições 70, 2011.

BERVIAN, P. I.; GIRARDON-PERLINI, N. M. O. A família (con)vivendo com a mulher/mãe após a mastectomia. Revista Brasileira de Cancerologia, Rio de Janeiro, v. 52, n. 2, p. 121-128, 2006. Disponível em: 6 dez. 2020.

CAMARGO, M. C.; MARX, A. G. Reabilitação física no câncer de mama. São Paulo: Roca, 2000.

CONSELHO NACIONAL DE SAÚDE (Brasil). Resolução $n^{\circ} 466$, de 12 de dezembro de 2012. Diário Oficial da União: seção 1, Brasília, DF, n. 112, p. 59, 13 jun. 2013. Disponível em: http://pesquisa. in.gov.br/imprensa/jsp/visualiza/index.jsp?data=13/06/2013\&jornal=1\&pagina=59\&totalArquivos=140. Acesso em: 6 dez. 2020.

DUARTE, T. P.; ANDRADE, A. N. Enfrentando a mastectomia: análise dos relatos de mulheres mastectomizadas sobre questões ligadas à sexualidade. Estud. psicol. (Natal), Natal, v. 8, n. 1, p. 155-163, 2003. Disponível em: https://www.scielo.br/pdf/epsic/v8n1/17245.pdf. Acesso em: 6 dez. 2020.

FERREIRA, M. L. S. M.; MAMEDE, M. V. Representação do corpo na relação consigo mesma após mastectomia. Rev. Latino-Am. Enfermagem, Ribeirão Preto, v. 11, n. 3, p. 299- 304, June 2003. Disponível em: https://www.scielo.br/pdf/rlae/v11n3/16538.pdf. Acesso em: 11 dez. 2020.

FUNDAÇÃO CENTRO DE CONTROLE DE ONCOLOGIA DO ESTADO DO AMAZONAS. Câncer de mama. FCECON, Manaus, 2005.

HUGUET, P. R. et al. Qualidade de vida e sexualidade de mulheres tratadas de câncer de mama. Rev. Bras. Ginecol. Obstet., Rio de Janeiro, v. 31, n. 2, p. 61-67, 2009.

INSTITUTO NACIONAL DO CÂNCER (Brasil). ABC do câncer: abordagens básicas para o controle do câncer. Rio de Janeiro: Instituto Nacional do Câncer, 2011b.

INSTITUTO NACIONAL DO CÂNCER (Brasil). Controle do câncer de mama: documento de consenso. Rio de Janeiro: Instituto Nacional do Câncer, 2004. Disponível em: http://www1.inca.gov.br/ publicacoes/Consensointegra.pdf. Acesso em: 6 dez. 2020. 
INSTITUTO NACIONAL DO CÂNCER (Brasil). Rastreamento organizado do câncer de mama: a experiência de Curitiba e a parceria com o Instituto Nacional de Câncer. Rio de Janeiro: Instituto Nacional do Câncer, 2011a. Disponível em: https://www.inca.gov.br/sites/ufu.sti.inca.local/files//media/ document//rastreamento- organizado-cancer-de-mama-2011.pdf. Acesso em: 6 dez. 2020.

INSTITUTO NACIONAL DO CÂNCER (Brasil). Recomendações para redução da mortalidade por câncer de mama no Brasil: balanço 2012. Rio de Janeiro: Instituto Nacional do Câncer, 2012.

LAKATOS, E. M.; MARCONI, M. A. Metodologia científica. São Paulo: Atlas, 2004.

MASCARENHAS, S. A. Metodologia científica. São Paulo: Pearson Education do Brasil, 2012.

MESSA, A. A. Análise de repercussões psicológicas de paciente mastectomizada, em seguimento ambulatorial. 2001. Monografia (Graduação) - Universidade Paulista, São Paulo, 2001.

MOURA, M. L. S.; FERREIRA, M. C. Projetos de pesquisa: elaboração, redação e apresentação. Rio de janeiro: EDUERJ, 2005.

PRADO, J. A. F. A. Supervivência: novos sentidos na vida após a mastectomia. 2002. 76 f. Dissertação (Mestrado em Psicologia) - Universidade Federal de Santa Catarina, Florianópolis, 2002. Disponível em: https://repositorio.ufsc.br/bitstream/handle/123456789/83955/186562.pdf?sequence=1\&isAll owed=y. Acesso em: 6 dez. 2020.

SALES, C. A. C. C. et al. Qualidade de vida de mulheres tratadas de câncer de mama: funcionamento social. Revista Brasileira de Cancerologia, Rio de Janeiro, v. 47, n. 3, p. 263-672, 2001.

VERONESI, U. Mastologia oncológica. Rio de Janeiro: Medsi, 2002.

VIEIRA, C. P.; LOPES, M. H. B. M.; SHIMO, A. K. K. Sentimentos e experiências na vida das mulheres com câncer de mama. Rev. Esc. Enferm. USP, São Paulo, v. 41, n. 2, p. 311- 316, 2007.

WORLD CANCER RESEARCH FUND INTERNATIONAL. Diet, nutrition, physical activity and cancer: a global perspective: a summary of the Third Expert Report. [S.I.]: WCRF, 2018. 


\section{CAPÍTULO 21}

\section{O ENFERMEIRO E O ACOLHIMENTO DE PACIENTES NO PRÉ OPERATÓRIO DE CÂNCER DE MAMA: RELATO DE EXPERIÊNCIA}

Data de aceite: $20 / 08 / 2021$

Data de submissão: 25/06/2021

Michelle Freitas de Souza

Ana Paula de Magalhães Barbosa

PALAVRAS - CHAVE: Acolhimento, Câncer de mama, Enfermeiro

\section{INTRODUÇÃO}

A Política Nacional de Humanização define acolher como reconhecer o que o outro traz como legítima e singular necessidade de saúde. Ele é construído de forma coletiva, a partir da análise dos processos de trabalho e tem como objetivo a construção de relações de confiança, compromisso e vínculo entre profissionais e pacientes tornando-se em uma rede socioafetiva. O câncer de mama é o mais temido entre as mulheres, porque ao receberem o diagnóstico significa incertezas, medo da morte, mutilação, distúrbio de imagem, depressão.

\section{OBJETIVO}

Descrever a experiência da atuação do enfermeiro no acolhimento de pacientes em pré operatório de câncer de mama.

\section{METODOLOGIA}

Trata-se relato de experiência de uma enfermeira da clínica cirúrgica feminina de um Hospital Universitário no Rio de Janeiro, no período de janeiro a abril de 21 .

\section{RESULTADOS}

O acolhimento acontece quando a paciente é admitida no setor de clínica cirúrgica feminina (CCF). O enfermeiro entrevista e colhe o histórico da paciente, logo após oferta uma esculta qualificada, apoio psicológico e emocional, fortalece que ela é capaz de vencer as adversidades da doença, explica a importância do tratamento precoce e do auto cuidado.

\section{CONCLUSÃO}

O acolhimento vem ao encontro do cuidado humanizado cujos elementos são a empatia, a compaixão e o respeito à dignidade da pessoa. A partir da relação dialógica e escuta ativa o enfermeiro favorece que a paciente se sinta mais segura e confiante para enfrentar o diagnóstico e superar os desafios do tratamento do câncer repercutindo na recuperação e conscientização quanto à importância do auto cuidado. 


\section{PREVALENCIA DE LINFEDEMA EN UN GRUPO DE MUJERES POSTMASTECTOMIZADAS}

Data de aceite: 20/08/2021

Data de submissão: 06/06/2021

\section{Sofía Elena Pérez-Zumano}

Escuela Nacional de Enfermería y Obstetricia. Universidad Nacional Autónoma de México,

Ciudad de México, México https://orcid.org/0000-0003-4643-566X

\section{Lourdes Azucena Matías-Garduño}

Escuela Nacional de Enfermería y Obstetricia. Universidad Nacional Autónoma de México,

Ciudad de México, México.

https://orcid.org/0000-0002-8976-3850

\section{Luis Manuel Mendoza-Cruz}

Facultad de Estudios Superiores Zaragoza. Universidad Nacional Autónoma de México,

Ciudad de México, México. https://orcid.org/0000-0003-0505-4772

Mónica Gallegos Alvarado Universidad Juárez del Durango, México y Secretaria de Salud. Centro Estatal de

Cancerología de Durango https://orcid.org/0000-0001-9241-1015

Investigación derivada del proyecto UNAM. DGAPA. PAPIIT IN310416 Modelo de cuidado para el seguimiento de mujeres postmastectomizadas: Valoración, prevención y manejo de la extremidad superior.

RESUMEN: El linfedema relacionado con el cáncer de mama se manifiesta con hinchazón crónica y progresiva del tejido subcutáneo que impacta el bienestar de las sobrevivientes. En México existe poca evidencia de la magnitud del problema, por lo que el objetivo del estudio fue estimar la prevalencia de linfedema en mujeres en tratamiento por cáncer de mama, así como los comportamientos para su prevención. El estudio fue observacional, descriptivo y transversal, se realizó en el servicio de oncología quirúrgica de una institución de salud, en un grupo de 82 mujeres seleccionadas por muestreo intencional. Las variables de estudio fueron: sociodemográficas, clínicas, de tratamiento, signos y síntomas, comportamientos de prevención y circometria comparada de ambos brazos para establecer el grado de linfedema. Se respetaron los principios éticos de la investigación y solicitó consentimiento informado. El promedio de edad de las mujeres fue $59 \pm 9$, solo el $21 \%$ tiene peso normal, más de la mitad recibieron quimio y radioterapia. La sensación de pesadez, hinchazón y dolor están presentes en mujeres que no tienen linfedema $\left(X^{2}, p \leq 0.05\right)$. La fibrosis y limitación de la movilidad del hombro se manifiesta en personas con linfedema III grado $\left(X^{2}, p \leq 0.05\right)$. La mitad de las mujeres presenta linfedema; no obstante, una proporción variable de ellas realiza comportamientos de prevención. Un porcentaje de los encuestadas desconocía aspectos de la enfermedad y el tratamiento recibido y presentaba deficiencias en las conductas que modifican la aparición del linfedema. En este contexto, la enfermera de práctica avanzada puede asumir la valoración y educación de las sobrevivientes con riesgo de desarrollar linfedema, en el marco de la atención multidisciplinaria de los profesionales 
de la salud, con el fin de contribuir en la calidad de vida de las personas.

PALABRAS - CLAVE: linfedema extremidad superior, cáncer de mama, enfermería, prevención

\begin{abstract}
Lymphedema related to breast cancer manifests itself with chronic and progressive swelling of the subcutaneous tissue that impacts the well-being of survivors. In Mexico there is little evidence of the magnitude of the problem, therefore the aim of this study is to estimate the prevalence of lymphedema in women undergoing treatment for breast cancer, as well as behaviors for its prevention. The study was observational, descriptive, cross-sectional and it was carried out in the oncological surgery service of a health institution, within a group of 82 women that were selected by intentional sampling. The variables of the study were: sociodemographic, clinical, treatment, signs and symptoms, prevention behaviors and comparative circometry of both arms to establish the degree of lymphedema. The ethical principles of the research were respected and informed consent was requested. The average age of the women was $59 \pm 9$, only $21 \%$ have normal weight, more than half received chemotherapy and radiotherapy. The sensation of heaviness, swelling, and pain are present in women who do not have lymphedema (X2, $p \leq 0.05)$. Fibrosis and limitation of mobility of the shoulder appear in people with grade III lymphedema (X2, $p \leq 0.05$ ). Half of the women present lymphedema, however, a variable proportion of them carry out preventive behaviors. A percentage of those surveyed were unaware of aspects of the disease and the treatment received and had deficiencies in the behaviors that modify the appearance of lymphedema. In this context, the advanced practice nurse can undertake the assessment and education of survivors at risk of developing lymphedema, within the framework of the multidisciplinary care of health professionals to contribute to people's quality of life.
\end{abstract}

KEYWORDS: upper limb lymphedema, breast cancer, nursing, prevention.

RESUMO: O linfedema relacionado ao câncer de mama se manifesta com edema crônico e progressivo do tecido subcutâneo que impacta o bem-estar dos sobreviventes, no México há poucas evidências da magnitude do problema, então o objetivo do estudo foi estimar a prevalência de linfedema em mulheres em tratamento para câncer de mama, bem como comportamentos para sua prevenção. O estudo foi observacional, descritivo e transversal, realizado no serviço de oncologia cirúrgica de uma instituição de saúde, em um grupo de 82 mulheres selecionadas por amostragem intencional, variáveis do estudo: sociodemográficas, clínicas, tratamento, sinais e sintomas, comportamentos prevenção e circometria comparativa de ambos braços para estabelecer o grau de linfedema. Os princípios éticos da pesquisa foram respeitados e foi solicitado consentimento informado. A idade média das mulheres foi de $59 \pm$ 9 anos, apenas $21 \%$ têm peso normal, mais da metade recebeu quimioterapia e radioterapia, sensação de peso, inchaço e dor estão presentes em mulheres que não têm linfedema (X2, $p$ $\leq 0,05)$, fibrose e limitação da mobilidade do ombro em pessoas com linfedema grau III (X2, $p$ $\leq 0,05)$. Metade das mulheres tem linfedema; no entanto, uma proporção variável deles realiza comportamentos preventivos. Uma porcentagem dos pesquisados desconhecia aspectos da doença e do tratamento recebido e apresentava deficiências nos comportamentos que modificam o aparecimento do linfedema. Neste contexto, o enfermeiro de prática avançada pode realizar a avaliação e educação dos sobreviventes em risco de desenvolver linfedema, 
no âmbito do atendimento multiprofissional dos profissionais de saúde, para contribuir para a qualidade de vida das pessoas.

PALAVRAS-CHAVE: Linfedema de membro superior, câncer de mama, enfermagem, prevenção.

\section{INTRODUCCIÓN}

El linfedema es la hinchazón crónica y progresiva del tejido subcutáneo provocado por insuficiencia del sistema linfático, con disminución de la capacidad funcional e inmunológica de la región afectada. La principal causa de linfedema secundario es el cáncer de mama (CaMa) y sus tratamientos, principalmente cirugía con disección ganglionar y radioterapia se asocian además de la presencia de linfedema, a deterioros físicos y limitaciones funcionales que se manifiestan con dolor, debilidad, fatiga, hormigueo, límite de rango del movimiento, neuropatía y adormecimiento en la extremidad ipsilateral. (HIDDING JT et al. 2014, HAYES SC et al 2012)

El linfedema se presentan entre el $10 \%$ y $60 \%$ de las personas con CaMa, algunos factores que incrementan el riesgo o lo agravan son el tipo de cirugía, número de ganglios extirpados, exposición a radioterapia y características de la paciente como: edad, índice de masa corporal (IMC), hipertensión, tratamiento en el brazo dominante, niveles de actividad física, distrés y estatus socioeconómico.( TOGAWA K, et al 2014, DISIPIO T, et al 2013) Además, se acompaña de alteraciones del sueño, dolor, fatiga, angustia, depresión, ansiedad, pensamientos negativos, miedo a la recurrencia del cáncer, a la muerte, soledad, baja autoestima, angustia emocional que originan repercusión en el bienestar psicológico. (PYSZEL A, et al 2006)

No obstante, la relevancia clínica del linfedema secundario al CaMa, el modelo actual de atención prioriza erradicar el cáncer y detectar la recurrencia, dejando de lado la prevención, detección y tratamiento de éste, aunque se ha demostrado la importancia de que las pacientes estén informadas para modificar comportamientos en aras de evitar trauma, lesión e infección, que junto con sobrepeso y obesidad son los principales predictores de linfedema, (FU MR, 2014. BORMAN P, et al 2017) esto implica nuevas habilidades de autocuidado y de un manejo interdisciplinario donde enfermería, por su formación disciplinar y la interacción continúa con las mujeres puede coordinar las aportaciones de otros profesionales de la salud para favorecer la rehabilitación temprana de las pacientes, y mejorar así su calidad de vida. En el país se desconoce la magnitud del problema por lo que el objetivo del estudio fue estimar la prevalencia de linfedema en mujeres con CaMa, así como la práctica de comportamientos para su prevención. 


\section{MÉTODOS}

Estudio observacional, descriptivo y transversal, 82 mujeres seleccionadas por muestreo intencional que cumplieron los siguientes criterios de inclusión: mayores de 25 años, en postoperatorio mediato o tardío de cirugía de seno por CaMa en tratamiento en una institución de tercer nivel de atención, excluyendo a las personas con comorbilidad crónica no controlada como hipertensión, cardiopatía y trastornos mentales. Fueron respetados los principios de confidencialidad, beneficencia y no maleficencia y la valoración de la persona fue previo consentimiento informado, en el servicio de oncología quirúrgica de febrero a diciembre del 2017. El protocolo fue aprobado por el Comité de Ética en Investigación de la ENEO UNAM con número de folio 098.

Para la recolección de datos, con base en la revisión de la literatura y criterio de expertos se construyó un instrumento que incluyó variables sociodemográficas, clínicas, de tratamiento, signos y síntomas de linfedema, así como los comportamientos de prevención. Para reducir los sesgos en la valoración se realizó una estandarización de las técnicas de medición entre los evaluadores.

El diagnóstico de linfedema se realizó mediante circometria comparada de ambos brazos, que es una técnica de medidas perimetrales reconocida como la forma de medición más eficiente y utilizada a nivel clínico por su disponibilidad, se realizó con una cinta métrica flexible no elástica en 14 puntos. Una diferencia mayor o igual a $2 \mathrm{~cm}$ en tres medidas en cualquiera de los puntos del brazo afectado indicó linfedema, que se clasificó en tres grados: leve o grado I de 2 a $3 \mathrm{~cm}$; moderado o grado II de 3.1 a $5 \mathrm{~cm}$, y grave o grado III mayor a $5 \mathrm{~cm}$. (FU MR 2014, ARIAS-CUADRADO A, et al 2010, CUELLO-VILLAVERDE E, et al 2010). Los datos fueron analizados en SPSS 23, se utilizaron medidas de frecuencia, porcentajes y Chi cuadrada para identificar diferencias en la sintomatología presentada.

Posterior a la valoración, todas las pacientes recibieron información sobre factores de riesgo, ajustes en actividades de la vida diaria, y ejercicios para mejorar la amplitud del rango de movimiento del hombro.

\section{RESULTADOS}

Caracterización de la muestra. Un dato relevante es que más de la mitad de las mujeres fueron valoradas por primera vez para identificar linfedema $5 \pm 4$ años después de la cirugía, rango de edad de 39 a 79 años, el 65\% tienen pareja, 46\% con escolaridad básica, $50 \%$ se dedica al hogar. Solo el $21 \%$ tiene peso normal. El $67 \%$ reportó distrés. (Cuadro 1). El 60\% desconoce el tipo de cáncer y estadio, el 23\% son avanzados (III y IV), al 53\% se les retiraron más de 10 ganglios, $85 \%$ recibió quimioterapia y 57\% radioterapia. (Cuadro 2)

EI $51 \%$ de las pacientes presentó linfedema: I leve 20\%, II moderado 15\%, III grave 
$16 \%$. Con relación a los signos y síntomas, la proporción de mujeres que tienen sensación de pesadez, hinchazón y dolor es diferente en el grupo de mujeres que no tienen linfedema $\left(n=40, X^{2}, p \leq 0.05\right)$, de igual manera se encontraron diferencias en cambios de la piel y limitación de movimiento en las mujeres con linfedema III grado $\left(X^{2}, p \leq 0.05\right)$. Asimismo, se identificó deterioro de la movilidad de la articulación del hombro en la tercera parte de las mujeres sin linfedema. (Cuadro 3)

En los comportamientos para reducir la presencia de linfedema, se identificó que la quinta parte de las mujeres que no tienen linfedema utilizan guantes y 1 de cada 10 usa manga de compresión entre quienes tienen linfedema grado I. ( $X^{2} p<0.05$, Cuadro 4). Asimismo, otras conductas para evitar trauma, lesiones e infección no están presentes en la totalidad de las mujeres independientemente del grado de linfedema.

\section{DISCUSIÓN}

El linfedema post CaMa es un síndrome crónico de hinchazón anormal, provocado por un desequilibrio entre la producción y transporte de linfa. Se prevé un incremento de este tipo de linfedema debido a tres condiciones; el CaMa es la primera causa de muerte por neoplasias malignas en mujeres mexicanas mayores de 25 años (IARC 2020); el diagnóstico se realiza en estadios avanzados que requieren tratamientos más invasivos (MAFFUZ-AZIZ A, et al. 2017) e incremento en la supervivencia de la población afectada. Sin embargo, en la atención estándar a esta población no se incluye la detección de linfedema, casi el $90 \%$ de las pacientes fueron valoradas un año después de la cirugía, en contraste, a nivel internacional se aplican modelos de seguimiento con el fin de prevenir, detectar y atender de manera oportuna las secuelas post tratamientos desde el periodo preoperatorio. (STOUT NL, et al 2012. CAMPELL KL, 2012)

En las mujeres se identificaron diversos factores que han sido documentados en la literatura; el 35\% tiene obesidad, una quinta parte disección de más de 20 ganglios, más de la mitad recibió tratamiento de radioterapia, por lo que tienen mayor riesgo de presentar linfedema en cualquier momento de su vida. (HIDDING JT et al 2014. DISIPIO T, et al 2013. REBEGEA L, et al 2015).

Un poco más de la mitad de las pacientes presentó linfedema en diferentes grados, proporción mayor a la encontrada en un estudio realizado en mujeres mexicanas (GUTIÉRREZ E et al. 2014.), en brasileñas con un 44.8\% (PAIVA MF et al 2013), en contraste con el 5.9\% reportado en otro estudio. (REBEGEA L, et al 2015) Estas diferencias pueden ser debido a las características clínicas de las pacientes; estadio del cáncer, tipo de cirugía, número de ganglios extirpados, radioterapia, sobrepeso u obesidad, que son factores de riesgo identificados en múltiples estudios, (DISIPIO T, et al 2013) ya que en países desarrollados el diagnóstico de CaMa es oportuno versus países con recursos limitados, por lo que la incidencia de linfedema varia del 3 al $60 \%$. 
Con respecto a los signos y síntomas se encontró que las mujeres que no tienen linfedema refirieron sensación de pesadez e hinchazón que pueden presentarse en estadio 0 , o latente en el que el edema no es evidente pero ya existe una alteración en el transporte linfático, (ARIAS-CUADRADO A, et al 2010. MOFFATT C. 2006) que las hace más vulnerables a desarrollar la complicación, por lo que es relevante la educación para el autocuidado. Los cambios en el aspecto y la consistencia de la piel como la fibrosis, son más notables a medida que los grados de linfedema aumentan. (CIUCCI JL. 2017)

El dolor no es un síntoma característico del linfedema, sin embargo, casi la mitad de las mujeres valoradas lo presentan, es ocasionado por la lesión del nervio braquial intercostal o toraco dorsal que ocurre cuando se hace la disección ganglionar que además provoca disfunción muscular y parestesia (HAYES SC et al 2012), razón por la cual está presente en mujeres sin linfedema. Cabe señalar que las pacientes refieren más de un síntoma, lo que concuerda con datos de un estudio en el que se identificó una relación significativa entre el incremento en el número de síntomas y aumento del volumen del brazo, traducido clínicamente en estadios de linfedema. (FU MR, 2014)

El deterioro de la movilidad de la extremidad está presente independientemente de la presencia y grado de linfedema, en mayor proporción en quienes no lo presentan, debido a que éste es una complicación derivada de la cirugía y radioterapia, (HIDDING JT et al. 2014) por lo que es un deterioro esperado en las mujeres, que requiere de una intervención oportuna para su rehabilitación durante y después del tratamiento. (STOUT NL, et al 2012).

Por otra parte, algunos comportamientos que afectan el flujo linfático de la extremidad son realizados por las pacientes y aunque no existen evidencias concluyentes sobre su papel en la detonación del linfedema, pueden contribuir al desarrollo de inflamación-infección, que junto con el trauma son predictores de linfedema. (JAKES AD et al 2015, CHENG CT, et al 2014. ASDOURIAN MS, et al. 2016), por lo que consensos de profesionales de la salud los incluyen como parte del autocuidado para prevenir y limitar la progresión del linfedema. (CIUCCI JL. 2017). Los comportamientos de las mujeres muestran en parte si la mujer está informada sobre los ajustes que debe hacer en su vida cotidiana. (SHERMAN $\mathrm{KA}$, et al 2015)

\section{LIMITACIONES DEL ESTUDIO}

Por política de la institución de salud no se tuvo acceso a los expedientes clínicos de las mujeres valoradas, lo que limito el análisis de los datos.

\section{CONCLUSIONES}

Los hallazgos del estudio mostraron que el linfedema es una afección común post tratamiento del CaMa que debe ser incluido en la valoración y seguimiento de las 
sobrevivientes que experimentan síntomas que deterioran su bienestar. Las personas requieren ser entrenadas para la prevención y detección temprana del linfedema, en aras de limitar su aparición y progresión. Enfermería puede ser el enlace entre la mujer, la familia y el equipo de salud, ejerciendo una practica avanzada que contribuya a mejorar la calidad de vida de las mujeres.

\section{FINANCIAMIENTO}

Proyecto UNAM. DGAPA. PAPIIT IN310416 Modelo de cuidado para el seguimiento de mujeres postmastectomizadas: Valoración, prevención y manejo de la extremidad superior

\section{CONFLICTO DE INTERESES}

Los autores declaran no tener conflicto de intereses.

\section{REFERENCIAS}

ARIAS-CUADRADO A, ÁLVAREZ-VÁZQUEZ MJ, MARTíN-MOURELLE R, VILLARINO-DÍAZ JIMÉNEZ C. Clínica, clasificación y estadiaje del linfedema. 2010;44(1):29-34 - DOI: 10.1016/j.rh.2010.06.00

ASDOURIAN MS, SKOLNY MN, BRUNELLE C, SEWARD CE, SALAMA L, TAGHIAN AG. Precautions for breast cancer-related lymphedema: risk from air travel, ipsilateral arm blood pressure measurements, skin puncture, extreme temperature, and cellulitis. Lancet Oncol 2016; 17(9): 393405.

BORMAN P, YAMAN A, YASREBI S, ÖZDEMIR O. The Importance of Awareness and Education in Patients with Breast Cancer-Related Lymphedema. J Cancer Educ. 2017 Sep;32(3):629-633. doi: 10.1007/s13187-016-1026-1. PMID: 27048148.

CAMPELL KL, PUSIC AL, ZUCKER DS, ET AL. A prospective model of care for breast cancer rehabilitation: function. Cancer. 2012;118(suppl 8):2300-2311.

CIUCCI JL. $6^{\circ}$ Consenso Latinoamericano para el tratamiento de linfedema. Buenos Aires: Ed. Nayarit, 2017. 185 p.

CUELLO-VILLAVERDE E, FORNER-CORDERO I, FORNER-CORDERO A. Linfedema: métodos de medición y criterios diagnósticos. Revisión. Rehabilitación. 2010 44(S1):21-28. doi:10.1016/j. rh.2010.05.009

CHENG CT, DEITCH JM, HAINES IE, PORTER DJ, KILBREATH SL. Do medical procedures in the arm increase the risk of lymphoedema after axillary surgery? A review. ANZ J Surg. 2014; 84(7-8): $510-4$

DISIPIO T, RYE S, NEWNAN B, HAYES S. Incidence of unilateral arm lymphoedema after breast cancer: a systematic review and meta-analysis. Lancet Oncol 2013, 14(6):500-15. doi: 10.1016/ S1470-2045(13)70076-7. 
FU MR. Breast cancer-related lymphedema: Symptoms, diagnosis, risk reduction, and management. World J Clin Oncol 2014; 5(3):241-247 Available from: URL: http://www.wjgnet. com/2218-4333/full/v5/i3/241.htm DOI: http://dx.doi.org/10.5306/wjco.v5.i3.241

GUTIÉRREZ E, AVALOS J, SALAS E, MONTES L, GUZMÁN J, PÁNUCO P. Prevalencia de linfedema en extremidades superiores secundario a mastectomía por cáncer. Cir Gen. 2014;36(3):145-149.

HAYES SC, JOHANSSON K, STOUT NL, PROSNITZ R, ARMER JM, GABRAM S, SCHMITZ KH. Upper-Body morbidity following breast cancer: incidence and evidence for evaluation prevention and management within a prospective surveillance model of rehabilitation. Cancer. 2012;118 (suppl 8):2237-2249.

HIDDING JT, BEURSKENS CHG, VAN DER WEES PJ, VAN LAARHOVEN HWM, NIJHUIS-VAN DER SANDEN MWG. Treatment Related Impairments in Arm and Shoulder in Patients with Breast Cancer: A Systematic Review. PLoS ONE 2014, 9(5): e96748. doi: 10.1371/journal.pone.0096748

INTERNATIONAL AGENCY FOR RESEARCH ON CANCER, OMS. Mexico Source: Globocan 2020. Disponible en: https://gco.iarc.fr/today/data/factsheets/populations/484-mexico-fact-sheets.pdf. Consultado el 31 de mayo 2021

JAKES AD, TWELVES C. Breast cancer-related lymphoedema and venepunture: a review and evidence-based recommendations. Breast Cancer Res Treat 2015;154(3):455-461.

MAFFUZ-AZIZ A, LABASTIDA-ALMENDARO S, ESPEJO-FONSECA A, RODRÍGUEZ-CUEVAS S. Características clinicopatológicas del cáncer de mama en una población de mujeres en México. Cirugía y Cirujanos (English Edition). 2017, 85 (3):201-207.

MOFFATT C. International Consensus. Best Practice for the management of lymphedema. 2006:10-11. Consultado el 13 de marzo 21 en: http://www.woundsinternational.com/media/issues/210/ files/content_175.pdf

PAIVA MF, RODRIGUES VO, CESCA MG, PALMA PV, LEITE CG. Prevalence of lymphedema in women undergoing treatment for breast cancer in a referral center in southeastern. Brazil. BMC Women's Health. 2013;13(6): 2-7.

PYSZEL A, MALYSZCZAK K, PYSZEL K, ANDRZEJAK R, SZUBA A. Disability, psychological distress, and quality of life in breast cancer survivors with arm lymphedema. Lymphology. 2006; 39(4):185-192.

REBEGEA L, FIRESCU D, DUMITRU M, ANGHEL R. The incidence and risk factors for occurrence of arm lymphedema after treatment of breast cancer. Chirugia 2015, 110(1):33-7.

SHERMAN KA, MILLER SM, ROUSSI P. TAYLOR A. Factor predicting adherence to risk management behaviors of women at increased risk for developing lymphedema. Support Care Cancer 2015;23(1): 61-69.

STOUT NL, ANDREWS K, BINKLEY JM, SCHMITZ KH, SMITH RA. A prospective surveillance model of rehabilitation for women whit breast cancer. Cancer. 2012;118 (suppl 8):2191-2200. 
TOGAWA K, MA H, SULLIVAN-HALLEY J, ET AL. Risk factors for self-reported arm lymphedema among female breast cancer survivors: a prospective cohort study. Breast Cancer Research: BCR. 2014; 16:414. doi:10.1186/s13058-014-0414-x.

\section{TABLAS Y/O FIGURAS}

\begin{tabular}{|c|c|}
\hline VARIABLE & Fo (\%) \\
\hline Edad & $58 \pm 9^{*}$ \\
\hline \multicolumn{2}{|l|}{ Estado Civil } \\
\hline Casada o unión libre & $53(65 \%)$ \\
\hline Solteras, divorciadas o viudas & $29(25 \%)$ \\
\hline \multicolumn{2}{|l|}{ Escolaridad } \\
\hline Básica & $17(46 \%)$ \\
\hline Bachillerato & $28(34 \%)$ \\
\hline Licenciatura & $16(20 \%)$ \\
\hline \multicolumn{2}{|l|}{ Ocupación } \\
\hline Hogar & $41(50 \%)$ \\
\hline Empleada & $20(25 \%)$ \\
\hline Jubilada & $18(21 \%)$ \\
\hline Comerciante & $3(4 \%)$ \\
\hline \multicolumn{2}{|l|}{ IMC } \\
\hline Normo peso & $17(21 \%)$ \\
\hline Sobrepeso & $34(42 \%)$ \\
\hline Obesidad & $29(35 \%)$ \\
\hline Obesidad mórbida & $1(1 \%)$ \\
\hline \multicolumn{2}{|l|}{ Estrés } \\
\hline$<3$ Eutrés & $15(18 \%)$ \\
\hline >4 Distrés & $55(67 \%)$ \\
\hline No respondió & $12(15 \%)$ \\
\hline
\end{tabular}

Cuadro 1 Variables sociodemográficas de un grupo de mujeres con cáncer de mama $\mathrm{n}=82,{ }^{*}$ media $\pm \mathrm{DE}$

\begin{tabular}{lr}
\hline Estadio & Fo \% \\
\hline I & $3(4 \%)$ \\
II & $11(13 \%)$ \\
III & $12(15 \%)$ \\
IV & $7(8 \%)$ \\
No sabe & $49(60 \%)$ \\
Años de cirugía agrupados & \\
Menos de 1 año & $9(11 \%)$ \\
1 a 2 años & $23(28 \%)$ \\
$2-4$ años & $8(10 \%)$
\end{tabular}


5 años y más

$42(51 \%)$

Lateralidad de la cirugía

Derecho

$31(38 \%)$

Izquierdo

$48(57 \%)$

Bilateral

$3(5 \%)$

Lado dominante de la paciente

Derecha

$75(92 \%)$

Izquierda

$7(8 \%)$

Operada del lado dominante

No

$48(59 \%)$

$\mathrm{Si}$

$34(41 \%)$

\section{Tipo de cirugía}

Mastectomía radical modificada

79 (95\%)

Mastectomía bilateral

$3(5 \%)$

No de ganglios extirpados

No sabe

$23(28 \%)$

Hasta 10

$16(19 \%)$

11 a 20

27 (33\%)

21 y más

$16(20 \%)$

\section{Quimioterapia}

No

$12(15 \%)$

$\mathrm{Si}$

70 (85\%)

Radioterapia

No

$35(43 \%)$

$\mathrm{Si}$

$47(57 \%)$

Cuadro 2. Características del tratamiento oncológico

$\mathrm{n}=82$

\section{Signos y síntomas en extremidad ipsilateral}

Linfedema

Sensación de pesadez

\begin{tabular}{llll}
$\begin{array}{l}\text { Sin linfedema } \\
\mathbf{n = 4 0}\end{array}$ & $\begin{array}{l}\text { Grado I } \\
\mathbf{n = 1 7}\end{array}$ & $\begin{array}{l}\text { Grado II } \\
\mathbf{n = 1 2}\end{array}$ & $\begin{array}{l}\text { Grado III } \\
\mathbf{n = 1 3}\end{array}$ \\
\hline $17(37 \%)^{*}$ & $10(22 \%)$ & $6(13 \%)$ & $13(28 \%)$ \\
$21(38 \%)^{*}$ & $13(23 \%)$ & $9(16 \%)$ & $13(23 \%)$ \\
$20(48 \%)^{*}$ & $13(31 \%)$ & $3(7 \%)$ & $6(14 \%)$ \\
$21(54 \%)$ & $7(18 \%)$ & $4(10 \%)$ & $7(18 \%)$ \\
$15(60 \%)$ & $5(20 \%)$ & $3(12 \%)$ & $2(8 \%)$ \\
$11(50 \%)$ & $8(36 \%)$ & $1(5 \%)$ & $2(9 \%)$ \\
$0(0 \%)$ & $1(6 \%)$ & $2(13 \%)$ & $13(81 \%)^{\star}$ \\
$11(32 \%)$ & $7(21 \%)$ & $3(9 \%)$ & $13(38 \%)^{*}$
\end{tabular}

Cuadro 3. Signos y síntomas en mujeres con y sin linfedema secundario a CaMa

$$
\mathrm{n}=82 \text {, Chi cuadrada }{ }^{*} \mathrm{p}=0.05
$$




\section{Linfedema}

Comportamientos de prevención de linfedema

\begin{tabular}{|c|c|c|c|c|}
\hline & $\begin{array}{l}\text { Sin } \\
\text { linfedema } \\
n=40\end{array}$ & $\begin{array}{l}\text { Grado I } \\
\mathrm{n}=17\end{array}$ & $\begin{array}{l}\text { Grado II } \\
\mathrm{n}=12\end{array}$ & $\begin{array}{l}\text { Grado III } \\
n=13\end{array}$ \\
\hline $\begin{array}{l}\text { No permito que me tomen la presión, inyecten o } \\
\text { extraigan sangre en el brazo afectado }\end{array}$ & $30(75 \%)$ & $13(77 \%)$ & $9(75 \%)$ & $12(92 \%)$ \\
\hline Mantengo el brazo afectado limpio y humectado & $38(95 \%)$ & $15(89 \%)$ & $10(83 \%)$ & $12(92 \%)$ \\
\hline $\begin{array}{l}\text { ¿Evito jalar cosas pesadas y realizar movimientos } \\
\text { vigorosos repetitivos con el brazo afectado? }\end{array}$ & $27(68 \%)$ & $13(77 \%)$ & $11(9 \%)$ & $9(70 \%)$ \\
\hline $\begin{array}{l}\text { No uso brasier ajustado, joyería o bandas elásticas } \\
\text { alrededor del pecho, brazo o dedos }\end{array}$ & $27(68 \%)$ & $10(59 \%)$ & $6(50 \%)$ & $10(77 \%)$ \\
\hline Evito calor excesivo sobre el brazo & $25(63 \%)$ & $13(77 \%)$ & $8(67 \%)$ & $6(46 \%)$ \\
\hline Evito lesionar brazo afectado & $34(85 \%)$ & $16(94 \%)$ & $9(75 \%)$ & $12(92 \%)$ \\
\hline $\begin{array}{l}\text { Uso guantes para trabajar en casa y para realizar } \\
\text { actividades de jardinería }\end{array}$ & $8(20 \%)^{*}$ & $7(41 \%)$ & $7(58 \%)$ & $6(47 \%)$ \\
\hline $\begin{array}{l}\text { Cuando hago ejercicio evito sobre esfuerzo del brazo } \\
\text { afectado }\end{array}$ & $25(63 \%)$ & $11(65 \%)$ & $9(75 \%)$ & $6(46 \%)$ \\
\hline Cuando viajo uso mangas de compresión & $7(18 \%)$ & $1(6 \%)$ & $5(42 \%)$ & $4(31 \%)$ \\
\hline $\begin{array}{l}\text { Si ocurre el linfedema uso manga de compresión en todo } \\
\text { el día }\end{array}$ & $8(20 \%)$ & $2(12 \%) \dagger$ & $7(58 \%)$ & $3(23 \%)$ \\
\hline $\begin{array}{l}\text { Consulto al médico inmediatamente si noto algún cambio } \\
\text { en mi brazo }\end{array}$ & $20(50 \%)$ & $9(53 \%)$ & $8(67 \%)$ & $5(39 \%)$ \\
\hline Evito incrementar de peso & $25(63 \%)$ & $8(48 \%)$ & $8(67 \%)$ & $6(46 \%)$ \\
\hline
\end{tabular}

Cuadro 4. Comportamientos de prevención para linfedema $n=82$, Chi cuadrada * $p=0.04, \dagger p=0.02$. 


\section{CAPÍTULO 23 \\ EPIDEMIOLOGIA DA MORTALIDADE POR CÂNCER DE PÊNIS NO BRASIL 2009-2019}

Data de aceite: 20/08/2021

\section{Ângela Maria Melo Sá Barros}

Universidade Federal do Rio de Janeiro - UFRJ Rio De Janeiro - RJ https://orcid.org/0000-0003-4087-3247

\section{Márcia Peixoto César} Universidade Federal do Rio de Janeiro UFRJ Niterói - RJ https://orcid.org/0000-0002-3667-7764

Ana Inês Souza Universidade Federal do Rio de Janeiro UFRJ Rio de Janeiro - RJ https://orcid.org/0000-0002-0214-0723 Ângela Maria Mendes Abreu Universidade Federal do Rio de Janeiro - UFRJ Rio De Janeiro - RJ https://orcid.org/0000-0002-7894-4242

Ikaro Daniel de Carvalho Barreto Universidade Federal Rural de Pernambuco Aracaju - SE https://orcid.org/0000-0001-7253-806X

\section{Larissa Rodrigues Mattos} Universidade Federal do Rio de Janeiro - UFRJ Rio de Janeiro - RJ https://orcid.org/0000-0002-8033-2667

Girzia Sammya Tajra Rocha Universidade Federal do Piauí Teresina - PI https://orcid.org/0000-0002-1624-3838
Weber de Santana Teles Centro de Hemoterapia de Sergipe - HEMOSE Aracaju - SE http://orcid.org/0000-0003-1770-8278

Alejandra Debbo Universidade Tiradentes - UNIT Aracaju - SE http://orcid.org/0000-0002-7743-5921

Max Cruz da Silva Faculdade Pio Décimo - FAPIDE Poço Redondo - SE http://orcid.org/0000-0002-6944-5986

Rute Nascimento da Silva Universidade Tiradentes - UNIT Aracaju - SE http://orcid.org/0000-0002-2719-1623

Ruth Cristini Torres Instituto de hematologia e hemoterapia de Sergipe-IHHS Aracaju - SE http://orcid.org/0000-0002-8664-192X Anita Cattleya Melo Sá Sales Barros Universidade Federal do Rio de Janeiro UFRJ Rio de Janeiro - RJ https://orcid.org/0000-0002-0520-9271

RESUMO: INTRODUÇÃO:O carcinoma de pênis é considerado raro e corresponde de $0,4 \%$ a $3 \%$ de todas as neoplasias malignas, responsável por até $20 \%$ dos óbitos por câncer de pênis em países emergentes. No Brasil representa cerca de $2 \%$ de todos os casos de câncer masculinos. 
OBJETIVO: Descrever aspectos epidemiológicos da mortalidade por câncer de pênis no Brasil. MÉTODO: Trata-se de um estudo ecológico, em uma série temporal, observacional e descritiva. Tem-se como amostra do estudo, óbitos por câncer de pênis com idades entre 20 a 80 anos e mais, nas regiões brasileiras. A coleta das informações sobre os óbitos por câncer de pênis se deu no período de 20 a 23 de junho de 2021. Realizada no Departamento de Informática do Sistema Único de Saúde - site Atlas On-line de Mortalidade, selecionada a Categoria CID-10: C60- Neoplasia maligna do pênis. O período escolhido para o estudo foi de 2009 a 2019. As variáveis são: faixa etária; óbitos por estado, ano de ocorrência, taxa por região de saúde. RESULTADOS: No período estudado ocorreram 4155 óbitos por câncer de pênis no Brasil. As Regiões Sudeste (1450) e Nordeste (1420) respondem pelo maior número de mortes. Na região Norte 2017 foi ano com maior mortalidade (52), no Centro Oeste $2015 \mathrm{e}$ 2018 (41) mortes em cada ano, 2019 foi ano com os maiores números de óbitos no Nordeste (157), Sudeste (155) e Sul (59) . Em taxas brutas destaca-se o Piauí com 0,76/100.000 homens, sendo o maior em mortalidade nacional. CONCLUSÃO: O ano de 2019 revela preocupante taxas de mortalidade nas regiões Nordeste, Sudeste e Sul. Percebe-se aumento dessas taxas entre homens jovens no Nordeste. Também no Nordeste estão os Estados com as maiores taxas de mortalidade: Piauí $(0,76)$, Maranhão $(0,68)$ e Sergipe $(0,61)$.

PALAVRAS - CHAVE: Câncer. Pênis. Saúde do homem. Políticas de Saúde Pública

\section{EPIDEMIOLOGY OF PENIS CANCER MORTALITY IN BRAZIL 2009-2019}

ABSTRACT: INTRODUCTION: Penile carcinoma is considered rare and accounts for $0.4 \%$ to $3 \%$ of all malignant neoplasms, accounting for up to $20 \%$ of deaths from penile cancer in emerging countries. In Brazil it represents about $2 \%$ of all male cancer cases. OBJECTIVE: Describe epidemiological aspects of penile cancer mortality in Brazil. METHOD: This is an ecological study, in a temporal, observational and descriptive series. The study sample has penile cancer deaths aged between 20 and 80 years and over, in the Brazilian regions. The collection of information on deaths from penile cancer took place between June 20 and 23, 2021. Carried out at the Informatics Department of the Unified Health System - Online Atlas of Mortality site, selected the ICD-10 Category: C60- Malignant neoplasm of the penis. The period chosen for the study was from 2009 to 2019 . The variables are: age group; deaths by state, year of occurrence, rate by health region. RESULTS: During the study period, 4155 deaths from penile cancer occurred in Brazil. The Southeast (1450) and Northeast (1420) regions account for the highest number of deaths. In the North, 2017 was the year with the highest mortality (52), in the Central West 2015 and 2018 (41) deaths each year, 2019 was the year with the highest numbers of deaths in the Northeast (157), Southeast (155) and South (59) . In crude rates, Piauí stands out with $0.76 / 100,000$ men, being the highest in national mortality. CONCLUSION: The year 2019 is worrying mortality rates in the Northeast, Southeast and South regions. There is an increase in these rates among young men in the Northeast. Also in the Northeast are the states with the highest mortality rates Piauí (0.76), Maranhão (0.68) and Sergipe (0.61).

KEYWORDS: Cancer. Penis. Men's Health. Public Health Policies 


\section{INTRODUÇÃO}

O câncer representa importante problema clínico, social e econômico em termos de anos de vida ajustados por incapacidade (DALYs) específicos por causa entre todas as doenças humanas. O risco geral em relação ao desenvolvimento do câncer é $22,4 \%$ nos homens e 18,2\% nas mulheres (MATTIUZZI, LIPPI, 2019). A nível global, uma em cada seis mortes estão relacionadas a essa patologia (BRASIL, 2020a). Aproximadamente 70\% das mortes por câncer ocorrem em países de baixa e média renda (MALTA, ANDRADE, et al., 2019).

O câncer de pênis é apontado como um tipo de tumor raro, mais incidente a partir dos 50 anos de idade (INCA, 2021). No contexto mundial os maiores índices desse tipo de câncer são descritos em países emergentes ou em desenvolvimento (COLBERG, VAN DER HORST, et al., 2018). Regiões como Ásia, América do Sul, apresentam alta incidência na sendo responsável por até $10 \%$ das neoplasias malignas em homens (COELHO, PINHO, et al., 2018). Em países desenvolvidos a taxa deste câncer na população masculina varia de baixa a inexistente (GAO, SONG, et al., 2016). Segundo (COLBERG, VAN DER HORST, et al., 2018), no Brasil o câncer de pênis representa $\%$ de todos os tipos de câncer que atingem a população masculina (INCA, 2021); (KOIFMAN, VIDES, et al., 2011). Estima-se uma incidência de 8,3 casos em cada 100.000 homens, que faz do Brasil uma das nações com maior índice deste câncer no mundo, de modo que as regiões Norte e Nordeste comportam os maiores índices, tornando-se foco de estudos internacionais e nacionais (GAO, SONG, et al., 2016) (COELHO, PINHO, et al., 2018); (MATTIUZZI, LIPPI, 2019); (INCA, 2021).

Este tipo de câncer pode estar diretamente vinculado a determinantes sociais, econômicos, culturais, comportamentais, dentre outros, que vão influenciar na ocorrência do problema (BRASIL, 2021) ;(GAO, SONG, et al., 2016) (KOIFMAN, VIDES, et al., 2011). Somado a isto, o problema pode ser agravado pelas desigualdades no direito ao acesso a saúde, a não implantação de políticas de saúde direcionadas a esta população, bem como serviços muitas vezes não preparados para esta atenção e com baixas ofertas para diagnóstico precoce, tratamento e acompanhamento dos casos (MALTA, ANDRADE, et al., 2019); (BARRETO, 2017).

Dentre vários fatores de risco destacam-se, baixo nível social e econômico, má higiene íntima, fimose, promiscuidades sexuais, infecções sexualmente transmissíveis, com destaque para o Papiloma vírus Humano (HPV), tabaco, alcoolismo dentre outros (COELHO, PINHO, et al., 2018); (COLBERG, VAN DER HORST, et al., 2018). Como principais sinais e sintomas podem ser destacados, ferida ou úlcera persistente, tumoração na glande, prepúcio ou corpo do pênis, aumento da secreção branca (esmegma) (INCA,2021).

No que tange aos processos preventivos ao câncer de pênis, pode-se citar a prevenção primária, com orientações adequadas sobre a doença, prevenção das IST, 
educação em saúde, campanhas informativas, vacinação para HPV, secundária com diagnósticos e tratamentos precoces e oportunos, e por fim, a prevenção terciária, está voltada para a reabilitação destes indivíduos e controle da doença (WIND, FERNANDES, et al., 2018) ;(WANICK, TEICHNER, et al., 2011); (BRASIL, 2008).

Nesta perspectiva os serviços de saúde, nos diferentes níveis de atenção vão ter papel fundamental na atenção à saúde do homem, e ao que tange ao câncer de pênis, seja no aspecto preventivo, diagnósticos, tratamentos, reabilitação, segmentos e outros, tendo a atenção primária à saúde, como porta de entrada preferencial para esta atenção e início do cuidado (BRASIL, 2017); (BRASIL, 2008).

Neste sentido este estudo se justifica face à incidência de câncer de pênis ser considerada elevada no país (WIND, FERNANDES, et al., 2018), pelos custos de saúde que este gera, consequências que o câncer de pênis provoca na população masculina, principalmente nas situações mais avançadas, onde há necessidade de cirurgias invasivas e que pode causar mutilações, deformações no órgão reprodutor, trazendo problemas de ordem psicológica, fisiológica, reprodutiva, social e familiar, além de medos, sofrimentos e distúrbio da auto imagem nesses indivíduos acometidos pela doença e que poderiam ser evitadas com diagnósticos e intervenções precoces (MADRIAGA, SOUZA, et al., 2020) (ANTIQUEIRA, 2020).

Traz como relevância evidências sobre as taxas de mortalidade por câncer de pênis no país, além de inferir reflexões sobre as diretrizes da Política Nacional de Atenção Integral à Saúde do Homem (PNAISH), implantada no país desde 2009, de forma a repensar ações a integralidade da atenção à saúde da população masculina, ampliação de acesso, ações preventivas, promoção da saúde, proteção, tratamento e recuperação e que ainda se encontram fragilizadas (BRASIL, 2008).

Contribui no sentido de sensibilizar gestores, profissionais, usuários e pesquisadores, para a magnitude deste câncer no país, principalmente em regiões com grandes vulnerabilidades sociais e econômicas, que aumentam o risco desta doença, e que precisam investir em maior rastreio e atenção, com profissionais capacitados e sensibilizados, além de serviços e rede organizada para atenção a esta população.

Além disso, fomentar discussões junto à comunidade acadêmica, gestores públicos, territórios de saúde, no sentido de ampliar a atenção a saúde do homem, as informações sobre esse tipo de câncer e outros, estratégias de promoção, da importância do diagnóstico precoce, do acesso aos tratamentos disponíveis, no sentido de reduzir mortes evitáveis e poder promover qualidade também entre a população masculina.

O objetivo deste estudo é: Descrever aspectos epidemiológicos sobre a mortalidade por câncer de pênis no Brasil. 


\section{MÉTODO}

Trata-se de um estudo ecológico, em uma série temporal, observacional e descritiva. Tem-se como amostra do estudo, óbitos de homens por câncer de pênis de 20 a 80 anos e mais, nas cinco regiões brasileiras. A coleta das informações sobre os óbitos por câncer de pênis se deu no período de 20 a 23 de junho de 2021. Foi realizada em dado secundário, no Departamento de Informática do Sistema Único de Saúde - site Atlas On-line de Mortalidade, sendo selecionada a Categoria CID-10: C60 relacionada à Neoplasia maligna do pênis. O período escolhido para o estudo foi de 2009 a 2019, período inicial face à implantação da Política Nacional de Atenção Integral à Saúde do Homem (PNAISH) no país, e final pela disponibilidade dos dados. Elegeu-se como variáveis de estudo: óbitos de ocorrência por regiões brasileiras, Unidade de Federação de ocorrência dos óbitos, ano em que ocorreu o óbito e faixa etária correspondente no momento do óbito. Os dados foram processados utilizando o DATASUS e disponibilizados por planilhas organizadas por regiões, unidades de federação, faixa etária e ano de óbito. Foi realizada uma análise descritiva dos dados, e os resultados apresentados em forma de tabelas em números absolutos e percentuais, taxas específicas e brutas, sendo considerada a mortalidade por 100.000/ homens. Não foi necessário a submissão ao Comitê de Ética e Pesquisa, conforme a Resolução n 466/2012 traz, por se tratar de informações agregadas sem possibilidade de identificação individual.

\section{RESULTADOS}

O número de óbitos de câncer de pênis nos 10 anos estudados varia entre as regiões do território brasileiro, sendo a região Sudeste a que detém o maior número de casos, com 1450, seguida da região Nordeste com 1420 casos. A região Centro Oeste é a que apresenta menor número de casos de óbito com 342 casos, acompanhada da região Sul com 531 casos.

Observa-se que na década estudada, o ano com maior número de óbitos na região Norte foi 2017 com 52 óbitos em um único ano. Já a região Centro Oeste tanto 2015 como 2018 tiveram igual prevalência (41) de mortes em cada ano. Nas regiões Nordeste (157), Sudeste (155) e Sul (59) os maiores números de óbitos ocorreram no ano de 2019 (Tabela $1)$. 


\begin{tabular}{lcccccccccc}
\hline Ano de ocorrência/ regiões & \multicolumn{3}{c}{$\mathbf{N}$} & \multicolumn{3}{c}{$\mathbf{N E}$} & \multicolumn{3}{c}{ SE } & \multicolumn{2}{c}{$\mathbf{C O}$} & \multicolumn{2}{c}{$\mathbf{S}$} \\
\cline { 2 - 11 } & $\mathbf{n}$ & $\%$ & $\mathbf{n}$ & $\%$ & $\mathbf{n}$ & $\%$ & $\mathbf{n}$ & $\%$ & $\mathbf{n}$ & $\%$ \\
\hline 2009 & 20 & 8 & 101 & 40 & 117 & 46 & 17 & 7 & 41 & 16 \\
2010 & 22 & 8 & 122 & 42 & 114 & 39 & 33 & 11 & 49 & 17 \\
2011 & 30 & 11 & 114 & 41 & 110 & 39 & 25 & 9 & 35 & 13 \\
2012 & 35 & 11 & 130 & 40 & 127 & 39 & 34 & 10 & 36 & 11 \\
2013 & 37 & 11 & 128 & 38 & 147 & 44 & 24 & 7 & 48 & 14 \\
2014 & 42 & 13 & 122 & 38 & 124 & 39 & 33 & 10 & 49 & 15 \\
2015 & 42 & 12 & 118 & 35 & 139 & 41 & 41 & 12 & 54 & 16 \\
2016 & 48 & 14 & 129 & 38 & 133 & 39 & 28 & 8 & 52 & 15 \\
2017 & 52 & 14 & 144 & 39 & 139 & 38 & 35 & 9 & 53 & 14 \\
2018 & 44 & 11 & 155 & 40 & 145 & 38 & 41 & 11 & 55 & 14 \\
2019 & 40 & 10 & 157 & 41 & 155 & 40 & 31 & 8 & 59 & 15 \\
Total absoluto & 412 & 1420 & 1450 & 342 & 531 \\
\hline
\end{tabular}

Legenda: N- Números absolutos

Tabela 1: casos de óbitos por câncer de pênis por ano, segundo as regiões brasileiras, período de 2009 a $2019, n=4155$.

Fonte: DATASUS/Atlas de mortalidade.

Verifica-se que o maior número de casos de óbitos por câncer de pênis, nas faixas etárias entre 20 a 80 anos e mais, dos anos estudados, ocorreram nas regiões Sudeste e Nordeste, contudo, ressalta-se que no Nordeste o número de casos entre homens menores de 50 anos é maior em valores absolutos. Em relação a taxa específica por câncer de pênis (relação de óbitos por câncer de pênis por 100.000/homens na população residente), nas faixas etárias de 20 a 49 anos, 50 a 69 anos e 80 anos e mais, as regiões Norte e Nordeste apresentam-se mais elevadas. Nota-se que as mortes entre homens de 70 a 79 anos nas regiões Norte e Centro Oeste foram mais elevadas ao se tratar de taxa específica (Tabela 2).

\begin{tabular}{lcccccccccc}
\hline Regiões/faixa etária & \multicolumn{3}{c}{$\mathbf{N}$} & \multicolumn{2}{c}{ NE } & \multicolumn{2}{c}{ SE } & \multicolumn{2}{c}{ CO } & \multicolumn{2}{c}{ S } \\
\cline { 2 - 11 } & $\mathbf{n}$ & TME & $\mathbf{n}$ & TME & n & TME & $\mathbf{n}$ & TME & $\mathbf{n}$ & TME \\
\hline 20 a 29 & 5 & 0,03 & 28 & 0,05 & 21 & 0,03 & 7 & 0,05 & 6 & 0,02 \\
30 a 39 & 31 & 0,21 & 109 & 0,23 & 90 & 0,12 & 22 & 0,16 & 19 & 0,08 \\
40 a 49 & 53 & 0,51 & 220 & 0,62 & 176 & 0,25 & 65 & 0,6 & 56 & 0,26 \\
50 a 59 & 99 & 1,42 & 277 & 1,11 & 319 & 0,64 & 73 & 0,95 & 111 & 0,63 \\
60 a 69 & 97 & 2,55 & 306 & 2,0 & 345 & 1,15 & 72 & 1,66 & 137 & 1,26 \\
70 a 79 & 76 & 4,39 & 268 & 3,4 & 297 & 2,05 & 65 & 3,13 & 117 & 2,23 \\
80 e mais & 60 & 9,69 & 293 & 8,8 & 243 & 3,99 & 46 & 5,93 & 105 & 5,15 \\
\hline
\end{tabular}

Legenda: $\mathrm{n}$ - frequência absoluta. TME - Taxa de Mortalidade Específica (100 mil homens)

Tabela 2: Casos de óbitos e taxa de mortalidade por câncer de pênis nas regiões brasileiras, por faixa etária entre 2009 a 2019.

Fonte: DATASUS/Atlas de mortalidade.

Abaixo percebeu-se que os estados com maior representatividade em taxa de mortalidade por câncer de pênis no território nacional foram Piauí $(0,76)$, Maranhão $(0,68)$, 
Tocantins $(0,65)$ e Sergipe $(0,61)$. Quanto às menores taxas, os estados do Amapá $(0,25)$ e São Paulo $(0,28)$ foram os destaques. Verificou-se que na Região Norte os estados de Tocantins $(0,65)$ e Pará $(0,48)$ apresentaram as maiores taxas brutas. No Nordeste as taxas mais elevadas ocorreram nos estados de Piauí $(0,76)$ e Maranhão $(0,68)$. Já na região Sudeste o Espírito Santo $(0,47)$ e Minas Gerais $(0,39)$ obtiveram destaque. As regiões Centro Oeste e Sul trouxeram respectivamente os estados de Goiás $(0,46)$ e Mato Grosso $(0,37)$, Rio Grande do Sul $(0,38)$ e Paraná $(0,34)$ como as maiores taxas (Tabela 3$)$.

\begin{tabular}{lclc}
\hline Regiões/UF & $\begin{array}{c}\text { Taxa bruta por } \\
\mathbf{1 0 0 . 0 0 0 / h o m e n s}\end{array}$ & Regiões/UF & $\begin{array}{c}\text { Taxa bruta por } \\
\mathbf{1 0 0 . 0 0 0 / h o m e n s}\end{array}$ \\
\hline Norte & 0,37 & Nordeste & 0,68 \\
AM & 0,25 & MA & 0,76 \\
AP & 0,44 & PI & 0,46 \\
AC & 0,48 & PE & 0,48 \\
PA & 0,40 & AL & 0,44 \\
RO & 0,65 & SE & 0,61 \\
TO & 0,33 & CE & 0,40 \\
RR & & BA & 0,47 \\
Sudeste & 0,47 & PB & 0,42 \\
ES & 0,39 & Centro & \\
MG & & Oeste & 0,46 \\
RJ & 0,35 & GO & 0,37 \\
SP & 0,28 & MT & 0,48 \\
Região Sul & & MS & 0,35 \\
PR & 0,34 & DF & \\
RS & 0,38 & & \\
SC & 0,32 & & \\
\hline
\end{tabular}

Tabela 3: Taxas brutas de mortalidade por câncer de pênis, por 100 mil homens, pelas Unidades de Federação do Brasil, entre 2009 a 2019.

Fonte: Datasus/atlas de mortalidade

Ao estabelecer uma ordem entre taxas brutas de mortalidade por câncer de pênis, por 100.000/homens entre os Estados brasileiros destacam-se na região Nordeste Piauí $(0,76)$, Maranhão $(0,68)$, Sergipe $(0,61)$. Na região Norte estão os estados de Tocantins $(0,65)$ e o Pará $(0,48)$. Na região Espírito Santo $(0,47)$. Centro oeste Mato Grosso $(0,48)$, Goiás $(0,46)$. Na Região Sul o Rio Grande do Sul $(0,38)$, representa a maior taxa de mortalidade daquela região, ainda assim essa é a metade da taxa verificada no estado Piauí.

\section{DISCUSSÃO}

A Política Nacional de Atenção Integral à Saúde do Homem (PNAISH), tem por direção dois eixos de atenção: atendimento às necessidades de saúde do homem, ao promover o acesso a graus de crescente utilização de complexidade tecnológica pelo SUS, garantindo acesso a ações de promoção, prevenção, proteção, tratamento e recuperação; e entendimento transdisciplinar das questões de saúde do homem como fenômenos 
biopsicossociais e culturais (BRASIL, 2008).

O câncer de pênis é uma doença que apesar de baixa ou de quase inexistência em países desenvolvidos, nos países em subdesenvolvimento ou em desenvolvimento tendem apresentar taxas maiores de morbimortalidade. Além disto as consequências que este câncer traz para os indivíduos acometidos, seja de ordem psicológica, fisiológica, reprodutiva, funcional e produtiva, também afeta suas famílias e sociedade (KOIFMAN, VIDES, et al., 2011); (COLBERG, VAN DER HORST, et al., 2018); (MARCHIONI, BERARDINELLI, et al., 2018).

Enquanto fator de risco a fimose parece ser crucial para o desenvolvimento do câncer de pênis. Além disso, constatou-se que as doenças inflamatórias crônicas do pênis estão associadas a um maior risco (COLBERG, VAN DER HORST, et al., 2018). Outro fator de risco discutido no estudo de (YU, WANG, et al., 2019), verifica que quase metade dos casos de câncer de pênis são associados à infecção pelo papilomavírus humano (HPV). O genótipo mais comumente associado é o HPV16, mas vários outros genótipos também foram detectados (F, A, et al., 2015); (IARC, 2021); (GAO, SONG, et al., 2016)).

Na perspectiva das políticas públicas de saúde o câncer de pênis se torna relevante, face aos custos elevados quando ocorre o tratamento, e principalmente por ser uma patologia que pode ser evitada por meio de medidas preventivas e educativas e por meio do diagnóstico precoce e tratamentos oportunos, preservando vidas (BRASIL, 2021).

As faixas etárias que estão ocorrendo mais óbitos que são de 50 a 69 anos, traz preocupação pois são homens que em relação a taxa específica por câncer de pênis, em relação às faixas etárias de 20 a 49 anos, 50 a 69 anos e 80 anos e mais, as regiões Norte e Nordeste apresentaram maiores valores. Já na faixa etária de 70 a 79 anos as regiões Norte e Centro Oeste foram as que estiveram mais altas.

Nesse contexto, os serviços primários de saúde tornam-se fundamentais no processo de rastreio, diagnóstico inicial e acompanhamento dos casos, além de referenciamento para os demais níveis de complexidade. Diante de lesões precursoras identificadas os protocolos terapêuticos de baixo custo são efetivos quando bem conduzidos de modo a não exigir serviços de maior complexidade (GAO, SONG, et al., 2016); (BRAY, LAVERSANNE, et al., 2021).

No Brasil a mortalidade por este tipo de câncer conforme o estudo revela é variável entre as regiões. O óbito por câncer de pênis no Brasil conforme o estudo revela é variável entre as regiões. As regiões Sudeste e Nordeste apresentaram os maiores números e percentuais de casos no período entre 2009-2019. De acordo com (BARBOSA, 2015), ao realizar projeção da taxa de mortalidade padronizada a população mundial (ASW/100.000 habitantes) para o Brasil e Regiões Brasileiras de 2011 a 2030, referentes a câncer raros como o de pênis, informa que haverá aumento progressivo deste câncer no Brasil, e nas Regiões apesar da Sudeste apresentar queda nas taxas, todas as demais regiões vão manter a ascensão, ainda deixando o nordeste uma das taxas maiores. 
Corroborando com os achados deste estudo que evidenciou aumento de casos de óbitos em algumas regiões nos anos estudados, pesquisas da International Agency for Research on Cancer (IARC), afirmam sobre o aumento anual dos casos e óbitos até 2030, face ao envelhecimento e crescimento populacional, sendo este aumento mais característicos em países em subdesenvolvidos e em desenvolvimento (SYLLA, WILD, 2012).

Em relação a região nordeste em estudo realizado em Pernambuco com o diagnóstico de $(64,7 \%)$ dos casos em estadiamento T2, diante do avanço da doença $27,3 \%$ casos foram a óbito (COUTO, ARRUDA, et al., 2014).

No estado do Maranhão entre (2004-2014), chama-se atenção por ser o maior em incidência de câncer de pênis no Brasil e no mundo. Confirmando as considerações de pesquisadores mundiais, que alertam sobre os tumores serem diagnosticados localmente avançados e alta frequência casos entre homens jovens. Em tempo ressaltam que os pacientes apresentam baixo nível socioeconômico, dificultando a conclusão do tratamento e o acompanhamento adequado (COELHO, PINHO, et al., 2018).

Em pesquisa realizada na região Centro-oeste sobre a epidemiologia do referido câncer no Mato Grosso entre 2010-2015. Nesse período houve o registro de 61 casos de Câncer, com mais de 10 casos ao ano. Em relação à mortalidade por Câncer de Pênis naquele estado, a maior taxa bruta de mortalidade ocorrida em 2012 foi de 0,43/100.000 homens. Chama atenção para que proposições políticas efetivas a prevenção e diagnóstico precoce desta neoplasia na Atenção Básica (ANTIQUEIRA, 2020). Nesse estudo, confirmase na década abordada que Mato Grosso com 0,48/100.000 permanece no primeiro lugar nas taxas de mortes por câncer de pênis e Goiás com 0,46/100.000 representa o segundo lugar na região Centro-oeste brasileira.

Ao reconhecer a gravidade relacionada a alta incidência e mortalidade por câncer de pênis nos estados do Tocantins, Pará na região Norte e Piauí, Maranhão e Sergipe na região Nordeste, receberam recursos para implementar um projeto para o desenvolvimento de ações integral à saúde do homem e prevenção do câncer de pênis no âmbito da Atenção Primária à Saúde (BRASIL, 2020c).

Tal condição relaciona-se a vulnerabilidades, determinantes sociais, iniquidades, desigualdades de condições de saúde, oferta de serviços e recursos, visto que o referido câncer é associado a tais fatores, além de questões culturais, comportamentais, não adesão ao autocuidado masculino, processos preventivos e de promoção da saúde (BARRETO, 2017).

Nesse sentido, entende-se a importância de estratégias da Gestão pública de saúde, no sentido da ampliação do acesso à saúde das populações nos territórios e no fortalecimento do rastreamento e diagnóstico do câncer. Vale ressaltar que se observa possível resposta à demanda relacionada ao rastreamento do câncer. Nisso espera-se que Portaria GM/MS n 3712 , de 22 de dezembro de 2020, que institui, em caráter excepcional, 
incentivo financeiro federal de custeio para o fortalecimento do acesso às ações integradas para rastreamento, detecção precoce e controle do Câncer no Sistema Único de Saúde (BRASIL, 2020b).

Enfatiza-se a importância do investimento na imunização contra o HPV, para a prevenção de outros tipos de câncer associados à infecção por tal vírus oncogênicos, a vacina também é uma das grandes esperanças do controle parte dos cânceres de pênis consequente redução das taxas de mortalidade (OLESEN, SAND, et al., 2019); (IARC, 2021), (F, A, et al., 2015); (DE SAN JOSÉ, DÍAZ, et al., 2007).

\section{CONSIDERAÇÕES}

O estudo dá visibilidade aos casos de óbitos por câncer de pênis, instiga reflexões, como a importância dos serviços de saúde, principalmente os primários, no processo de conhecer suas realidades epidemiológicas e população masculina, para melhor elaborarem e planejarem ações e estratégias de saúde, que englobem a saúde do homem de forma integral e abrangente, e com sensibilidade para detecção precoce de patologias menos frequentes.

O câncer de pênis pode ser relacionado às iniquidades sociais, além de aspectos culturais e comportamentais das regiões brasileiras. Alguns territórios devem estabelecer alertas, principalmente os de maior incidência e mortes. Nesse sentido, atuar de forma sensível e resolutiva na saúde do homem, ao prevenir a patologia, rastrear, diagnosticar e obter resposta terapêutica efetiva.

Outra reflexão ao descrever sobre a mortalidade de homens de uma patologia que poderia ser evitável, chama atenção para os estados e seus municípios que por meio de suas redes de atenção à saúde, incentivarem a adesão da população masculina culturalmente resistente aos cuidados em saúde e autocuidado. Na organização dos serviços, acesso, com ofertas ampliadas de ações em horários flexíveis. É de suma importância a capacitação permanente dos profissionais de saúde para ações de prevenção e promoção da saúde, e não somente tratamento e cura.

\section{REFERÊNCIAS}

ANTIQUEIRA, V. M. A. "ASPECTOS EPIDEMIOLÓGICOS DO CÂNCER DE PÊNIS EM MATO GROSSO. Tese (Doutorado). Fundação Antônio Prudente. Curso de Pós-Graduação em Ciências - Área de concentração: Oncologia. Orientador: Fernando Augusto Soares”, p. 110, 2020. Disponível em: https://accamargo.phlnet.com.br/Doutorado/2020/pdf.

BARBOSA, I. R. "Tendências e projeções da mortalidade pelos cânceres específicos ao gênero no Brasil”. Disponível em: https://repositorio.ufrn.br/handle/123456789/19917. Acesso em: 23 jun. 2021. 
BARRETO, M. L. "Desigualdades em Saúde: uma perspectiva global”, Ciência \& Saúde Coletiva, v. 22, p. 2097-2108, 2017. DOI: 10.1590/1413-81232017227.02742017. Disponível em: https://www. scielosp.org/article/csc/2017.v22n7/2097-2108/. Acesso em: 19 jun. 2021.

BRASIL. "Câncer de pênis: causas, sintomas, tratamento, diagnóstico e prevenção.", 2021. Disponível em: https://antigo.saude.gov.br/saude-de-a-z/cancer-de-penis.

BRASIL. Estatísticas do câncer. 2020a. INCA - Instituto Nacional de Câncer. Disponível em: https:// www.inca.gov.br/numeros-de-cancer. Acesso em: 19 jun. 2021.

BRASIL. Política Nacional de Atenção Básica. PNAB. PORTARIA № 2.436, DE 21 DE SETEMBRO DE 2017. 2017. PORTARIA № 2.436, DE 21 DE SETEMBRO DE 2017. Disponível em: https://bvsms. saude.gov.br/bvs/saudelegis/gm/2017/prt2436_22_09_2017.html. Acesso em: 16 jun. 2021.

BRASIL. "Política Nacional de Atenção Integral à Saúde do Homem: Princípios e Diretrizes", p. 40, 2008. Disponível em: https://bvsms.saude.gov.br/bvs/publicacoes/politica_nacional_atencao_homem. pdf.

BRASIL. Portaria GM/MS № 3.712, DE 22 DE DEZEMBRO DE 2020 - DOU - Imprensa Nacional. 2020b. Institui, em caráter excepcional, incentivo financeiro federal de custeio para o fortalecimento do acesso às ações integradas para rastreamento, detecção precoce e controle do Câncer no Sistema Único de Saúde.Disponível em: https://www.in.gov.br/web/dou. Acesso em: 12 jun. 2021.

BRASIL. A Saúde destinará $\mathbf{R}$ \$20 milhões à prevenção do câncer de pênis. 2020c. Agência Brasil. Disponível em: https://agenciabrasil.ebc.com.br/saude/noticia/2020-11/saude-destinara-r-20-milhoesprevencao-do-cancer-de-penis. Acesso em: 23 jun. 2021.

BRAY, F., LAVERSANNE, M., WEIDERPASS, E., et al. "The ever-increasing importance of cancer as a leading cause of premature death worldwide", Cancer, 4 jun. 2021. DOI: 10.1002/cncr.33587. .

COELHO, R. W. P., PINHO, J. D., MORENO, J. S., et al. "Penile cancer in Maranhão, Northeast Brazil: the highest incidence globally?", BMC Urology, v. 18, n. 1, p. 50, 29 maio 2018. DOI: 10.1186/s12894018-0365-0. Disponível em: https://doi.org/10.1186/s12894-018-0365-0. Acesso em: 23 jun. 2021.

COLBERG, C., VAN DER HORST, C., JÜNEMANN, K.-P., et al. "[Epidemiology of penile cancer]", Der Urologe. Ausg. A, v. 57, n. 4, p. 408-412, abr. 2018. DOI: 10.1007/s00120-018-0593-7. .

COUTO, T. C. do, ARRUDA, R. M. B., COUTO, M. C. do, et al. "Epidemiological study of penile cancer in Pernambuco: experience of two reference centers", International braz j urol, v. 40, p. 738-744, dez. 2014. DOI: 10.1590/S1677-5538.IBJU.2014.06.04. Disponível em: https://www.scielo.br/j/ibju/a/ x6xRSxNdg9mHbnmdzGJKjYM/?lang=en. Acesso em: 23 jun. 2021.

DE SAN JOSÉ, S., DIAZ, M., CASTELLSAGUÉ, X., et al. "Worldwide prevalence and genotype distribution of cervical human papillomavirus DNA in women with normal cytology: a meta-analysis", The Lancet Infectious Diseases, v. 7, n. 7, p. 453-459, 1 jul. 2007. DOI: 10.1016/S1473-3099(07)70158-5. Disponível em: https://www.sciencedirect.com/science/article/pii/S1473309907701585. Acesso em: 14 jun. 2021. 
F, B., A, Z., P, C., et al. Planning and Developing Population-Based Cancer Registration in Low- and Middle-Income Settings. [S.I: s.n.], 2015. Disponível em: https://publications.iarc.fr/BookAnd-Report-Series/larc-Technical-Publications/Planning-And-Developing-Population-Based-CancerRegistration-In-Low--And-Middle-Income-Settings-2014. Acesso em: 16 jun. 2021.

GAO, W., SONG, L., YANG, J., et al. "Risk factors and negative consequences of patient's delay for penile carcinoma", World Journal of Surgical Oncology, v. 14, p. 124, 27 abr. 2016. DOI: 10.1186/ s12957-016-0863-z. Disponível em: https://www.ncbi.nlm.nih.gov/pmc/articles/PMC4848776/. Acesso em: 23 jun. 2021.

IARC. HPV INFORMATION CENTRE. 2021. HPV INFORMATION CENTRE. Disponível em: https:// hpvcentre.net/. Acesso em: 14 jun. 2021.

INCA. Câncer de pênis. 2021. INCA - Instituto Nacional de Câncer. Disponível em: https://www.inca. gov.br/tipos-de-cancer/cancer-de-penis. Acesso em: 19 jun. 2021.

KOIFMAN, L., VIDES, A. J., KOIFMAN, N., et al. "Epidemiological aspects of penile cancer in Rio de Janeiro: evaluation of 230 cases", International braz j urol, v. 37, p. 231-243, abr. 2011. DOI: 10.1590/S1677-55382011000200010. Disponível em: https://www.scielo.br/j/ibju/a/ WbF5VcJmyrvybJZCVLTbNPG/?lang=en. Acesso em: 19 jun. 2021.

MADRIAGA, L. C. V., SOUZA, S. S. S. de, PEREIRA, G. L., et al. "Perspectivas do homem submetido à penectomia", Rev. Pesqui. (Univ. Fed. Estado Rio J., Online), p. 573-578, 2020. Disponível em: http://seer.unirio.br/index.php/cuidadofundamental/article/viewFile/8829/pdf_1. Acesso em: 23 jun. 2021.

MALTA, D. C., ANDRADE, S. S. C. de A., OLIVEIRA, T. P., et al. "Probabilidade de morte prematura por doenças crônicas não transmissíveis, Brasil e regiões, projeções para 2025”, Revista Brasileira de Epidemiologia, v. 22, p. e190030, 2019. DOI: 10.1590/1980-549720190030. Disponível em: http:// www.scielo.br/scielo.php?script=sci_arttext\&pid=S1415-790X2019000100428\&tIng=pt. Acesso em: 19 jun. 2021.

MARCHIONI, M., BERARDINELLI, F., DE NUNZIO, C., et al. "New insight in penile cancer", Minerva Urologica E Nefrologica $=$ The Italian Journal of Urology and Nephrology, v. 70, n. 6, p. 559-569, dez. 2018. DOI: 10.23736/S0393-2249.18.03215-0. .

MATTIUZZI, C., LIPPI, G. “Current Cancer Epidemiology”, Journal of Epidemiology and Global Health, v. 9, n. 4, p. 217-222, dez. 2019. DOI: 10.2991/jegh.k.191008.001. .

OLESEN, T. B., SAND, F. L., RASMUSSEN, C. L., et al. "Prevalence of human papillomavirus DNA and p16INK4a in penile cancer and penile intraepithelial neoplasia: a systematic review and meta-analysis", The Lancet. Oncology, v. 20, n. 1, p. 145-158, jan. 2019. DOI: 10.1016/S1470-2045(18)30682-X. .

SYLLA, B. S., WILD, C. P. "Cancer burden in Africa in 2030: Invest today and save tomorrow", Journal Africain du Cancer / African Journal of Cancer, v. 4, n. 1, p. 1-2, 1 fev. 2012. DOI: 10.1007/s12558012-0199-4. Disponível em: https://doi.org/10.1007/s12558-012-0199-4. Acesso em: 23 jun. 2021.

WANICK, F. B. F., TEICHNER, T. C., SILVA, R., et al. "Carcinoma epidermoide do pênis: estudo clínicopatológico de 34 casos", Anais Brasileiros de Dermatologia, v. 86, p. 1082-1091, dez. 2011. DOI:

10.1590/S0365-05962011000600004. Disponível em: https://www.scielo.br/j/abd/a/8BQDbkgSQDY5WN 9JFQtzYpd/?lang=pt. Acesso em: 23 jun. 2021. 
WIND, M. M. FERNANDES, L. M. S., PINHEIRO, D. H. P., et al. "PERFIL EPIDEMIOLÓGICO DO CÂNCER DE PÊNIS E SUAS CONSEQUÊNCIAS PSÍQUICAS”, CIPEEX, v. 2, p. 932-936, 28 dez. 2018. Disponível em: http://anais.unievangelica.edu.br/index.php/CIPEEX/article/view/2998. Acesso em: 23 jun. 2021.

YU, Y.-B., WANG, Y.-H., YANG, X.-C., et al. "The relationship between human papillomavirus and penile cancer over the past decade: a systematic review and meta-analysis", Asian Journal of Andrology, $\mathrm{v}$. 21, n. 4, p. 375-380, ago. 2019. DOI: 10.4103/aja.aja_39_19. . 


\section{SOBRE A ORGANIZADORA}

ANA MARIA AGUIAR FRIAS - Doutora em Psicologia (Julho-2010); Mestre em Ecologia Humana (2004); Enfermeira Especialista em Saúde Materna e Obstétrica (Agosto1996). Enfermeira (1986-2003). Professora Coordenadora no Departamento de Enfermagem da Escola Superior de Enfermagem S. João de Deus (ESESJD) da Universidade de Évora. Presidente do Conselho Pedagógico (2008-2010) e desde Janeiro 2019. Elemento da assembleia de representantes da ESESJD, Vice Presidente da assembleia de representante (2017-2019). Elemento da Comissão Executiva e de acompanhamento do Mestrado em Enfermagem de Saúde Materna e Obstétrica. Adjunta da Diretora de curso. Investigadora do Comprehensive Health Research Centre, investigadora colaboradora do centro de investigação em Educação e Psicologia da Universidade de Évora. Coordenadora principal do projeto "Conhecer e prevenir o VIH_SIDA". Assessora Cientifico da Revista RIASE. Revisor da Revista de Enfermagem (Referência), da Revista Millenium-Journal of Education, Technologies, and Health, da Revista Cubana de Enfermería, da Revista Eletrônica Gestão e Saúde - G\&S, da revista de Enfermagem Anna Nery. Representante dos professores no conselho técnico-científico da Escola Superior de Enfermagem S. João de Deus (até Janeiro 2019). Diretora da comissão de curso da licenciatura em Enfermagem (2010-2012). Adjunta da Diretora da Comissão de Curso da Licenciatura em Enfermagem (2012-2014). Diretora da Pós-graduação em Medicina Chinesa (2008-2012). Diretora do 6. ${ }^{\circ}$ Curso de Póslicenciatura de Especialização em Enfermagem de Saúde Materna e Obstetrícia, na llha da Madeira (2008-2010). Elemento da comissão editorial da revista da ESESJD "Enfermagem e Sociedade" (2004-2009). Autora de vários trabalhos científicos com publicações relevantes em periódicos nacionais e internacionais, livro, capítulos de livros e comunicações nas áreas da Enfermagem, Educação para a Saúde, Psicologia. Abordou temas como Gravidez e Parto. Vinculação, Adolescência, Comportamentos Saudáveis e de Risco, VIH, Urgências e Emergências, Simulação Clínica e e-learning. 


\section{ÍNDICE REMISSIVO}

A

Ações Educativas 107, 112, 198

Acolhimento 15, 42, 81, 95, 103, 104, 169, 174, 175, 180, 182, 183, 184, 213

Adolescente $9,12,16,17,18,20,21,22,26,80,81,82,83,84,85,86,87,90,91,92,93$, $147,152,156,162,170,172,173,174,175,184,185$

Assistência ambulatorial 37, 39

Atenção Básica 12, 23, 45, 54, 93, 95, 97, 98, 110, 112, 185, 233, 235

B

Bactéria 47, 48, 51

Benefícios 10, 12, 1, 2, 3, 8, 9, 13, 14, 40, 77, 78, 111, 114, 115, 122, 123, 124, 127, 134, 159, 160, 161, 164, 169

Brasil 15, 3, 16, 19, 20, 23, 24, 25, 26, 28, 34, 38, 39, 41, 44, 45, 46, 48, 49, 54, 55, 59, $63,64,65,66,67,72,73,74,75,81,84,87,89,93,102,104,105,106,108,111,112,113$, $115,124,125,130,138,139,140,141,142,144,145,149,152,165,167,170,178,184$, $185,188,189,190,192,193,198,200,201,203,206,211,212,225,226,227,228,231$, 232, 233, 234, 235, 236

\section{C}

Câncer de colo do útero 14, 188, 189, 190, 191, 192, 193, 194, 195, 197, 198, 199

Cardiopatia 14, 164, 165, 166, 167, 168, 170

Cesárea 66, 69, 73, 78, 102

Comunicação efetiva $77,78,79$

Criança $9,14,16,20,48,82,85,86,87,88,92,99,105,111,147,151,152,153,154,156$, $157,158,159,160,162,163,164,166,170,171,172,173,174,175,176,177,179,180$, $181,182,183,184,185,186$

Criança hospitalizada 151, 152, 153, 154, 156, 158, 162, 176, 179, 181

Cuidado pré-natal 16, 19, 45

Cuidados de enfermagem 9, 27, 40, 43, 46, 58, 127, 129, 130, 131, 132, 134, 148, 159, $164,166,167,168,169,170,171,172,176$

\section{D}

Deambulação $12,77,78$

Depressão 12, 2, 13, 17, 22, 29, 95, 96, 97, 98, 99, 100, 101, 102, 103, 104, 105, 106, 107, $108,109,110,111,112,113,121,213$

Depressão Pós-Parto 12, 95, 97, 98, 101, 102, 103, 104, 105, 106, 107, 112, 113 
Dor $13,13,14,25,30,31,32,42,61,62,84,131,136,137,138,139,140,141,142,143$, $144,145,146,147,151,161,163,169,182,215$

\section{$\mathbf{E}$}

Eclâmpsia 3, 9, 17, 22, 28, 33, 37, 38, 39, 40, 41, 42, 43, 45, 46

Enfermagem 2, 9, 10, 11, 12, 13, 14, 1, 23, 24, 25, 27, 29, 31, 32, 33, 34, 36, 37, 39, 40, $42,43,44,45,46,56,57,58,59,60,61,62,63,75,77,78,79,80,92,93,94,95,97,102$, $103,104,106,107,108,109,110,111,112,113,114,125,126,127,128,129,130,131$, $132,133,134,136,139,140,141,142,145,146,147,148,149,150,151,152,153,154$, $155,156,157,158,159,160,161,162,163,164,166,167,168,169,170,171,172,175$, $176,177,178,179,180,181,183,184,185,186,187,188,189,197,198,199,201,202$, 211, 216, 238

Enfermagem Pediátrica 152, 154, 157, 161, 163

Enfermeiro 15, 39, 42, 43, 44, 46, 63, 78, 81, 85, 92, 96, 97, 98, 103, 105, 108, 109, 110, $111,112,131,132,133,134,135,136,148,150,153,157,158,159,160,162,164,166$, 167, 168, 169, 179, 180, 181, 182, 183, 184, 187, 193, 194, 198, 199, 213, 215

Exercício Físico 10, 1, 2, 3, 6, 8, 9, 10, 11, 12, 13, 14, 15

F

Fatores de risco 14, 23, 54, 97, 188, 189, 191, 193, 199

Fenomenologia $12,80,82,84,94,178,186$

G

Gestantes 10, 12, 6, 7, 9, 10, 15, 16, 18, 20, 21, 22, 23, 27, 28, 29, 30, 31, 33, 34, 44, 45, $46,47,48,49,50,51,52,53,54,58,62,63,68,73,76,88,94,95,102,103,104,107$, $109,111,112$

Gravidez $9,10,1,2,3,6,7,8,9,10,11,12,13,14,15,16,17,18,19,20,21,22,24,25$, $27,28,29,33,34,35,41,46,48,51,52,57,61,62,67,87,88,91,93,94,99,110,118$, 120, 238

Gravidez na adolescência 16, 17, 19, 20, 22, 24, 25, 88, 93, 94

\section{$\mathrm{H}$}

Hipotermia Induzida 127, 129, 131, 133

Hipóxia-Isquemia Encefálica 127, 129

Humanização $9,14,24,74,75,101,124,127,140,151,155,158,159,171,174,180$, 182, 185, 213

J

Jogos e brinquedos 154 
Linfedema de membro superior 216

Lúpus Eritematoso Sistêmico 10, 27, 28, 34, 35

M

Maternidade Precoce 80, 82, 83, 84, 86, 90, 91, 92

Maus-tratos $14,171,173,174,175,176,177,179,180,181,182,183,185,186$

$\mathbf{N}$

Neonato $16,33,137,138,140,143,144,145,167,168,170$

$\mathbf{P}$

Parto normal $30,66,68,70,71,74,76,78,92$

Parturiente 22, 43, 46, 66, 98, 99

Pênis 15, 225, 226, 227, 228, 229, 230, 231, 232, 233, 234, 235, 236, 237

Prematuro 9, 10, 18, 22, 33, 38, 57, 59, 91, 102, 114, 119, 120, 122, 123, 124, 125, 132, 147, 149

Pré-Natal 10, 16, 20, 24, 44, 93, 95, 97, 101, 104, 105, 106, 107

Prevenção 1, 2, 13, 29, 37, 38, 41, 43, 46, 47, 77, 101, 103, 106, 107, 111, 112, 113, 125, 137, 143, 145, 164, 169, 173, 189, 193, 194, 197, 198, 199, 200, 203, 215, 216, 227, 228, 231, 233, 234, 235

Puérperas 25, 46, 69, 70, 71, 72, 77, 78, 79, 80, 82, 83, 84, 87, 90, 91, 92, 95, 97, 103, 104, 111, 112

Puerpério Mediato 12, 77

Q

Qualidade de vida 9, 14, 2, 14, 127, 134, 152, 164, 166, 189, 198, 199, 201, 202, 204, 205, 206, 207, 208, 209, 210, 211, 212, 216

$\mathbf{R}$

Recém-nascido 114, 119, 120, 127, 129

Robotização 14,171

S

Saúde da mulher 1, 8, 44, 60, 101, 197, 199, 203

Saúde do homem 226, 228, 231, 233, 234

Saúde Pública 9, 16, 20, 23, 24, 25, 26, 46, 47, 48, 54, 65, 68, 72, 95, 96, 104, 105, 108, 170, 171, 185, 200, 203, 226 
Unidade de terapia intensiva neonatal $8,125,133,145,146,148$ 


\section{A enfermagem a partir de uma visão crítica: Excelênciadas práticas de cuidado}

www.atenaeditora.com.br

\. contato@atenaeditora.com.br

0 @ @atenaeditora

f www.facebook.com/atenaeditora.com.br

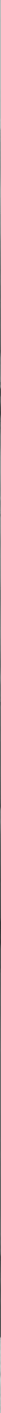

Ano 2021 


\section{A enfermagem a partir de uma visão crítica: Excelência das práticas de cuidado}

Www.atenaeditora.com.br

\. contato@atenaeditora.com.br

0 ㅇatenaeditora

f www.facebook.com/atenaeditora.com.br



Ano 2021 